\title{
GEOTHERMAL ENERGY DEVELOPMENT ANNUAL REPORT 1979
}

Excerpt from Earth Sciences Division

Annual Report 1979 (LBL-10686)

\author{
Lawrence Berkeley Laboratory \\ University of California \\ Berkeley, California 94720
}

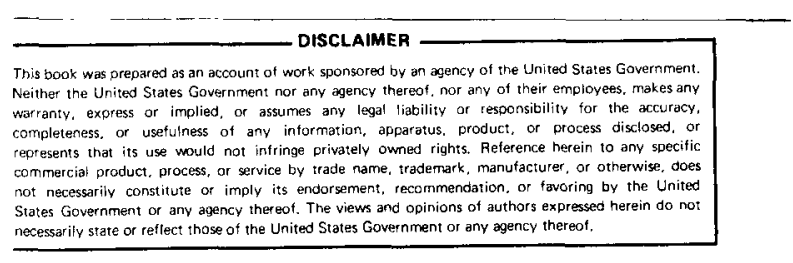

This work was supported by the U.S. Department of Energy, Division of Geothermal Energy 


\section{DISCLAIMER}

This report was prepared as an account of work sponsored by an agency of the United States Government. Neither the United States Government nor any agency Thereof, nor any of their employees, makes any warranty, express or implied, or assumes any legal liability or responsibility for the accuracy, completeness, or usefulness of any information, apparatus, product, or process disclosed, or represents that its use would not infringe privately owned rights. Reference herein to any specific commercial product, process, or service by trade name, trademark, manufacturer, or otherwise does not necessarily constitute or imply its endorsement, recommendation, or favoring by the United States Government or any agency thereof. The views and opinions of authors expressed herein do not necessarily state or reflect those of the United States Government or any agency thereof. 


\section{DISCLAIMER}

Portions of this document may be illegible in electronic image products. Images are produced from the best available original document. 


\section{CONTENTS}

\section{GEOTHERMAL ENERGY DEVELOPMENT}

\section{Geothermal Exploration Technology}

INTERPRETATION OF ELECTRICAL AND ELECTROMAGNETIC SURVEY DATA

H. F. Morrison, K. H. Lee, E. Mozley, and M. Hoversten

FIELD PROCESSING OF MAGNETOTELLURIC DATA $\mathbf{5}$

J. Clarke, T. D. Gamble, W. M. Goubau, R. Koch, and R. Miracky

AUTOMATED SEISMIC PROCESSOR $\quad 7$

T. V. McEvilly, E. L. Majer, J. Bartschi, J. Heinsen, and R. O'Connell

CONTROLLED-SOURCE ELECTROMAGNETIC MEASUREMENTS AT GEOTHERMAL SITES IN NEVADA 11

M. J. Wilt, N. E. Goldstein, R. Haught, and M. Stark

GEOPHYSICAL AND GEOCHEMICAL INVESTIGATIONS AT MT. HOOD, OREGON

N. E. Goldstein, H. A. Wollenberg, E. Mozley, and M. J. Wilt

KLAMATH BASIN GEOTHERMAL RESOURCE AND EXPLORATION TECHNIQUE EVALUATION 19

M. A. Stark, N. E. Goldstein, and H. A. Wollenberg

MAGNETOTELLURIC STUDIES IN THE HIGH CASCADE, OREGON

24

N. E. Goldstein, R. Miracky, W. M. Goubau, and T. D. Gamble

\section{Geothermal Energy Conversion Technology}

BINARY FLUID EXPERIMENT

26

B. W. Tleimat

ACTIVITIES IN DIRECT-CONTACT HEAT EXCHANGE

P. M. Rapier

27

\section{Reservoir Engineering $\quad 31$}

MEXICAN-AMERICAN COOPERATIVE PROGRAM AT THE CERRO PRIETO

GEOTHERMAL FIELD, BAJA CALIFORNIA, MEXICO

31

M. J. Lippmann, P. A. Witherspoon, and N. E. Goldstein

REGIONAL GEOLOGIC SETTING OF THE CERRO PRIETO GEOTHERMAL FIELD

S. P. Vonder Haar and J. H. Howard 
SUBSURFACE GEOLOGY OF THE CERRO PRIETO GEOTHERMAL FIELD

S. P. Vonder Haar, J. Noble, M. T. O'Brien, and J. H. Howard

NUMERICAL MODELING STUDIES OF THE CERRO PRIETO RESERVOIR

M. J. Lippmann and K. P. Goyal

SIMULATION OF REINJECTION AT CERRO PRIETO USING AN IDEALIZED TWORESERVOIR GEOLOGICAL MODEL $\mathbf{5 2}$

C. F. Tsang, D. C. Mangold, and M. J. Lippmann

RESISTIVITY STUDIES AT CERRO PRIETO $\quad 57$

M. J. Wilt and N. E. Goldstein

MAGNETOTELLURIC STUDIES AT CERRO PRIETO

61

T. D. Gamble, W. M. Goubau, R. Miracky, J. Clarke, and N. E. Goldstein

PRECISION GRAVITY STUDIES AT THE CERRO PRIETO GEOTHERMAL FIELD

66

R. B. Grannell, D. W. Tarman, R. C. Clover, R. M. Leggewie, P. S. Aronstam, R. C. Kroll, and J. Eppink

GEOTHERMAL RESERVOIR ENGINEERING MANAGEMENT PROGRAM:

DEVELOPMENTS IN FISCAL 1979

66

J. H. Howard and W. J. Schwarz

EVALUATION OF CITY WELL 1, KLAMATH FALLS, OREGON

69

S. M. Benson, C. B. Goranson, and R. C. Schroeder

EVALUATION OF THE SUSANVILLE, CALIFORNIA, GEOTHERMAL RESOURCE, 1979

S. M. Benson, C. B. Goranson, J. P. Haney, and R. C. Schroeder

RECENT MODIFICATIONS OF THE NUMERICAL CODE CCC

87

G. S. Bodvarsson, M. J. Lippmann, and T. N. Narasimhan

DEVELOPMENT OF THE TWO-PHASE RESERVOIR SIMULATION PROGRAM, SHAFT79 91

K. Pruess, R. C. Schroeder, and P. A. Witherspoon

PROPERTIES OF $\mathrm{H}_{2} \mathrm{O}-\mathrm{CO}_{2}$ MIXTURES FOR GEOTHERMAL RESERVOIR AND WELLBORE SIMULATORS 95

E. R. Iglesias and R. C. Schroeder

PRELIMINARY STUDIES OF THE RESERVOIR CAPACITY AND LONGEVITY OF THE BACA GEOTHERMAL FIELD, NEW MEXICO 98

G. S. Bodvarsson, S. P. Vonder Haar, M J. Wilt, and C. F. Tsang

MODELING TRANSIENT TWO-PHASE FLOW IN A WELLBORE

103

C. W. Miller

CORRECTION OF DOWNHOLE PRESSURE TRANSIENTS MEASURED WITH A

FLUID-FILLED CAPILLARY TUBE

105

C. W. Miller and J. M. Zerzan 
WELLBORE STORAGE EFFECTS IN GEOTHERMAL WELLS

C. W. Miller

HYDRAULICS OF A WELL INTERCEPTING A SINGLE HORIZONTAL FRACTURE

G. S. Bodvarsson, T. N. Narasimhan, and C. F. Tsang 109

PRELIMINARY STUDY OF SUBSIDENCE AT WAIRAKEI, NEW ZEALAND, USING A NUMERICAL MODEL

112

T. N. Narasimhan and K. P. Goyal

USE OF PRESSURE TRANSIENT ANALYSIS IN MODELING THE HYDRAULIC

FRACTURING PROCESS

115

W. A. Palen and T. N. Narasimhan

\section{Geothermal Environmental Research}

\section{8}

GEOTHERMAL SUBSIDENCE RESEARCH PROGRAM

J. E. Noble

INDUCED SEISMICITY STUDIES AT THE CERRO PRIETO, MEXICO, AND EAST MESA, CALIFORNIA, GEOTHERMAL FIELDS 123

E. L. Majer and T. V. McEvilly

REMOVAL OF SILICA FROM CERRO PRIETO BRINES

O. Weres and L. Tsao

THEORETICAL STUDIES OF CERRO PRIETO BRINES CHEMICAL EQUILIBRIA

E. R. Iglesias and O. Weres 


\section{GEOTHERMAL ENERGY DEVELOPMENT}

The Earth Sciences Division program in Geothermal Energy Development began in 1973 in response to the national goal of developing alternate energy sources for electric and non-electric applications. The program initially consisted of: an exploration assessment of sites in northern Nevada for a proposed demonstration plant; development of a binaryfluid conversion process for high-temperature, lowsalinity brines; and various geochemical studies related to brine chemistry, scaling, and corrosion. An additional support project, the National Geothermal Information Resource (GRID) was begun to compile a data bank on topics related to geothermal energy.

Many of these general programs continue in modified or expanded form and others have begun in recent years. Most have been funded by the U.S. Department of Energy, Division of Geothermal Energy; the U.S. Bureau of Reclamation has contracted with LBL for site specific studies. Within this section of the Annual Report we present our current geothermal research activities subdivided into four principal areas: (1) Geothermal Exploration Technology, (2) Geothermal Energy Conversion Technology, (3) Reservoir Engineering, and (4) Geothermal Environmental Research.

Exploration Technology projects deal with generic research to improve our ability to locate and define a geothermal reservoir using surface, mainly geophysical, techniques. Historically, our emphasis has been on electrical, electromagnetic, and seismic techniques because of the expertise available to us at the University of California, Berkeley, and because of the recognized need to evaluate and develop these techniques to the point where they can be better used by industry. Tests and demonstrations of research results are done by LBL at various geothermal sites as part of sitespecific resource assessments (e.g., Mt. Hood and Klamath Falls, Oregon, and northern Nevada sites) or as site-specific reservoir definition studies (e.g., Cerro Prieto). Technology transfer to industry in this and other program areas is an everpresent concern; one that is accomplished through workshops, conferences, and consultations with geothermal developers and field demonstrations.

Geothermal Energy Conversion Technology projects develop basic data and analytical tools in heat exchange and thermodynamics needed for the development of moderate-temperature geothermal resources. LBL has been studying the thermodynamic properties of isobutane/isopentane mixtures to learn how to optimize binary Rankine cycle heat conversion to electric power for various resource temperatures. We are also managing the design, fabrication and testing of a $500-\mathrm{kW}$ pilot plant using a directcontact heat exchanger. This energy conversion process may have potential importance to the economics of second-generation geothermal power plants.

Reservoir Engineering studies can be subdivided into two main areas: fundamental research and reservoir case studies. Under the first, LBL manages a Geothermal Reservoir Engineering Management Program (GREMP) for the U.S. Department of Energy Division of Geothermal Energy, for which LBL prepares and implements a research program involving various academic, industry, and other research groups. Tied into the overall plan are the separate in-house research efforts consisting of (a) the development and testing of new and improved geothermal well test equipment, field techniques, and interpretative methods; (b) the development of reservoir simulation codes capable of dealing with two-phase conditions in the reservoir wel1-bores and mixtures of $\mathrm{H}_{2} \mathrm{O}-\mathrm{CO}_{2}$ gases; and (c) modeling the hydraulic stimulation of reservoirs. In the area of reservoir case studies, LBL directs for DOE a U.S./Mexican cooperative study of the Cerro Prieto, Baja California, geothermal field. The elements of this study are geologyhydrology, geochemistry, geophysics, and reservoir testing and modeling. We have also provided advice on reinjection. LBL also assists DOE in evaluating reservoir data for the Valles Caldera, New Mexico, the site of a 50-MW demonstration plant.

Geothermal Environmental Research consists of subsidence, induced seismicity, and brine chemistry. LBL manages for DOE a Geothermal Subsidence Research Program (GSRMP) for which we prepare and implement research efforts into the causes, prediction, monitoring, and mitigation of subsidence. Research contracts are given to academic, industry, and other laboratory groups. In addition, LBL also maintains an in-house research component which has been chiefly concerned with and has succeeded in developing a numerical code that provides new insight into the possible physical mechanisms of the complex subsidence at Wairakei, New Zealand.

Induced seismicity work, which ties in closely with subsidence and the general topic of reservoir dynamics under production conditions, involves monitoring at East Mesa and Cerro Prieto. 


\title{
Geothermal Exploration Technology
}

\section{INTERPRETATION OF ELECTRICAL AND ELECTROMAGNETIC SURVEY DATA}

\author{
H. F. Morrison, K. H. Lee, E. Mozley, and M. Hoversten
}

\section{INTRODUCTION}

As part of a continuing research and development program directed towards interpreting electrical and electromagnetic survey data, a number of computer programs have been written to calculate the response of one-, two-, and three-dimensional subsurface structures to electromagnetic sources. Sources of interest are plane electromagnetic waves (for magnetotelluric studies) and current loop magnetic dipoles (for controlled-source EM studies.)

In addition, an integrated interpretation procedure has been developed and used on magnetotelluric field data from Mt. Hood, Oregon.

PROGRESS IN FISCAL YEAR 1979

In this section we summarize the features of various computer programs that have been developed or improved upon during fiscal year 1979 .

\section{Program DECAY}

DECAY calculates the electric and magnetic fields on or above a layered earth in both the frequency and time domains. The EM source is a current loop of arbitrary radius on or above the surface. The earth response is calculated in the frequency domain via equations given by Morrison et al. (1969). To obtain the time-domain response for a given current waveform, we multiply the waveform harmonics by the earth response and these products are added in a Fourier series to give the transient response.

\section{Program GRADMAG}

GRADMAG calculates the induced electric fields within a layered earth for a current loop source. The E fields are calculated as a function of frequency and transformed to the time domain. This program is being used to understand the relationships between the induced $E$ field in the ground and the observed electric and magnetic fields on the surface.

\section{Program TDINVER}

TDINVER is a weighted-least-squares algorithm for finding layered models that fit time-domain electromagnetic sounding data. This program is now under development and will be refined in the coming year.

\section{Program HYBRID}

Program HYBRID calculates the electric and magnetic fields scattered by a three-dimensional inhomogeneity of finite extent buried in a one- or two-layer half space. The algorithm is based on two independent sets of equations: (1) a system of finite-element equations derived from a variational integral and (2) a set of equations obtained from the integral relations between the field at the boundary and the field inside the boundary. The maximum size of the inhomogeneity that we can model with the program is 1 imited up to $10 \times 10 \mathrm{x}$ 10 array. The program uses $47 \mathrm{~K}$ decimal words in small core memories (SCM) along with four disk files. Both magnetic dipole (vertical or horizontal) and plane wave sources can be used.

\section{Program MSE2D}

Program MSE2D has been written exclusively for a magnetic dipole source on or above a twodimensional half space, where the extent of the inhomogeneity can be arbitrary. The method used is a finite element technique with a mesh limited to $55 \times 18$ nodes in $x$ and $z$ directions, respectively. The memory requirement is $46 \mathrm{~K}$ in SCM, $295 \mathrm{~K}$ in LCM, and one disk file.

\section{Program ESE2D}

The algorithm for this program is exactly the same as the one used for MSE2D. The only difference is that program ESE2D calculates the fields for a grounded electric dipole source. This program is used in the evaluation of the controlledsource AMT technique.

\section{Program TEMINTG}

Program TEMINTG has been written to study scattering by a simple two-dimensional inhomogeneity where the primary field is a normally incident plane wave with arbitrary orientation with respect to the inhomogeneity. The technique used is the integral equation point-matching method. The TE-mode plane wave solution was given by Hohmann (1971). The integral equation solution for the TM-mode incident has been developed recently by Lee (1980). If the inhomogeneity contains less than 100 cells we find that this program is less expensive to run than the finite element solution developed by Ryu (1971). This program uses $38 \mathrm{~K}$ words of SCM and $123 \mathrm{~K}$ words of LCM.

Interpretation of MT Data from Mt. Hood, Oregon

For processing and displaying of multi-site magnetotelluric data we have developed programs capable of treating and displaying large amounts of data, e.g., regional strike and impedance estimates as a function of frequency as well as angle of rotation and position.

Three different one-dimensional inversion techniques have been used on selected MT field data from Mt. Hood, Oregon, and the results were compared. The first method used, and the one most relied upon, was the discrete iterative inversion 
method developed by Jupp and Vozoff (1977). Second, the iterative-continuous method by o1denberg (1979) was used in a limited manner. This technique iteratively constructs a model minimizing the residual error and evaluates the model via Backus-Gilbert techniques. The third approach was a continuous inversion based on non-uniform transmission line solutions via rational approximations developed by Becher and Sharpe (1969). Stability problems were encountered which limited the use of this approach.

For the second stage of interpretation we concentrated on local areas where a two-dimensional conductivity structure dominates the frequency response of the earth. Two approaches were used. First, we used forward modeling using programs by Lee (1978) and Lee and Pridmore (1979) to first approximate the observed responses. Then, where possible, an automatic inversion scheme by Jupp and Vozoff (1977) was used. This method is similar to their one-dimensional inversion, with the forward problem being calculated by the network methods developed by Madden (1972).

A study of effect of topography on MT data was begun. The initial studies were done using an integral equation method developed by Oppliger (1980). This provided the dc current distributions in the region for plane wave sources.

PLANS FOR WORK IN FISCAL YEAR 1980

One of the top priorities will be to document the computer programs developed in 1979, and to provide user's instructions.

Independent of the forward-modeling technique development, we will also give a high priority to the generalized direct inverse problem associated with EM waves. Initial studies have uncovered a new technique which may allow us to reconstruct the shape and location of a scatterer directly from the reflected tangential electric and magnetic fields measured on an arbitrary surface. This approach to EM interpretation will be evaluated for simple scattering bodies, such as circular cylinder.
REFERENCES CITED

Becher, C. N., and Sharpe, C. B., 1969. A synthesis approach to magnetotelluric exploration. Radio Science, v. 4, no. 11, p. 1089.

Hohmann, G. W., 1971. Electromagnetic scattering by two-dimensional inhomogeneities in the earth. (Ph.D. dissertation) Berkeley, University of California.

Jupp, D. L. B., and Vozoff, K., 1975. Stable iterative methods for the inversion of geophysical data. Geophysical Journal R. Astr. Soc., v. 42, p. 957.

, 1977. Two-dimensional magnetotelluric inversion. Geophys. Journa1 R. Astr. Soc., v. 50, p. 333 .

Lee, K. H., 1978. Program TEM-two dimensiona1 plane wave scattering solution by the finite element method for a two-dimensional conductivity distribution. Berkeley, University of California.

1980. A solution for TM-mode plane waves incident on a two-dimensional inhomogeneity. To be submitted to Geophysics.

Madden, J. R., 1972. Transmission systems and network analogies to geophysical forward and inverse problems. Cambridge, Mass., Massachusetts Institute of Technology Technical Report N000-14-67-A 0204-0045.

Morrison, H. F., Phillips, R. J., and O'Brien, D. P., 1969. Quantitative interpretation of transient electromagnetic fields over a layered half space. Geophysical Prospecting, v. 17 , no. 1, p. 82 .

Oldenburg, D. W., 1979. One-dimensional inversion of natural source magnetotelluric observations. Geophysics, v. 44, no. 7, p. 1218.

Oppliger, G. L., 1980. Program MTOPO: Electric potential solution in the vicinity of a three-dimensional topographic feature ( $\mathrm{Ph} . \mathrm{D}$. dissertation). Berkeley, University of California.

Ryu, J., 1971. Low frequency electromagnetic scattering (Ph.D. dissertation). Berkeley, University of California.

\section{FIELD PROCESSING OF MAGNETOTELLURIC DATA}

\section{J. Clarke, T. D. Gamble, W. M. Goubau, R. Koch, and R. Miracky}

\section{INTRODUCTION}

Recent advances in semiconductor technology have reached the point that battery-operated microcomputers can now analyze magnetotelluric data in the field. In 1979 we completed the construction of a system based on a Digital Equipment Corporation LSI-11 microcomputer for in-field magnetotelluric analysis and used it for the execution of several surveys.

\section{PROGRESS IN 1979}

The LSI-11 has proven to be a very fieldworthy instrument, performing in real time a data analysis essentially identical to that formerly done on the CDC-7600 computer at LBL. The system operates on approximately $200 \mathrm{~W}$ provided by $12-\mathrm{V}$ golf-cart batteries. The limited capacity of the battery power supply, however, restricts the peripheral equipment that can be used in the field and this limits the quality and modes of results presentation. Therefore, our present analyses are limited to those selected by the operator to evaluate the quality and sufficiency of the data. Final data selection and graphic display are performed in the laboratory.

Figure 1 is a block diagram of the complete magnetotelluric data collection system. Our mag- 
Data Collection System
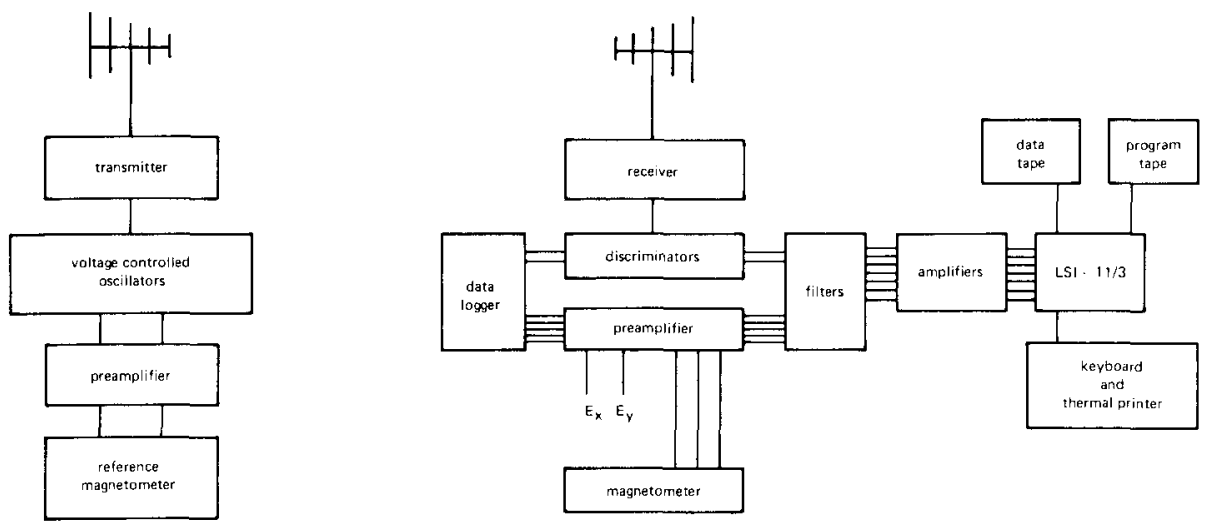

Figure 1. Block diagram of the magnetotelluric

data collection system. (XBI 7910-13064)

netotelluric measurements are always made with the remote reference technique (Gamble, 1978; Gamble et a1., 1979a,b). The equipment at the remote site, shown at the left of the figure, consists of a dc SQUID magnetometer, preamplifier, and FM analog telemetry equipment. Horizontal components of the magnetic field changes at the remote site are telemetered to the base station. At the base station the horizontal components of the electric field and three components of the magnetic field are preamplified, the remote signals are received, and then two simultaneous operations, described below, are performed on all seven channels.

Al1 seven channels are digitized at a sampling rate of $1 \mathrm{~Hz}$ by the data logger so that the longperiod digital data can be stored for later analy- sis. Simultaneously, the signals are bandpass filtered, digitized at a selectable rate by the LSI-11 microcomputer, and analyzed in real time to determine the average autopower and crosspowers between all channels. These average powers are written on magnetic tape to be the permanent record of the high frequency measurements. A second tape deck is used to load the programs into the computer.

The operation of the programs is outlined in Figure 2. The analysis is split into two main programs, GGUT and RESULTS, to maximize the capacity of the hardware. GGUT is written entirely in MACRO assembly language to maximize the speed of the real-time calculations and to minimize the size of the program. GGUT controls the digitization of the data, performs the Fourier analysis and compu-
GGUT

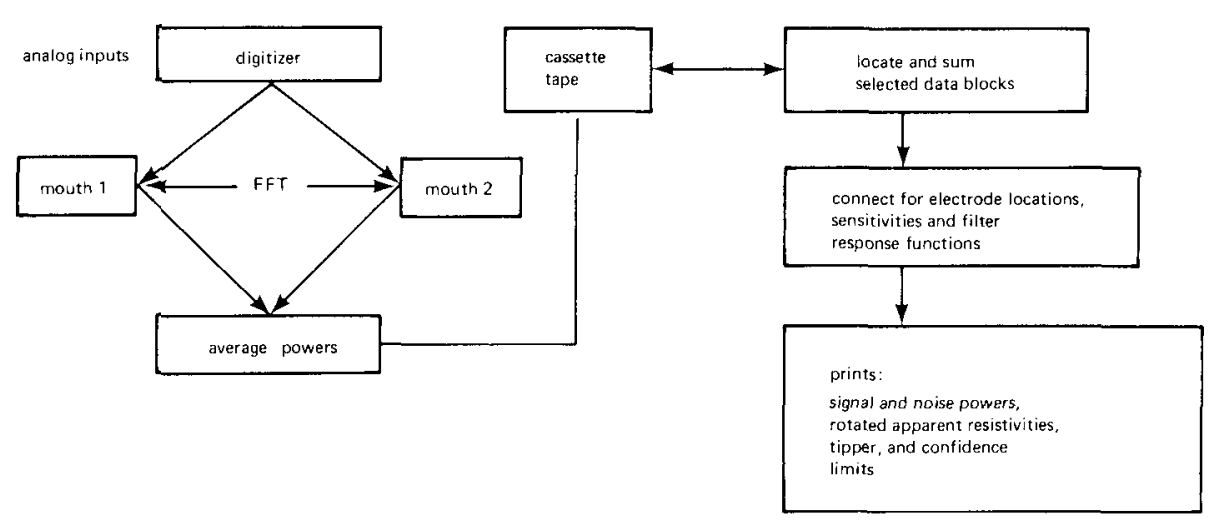

Figure 2. In-field processing of magnetotelluric data. 
tation of average powers, and writes them on the data tape. RESULTS is written in FORTRAN for ease of modification and to provide more sophisticated input-output formats. It reads the average powers of selected blocks of data from the data tape and prints out the results desired by the operator on a thermal printer.

The analysis proceeds as follows. The digitizer samples the channels under the control of a programmable clock. This digitization rate is limited to about $6 \mathrm{kHz}$ by the software and could be easily increased to the hardware limit of about $40 \mathrm{kHz}$. When a 1024-point data segment has been completed, the digitization continues to fill a second input buffer while the Fourier analysis is performed on the first data segment. The average powers are computed within frequency windows equally spaced on a logarithmic scale and are added to the average powers from previous data segments. This analysis requires 16 seconds for several channels of data. If the analysis is not completed by the time the second input buffer fills, then the sampling is simply discontinued until the analysis is complete and the first buffer is free again. When the operator feels that sufficient data have been collected he halts the collection and directs the LSI-11 to write the average powers on the data tape. The RESULTS program then reads and averages selected blocks of average powers from the data tape, corrects these for electrode lengths, dipole orientations, filter response functions, and magnetometer sensitivities. The results are printed, as specified by the operator. These may include the signal-to-noise ratios of any measurement, the rotated apparent resistivities with their phases, rotation angles, skewnesses and tipper magnitudes, and phases, all with their probable errors. Examples of data collected and analyzed with this system are included in another article in this volume, "Magnetotelluric Studies at Cerro Prieto."

\section{PLANS FOR FISCAL YEAR 1980}

The LSI-1 I microcomputer has proven to be a fieldworthy instrument powerful enough for all the calculations involved in real-time magnetotelluric data analysis. More importantly, as a research tool, the system can be reprogrammed to perform almost any analysis of electromagnetic measurements involving up to 16 channels of data. Thus it is an integral tool for further studies involving simultaneous measurements at several sites. Such studies may include investigating the coherence length of the incident electromagnetic fluctuations, determining the noise spectra, and performing relative calibrations of various types of magnetometers in the field.

\section{REFERENCES CITED}

Gamble, T. D., 1978. Remote reference magnetotellurics with SQUID (Ph.D. dissertation). Berkeley, University of California, and Lawrence Berkeley Laboratory, LBL-8062.

Gamble, T. D., Goubau, W. M., and Clarke, J. 1979a. Magnetotellurics with a remote magnetic reference. Geophysics, v. 44, no. 1, p. 43-68. , 1979b. Error analysis for remote reference magnetotellurics. Geophysics, v. 44, no. 1, p. 959-968.

\section{AUTOMATED SEISMIC PROCESSOR}

\section{T. V. McEvilly, E. L. Majer, J. Bartschi, J. Heinsen, and R. O'Connell}

\section{SYSTEM DESCRIPTION}

As first conceived, the Automated Seismic Processor (ASP) is a low-power ( $1 \mathrm{~W} /$ per channe1), fast 16-bit, in-field seismic data processing computer (McEvilly et al., 1979). The ASP is designed around the RCA 1802 COSMAC CMOS microprocessor. Its principle use is for microearthquake detection and analysis. In 1979 a 16-channel ASP was built. It has essentially met all specified requirements. ASP is a parallel processing device with 15 microcomputers (WORKERS) responsible for feeding preprocessed data to a central microcomputer (the BOSS) for final processing (Figure 1). Each WORKER as well as the BOSS is capable of addressing $32 \mathrm{~K}$ of memory, either PROM or RAM. Presently the WORKERS each contain $4 \mathrm{~K}$ of RAM and $12 \mathrm{~K}$ of PROM. The BOSS contains $8 \mathrm{~K}$ of RAM and $24 \mathrm{~K}$ of PROM memory. The WORKER and BOSS programs are configured as shown in Figure 2 . The routines SYSTEM, MISC, and SINTP are service programs that handle the intialization of the CPU, the basic interrupts and the calls and returns between the BOSS and WORKER computers. These routines also handle the BOSS messages, printing of output, input processing and the manipulation of data. 'Worker' in the WORKER, and 'boss' in the BOSS are the main computer programs from which all calls to the different subroutines are made.
ICALC in the WORKER handles the ADC interrupt routines that sample the data, remove the dc component, form the long-term-average (LTA), the shortterm-average (STA), check for trigger, and time the arrival of the $P$-phase, if there is a trigger, all in real time between samples. At present, the maximum sample rate is 100 samples/sec with the CPU clock rate at $2 \mathrm{MHz}$. By increasing the clock rate to $3 \mathrm{MHz}$ and cleaning up the program it is anticipated that a sample rate of 200 samples/sec can be achieved. Except for the FFT routines, all arithmetic in the WORKER is done in fixed point format. Also, every effort is made to use multiplication and division by twos. FIX is the RCA fixed point arithmetic package. Figure 3 is an example of the worker operations. If $x\left(t_{i}\right)$ is the original time series (the mean is first removed by subtracting a 4096 point long-term average), then a new time series $x^{\prime}\left(t_{i}\right)$ is formed as:

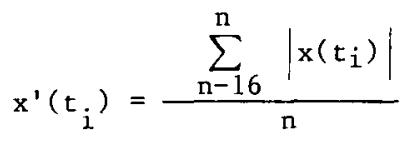

i.e., rectifying the time series and smoothing with an n-point boxcar. For microearthquake data 

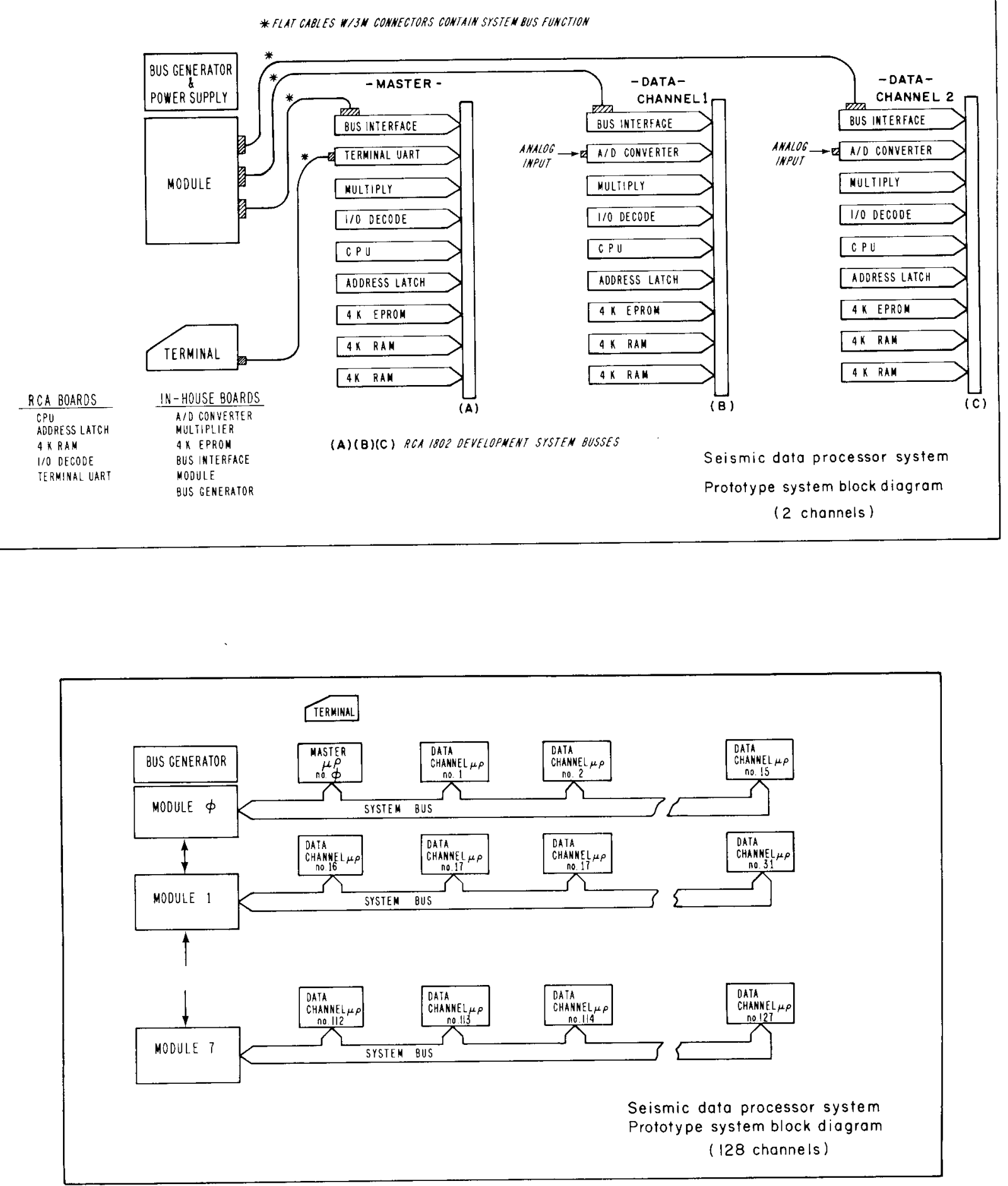

Figure 1. Top: Block diagram, two-channel prototype seismic data aquisition/processing system, showing card structures for BOSS (master) and WORKER (channel) modules. Bottom: Generalized block diagram of 128-channel seismic field system, illustrating 16-channel modular architecture. (XBL 7812-14137; XBL 7812-14138) 


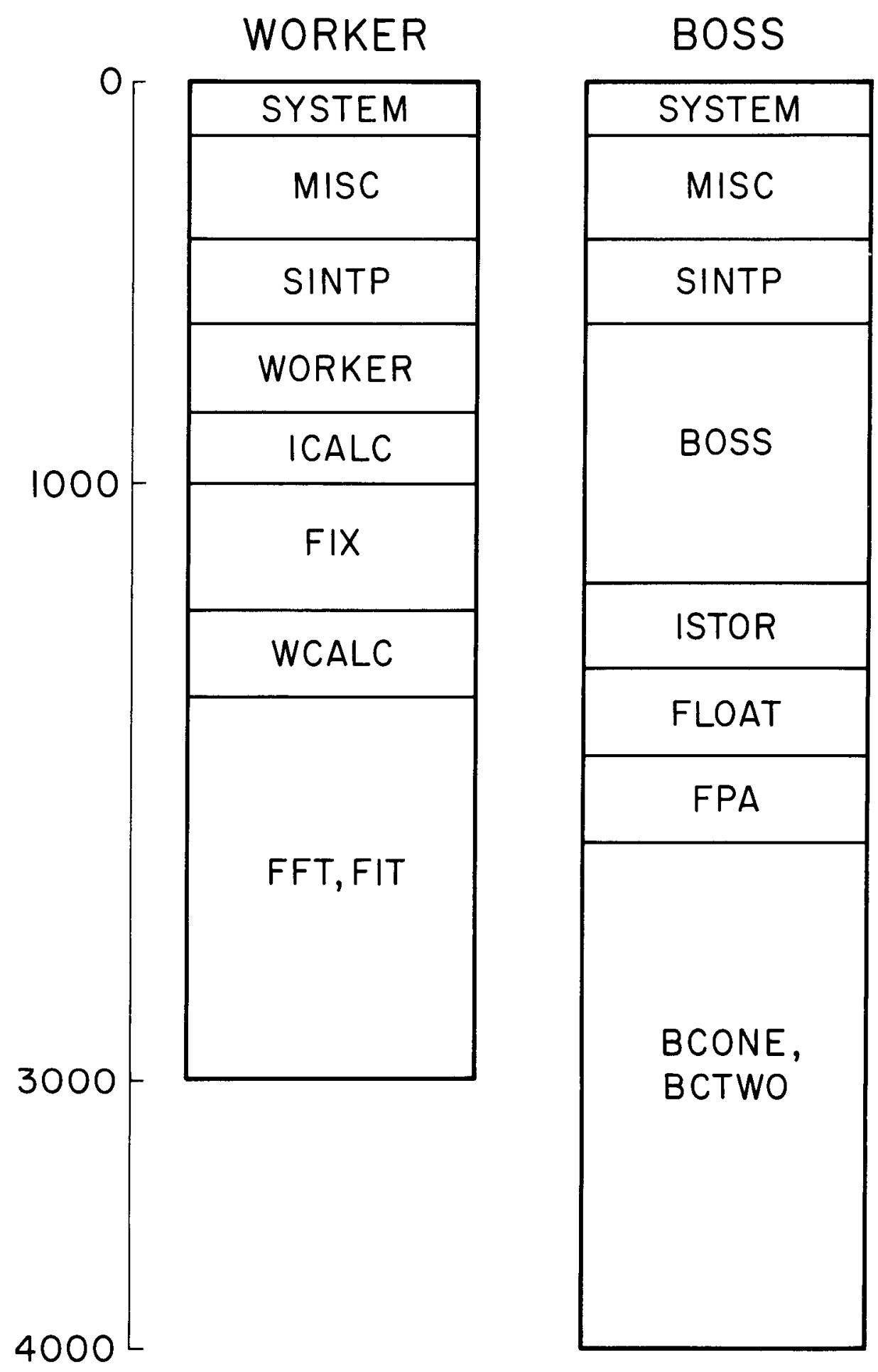

Figure 2. System program maps for WORKER and BOSS showing program location and lengths. Numbers are in hexadecimal. (XBL 807-7257) 

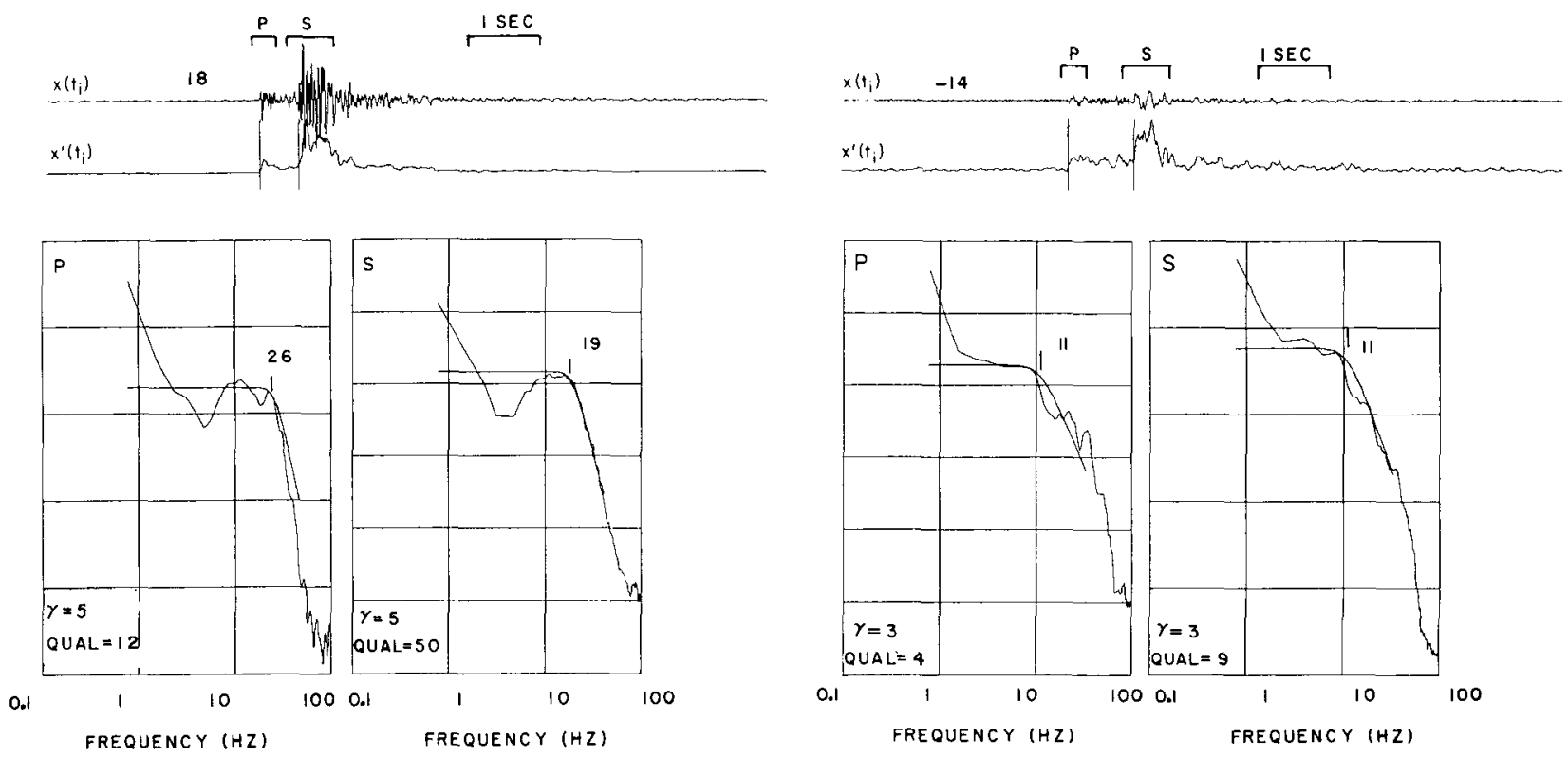

Figure 3. Examples of ASP processing and two different events. Shown on each event are the $P$ and $S$ windows selected for FFT processing polarity of the events $(18$ and -14$)$ quality of $P$ waves and $S$ waves $(P=12,4, S=50,9)$, arrival times of $P$ and $S$ waves [bars on $x^{\prime}\left(t_{i}\right)$ ] corner frequences $(26,19,11,11)$ and high frequency slope values $(\gamma=5,5,3,3)$.

(XBL 802-8307)

sampled at $200 \mathrm{samples} / \mathrm{sec}, \mathrm{n}=16$ was found to be the optimum window. $x^{\prime}\left(t_{i}\right)$ is then analyzed for detection and timing of the $P$ - and $s$-waves, as shown in Figure 3. To do so, a 16-point shortterm average (STA) and a 4096 long-term average (LTA) are taken on $x^{\prime}\left(t_{i}\right)$. When STA $=c_{1}$ * LTA, a trigger point is found. However, the time when STA $=C_{2}$ * LTA, $\left(C_{2}<C_{1}\right)$, is taken to be the Pwave arrival time, PT. Because $\mathrm{C}_{2}$ is less than $\mathrm{C}_{1}$, PT will always be before the trigger point. Typical values for $C_{1}$ and $C_{2}\left(C_{1}, C_{2}\right.$ are variable input parameters) are 3 and 1.25 respectively. After an event is detected and the p-wave is timed, further processing requires that the worker be put in a "hold" mode to prevent subsequent event detection. The LTA and STA are still computed but detection is disabled. The P-wave amplitude, $\mathrm{PA}$, is found by taking the average of the next 64 points after the PT. The quality of the P-wave, $P Q$, is $P A /$ (the LTA just prior to trigger). At this point, $P T, P A, P Q$ are sent to the BOSS. An S-wave is detected when STA $=C_{3}$ *PA and its arrival time, ST, is at STA $=\mathrm{C}_{4} * \mathrm{PA}$, with $\mathrm{C}_{3}=2$, and $\mathrm{C}_{4}=1.5$. SA, S-wave amplitude, is the average of the next 128 points after ST. S-wave quality, $\mathrm{SQ}=\mathrm{SA} /$ (LTA just prior to P-wave trigger). With $S T$ and PT, the S-P time, DT, is calculated and variable window lengths around the $\mathrm{P}-$ and $\mathrm{S}$-waves for the FFTs are selected. ST, SA, SQ, and DT are then sent to BOSS. The polarity of the P-wave, $P P$, is then calculated and sent to BOSS, PP is formed by summing the four points after PT, then dividing this difference by the LTA prior to the $P$-wave trigger. The sign of this result, $+=$ up, - = down, is the direction of the first motion, and its magnitude is the quality of the polarity determination, i.e., the degree of sharpness of the onset. The event is over when the STA of $x^{\prime}\left(t_{i}\right)$ is less than 1.25 * (LTA prior to trigger) for 256 points.

After an end is detected, the FFTs are then calculated and fit in FFT and FIT. Before an FFT is done, a cosine taper is applied to the demeaned data. The resulting spectra are then smoothed with an eight-point boxcar and corrected for instrument response before the long period level, corner frequency and high frequency roll-off are calculated. The window lengths depend on the DT ( $S-P$ time), and are either 64,128 , or 256 points for the P-wave, and 128,256 , or 512 points for the S-wave. Each FFT result is fit for long period level, corner frequency, and high frequency slope, $\gamma$, with a $\gamma$-pole Butterworth filter, i.e.,

$$
A=\frac{1}{\left[1+\left(f / f_{o}\right)^{2} \gamma\right]^{1 / 2}}
$$

These results, along with the window lengths used, are sent to BOSS for further processing. After completion of the FFT, WORKER is ready to start looking for another event. However, until BOSS sends a release to each WORKER the hold mode is still in effect. This is to insure that Boss has completed its duties before another set of data is taken in.

The order of messages on the line between BOSS and the WORKERS is determined by a system priority, with BOSS having number one priority. This allows Boss to perform abortions on the WORKERS if certan specified parameters or quality 
criteria are not met, and to return the WORKERS to looking for anothex event if BOSS determines that the event presently being processed is marginal. Upon power-on, the user is interrogated by Boss to determine triggering levels, minimum detection, and quality criteria, desired BOSS processing, station coordinates, number of stations, and other input parameters. All communication to the WORKERS is through the BOSS via keyboard input. All output is also performed by BOSS on a small printer.

'Boss' in the Boss computer is the main routine which controls the rest of the Boss programs. ISTOR picks up the BOSS messages (i.e., PT, PA, $\mathrm{PQ}, \mathrm{ST}, \mathrm{SA}, \mathrm{SQ}, \mathrm{DT}, \mathrm{PP}, \mathrm{FFT}$ results) and stores them in tables corresponding to the WORKER Number. FLOAT and EPA handle the fixed point to floating point conversion and the floating point arithmetic which is done in BOSS. Presently the arithmetic is done with an RCA software package. However, to increase the speed of calculation an Arithmetic Logic Unit is planned to handle all the floating point arithmetic in BOSS. Because the ALU requires a relatively large amount of power, it will only be used in BOSS. The WORKERS handle the floating point multiplication through an in-house designed hardware multiply board.

BCONE and BCTWO are the routines which contain the different modes of operation within BOSS.

The different modes are:

1. Event count, total number of events that meet specified requirements.
2. b-values, both cumulative and interval, using $P A$ and SA (maximum likelihood).

3. Event location.

4. Poisson's ratio using Wadati's method.

5. Source characteristics (moment, stress drop, displacement, fault area) from the spectral characteristics.

Also planned but not yet incorporated in the BOSS is the fault plane solution. Presently the first motions are printed out for each station. Another mode is the debug mode which prints out all the data from the Boss tables. These tables contain the information sent from each worker for a particular event. Any combination in any order of the above modes may be chosen.

\section{FUTURE ACTIVITIES}

ASP will be housed in a field van presently being modified. Its first field test will be in Spring 1980 at a geothermal site with known seismic activity. Another ASP presently under construction will be used for monitoring acoustic emissions at the climax stock nuclear waste repository at the Nevada test site. Besides geothermal exploration ASP will also be used for monitoring geothermal reservoir dynamics associated with fluid withdrawal and reinjection.

\section{CONTROLLED-SOURCE ELECTROMAGNETIC MEASUREMENTS AT GEOTHERMAL SITES IN NEVADA}

M. J. Wilt, N. E. Goldstein, R. Haught, and M. Stark

\section{INTRODUCTION}

In 1976 LBL, in conjunction with U.C. Berkeley, made preliminary measurements with a prototype large-moment, horizonta1-10op EM prospecting system (Jain, 1978) in a geothermal area in Nevada. Encouraging results from this work led to the development of the EM-60 horizonta1-loop system (Morrison, et al., 1978), which has now been operated for over 500 hours at various geothermal sites in Nevada and Oregon.

The objectives of the controlled-source EM project are to develop new hardware and software tools for geothermal exploration. The LBL program is designed to fill the gap in existing technology with EM and to demonstrate the technical feasibility and cost-effectiveness of the technique to industry.

The EM method may be a significant improvement over existing techniques [dc resistivity and magnetotellurics (MT)] in geothermal exploration for three reasons. (1) The depth of exploration with EM is approximately equal to the distance between the transmitter and receiver; this is almost five times the source receiver separation for dc resistivity. (2) The EM method is faster and less expensive than dc resistivity or MT. (3) Distant lateral inhomogeneities, which often affect MT data, have relatively minor significance for EM because the strength of the fields strongly decreases with increasing distance from the transmitter.

\section{SYSTEM DESCRIPTION}

With the EM-60 system the earth is energized by means of alternating magnetic field created by a square-wave current applied to a horizontal loop (Figure 1). Power is provided by a Hercules gasoline engine linked to an aircraft $60-\mathrm{kW} 400-\mathrm{Hz}$, three-phase alternator. The output is full-wave rectified and capable of providing $150 \mathrm{~V}$ at up to $400 \mathrm{~A}$ to the loop. The current waveform is created with a transistorized switch, controlled remotely by the operator who sets the fundamental frequency over the ranges of $10^{-3}$ to $10^{3} \mathrm{~Hz}$ (Morrison et al., 1978). In practice, four turns of \#⿰ welding wire in a circular loop, $50 \mathrm{~m}$ in radius, yields a dipole moment of about $3 \times 10^{6}$ mks, corresponding to a current of $65 \mathrm{~A}$. This configuration has been found satisfactory for most normal exploration activities where the maximum depth of exploration is 1 to $3 \mathrm{~km}$.

The fields are detected at a point 1 to $4 \mathrm{~km}$ distant from the transmitter with a three-component SQUID magnetometer oriented to measure the vertical, radial, and tangential components with respect to the loop. Signals are amplified, anti-alias fil- 


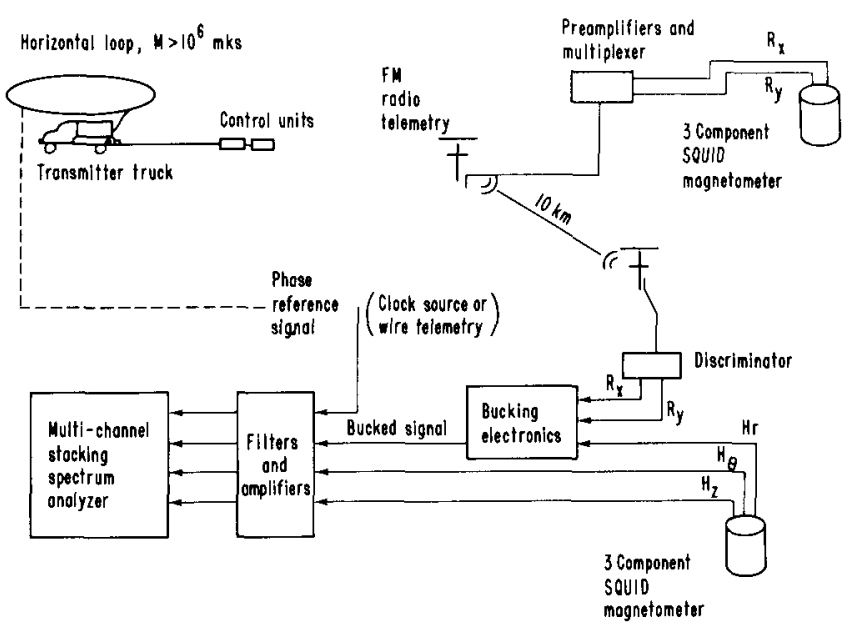

Figure 1. Schematic diagram of the EM-60 horizontal loop electromagnetic prospecting system as used in Nevada in 1979 .

(XBL 797-11400)

tered and input to a six-channel, programmable, multi-frequency phase-sensitive receiver. Through the receiver key-pad the operator sets parameters controlling signal processing: (a) fundamental period of the waveform to be processed; (b) maximum number of harmonics to be analyzed, up to 15 ; (c) number of cycles in increments of $2^{\mathrm{N}}$ to be stacked prior to Fourier decomposition; and (d) number of input channels of data to be processed. Processing results in a raw amplitude estimate for each component and a phase estimate relative to the phase of the current in the loop. Phase referencing is maintained with a hard-wire link between a shunt on the loop and the receiver and this reference voltage is applied directly to channel 1 of the receiver for phase comparison. Raw amplitude estimates must be later corrected for dipole moment and distance between loop and magnetometer.

In practice the hard-wire link was found to be a source of noise, particularly above $50 \mathrm{~Hz}$. This has required the elimination of the absolute phase reference at high frequencies in favor of relative phase measurements between vertical and radial components. With relative phase measurements interpretation is based on the ellipticity and tilt angle of magnetic field rather than amplitude-phase of the vertical and radial fields.

Basic interpretation is accomplished by comparing field curves with calculated curves. Usually, amplitude-phase or ellipticity spectra are fit to one-dimensional layer model curves by trial and error or direct inversion. Two-dimensioal modeling, although possible, is currently cumbersome and prohibitively expensive (Lee, 1979).

\section{ACTIVITIES IN 1979}

The most significant change to field procedures in 1979 was the addition of a reference magnetometer to the system for geomagnetic "noise" cancellation. At low frequencies $(\leq 0.1 \mathrm{hz})$ natural geomagnetic signal amplitude increases roughly as $1 / f$ while the signal sought decreases as $1 / f$. The net result is an effective signal-to-noise ratio that decreases as $1 / \mathrm{f}^{2}$, making noise cancellation imperative for recovery of low-frequency information. In practice, the reference magnetometer is placed at least 10 to $12 \mathrm{~km}$ from the transmitter $100 \mathrm{p}$, so that the observed fields will consist only of the geomagnetic fluctuations (Figure 1). Once installed, the reference magnetometer can often remain fixed over the course of a survey. The remote signals are transmitted to the mobile receiver station from the transmitter via FM radio telemetry. Before the loop is energized, the remote signals are inverted, adjusted in amplitude, and then added to the base station geomagnetic signal to produce essentially a nu11 signal. A good example of this simple noise cancellation scheme is shown in Figure 2. The resulting signal-to-noise improvement of roughly $20 \mathrm{~dB}$ has allowed us to obtain reliable data to $0.05 \mathrm{~Hz}$, a gain of three or four important data points on the sounding curve. These points are invaluable for resolution of deeper horizons.

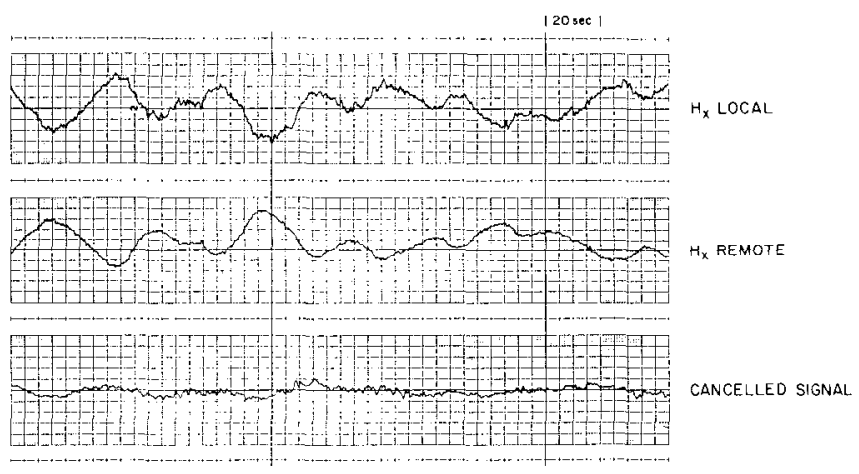

NATURAL MAGNETIC FIELD CANCELLATION

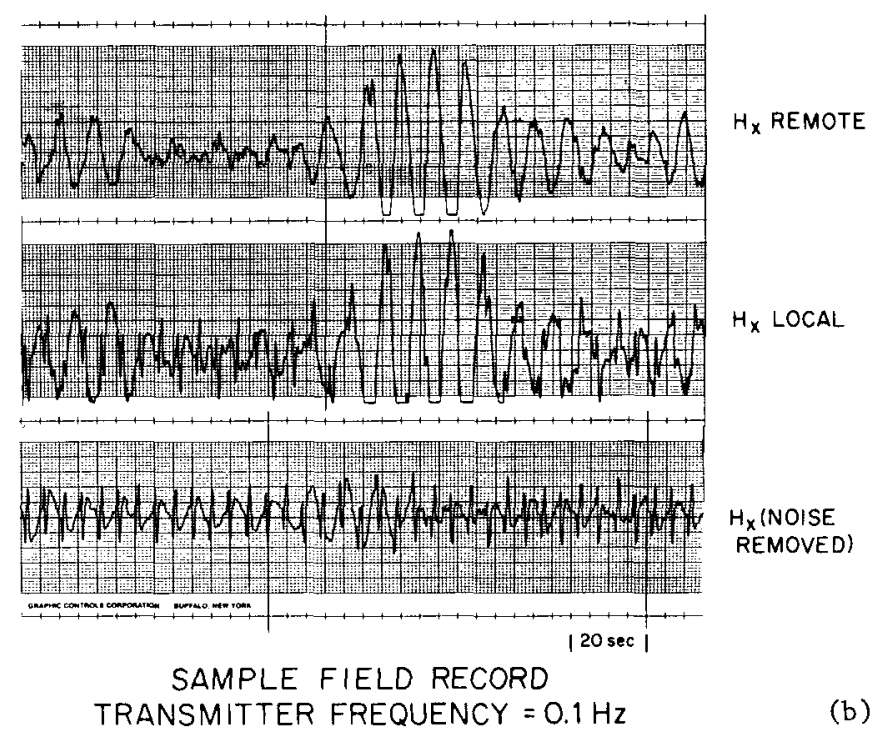

Figure 2. Example of data improvement using the telluric noise cancellation scheme. (a) Natural geomagnetic signal and initial cancelling at the receiver site with transmitter off; (b) the same system but with transmitter on.

(a) XBL 7911-13079; (b) XBL 7911-13078 
As part of the DOE Industry Case Studies Program for the northern Basin and Range province, LBL conducted EM-60 surveys at three geothermal target areas in northern Nevada: Panther Canyon in Grass Valley, Soda Lake near Fallon, and McCoy west of Austin (Figure 3). Using the noise cancellation scheme, we obtained two soundings per day during favorable weather conditions. A total of more than 40 soundings were made at the three sites, some under conditions of high wind, low temperatures and snow. Because most of the data were collected between August and November, a complete analysis and interpretation is not yet ready. A summary of findings, however, for each prospect area is reported below:

\section{Panther Canyon}

At this site eight receiver stations relative to one transmitter loop were occupied along two orthogonal survey lines originally used by LBL for dipole-dipole resistivity profiling (Beyer, 1977). Good quality data were obtained from 0.1 to $500 \mathrm{~Hz}$. The data were collected to investigate the geometry and extent of a long, narrow conductive body originally detected with the dc resistivity measurements. The body may be related to a heat flow high centered over the same region so its determination may have some geothermal significance.

In Figure 4 the two-dimensional dipole-dipole resistivity model calculated by Beyer (1977) is shown over the section corresponding to the long

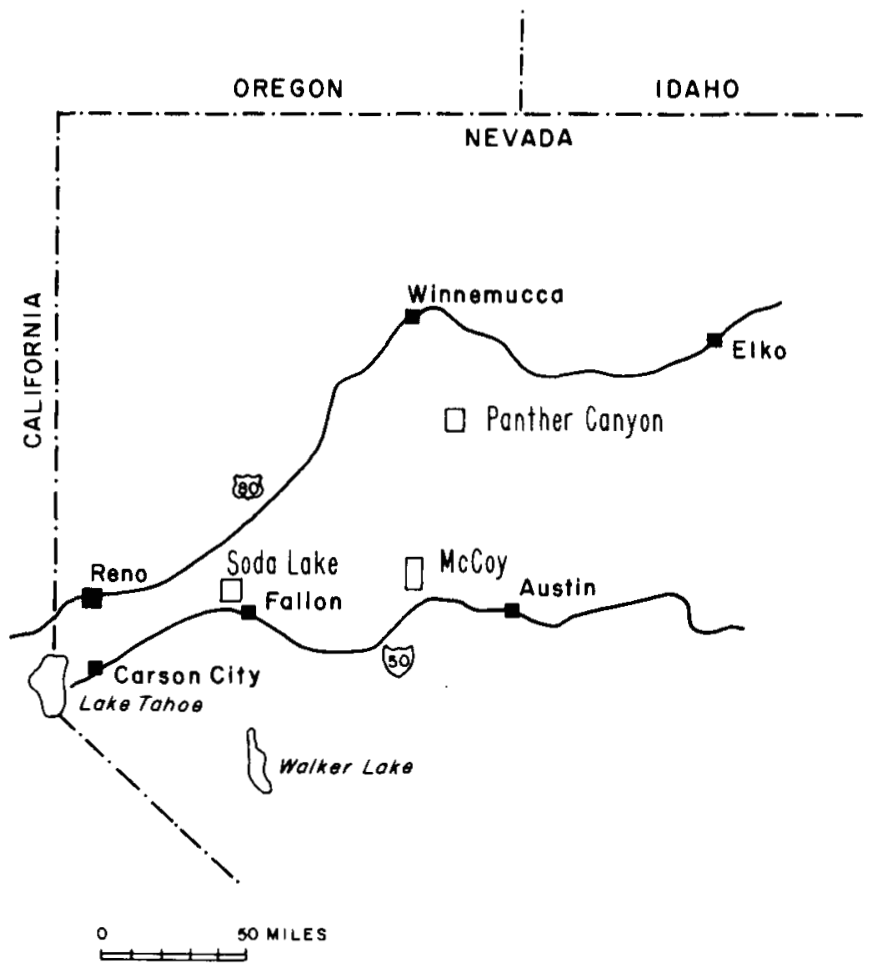

Prospect orea

Figure 3. Prospect location map for the 3 EM-60 surveys conducted in 1979 by LBL. (XBL 802-6771) dimension of the conductive body; also shown is the EM-60 sounding profile over the same line. Although the two models give similar information, the differences in the techniques are: (a) the acquisition cost of the dipole-dipole data is approximately three times that of EM-60 data; (b) the EM profile is based on one-dimensional inversions so that the depths to the various horizons are weighted average values for the region between the transmitter and receiver; the EM soundings therefore give a smooth version of the resistivity cross-section.

Samples of EM-60 amp1itude-phase spectra soundings are given in Figures 5 and 6 ; the error bars signify one standard deviation. The fit to a threelayer model is fairly good, but note that data were interpreted only to $50 \mathrm{~Hz}$ because high noise due to the use of the reference wire prohibited obtaining higher frequency amplitude-phase data. Ellipticity data, however, could usually be interpreted to $500 \mathrm{~Hz}$.

Grass Valley, Line $T-T^{*}$

Dipole-Dipole Resistivity Model

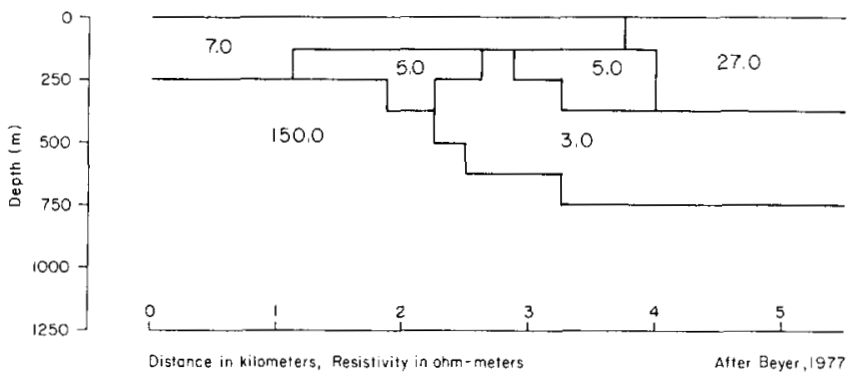

EM-60 Resistivity Profile
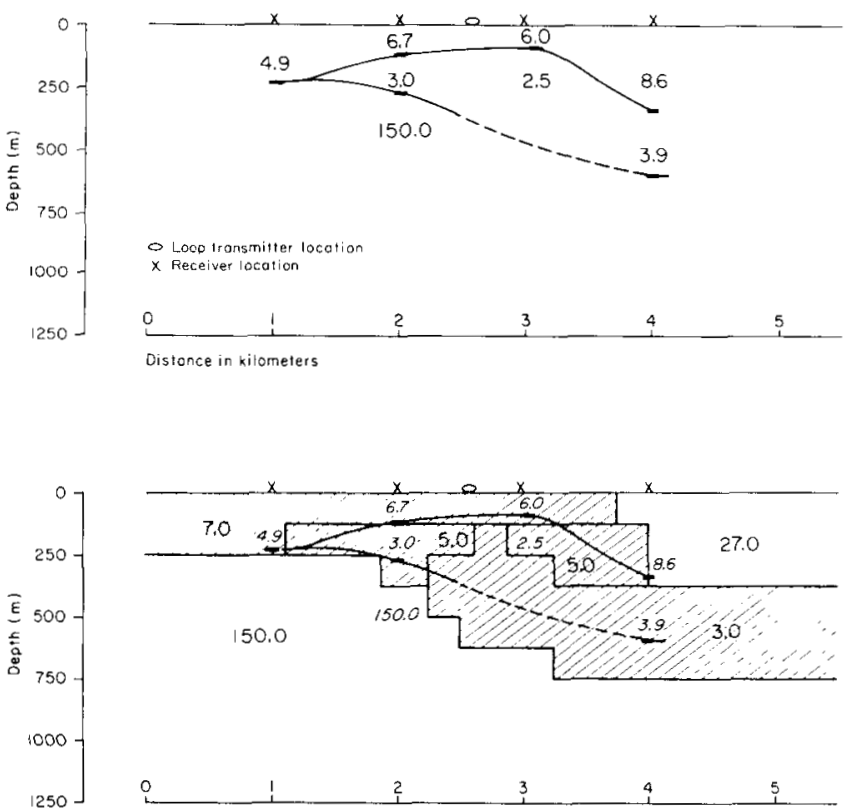

Figure 4. Resistivity cross section over a conductive body in Panther Canyon: (a) two-dimensional dipole-dipole resistivity model (after Beyer, 1977); (b) profile of one-dimensional EM-60 electromagnetic soundings; (c) a comparison of parts $a$ and $b$.

(XBL 802-6775) 


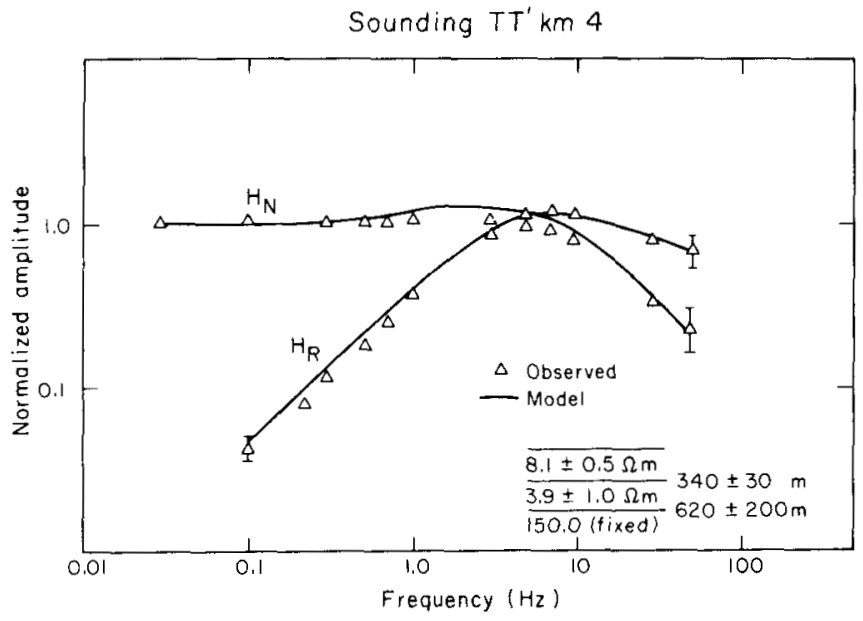

Figure 5. Normalized magnetic field amplitude spectra normal and radial fields sounding TTS Panther Canyon.

(XBL 802-6816)

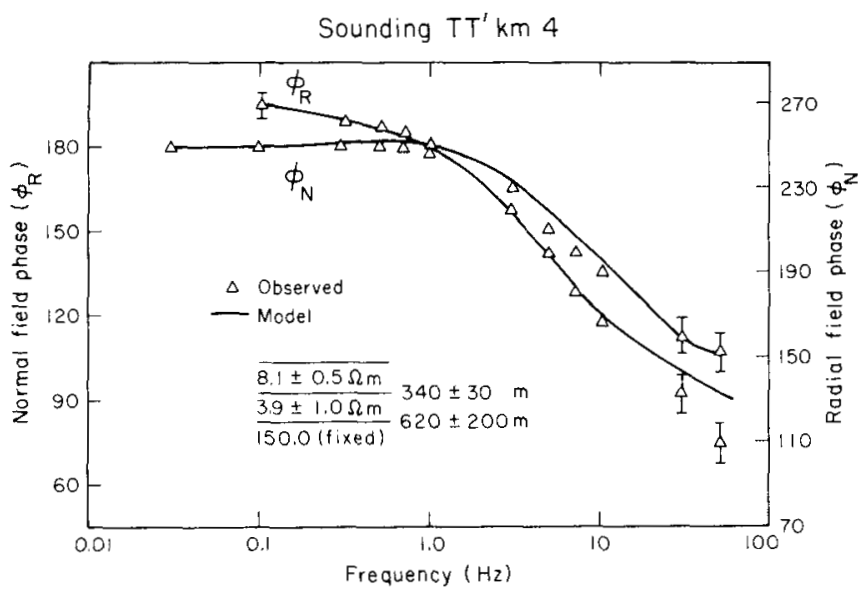

Figure 6. Normalized magnetic field phase spectra normal and radial fields sounding TTS Panther Canyon.

(XBL 802-6815)

Soda Lake

A one week survey of the Soda Lake geothermal anomaly was conducted in late summer of 1979. The study involved two transmitter loops and 13 receiver sites; data quality was good at all sites. Magnetotelluric and seismic reflection data made available to the study by the Chevron Resource Company has aided somewhat in the interpretation of the EM data by allowing us to better fix certain parameters (Hill et a1., 1979).

From the EM data we hoped to determine the depth to and thickness of an extensive gently dipping conductive zone which may serve as the reservoir for hydrothermal fluids. A resistive volcanic horizon detected first from magnetotelluric data lies some 1 to $2 \mathrm{~km}$ below the surface and may form a confining layer for the hot water zone. The definition of this layer is also important.

Preliminary analysis indicates that the conductive zone is well determined at all sites, but interpretation of the deeper horizons is somewhat more difficult.

\section{$\underline{\text { McCoy }}$}

The McCoy prospect located in a remote mountainous area some 40 miles west of Austin was the most difficult survey attempted because of the mountainous terrain and the two- and three-dimensional geology (0lsen et al., 1979). Although 19 stations were occupied, about 50 percent of the data cannot yet be interpreted with existing software. Modifications to the existing layered model inversion codes should help in interpreting data distortions due to loop misorientation and topography, but twodimensional modeling may be necessary to interpret other data.

\section{ACTIVITIES PLANNED FOR 1980}

A1l data obtained in 1979 will be interpreted to the fullest extent possible. Results will be compiled and issued in short technical reports. Results will also be turned over to the Earth Science Laboratory, University of Utah Research Institute (ESL/UURI), who have the responsibility of preparing complete case histories for each of the study areas.

During the course of the field surveys we found that the phase reference wire was introducing noise, resulting in lower accuracy at frequencies above $50 \mathrm{~Hz}$. This problem was remedied by eliminating the reference wire and determining ellipticity at the higher frequencies. As a consequence, the one-dimensional inversion program will be modified to interpret a sounding curve composed of mixed amplitude-phase and ellipticity data points. We also plan to include a highly accurate quartz clock in our system, thereby giving us phase information without the need for a hard-wire link.

System software will be improved. There re mains a need for simplifying and accelerating the procedures for going from the printed tapes taken in the field to displaying the finished interpretations in the laboratory. This may be done by including a tape recorder in the system. In addition, we will address the problem of interpreting data from an inlined loop; more precisely, the common case in rugged terrain where the point of measurement does not lie in the plane of the loop. Here the fields observed can be treated as the superposition of effects from both vertical and horizontal magnetic dipoles.

\section{REFERENCES CITED}

Beyer, J. H., 1977. Telluric and resistivity techniques applied to the geophysical investigation of Basin and Range geothermal systems, Part III: The analysis of data from Grass Valley, Nevada (Ph.D. dissertation). Berkeley, University of California, Department of Engineering Geosciences, LBL-6325, 313 p. 
Hi11, P. G., Layman, E. B., Swift, C. M., and Yungul, S. H., 1979. Soda Lake, Nevada thermal anomaly, in Expanding the geothermal frontier. Transactions, Geothermal Resources Council Annual Meeting, v. 3.

Jain, B., 1978. A low frequency electromagnetic prospecting system (Ph.D. dissertation). Berkeley, University of California, Department of Engineering Geosciences, LBL-7042.

Lee, $\mathrm{Ki} \mathrm{Ha,} \mathrm{1978.} \mathrm{Electromagnetic} \mathrm{scattering} \mathrm{by} \mathrm{a}$ two-dimensional inhomogeneity due to an oscillating magnetic dipole (Ph.D. dissertation). Berkeley, University of California, Department of Engineering Geosciences, LBL-8275.
Morrison, H.F., Goldstein, N. E., Hoversten, N., Oppliger, G., and Riveros, C., 1978. Description, field test and data analysis of a controlled-source EM system EM-60. Berkeley, Lawrence Berkeley Laboratory, LBL-7088.

01 sen, H. J., Dellachaic, F., Pilkington, D., and Large, A. L., 1979. The McCoy geothermal prospect status report of a possible new discovery in Churchill and Lander counties, Nevada, in Expanding the geothermal frontier. Transactions, Geothermal Resources Council Annual Meeting, v. 3.

\section{GEOPHYSICAL AND GEOCHEMICAL INVESTIGATIONS AT MT. HOOD, OREGON}

\section{N. E. Goldstein, H. A. Wollenberg, E. Mozley, and M. J. Wilt}

\section{INTRODUCTION}

Mt. Hood is a Holocene volcano located $80 \mathrm{~km}$ east of Portland, Oregon. It is one of many stratocones in the High Cascade Range extending from northern California to southern British Columbia (Figure 1). In 1977, the U.S. Department of Energy, U.S. Geological Survey, U.S. Forest Service and Oregon Department of Geology and Mineral Industries (DOGAMI) began a program to evaluate the geothermal resource potential of this volcano. It was selected because of its proximity to a major city, the abundance of federally controlled land on which to work, evidence for a heat source, and growing interest of private developers in a source of hot water for the local area.

As part of the program, LBL was assigned the responsibility of conducting and coordinating surveys dealing with rock, gas, and water geochemistry, and electrical resistivity.
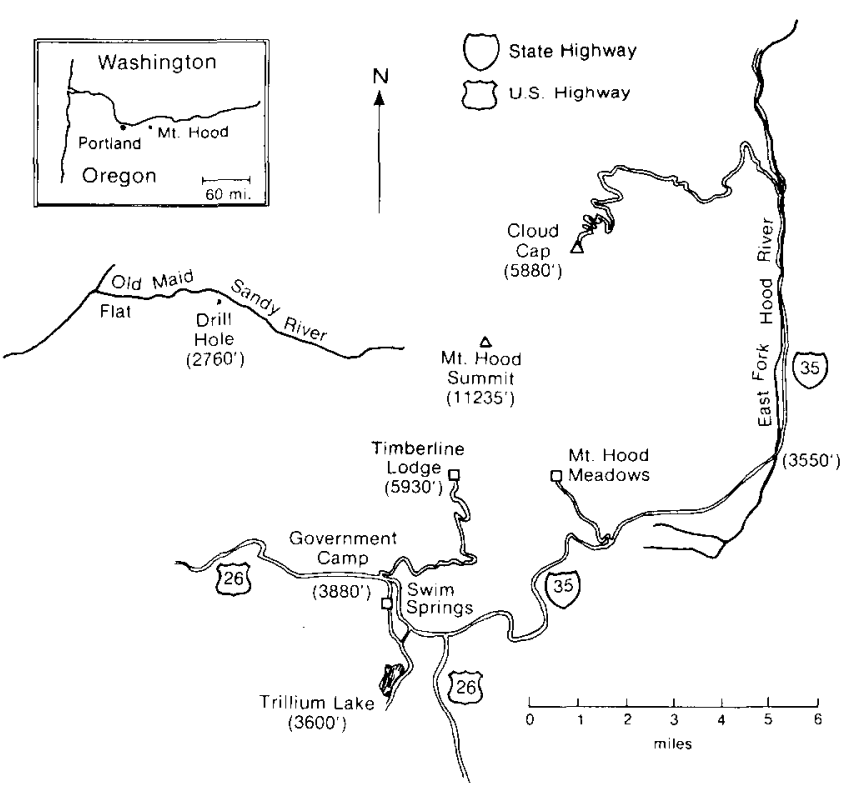

Figure 1. Location map of Mt. Hood area. (XBL 784-644)
ACTIVITIES IN FISCAL YEAR 1979

\section{Geochemical Studies}

Samples of warm- and cold-spring water, water from a geothermal test well in 01d Maid Flat, fumarolic gases, and rocks were collected and analyzed for major chemical constituents and trace elements. This project culminated in fiscal year 1979 with a report by Wollenberg et al. (1979), presenting and summarizing the analytical data and proposing an interpretation of the hydro-geochemical system of Mt. Hood.

The only warm-spring area on Mt. Hood is Swim Springs, located on the south flank. Orifices at Swim Springs were sampled repeatedly with little overall change noted in water chemistry between summer and winter. Oxygen and hydrogen isotope data and mixing calculations based on analyses of Swim Springs and numerous cold springs indicate that a large component of the warm water at Swim Springs is from near-surface runoff. Chemical geothermometry suggests that temperatures at depth in the Swim Springs system are within the range 104 to $170^{\circ} \mathrm{C}$; the temperature of unmixed hot water may exceed $200^{\circ} \mathrm{C}$. Higher-than-background chloride contents and specific conductances of cold springs on the south flank of the mountain (Figure 2) suggest that there is a small component of thermal water in these sources.

A geothermal model of Mt. Hood is proposed wherein snow- and glacier-melt water near the summit comes in close proximity to the hot central "neck" of the mountain, manifested by the summitcrater fumaroles (Figure 3 ). The hot water migrates downslope, mixing with cold water along its path; a small portion of the mixed warm water surfaces at Swim Springs.

Another possible explanation for the presence of warm water at Swim Springs is deep circulation along a fault zone. An east-west oriented fault zone in the vicinity of Swim Springs has been suggested from analyses of earthquake epicentral data (R. Couch, 1977, personal communication). However, to date, other geological and geophysical investigations have not confirmed the fault zone. If a fault zone were present and it contained permeable 


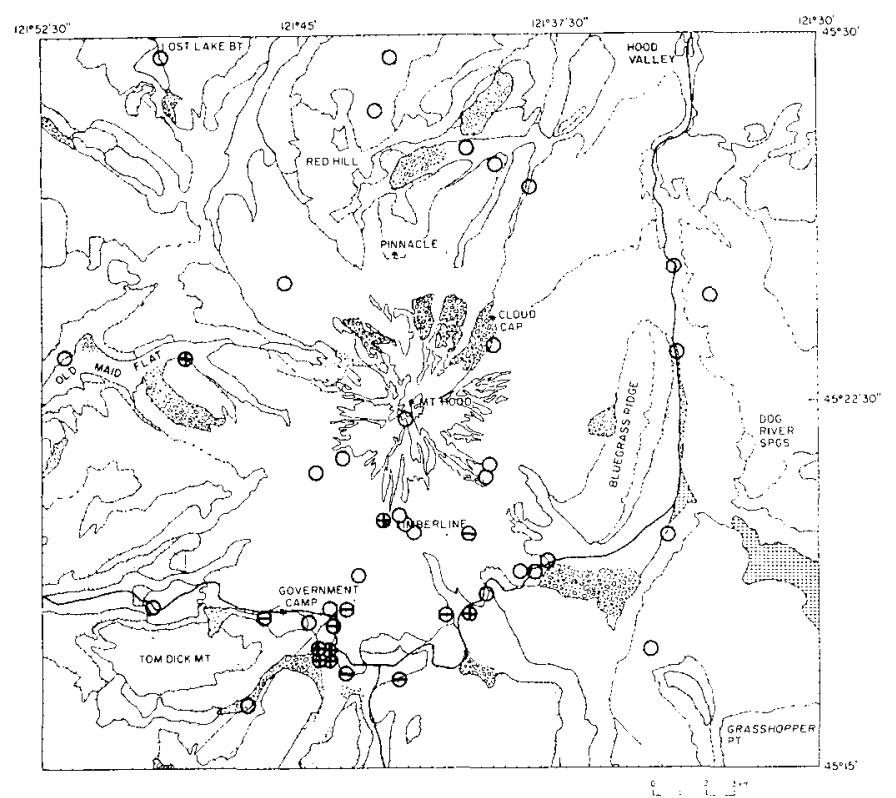

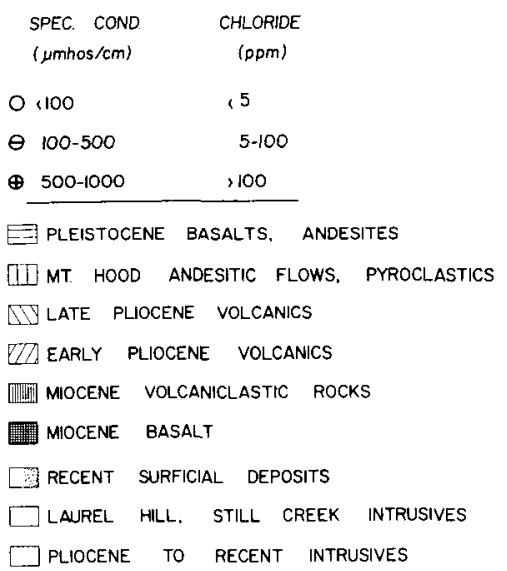

Figure 2. Specific conductance and chloride content of waters, plotted on the geologic map of Mt. Hood (after Wise, 1968). zones, these could serve as conduits for deep circulation of meteoric water. It is more likely that if a fault zone is present, it would serve as an impermeable barrier to warm water moving downslope, causing some impoundment and the emanation at Swim Springs. Neither the fault-zone nor the downslope moving warm water mechanisms for Swim Springs are mutually exclusive; both could be operating.

We were surprised to detect the platinum-group element, iridium, in warm- and cold-spring waters and in a sample of altered andesite. Iridium is generally considered to be associated with basic to ultrabasic igneous rocks; its association with an andesite volcano is believed to be without precedent.

\section{Geophysical Studies}

Field surveys consisting of telluric-magnetotelluric (MT) observations and controlled-source electromagnetic (EM) soundings were made in 1977 and 1978, respectively. Field work done in 1979 consisted of occupying several widely spaced MT stations in connection with the High Cascade project. The major effort during fiscal year 1979 was to analyze and to interpret the large amount of data previously obtained at the stations shown in Figure 4.

of the nine controlled-source EM soundings performed with the newly developed EM-60 system (Figure 5) four were successfully analyzed in terms of layered-earth models. Two were not interpretable because intervening terrain between transmitter and receiver gave results that badly distorted the sounding curves. Three soundings from the loop in Summit Meadow, at the southern base of the mountain, await interpretation based on two-dimensional models.

Interpretations are based on either (a) a combined inversion using the four components of amplitude and phase of the normal (i.e., normal to plane of loop) and radial magnetic fields, or (b) ellipticity of the magnetic field vector traced out by the normal and radial field components. Figures 6

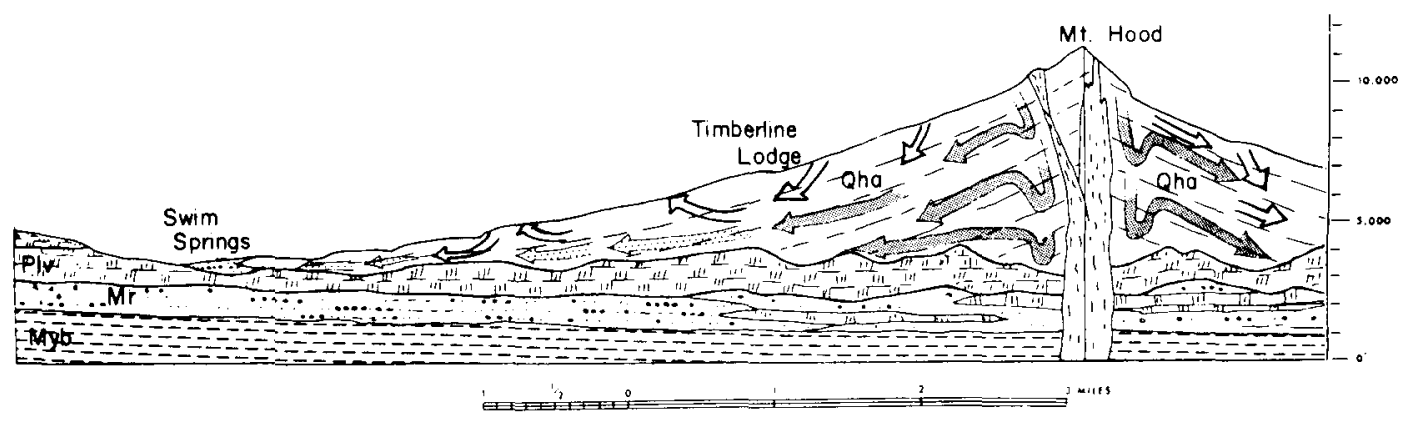

Figure 3. North-south geologic cross section of Mt. Hood (after Wise 1968) showing, schematically, the hypothesized circulation paths of hot water (dark arrows) heated near the volcano's central neck, mixed warm water (lighter arrows), and cold water (unshaded arrows). The warm water emanating at Swim Springs is strongly mixed, and cold water in springs on the south flank of the mountain may contain a small component of the deeper-flowing hot water. Myb = Yakima Basalt; $\mathrm{Mr}=$ Rhododendron Formation; $\mathrm{P} 1 \mathrm{~V}=$ Lower Pliocene basalt and andesite; $\mathrm{Qha}=\mathrm{Mt}$. Hood andesite flows.

(XBL 792-8469) 


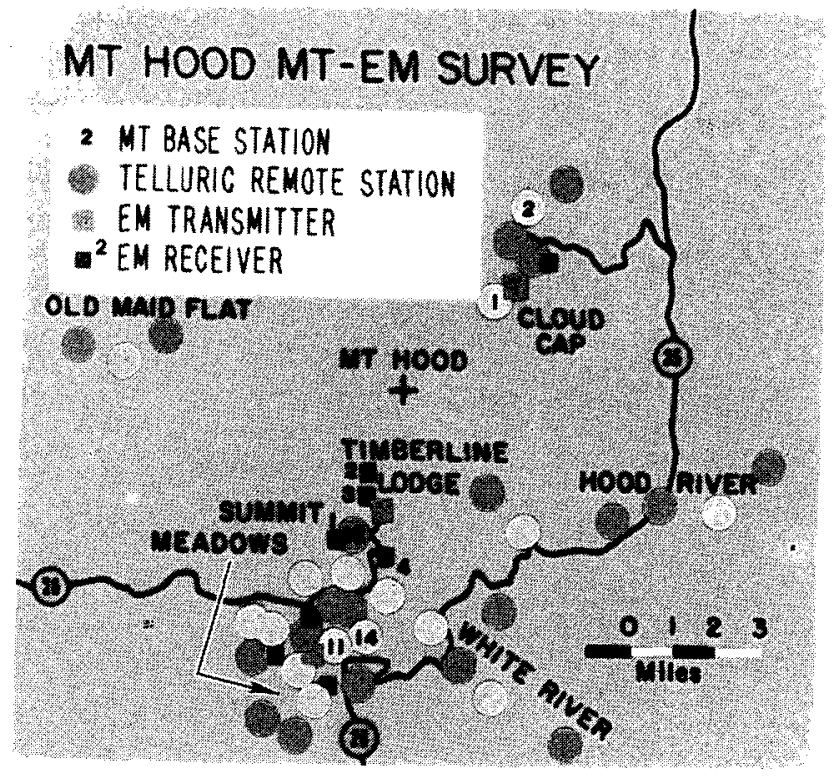

Figure 4. Magnetotelluric and controlled-source electromagnetic stations around Mt. Hood.

(BBC 7911-15939)

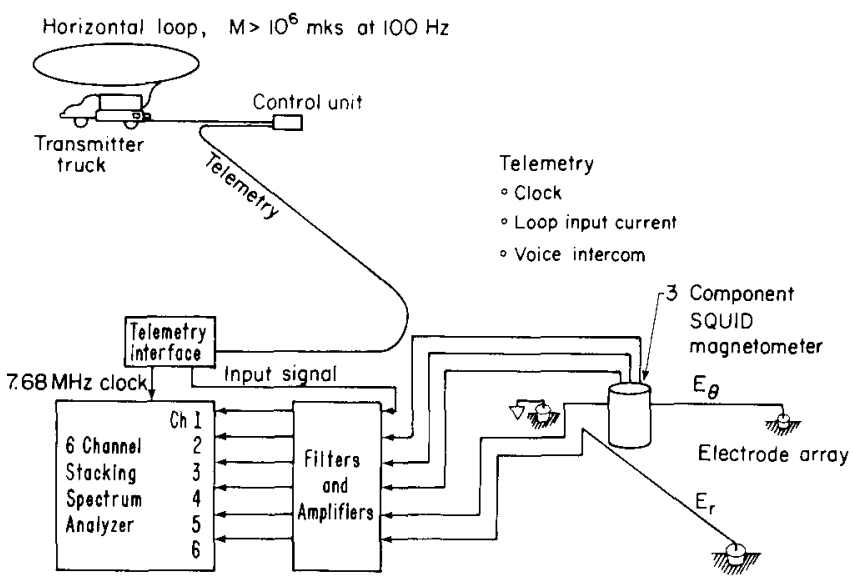

A low frequency electromagnetic prospecting system

Figure 5. Schematic of the EM-60 system.

(XBL 786-2575)

and 7 illustrate the amplitude-phase inversion at Cloud Cap Station and Figure 8 shows the corresponding ellipticity inversion (Wilt et a1., 1979). Both analyses show a good conductor beneath a resistive surface layer 650 to $690 \mathrm{~m}$ thick. The thickness of the conductor could not be resolved, but its presence had previously been noted from the magnetotelluric work (Goldstein and Mozley, 1978).

The telluric-magnetotelluric data obtained by the contractor (Geonomics, Inc.) were totally reprocessed using both remote electric and magnetic field references in an attempt to obtain more reliable MT sounding curves to interpret (Goubau, et al., 1978; Gamble et a1., 1979a,b). It was found that electric and magnetic references gave improved

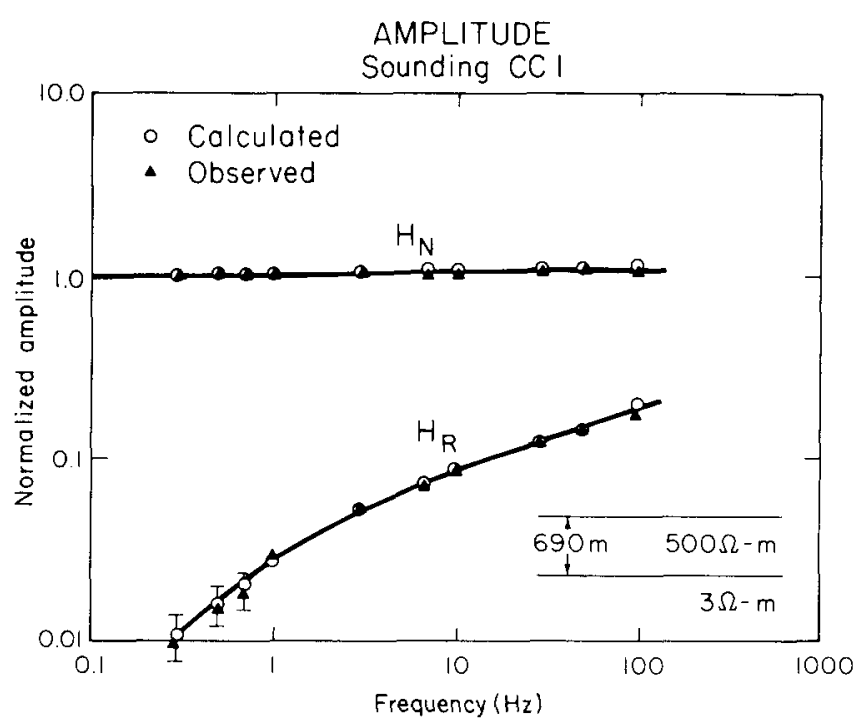

Figure 6. Magnetic field amplitude spectra for Cloud Cap sounding CCl.

(XBL 796-7522)

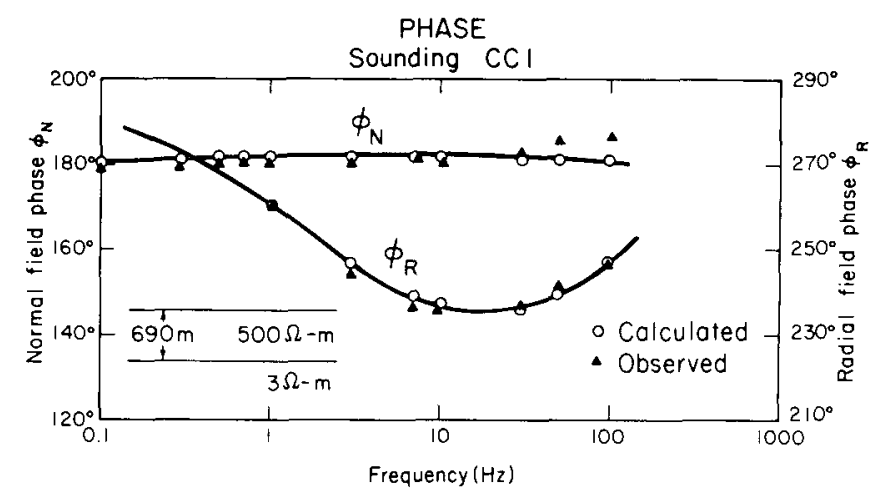

Figure 7. Magnetic field phase spectra for Cloud Cap sounding $\mathrm{CCl}$.

(XBL 796-7525)

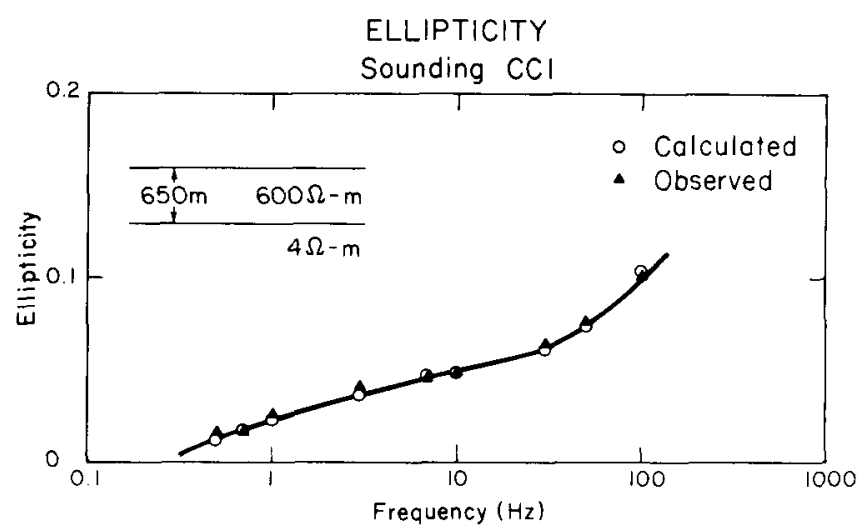

Figure 8. Magnetic field ellipticity spectrum for Cloud Cap sounding $\mathrm{CCl}$.
(XBL 796-7524) 
results (i.e., smaller error bars) but the magnetic reference seemed to be better for noise cancellation.

Because the Cloud Cap MT data gave results that appeared reasonable to interpret by means of one-dimensional inversions and because of the conductor found at $600 \mathrm{~m}$ depth, considerable effort went into a suitable interpretation of the stations in this cluster (Figure 9). These stations are on a fairly young basalt-andesite flow, one of several that are associated with eruptive centers (satellitic vents) on the north side of the volcano and dated at approximately 12,000 years B.P. Figure 10 shows a resistivity cross section along line B-B' derived from the one-dimensional inversions. This profile is normal to the electrical strike determined from the MT measurements, and we show only the results for the electric field parallel to strike. Here again we see clear evidence for a conductive zone, diminishing somewhat with distance from the summit. This zone may be due to hot water, heated either near the summit or near the cloud Cap eruptive center, and cooling as it mixes with cold meteoric water downslope. This interpretation is consistent with the geochemical interpretation discussed above. At a depth of $2+\mathrm{km}$ we also see a discontinuity near station 2 that seems to be the cause of the east-west strike. This has been interpreted as a possible cauldron-feature: resistive basement relatively high northward and a chaotic zone of rocks closer to the summit.

The conductive second layer is also noted near Timberline Lodge on the south flank. There the MT data suggest a shallower and thinner zone, but the two-dimensional effects appear to have distorted the sounding curves. The EM-60 results show that the conductive zone 1 ies at a depth of $500 \mathrm{~m}$ and has a resistivity of $>10$ ohm-m compared with 2 to $3 \mathrm{ohm}-\mathrm{m}$ at $\mathrm{Cloud}$ Cap. The warm water emanations at Swim Springs confirm that the conductive second layer may indeed signify a zone of heated water moving down the mountain.

\section{ACTIVITIES PLANNED FOR FISCAL YEAR 1980}

\section{Geochemical Studies}

The data on the chemistry of waters from cold and warm springs and wells was presented in a report to the American Geophysical Union's Fall 1979 meeting.

\section{Geophysical Studies}

During fiscal year 1980 the remaining MT data will be analyzed to the fullest extent possible, and a final report will be issued giving, in detail, the results of all EM and MT work. There are no plans to conduct additional EM or MT measurements in 1980 .

\section{REFERENCES CITED}

Gamble, T. D., Goubau, W. M., and Clarke, J., 1979a. Magnetotelluric with a remote magnetic reference. Geophysics, v. 44, p. 43-68. , 1979b. Error analysis for remote reference magnetotellurics. Geophysics, v. 44, p. $959-968$.

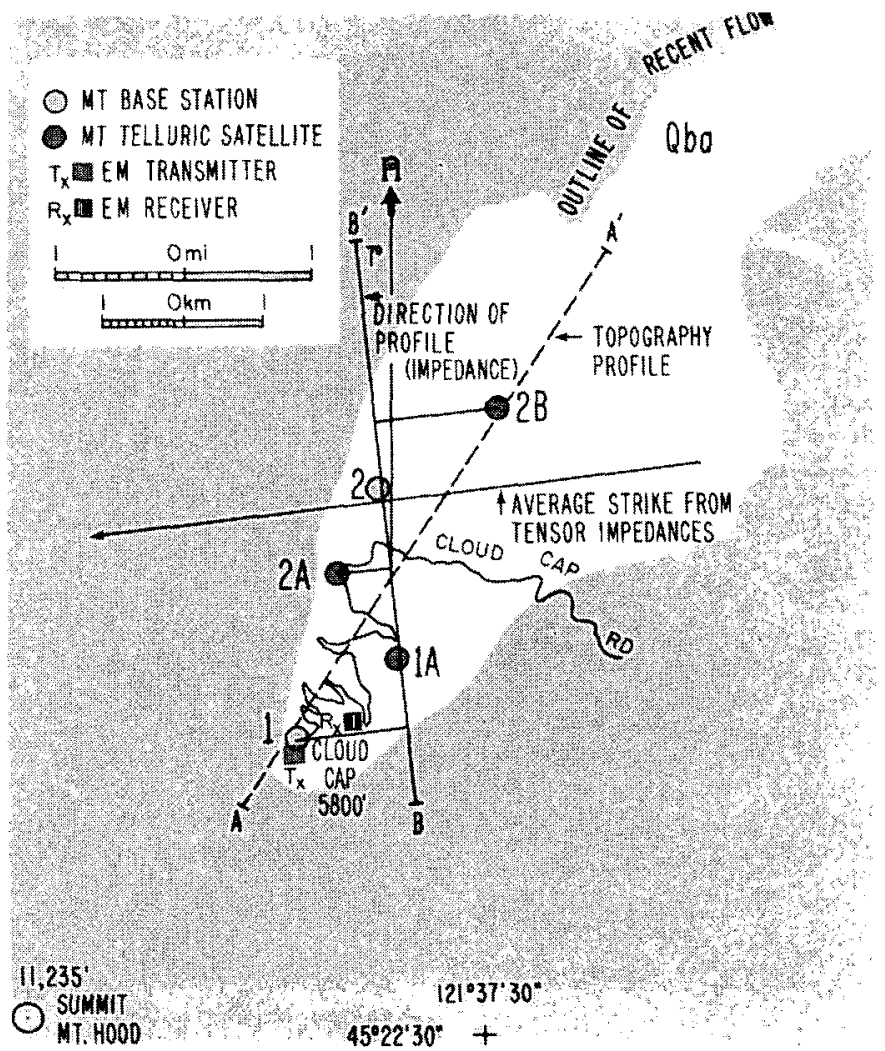

Figure 9. Magnetotelluric and controlled-source EM stations at Cloud Cap. (BBC 7911-15943)

One dimensional inversion of $\rho_{y x}(\Omega \cdot m)$ projected to section $B-B^{\prime}$ ( TE mode)

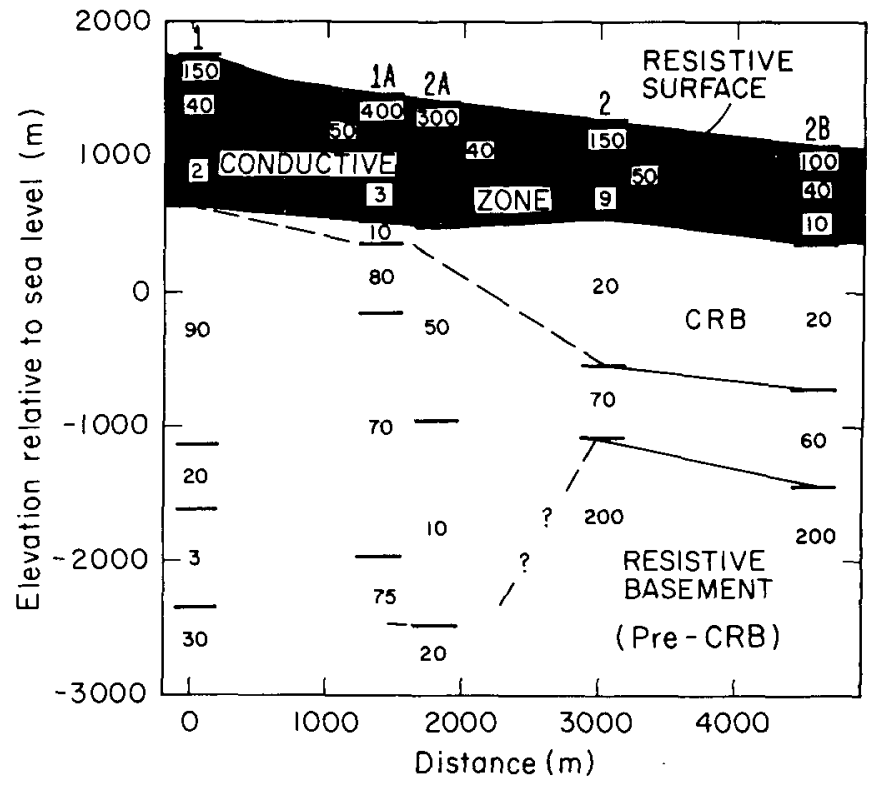

Figure 10. Interpreted resistivity cross section at Cloud Cap.

(BBC 7911-15937) 
Goldstein, N. E., and Mozley, E., 1978. A telluricmagnetotelluric survey at Mt. Hood, Oregon-a preliminary study. Berkeley, Lawrence Berkeley Laboratory, LBL-7050.

Goubau, W. M., Gamble, T. D., and Clarke, J., 1978. Magnetotelluric data analysis: removal of bias. Geophysics, v. 43, p. 1157-1166.

Wi1t, M., Goldstein, N. E., Hoversten, M., and Morrison, H. F., 1979. Controlled-source EM experiments at Mt. Hood, Oregon. Geothermal Resources.Council, Transactions, v. 3, p. 789-792.
Wise, W. S., 1968. Geology of Mt. Hood, Oregon. Oregon Dept. Geol. Min. Ind., v. 62, p. 81-98. , 1969. Geology and petrology of the Mt. Hood area: A study of the High Cascade volcanism. Geol. Soc. Am. Bull., v. 80, p. 969-1006.

Wollenberg, H. A., Bowen, R. G., Bowman, H. R., and Strisower, B., 1979. Geochemical studies of rocks, water, and gases at Mt. Hood, Oregon. Berkeley, Lawrence Berkeley Laboratory, LBL-7092.

\title{
KLAMATH BASIN GEOTHERMAL RESOURCE AND EXPLORATION TECHNIQUE EVALUATION
}

\author{
M. A. Stark, N. E. Goldstein, and H. A. Wollenberg
}

\section{INTRODUCTION}

The Klamath Basin, located in south-central Oregon and northern California, has been a locus of geothermal exploration for several years. Three Known Geothermal Resource Areas (KGRAs) have been identified in the area; they are delineated in Figure 1. Hundreds of warm springs and wells, mostly in Klamath Falls KGRA, are used in space heating and other direct applications. The waters range in temperature up to $145^{\circ} \mathrm{C}$, and several companies and government agencies have searched for hotter water or steam suitable for electric power generation. Outside the main geothermal area in the city two exploratory deep holes have been drilled thus far in the basin but without finding hot water or steam. Interest in the region has consequently waned over the last two or three years.

In an attempt to restimulate exploration activity, LBL, working with the State of Oregon's Department of Geology and Mineral Industries (DOGAMI) and the U.S. Geological Survey (USGS) has attempted to collect, integrate, and reinterpret all available exploration data from both public and private sources. Our primary goals were to develop a conceptual model for the hydrothermal system, to suggest targets for further exploration, and to evaluate the exploration techniques on a site-specific basis.

The Klamath graben can be traced from $80 \mathrm{~km}$ from the Medicine Lake volcanic field in northern California to Crater Lake, Oregon, attaining a width of $15 \mathrm{~km}$. The local geologic structure is characterized by numerous northwest-trending normal faults with occasional northeast-trending crossfaults. Important rock units are late Tertiary and Quaternary extrusive rocks and a late Tertiary lacustrine and volcanic unit known as the Yonna Formation.

The results from our fiscal year 1978 study are discussed in Stark et al. (1979). In that report we examined geophysical data concentrated in the Swan Lake Valley and Klamath Hills areas (Figure 1). These included data from magnetote1luric (MT), audio-magnetotelluric (AMT), roving dipole resistivity, aeromagnetic, and gravity surveys. Two-dimensional computer modeling was used to develop subsurface resistivity and density models to satisfy the data. Both areas showed evidence for electrically conductive bodies associated with normal faulting and cross-faulting. In the Klamath Hills area, the conductive zone coincides with a shallow hot well area along the southwestern margin of the hills. In the Swan Lake Valley area, there are indications of a dike-shaped conductive zone in Meadow Lake Valley, but only minor evidence of surface hydrothermal activity. We also found geophysical evidence for a concealed cross fault between the Klamath Hills and Olene Gap.

\section{ACCOMPLISHMENTS FOR 1979}

In fiscal year 1979 we concentrated our efforts on data from the west and east shores of Upper Klamath Lake. Figure 1 shows the survey areas covered. Since this was the last year of the project, we also emphasized geological and geochemical considerations in an effort to understand the system as a whole. The work is reported in Stark et al. (1980).

Figure 2 shows the locations of dipole-dipole, roving dipole, and Schlumberger resistivity surveys carried out on the west shore of the lake. By means of two-dimensional computer modeling we were able to find earth resistivity models to satisfy these data. Our model for Line DDG, near Spence Mountain, is shown in Figure 3. This area was of interest because it was the site of a 2000-ft hole, which was designed, in part, to investigate a local resistivity-low inferred from the electrical surveys. Our model (Figure 3), which satisfies both the dipole-dipole (DDG, Figure 2) and the Schlumberger (KF3, Figure 2) data, indicates that low resistivities should not be expected less than $4000 \mathrm{ft}$ beneath the drill site.

Similar conductive anomalies were detected on other resistivity 1 ines on the west shore of Upper Klamath Lake. Our models indicate conductive horizons at depths from 1200 to $10,000 \mathrm{ft}$; the horizons are usually shallower beneath the valleys. Because these extensive conductive units effectively shortcircuit the current, there is no evidence for a resistive basement in the soundings.

It is not known whether the conductive units represent anomalously high temperatures at shallow depth. We have suggested possible drill tests near 
- Known geothermal resources orea boundary

Dipole-dipole and Schlumberger survey area

(Harding - Lawson, 1974)

- - - Schlumberger sounding and roving dipole survey area

(Geoterrex, 1975)

-- Schlumberger, time domain electromagnetic, and roving dipole survey oreo (Argonaut, 1975)

Gravity and magnetics (VanDeusen, 1978) covers whole oreo

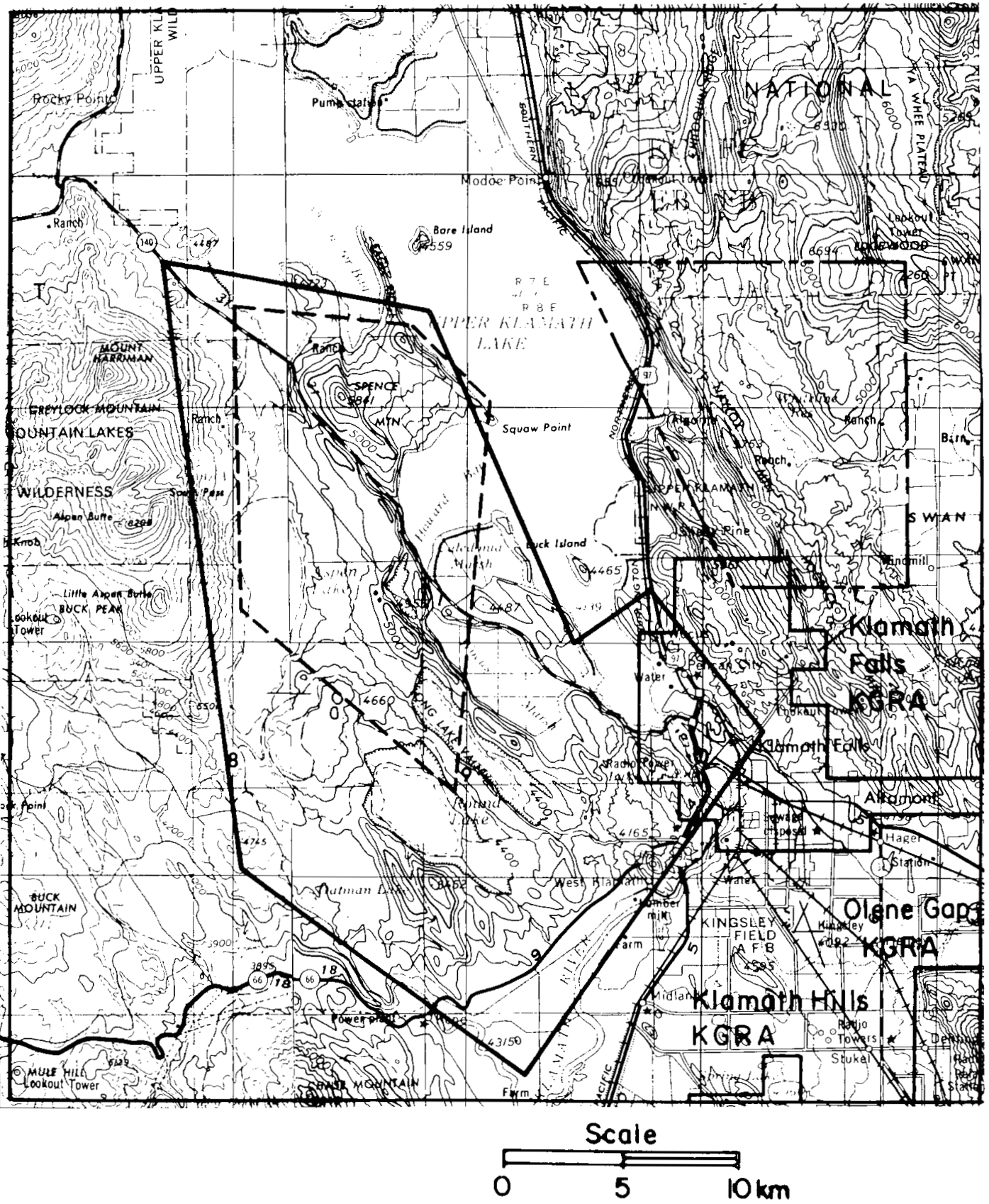

Figure 1. Index map of geophysical survey areas. 


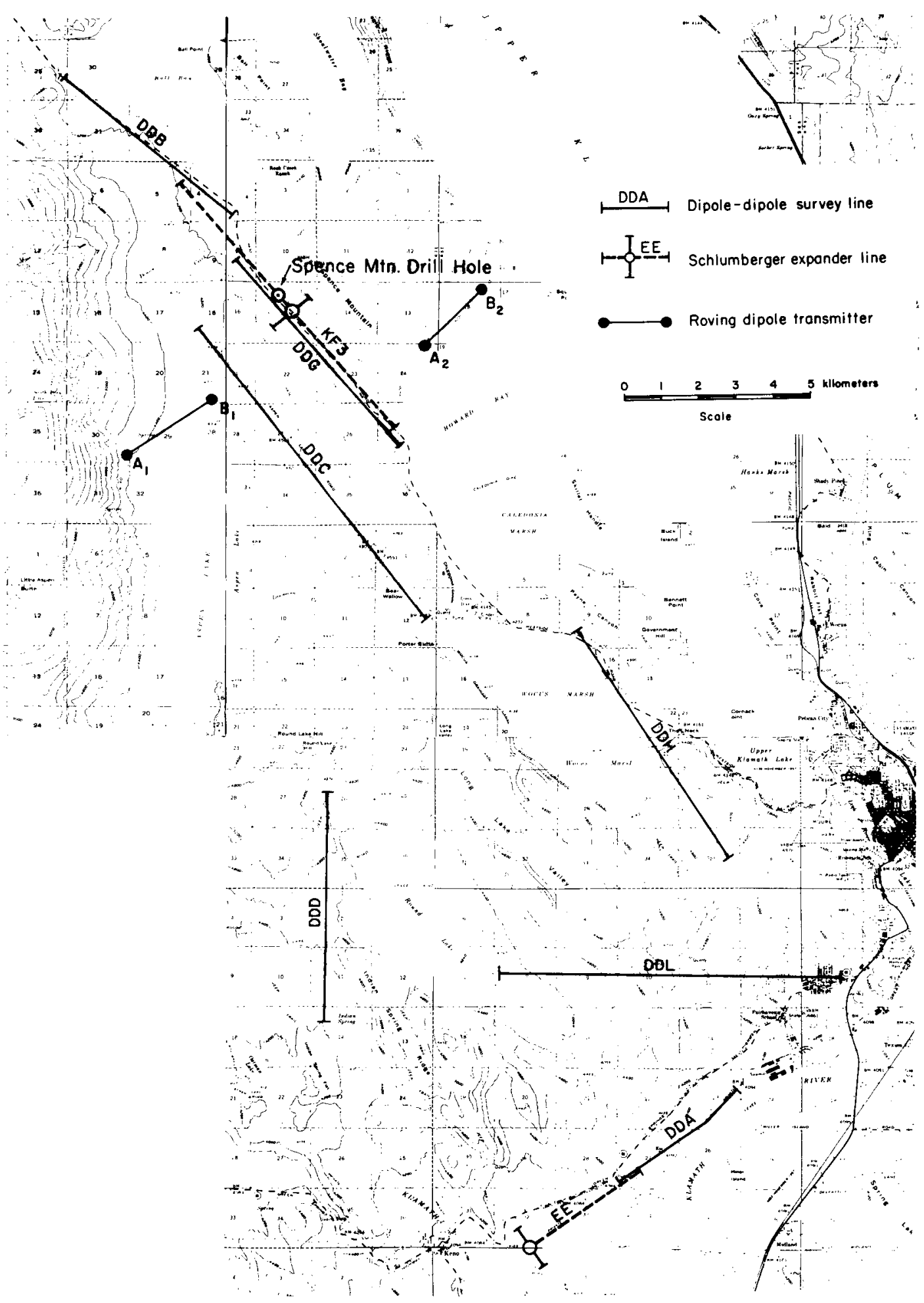

Figure 2. Location map of electrical resistivity surveys, west shore of Klamath Lake. 


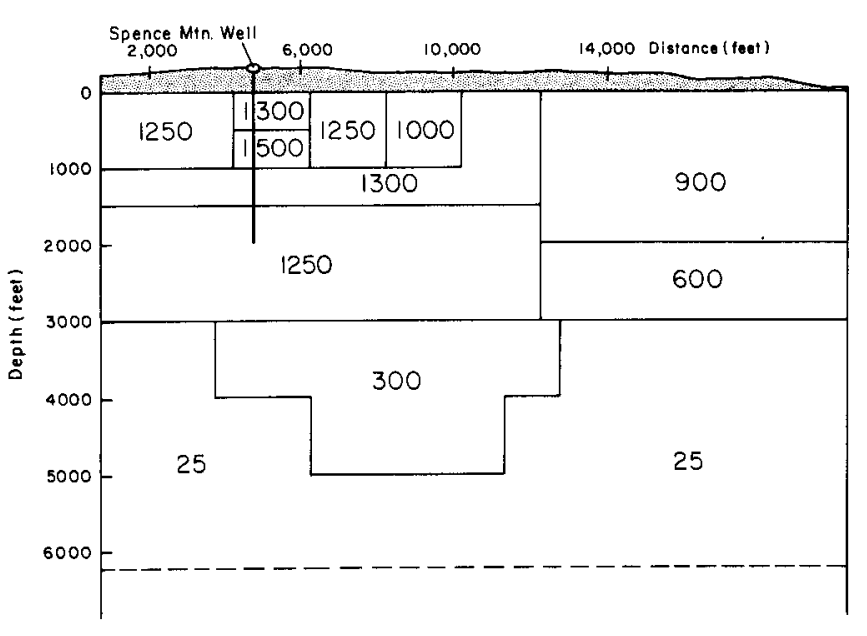

Figure 3. Two-dimensional resistivity model for line DDG: values in ohm-m. (XBL 798-11452)

lines DDL and DDA where the conductive horizons come closest to the surface.

On the east shore of the lake (Figure 1) we examined roving dipole, Schlumberger, and electromagnetic survey data. We made no effort at quantitative reinterpretation of these data. Qualitatively, the data show decreasing resistivity with depth, especially in Plum Valley (east of Naylox Mountain in Figure 1), and south of Whiteline Reservoir. The latter anomaly is adjacent to Meadow Lake Valley, site of a strong MT apparent resistivity low discussed in Stark et al. (1979). Soundings should be undertaken to investigate the specific anomalies.

We also analyzed regional geochemical and geological information. Reservoir temperature estimates for the Klamath Basin hot water aquifer were made independently by Sammel (1976) and by Koenig and Gardner (1972) based on silica and $\mathrm{Na}: \mathrm{K}$ geothermometers. Both workers estimated equilibration temperatures in the 120 to $130^{\circ} \mathrm{C}$ range, and they both invoked the possibility of a deeper steam reservoir to explain the high sulfate content of the waters. Since publication of these studies, higher temperatures have been measured in a new well in Klamath Falls city. The new well is $1200-\mathrm{ft}$ deep with a reported bottom-hole temperature of $145^{\circ} \mathrm{C}$.

Samel (1976) also measured specific electrical conductivities of well and spring waters. We analyzed the relationship between conductivity and temperature in these waters. In the Klamath Falls/Olene Gap area, the expected trend prevails, i.e., the hotter waters are more conductive. South and west of Olene Gap, however, the opposite trend emerges, with the warmer waters associated with lower conductivity. This trend, though less clearcut, is partly due to saline groundwater in the marsh environment. This hypothesis does not explain al1 the data; we have recommended additional geochemical work to investigate the history of these waters.

We also examined geologic maps and aerial infrared imagery, tying these into the geophysical data in a basin-wide tectonic analysis. Figure 4 shows an idealized conception of an offset in the graben axis. The northeast-trending fault between the Klamath Hills and Olene Gap was inferred in Stark et al. (1979) based on audio-magnetotelluric, gravity, and aeromagnetic data. The other northeast-trending fault, located northwest of the Klamath River, was inferred in Stark et a1., (1980) based on remote sensing, gravity, and aeromagnetic data. We believe that the graben has been offset along these faults in the right-lateral strikeslip sense.

These cross-faults seem to be regional features; the one northwest of the river may extend through Klamath Falls and Swan Lake Valley. Intersections of these cross-faults with the northwesttrending normal faults seem to be favorable locations for near-surface geothermal activity.

In this work we have had a chance to evaluate the exploration techniques on a site-specific basis. Our impressions follow:

1. Remote Sensing. Aerial infrared photographs proved most useful in substantiating the presence of cross-faulting inferred from other methods.

2. Geochemistry. Available wells and springs should always be inventoried at an early stage of exploration. The new $145^{\circ} \mathrm{C}$ well in Klamath Falls has shown that the reservoir temperature estimates by Sammel (1976) and Koenig and Gardner (1972) should be regarded as minimum values. We found the specific conductivity measurements useful in interpretating resistivity anomalies.

3. Gravity and Magnetics. These methods are hampered by the fundamental non-uniqueness problem of potential field data, particularly in the volcanic terrain of the Klamath Basin where rock magnetizations and densities can be so variable. In conjunction with other information, however, the data can be extremely useful for tracing faults and for estimating depth to basement. In this area, direct associations of gravity and/or magnetic anomalies with geothermal targets are not recommended. Structural and lithologic changes can account for more variation than geothermal processes such as hydrothermal metamorphism and elevated Curie point isotherms.

4. Roving Dipole Resistivity. This is a useful reconnaissance tool, but the data are difficult to interpret quantitatively unless supplemented by data from other resistivity methods. Schlumberger and EM soundings were conducted at the Whiteline Reservoir for control, but in retrospect these soundings might have been more usefully employed at a later time to define targets outlined by the roving dipole survey. Similarly, the west shore roving dipole survey should have been completed and analyzed before the dipole-dipole and Schlumberger work began there. Computer modeling can help pinpoint the sources of the often-deceptive roving dipole anomalies.

5. Schlumberger and Dipole-Dipole Resistivity. Schlumberger and dipole-dipole sounding can of fer detailed, quantitative earth resistivity information 


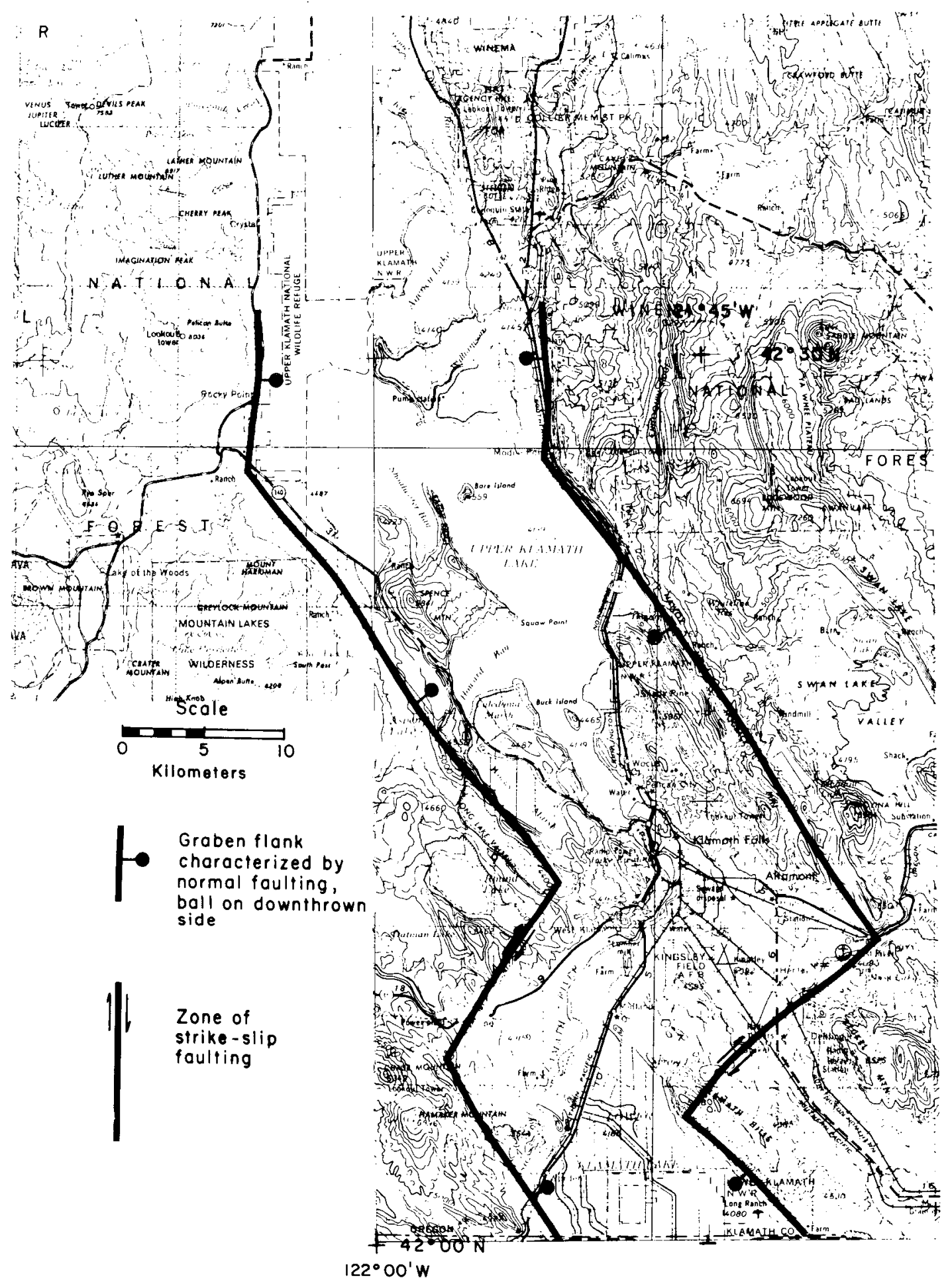

Figure 4. Idealized tectonic map of Klamath graben. (XBL 7910-13077) 
if the surveys are properly implemented. If possible, lines should be laid out perpendicular to geologic strike, so that two-dimensional modeling can be used effectively to separate lateral resistivity changes from changes with depth. We found that collinear, overlapping Schlumberger and dipoledipole soundings were necessary to allow a wel1constrained interpretation. Finally, joint computer modeling of the data sets should be undertaken. When these conditions are satisfied, a quantitative subsurface resistivity picture emerges that can be valuable in selecting a drill target.

6. Time Domain EM. The data we received are rather difficult to interpret. We certainly applaud efforts to develop and deploy field equipment to make these measurements, but at this time most interpreters are 1 imited to very simple models. If more powerful methods of analysis can be developed, the technique could become quite useful.

7. Temperature Gradient Surveys. These seemed to be on1y marginally useful in the exploration efforts to which they pertained. In the Klamath Basin, there appear to be difficulties related to the complicated groundwater flow which reduce the effectiveness of these methods.
PLANS FOR FISCAL YEAR 1980

The second of the two technical reports (Stark et al., 1980) will be completed, reviewed by an industry committee, and issued at midyear.

\section{REFERENCES CITED}

Koenig, J., and Gardner, M., 1972. Geochemical interpretation of spring and well waters southcentral Oregon and adjacent California. Berkeley, Geothermix.

Sammel, E. A., 1976. Hydrologic reconnaissance of the geothermal area near Klamath Falls, Oregon. U.S. Geological Survey Open File Report WRI 76-127.

Stark, M., Goldstein, N.E., Wollenberg, H., Strisower, B., Hege, M., and Wilt, M., 1979. Geothermal exploration assessment and interpretation, Klamath Basin, Oregon: Swan Lake and Klamath Hills areas. Berkeley, Lawrence Berkeley Laboratory, LBL-8186.

Stark, M., Goldstein, N. E., and Wollenberg, H. A., 1980. Geothermal exploration assessment and interpretation, Upper Klamath Lake area, $\mathrm{K}$ lamath Basin, Oregon. Berkeley, Lawrence Berkeley Laboratory, LBL-10140 (draft).

\section{MAGNETOTELLURIC STUDIES IN THE HIGH CASCADE, OREGON}

\section{N. E. Goldstein, R. Miracky, W. M. Goubau, and T. D. Gamble}

\section{INTRODUCTION}

In 1979, the U.S. Geological Survey, as part of its Geothermal Research Program, began a number of long-term geologic, geophysical, geochemical, and hydrologic studies of the Cascade Range on both regional and local scales. Upon completion, this work will provide basic information for an assessment of the geothermal potential of the Cascades, one of the major active volcanic belts in the world. To help support these studies, the U.S. Department of Energy, Division of Geothermal Energy, has contributed financially to the geoelectric studies. In connection with this involvement, LBL has undertaken magnetotelluric soundings in concert with similar work by the U.S. Geological Survey and a commercial contractor.

\section{PROGRESS IN FISCAL YEAR 1979}

During August and September 1979, LBL performed a reference magnetic-magnetotelluric (MT) survey at widely spaced stations along two east-west lines (Figure 1). The northern 1 ine, 1at 45030', extends from the Willamette Valley, southwest of Portland, across the Cascades at Mt. Hood, and terminates between the Deschutes and John Day Rivers in the Deschutes-Umatilla plateau province. The southern line, $42^{\circ} 15^{\prime}$, extends from Cave Junction in the Siskyou Mountains eastward through Klamath Falls, terminating in the Basin and Range provinces, at about long $121^{\circ} \mathrm{W}$. These lines, referred to as the Mt. Hood and Klamath 1 ines, respectively, are two of six MT lines straddling the High Cascade Range. The others were surveyed by a contractor to the U.S. Geological Survey (Geotronics, Inc.), but these are conventional MT stations without the magnetic reference. LBL station separations vary between

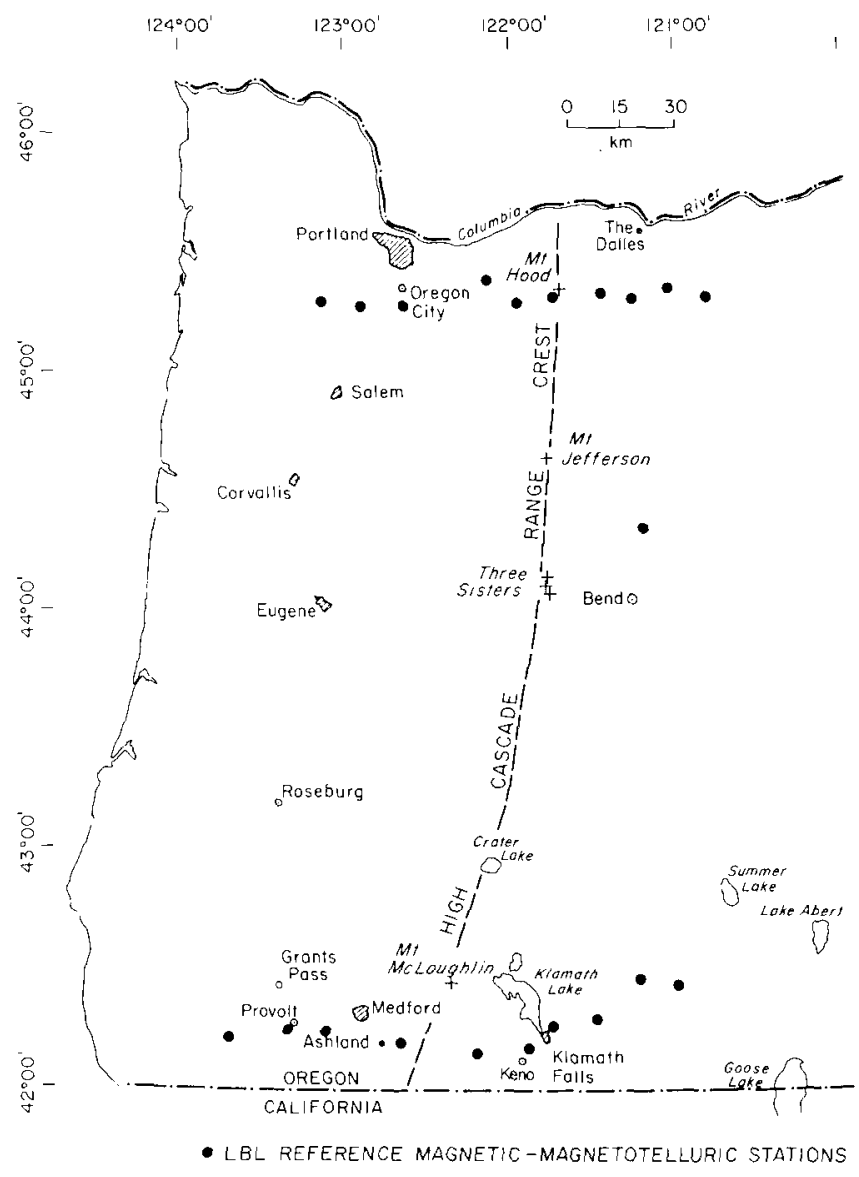

Figure 1. Location of LBL magnetotelluric stations for the High Cascade Program.

(XBL 803-6821) 
10 and 30 miles, resulting in a station density too coarse to permit anything more than a very general look at deep features across the Cascades. As we learned in our previous MT work around Mt. Hood, the impedance tensor can change rapidly over short distances (e.g., 2 to $3 \mathrm{~km}$ ).'

Readings were made at ten stations along each line; and two other stations were occupied in westcentral Oregon, near Bend. The latter were occupied to obtain comparative results for the three MT data aquisition and processing systems being used for the geoelectric studies.

In general, results from Mt. Hood line are disappointing in terms of usable data obtained. Changes made to the DEC LSI-11 computer's software prior to the field work caused a system error that went undetected in laboratory runs. This resulted in the total loss of usable data at frequencies above $0.1 \mathrm{~Hz}$. Low-frequency data were collected, but severe man-made noise between Portland and Mt. Hood caused the SQUID magnetometers to lose lock often, degrading the quality of the low-frequency data. Results from the Klamath line are much better; man-made noise was not a problem there, and data with low error bars were obtained over the 10- to 1000-sec range. The regional MT results clearly define the 50-km-wide Klamath Graben and suggest a relatively shallow heat source within the graben.

\section{PLANS FOR FISCAL YEAR 1980}

The magnetotelluric data will be processed to the fullest extent possible. Results will be plotted both as individual station soundings and as pseudosections of apparent resistivities, tipper, and tipper phase. The results will be turned over to the U.S. Geological Survey for open-filing and an LBL report will be prepared. 


\title{
Geothermal Energy Conversion Technology
}

\section{BINARY FLUID EXPERIMENT}

\author{
B. W. Tleimat
}

The objective of the Binary Fluid Experiment (BFE) is to obtain data on heat-transfer film coefficient for the heating and condensing of working fluids proposed for use in binary-cycle geothermal power plants.

The experiment simulates the binary cycle using steam as the heat source for the working fluid instead of geothermal brine, and using a throttling valve instead of a turbine. Depending on the temperature range of the geothermal brine, the working fluid may be water, ammonia, isobutane and other light hydrocarbons, other fluids, or appropriate mixtures thereof. Although isobutane has received the most attention for use in geothermal power plants using the binary cycle, mixtures of isobutane and isopentane are being considered.

In specifying heat-transfer equipment for a process, the designer is usually armed with welltested information on the performance of similar equipment under similar or identical conditions. In an unusual application, such as specifying heattransfer equipment in a geothermal binary cycle plant using isobutane as the working fluid, designers usually refer to the heat-transfer coefficient prediction method embodied in the empirical correlation equations, such as those of Dittus and Boelter, Colburn, Sieder and Tate, and of others found in standard works. These general correlations are based on fluid transport properties and give the mean, or most probable value of a large amount of reliable experimental data. Unfortunately, because of the large influence sometimes exerted on heat transfer by minor and frequently unrecognized variations in conditions, a designer can only be reasonably sure that the performance of an individual heat exchanger will be within $\pm 35 \%$ of the mean. Consequently, to assure fulfillment of a performance guarantee on a design embodying a minor innovation, the designer would select a heat-transfer coefficient value at the lower 1 imit, that is, $35 \%$ less than the mean.

The correlation equations for the prediction of the heat-transfer coefficients need accurate and reliable data on the transport properties of the fluid at the operating conditions. Lack of data at these conditions makes the designer's task difficult at best. This lack of data is especially true for designs where the working fluid is in the supercritical region. This is important because computer studies (LBL's GEOTHM, for example) indicate that heating the secondary fluid in the

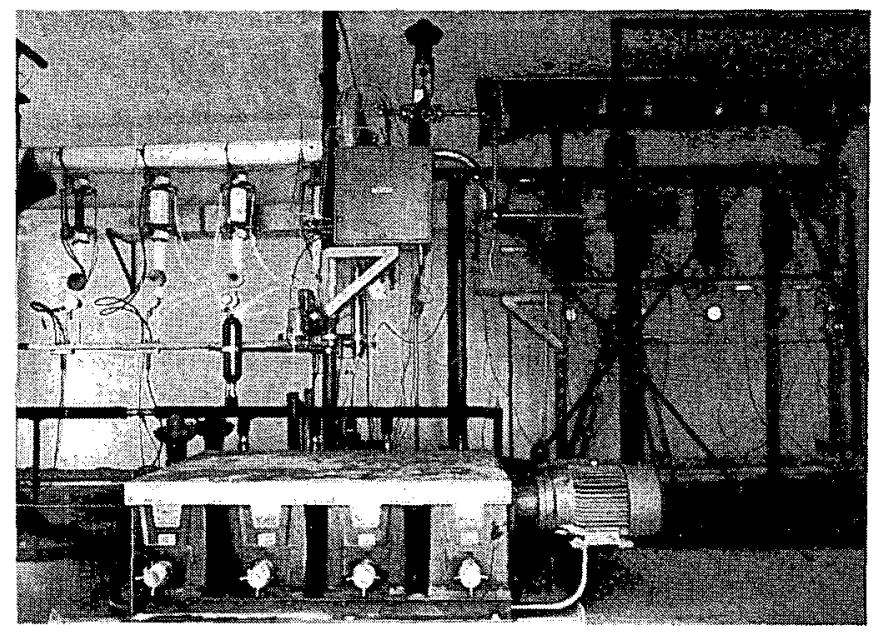

supercritical region will result in high cycle efficiency. Consequently, the most effective and reliable method for specifying equipment design parameters is to determine the heat-transfer coefficient experimentally at the proposed operating conditions.

The BFE (Tleimat) has the capability of providing definitive baseline heat-transfer coefficient data for the heating and condensing of hydrocarbon mixtures of interest over the ranges of temperatures and pressures relevant to geothermal power plants.

The BFE is located at the University of California's Richmond Field Station. Figure 1 is a photograph of part of the apparatus and Figure 2 is a schematic flow diagram of the apparatus showing the major components. A detailed description of the apparatus is given elsewhere (Tleimat and Laird, 1979; Tleimat et al., 1979a,b).

Figure 1. Binary Fluid Experiment showing highpressure pump in the foreground; isobutane heater and its special condensate flowmeters in the upper left; isobutane throttling valve in the middle; and surface desuperheater, isobutane condenser and its special condensate flowmeters in the upper right.

(CBB 780-15079) 


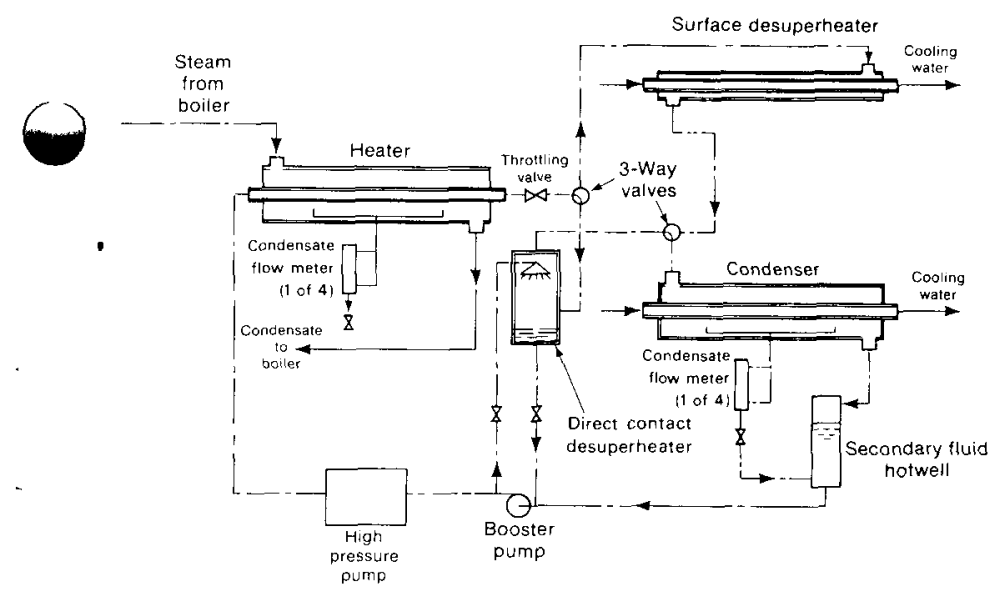

Figure 2. Schematic flow diagram of the Binary Fluid Experiment.

(XBL 783-7893)

\section{ACCOMPLISHMENTS DURING 1979}

Data on the heating of isobutane at supercritical pressure (600 psia) and at various flow rates and temperatures were obtained. Simultaneously data on the condensation of isobutane at various temperatures and condensation rates were obtained. These data were analyzed. The results of the analysis were published in two reports (Tleimat et al., $1979 a, b)$.

The system was charged with a mixture of $80 / 20$ by mole of isobutane-isopentane in April. Trial runs were made and preliminary data were obtained. These data were examined to determine the need for additional instruments to obtain heat-transfer data on mixtures.
The system was shut down in June to install thermocouples in the vapor space in the condenser. These thermocouples will be used to determine the temperature profile in the vapor space along the length of the tube. Sampling valves were also installed at the condensate outlet from each of the condensate meters. These samples will be analyzed to determine the composition of the condensate along the length of the tube and the effect of composition on condensation film coefficient.

\section{FUTURE PLANS}

Data will be obtained on heat-transfer film coefficients for heating and condensing mixtures of different compositions in the loop. These data will be analyzed to determine the effects of varying compositions on the performance of the heater and condenser and the need for further tests.

\section{REFERENCES CITED}

Tleimat, B. W., Laird, A. D. K., Rie, H., and Hsu, I. C., 1978. Heat transfer coefficients for isobutane, in Earth Sciences Division Annual Report 1978. Berkeley, Lawrence Berkeley Laboratory, LBL-8648, p. 47-51.

Tleimat, B. W., and Laird, A. D. K., 1979. Investigation of heat transfer coefficients of binary cycle working fluids, in Earth Sciences Division Annual Report 1977. Berkeley, Lawrence Berkeley Laboratory, LBL-7028, p. 109-112.

Tleimat, B. W., Laird, A. D. K., Rie, H., Hsu, I. C., and Seban, R. A., 1979a. Hydrocarbon heat transfer coefficients; preliminary isobutane results. Berkeley, Lawrence Berkeley Laboratory, LBL-8645, 45 p.

Tleimat, B. W., Laird, A. D. K., Hsu, I. C., and Rie, H., 1979b. Baseline data on film coefficient for heating isobutane inside a tube at $4.14 \mathrm{MPa}$ (600 psia). ASME publication 79-HT-14.

\section{ACTIVITIES IN DIRECT-CONTACT HEAT EXCHANGE}

\section{P. M. Rapier}

\section{INTRODUCTION}

The U.S. Department of Energy's Division of Geothermal Energy has undertaken a program to delineate and demonstrate the economic advantage of the Direct Contact Heat Exchange (DCHX) process in generating power from liquid-dominated geothermal resources. Following a proof-of-concept phase and pilot plant construction, the program elements will measure and demonstrate both subsystem and overall system performance. Development of technically and economically viable process designs will be followed by estimates of the cost of electric energy produced by such optimized plants.

\section{ACTIVITIES}

During fiscal year 1979 , LBL was engaged in both overall system and subsystem program elements related directly to the DCHX. These activities included the following.
Data and operational notes were assembled for proof-of-concept and reduction to practice of an equilibrium-flash boiler section, which was to be used directly on top of the $500-\mathrm{kW}$ pilot plant DCHX preheater section of the tower (Rapier, 1978). The notes show a volumetric heat transfer coefficient for this section of up to five times that theoretically obtainable with alternative liquid/liquid volumetric boilers (Urbanek, 1978).

Mathematical models were developed for:

1. Determining the setting depth in a geothermal well for a downhole pump (Rapier, 1979a).

2. Performing a multistage flash evaporator of $n$ stages for degassing geothermal brine feeds to a DCHX power plant (Rapier, 1979b).

3. Modifying the GEOTHM binary fluid code for passive simulaion of the direct-contact process. 
A general code for the direct-contact mixtures and process, including economics, remains to be done.

4. DCHX preheater, boiler, and in-shell condenser model with brine chemistry (Perona, 1979). In-tube condenser, equilibrium-flash boiler, heat-and-mass balance for entire $500-\mathrm{kW}$ pilot plant remain to be done.

At DOE's request, we reviewed unsolicited proposals submitted to DOE on various aspects of the DCHX.

\section{Pilot Plant}

Figure 1 is a simplified flowchart for the 500-kW plant. Incoming brine is first pressurized to 175 psia by a downhole pump to insure singlephase flow, and enters the plant at 320 to $340^{\circ} \mathrm{F}$ and $220 \mathrm{gpm}$, at the flash tank. Here, about $85 \%$ of the well gases are flashed off along with a small amount of steam, to prevent them from entering the turbine cycle. The heat from the off-gases is used to vaporized about $2.6 \%$ of the isobutane working fluid, which powers the turbine. The degassed brine from the flash tank next enters the brine booster pump, which pressurizes it to 458 psia and sprays it into a special equilibrium-flash boiler section at the top of the 35-ft-high, 40-in.-diameter DCHX tower. Here the preheated isobutane is flashevaporated by live steam and brine from the spray and enters the boiler dome along with $1.4 \%$ residual steam.

In the boiler dome, the vapors are demisted. Then they are admitted at a rate of $99,4001 \mathrm{~b} / \mathrm{hr}$ and a temperature of about $253^{\circ} \mathrm{F}$ into a radial inflow turbine. From the turbine exit the vapors flow into an evaporative condenser, where they are liquified, and then into the hotwell, where about $1400 \mathrm{lb} / \mathrm{hr}$ of water is separated from the isobutane. The isobutane reaches the isobutane return pump at about $94^{\circ} \mathrm{F}$ and $70 \mathrm{psia}$ and is pressurized to 485 psia for injection into the base of the DCHX column through a large droplet distributor.

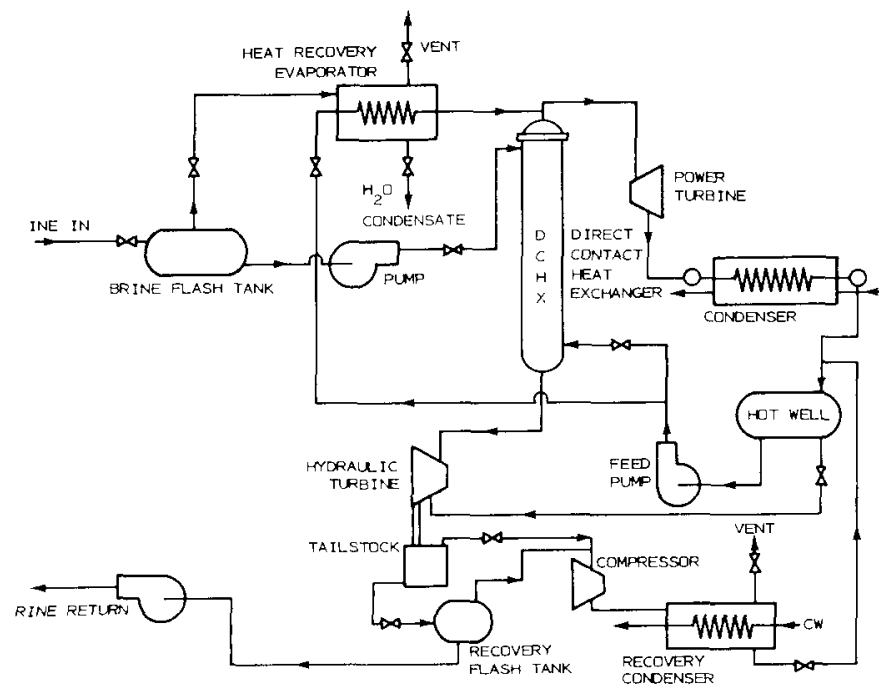

Figure 1. Flowchart for 500-kW DCHX pilot plant. (XBL 801-6739)
Spent brine leaves the tower base at $150^{\circ} \mathrm{F}$ and 450 psia, passes through a hydraulic turbine for recovery of the flow-work, thence through two stages of isobutane vapor recovery, and finally to the brine discharge pump and reinjection pond. Flow-work recovery at the hydraulic turbine reduces the external power requirement of the brine booster pump by about $50 \%$. Isobutane recovery from the spent brine is estimated to be about $95 \%$, so that less than $10 \mathrm{ppm}$ will remain in the brine going to the reinjection pond.

The energy yield of the pilot plant per unit of well flow is expected to range between 5.2 and 3.6 Whr/lb of brine depending upon the build-up of condenser back pressure as shown by Figure 2 (Barber-Nichols, 1979).

\section{Supporting Studies on Effects of Noncondensables}

Noncondensables entering the pilot plant in the brine supply affect all subsystems adversely, starting with the geothermal well itself. Their presence in the brine, particularly when reinjecting will help provide compatibility in the geothermal strata; yet, they must be absent in the DCHX working fluid, where they disrupt operations of the DCHX unit, the turbine, the condenser, and the hydrocarbon recovery system.

In the wellbore and in the brine supply lines to the plant, noncondensables create two-phase flow problems, such as burping, scaling, and plugging. LBL's solution to this has been to set a newly developed electrically driven REDA pump at a 600-ft depth in the East Mesa 8-1 wel1. This setting depth is $50 \%$ greater than the theoretical minimum depth

\section{$\% \mathrm{CO}_{2}$ removal efficiency}

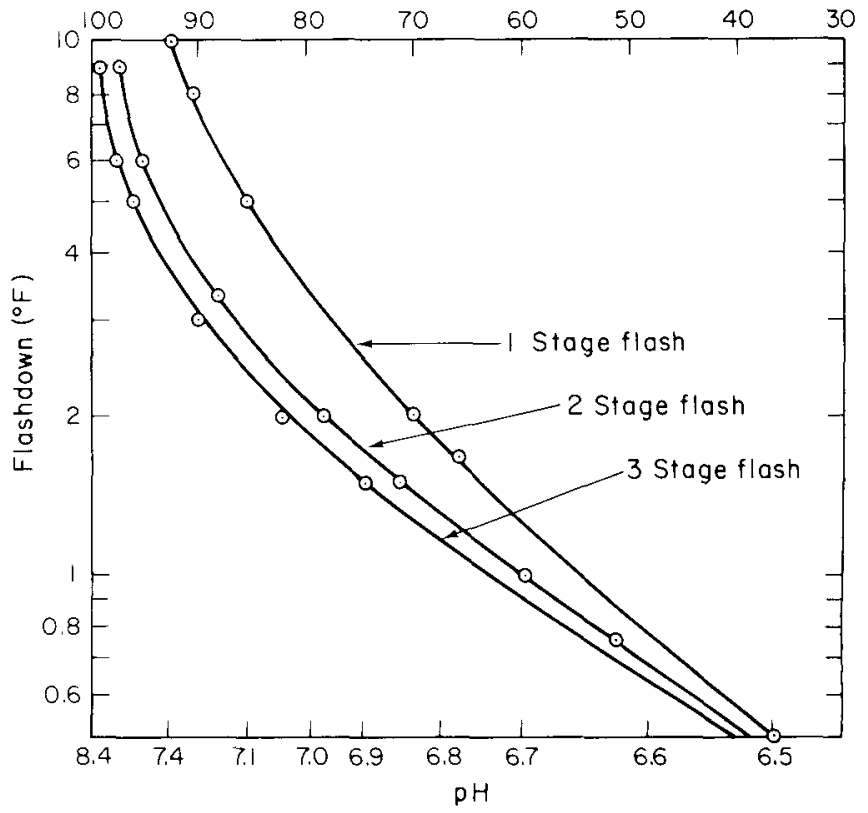

Figure 2. Carbon dioxide removal efficiency and $\mathrm{pH}$ of brine after a given flashdown taken over one, two, and three stages. Calculated for 8-1 well data, based on initial $6.27 \mathrm{pH}$ and $422 \mathrm{ppm}$ alkalinity, as bicarbonate ion.

(XBL 803-6819) 
of $402 \mathrm{ft}$ after four years flow at $220 \mathrm{gpm}$ as determined by LBL's calculator code (Rapier, 1979a). This 50\% increase includes the manufacturer's recommended NPSH plus a reasonable safety factor. No evidence of two-phase flow has been observed since startup, and so this first-of-its-kind downhole pump installation is now regarded as an adequate solution to this problem.

The single-stage flash tank of the pilot plant is expected to provide experimental data for the design of a fully commerical multistage flash (MSF) degasser, capable of removing $96 \%$ of the gas, thus allowing a close approach to the ideal gas-free operation. Figure 3 shows the gas removal efficiency and $\mathrm{pH}$ of the flashed brine for a given flashdown taken over one, two, and three stages (Rapier, 1979b). The heat-recovery efficiency of the MSF degasser is expected to be close to unity, inasmuch as it possesses several features not found on the experimental flash tank:

1. The steam condensate from each stage drips directly into the brine, so that the total brine supplied enters the DCHX unit. This returns all of the enthalpy to the process.

2. The steam condenses within the stage at about the brine temperature instead of in a separate heat recovery vessel at a much lower temperature and pressure. This provides a maximum temperature for boiling the isobutane in the condenser tubes of the stage.

3. The noncondensables are subcooled before being discharged, so that steam losses from the vent are inconsequential.

4. The back-pressure condensing principle employed from stage to stage insures an equilibrium flash in each stage and provides fly-wheel stability to the operation by coupling the heat and mass flows of the process and eliminating nonessential controls.

Noncondensables, remaining in the brine entering the DCHX, will build up an equilibrium concentration in the recirculating isobutane working

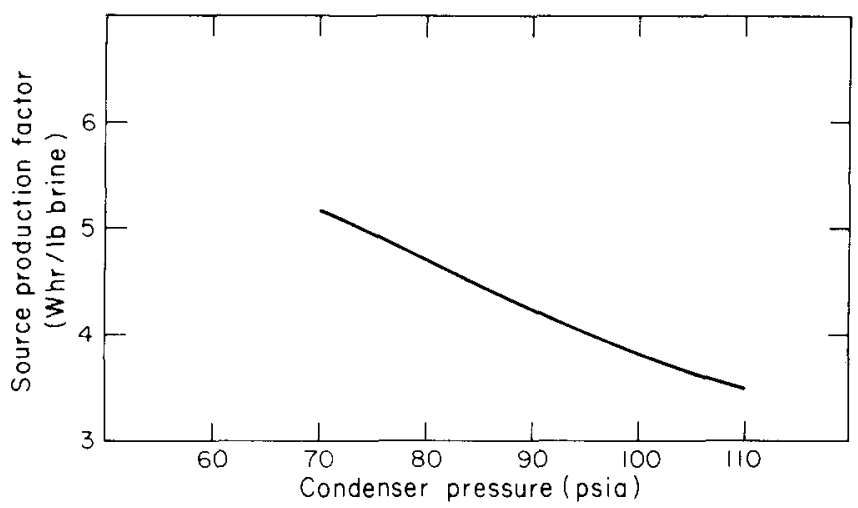

Figure 3. Influence of condenser pressure on system performance: brine flow $=26.5 \mathrm{lb} / \mathrm{s}$; turbine efficiency $=0.8$. fluid that depends upon their entering rate. They recirculate through the turbine to form as much as $1 \%$ of the total mass flow, but do not contribute a corresponding enthalpy drop, thereby reducing the turbine efficiency. They also add their partial pressure to the working-fluid condensing pressure, reducing the available pressure ratio across the turbine. In an unvented condenser, the pressure builds up to an equilibrium point such that noncondensables can be transferred from the working fluid to the spent brine stream at the same rate as they are entering the DCHX unit. The recycled noncondensables form a blanket through which the isobutane must diffuse to reach the heat exchange surface, and thereby lower the heat transfer coefficient by as much as 50\% (Urbanek, 1979, p. 7-1). Consequently, for a given cooling system to perform its duty the condensing temperature and pressure of the isobutane will have to rise. Additionally, because of the recycled noncondensable load, vapors from the turbine exit will reach the condenser more highly superheated than for a pure isobutane vapor. Consequently, desuperheating will be more of a problem.

In the isobutane vapor recovery section following the hydraulic turbine, noncondensables can aid in stripping the $200 \mathrm{ppm}$ soluble isobutane from the brine; however, the resulting gas mixture is more difficult and costly to condense and separate than pure isobutane. The most cost-effective procedure is to remove the noncondensables ahead of the DCHX unit.

Recommended for future investigation are the following problems: in the upper part of the DCHX preheater section, dissolution of the recycling concentrated noncondensable gases from the isobutane droplets, prior to any active boiling, may stifle the expected 1 iquid/liquid heat transfer, blanket the droplets, buoy them to the surface prematurely, form metastable cellular gas structures, and otherwise disrupt the orderly counter-current heat exchange of the device. Preflashing the brine ahead of the DCHX unit and use of sieve trays beneath the equilibrium-flash boiler section are feasible solutions to these gas difficulties.

At the condenser, higher-than-expected backpressures may occur because of bypassing of superheated vapors and subcooling of the condensate. Desuperheating at the turbine exit, together with the use of a vent compressor/condenser may reduce these irreversibilities.

\section{REFERENCES CITED}

Barber-Nichols Engineering Company, 1978. $500 \mathrm{~kW}$ pilot plant design review, July 20, 1978. Barber-Nichols Engineering Company. , 1979. Final report, direct contact heat exchanger $10 \mathrm{~kW}$ power loop test series no. 2 . Berkeley, Lawrence Berkeley Laboratory, LBL-7036, v. 2, P. 5.

Fulton, R. L.; 1979. Developments in direct-contact heat exchange, in Earth Science Division annual report 1978. Berkeley, Lawrence Berkeley Laboratory, LBL-8648, p. 55-57.

Perona, J., 1979. Periodic Reports for DGE on Analysis of Mass Transfer Processes in Geothermal Power Cycles Utilizing Direct Contact 
Heat Exchanger. Knoxville, University of Tennessee.

Rapier, P. M., 1978. Proposed design for direct contact isobutane boiler. Berkeley, Lawrence Berkeley Laboratory, LBL Engineering Note, UCID-8029, GT1808, Serial M5194, May 23, 1978 .

, 1979a. Calculations for the proposed downhole pumping of East Mesa 8-1 well at $220 \mathrm{gpm}$. Berkeley, Lawrence Berkeley Laboratory, LBL Engineering Note, LBID-008, GT1808, Serial M5314, March 16, 1979.

, 1979b. SR-59 program for vapor pressure of geothermal brine at constant alkalinity vs
$\mathrm{pH}, \mathrm{flashdown}{ }^{\circ} \mathrm{C}$ versus number of MSF stages, carbonate composition and percent $\mathrm{CO}_{2}$ removal for each stage. Berkeley, Lawrence Berkeley Laboratory, LBL Engineering Note, LBID-096, . GT1702, Serial M5391, May 16, 1979.

Urbanek, M. W., 1978. Development of direct-contact heat exchangers for geothermal brines, DDS Engineers, Final report, October 1977-June 1978. Berkeley, Lawrence Berkeley Laboratory, LBL-8558.

, 1979. Experimental testing of a directcontact heat exchanger for geothermal brine, Final report, December 1979 . ORNL/SUB-79/ $13564 / 1$ and ORNL/SUB-79/45736/1 DSS-079. 


\section{Reservoir Engineering}

\section{MEXICAN-AMERICAN COOPERATIVE PROGRAM AT THE CERRO PRIETO GEOTHERMAL FIELD, BAJA CALIFORNIA, MEXICO}

M. J. Lippmann, P. A. Witherspoon, and N. E. Goldstein

\section{INTRODUCTION}

The Cerro Prieto field is located in the Salton Trough just south of the California/ Baja California border (Figure 1). The field is the site of a cooperative effort between Mexico and the United States to understand the behavior of a geothermal system under full-scale fluid exploitation.

The Comisión Federal de Electricidad of Mexico ( $C F E$ ), which manages and operates the field, began generating electric power at Cerro Prieto in 1973. Last April, the original 75-MWe power output was doubled to $150 \mathrm{MWe}$ as the third and fourth $37.5 \mathrm{MW}$ higher-pressure single-flash units were placed in operation.

At the present time, about 480 MWt contained in hot separated waters are being wasted. To recover some of the energy of these $169^{\circ} \mathrm{C}$ waters, now being disposed of into an evaporation pond at a rate of about 3000 tonnes/day; a 30-MWe lowerpressure double-flash unit is scheduled for commercial operation in 1982 (Hernandez, 1979).

The total generating capacity at the field is expected to reach 400 MWe by 1985 . The probable total capacity of the Cerro Prieto field is estimated to be about 1000 MWe and that of the entire

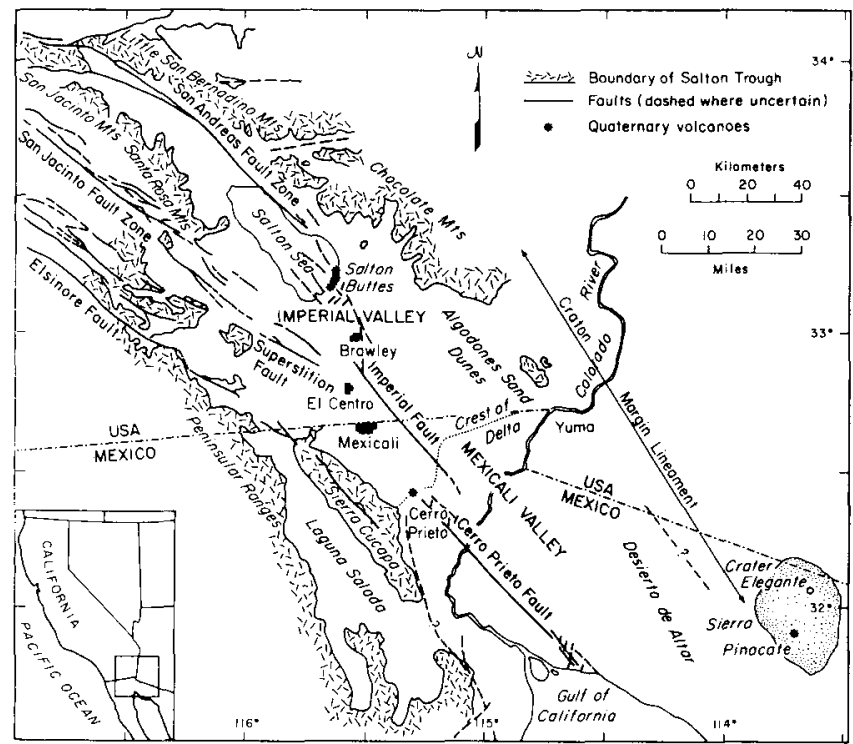

Figure 1. Salton Trough (or Salton Sea/Sea of Cortez Trough) showing the location of the Imperial and Mexicali Valley and the Cerro Prieto field.

(XBL 801-6718)
Mexicali Valley is believed to be much larger (Mañon and Guiza, 1979). Based on CFE's resource estimates, the available geothermal power will exceed the local demand for electricity, and CFE has tentatively agreed to sel1 large blocks of electrical power to San Diego Gas and Electric Company, of southern California.

The intensive drilling program initiated in 1976 continues. At the present time about 65 deep wells have been completed (Figures 2 and 3 ). The new wells in the eastern and southeastern parts of the field confirmed the existence of a very hot $\left(>320^{\circ} \mathrm{C}\right.$ ) reservoir below $2000 \mathrm{~m}$ depth (Alonso et al., 1979).

Geothermal studies are now being performed as part of a cooperative project, which was established

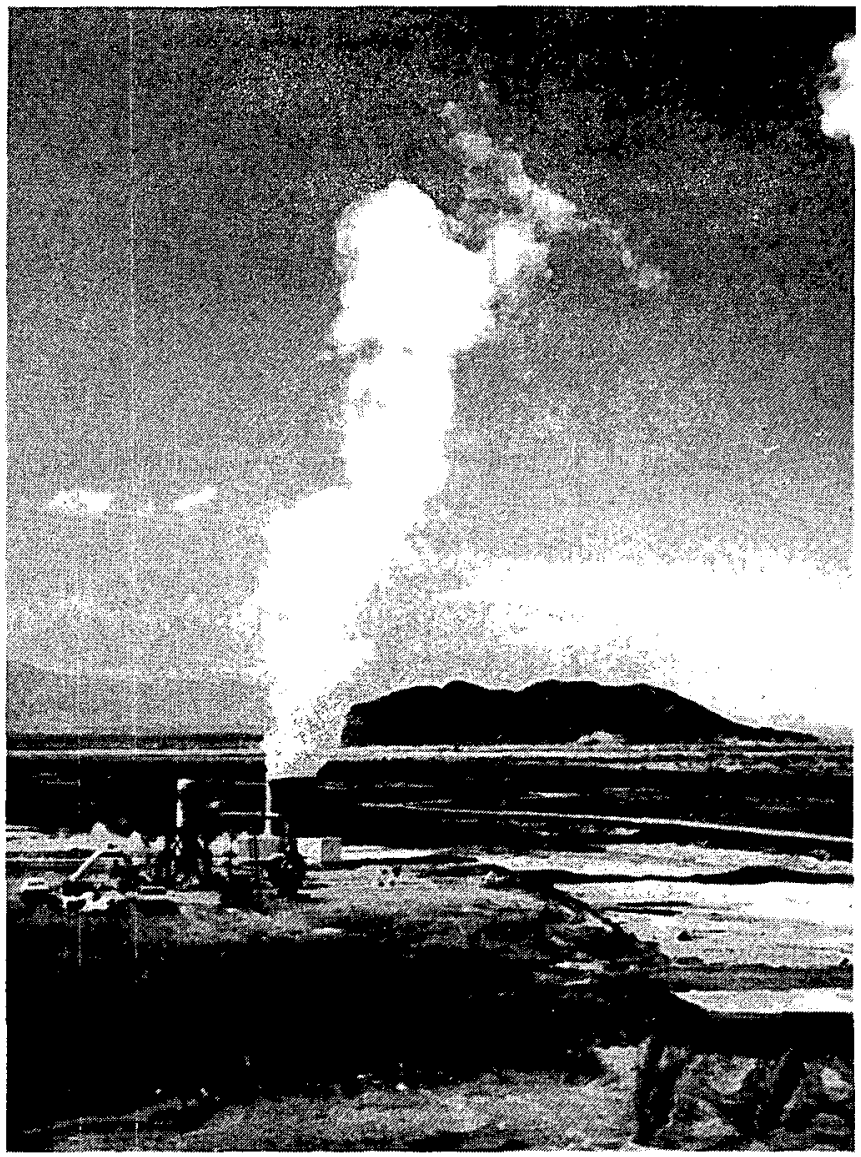

Figure 2. One of the wellhead installations. Cerro Prieto Volcano and Sierra Cucapa in the background.

(CBB 802-1912) 


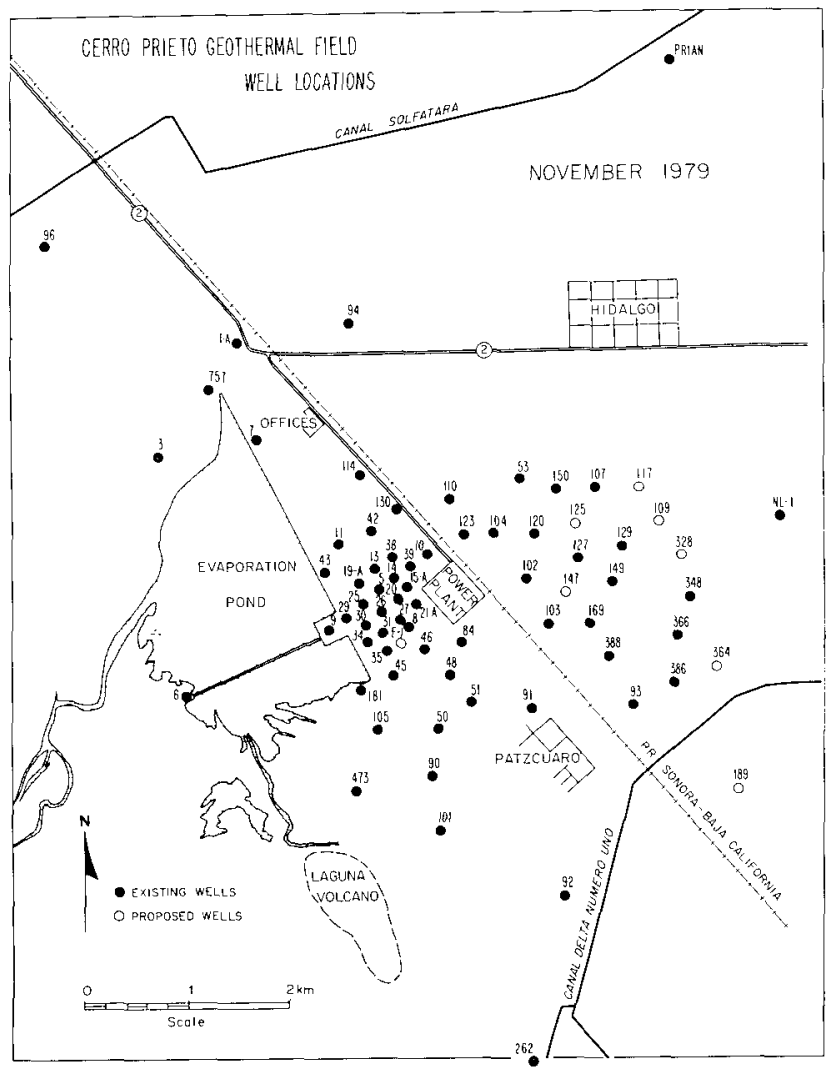

Figure 3. Cerro Prieto geothermal field--well locations.

(XBL 7911-13432)

and operated through an agreement signed on July 21 , 1977, between CFE and the U.S. Department of Energy (DOE). Lawrence Berkeley Laboratory (LBL) coordinates U.S. technical activities carried out under this project. The Coordinadora Ejecutiva de Cerro Prieto of CFE is organizing all Mexican participation (Witherspoon et al., 1978).

The Cerro Prieto project incorporates studies of the geologic, hydrogeologic, geochemical, and geophysical settings of the geothermal field, as well as investigations of its structural, reservoir engineering, and subsidence characteristics. The primary objective of the program is to develop an understanding of the geologic setting and hydrothermal circulation of this geothermal system.

Cerro Prieto is considered an ideal system for studying the long-term response of a liquiddominated geothermal field in continuous production. Much of the information obtained here will be applicable to the development of geothermal resources in similar geologic settings such as the Mexicali Valley, Mexico, and the Imperial Valley, California. This information will be useful for geothermal development in other parts of the world.

\section{FISCAL YEAR 1979 ACTIVITIES}

Most of the results obtained since the beginning of this international project in 1977 have been published in the Proceedings of the First
Symposium on the Cerro Prieto Field, San Diego, California, September 20-22, 1978 (Lawrence Berkeley Laboratory, 1978) or will be included in those of the Second Symposium, Mexicali, Baja California, October 17-19, 1979, expected to be issued by CFE in the latter part of 1980 .

Further details of the activities and results described below are discussed elsewhere in this volume.

Geology

Data from surface geophysical surveys, well sample descriptions and analysis, and geophysical well logs were used to obtain new insights into the stratigraphy, structure, hydrothermal alteration, reservoir properties, and geohydrology of the area.

Lyons and van de Kamp (1980) completed a comprehensive geologic study using geophysical well logs and surface geophysical results, in addition to borehole lithology and mineralogy. They developed a new regional depositional model which indicates the reservoir rocks occupy a transition zone from an upper delta plain environment to the east to a marine environment west of the field. They recognized three principal types of faults: (1) older faults offsetting only the deeper part of the geologic section, (2) reactived older faults with smaller offset or reversed sense of offset above some horizon, and ( 3 ) young faults offsetting the entire section. Some of the faults previously identified by other workers were not recognized by them. For example, the major fault previously assumed to run almost along the railroad track (Michoacan fault) seems not to contiune farther south than about well M-103.

The vertical transition from unconsolidated and semiconsolidated to consolidated sediments, the so-called A/B boundary, was found not to occur at one stratigraphic horizon, but cuts across the sedimentary strata suggesting localized postdepositional alteration.

Vonder Haar and Howard (1979) hypothesize that where the important northwest-southeast Michoacan fault obliquely intersects shorter northeast-southwest trending faults (e.g., near M-103) there is greater permeability and increased natural convective fluid flow. In addition, a shear zone near wells $M-48, M-91$, and $M-101$ seems to enhance the distribution of the geothermal fluids away from the major northwest-southeast faults, thus increasing the recharge capacity of the field.

By means of petrological and geochemical studies of well cuttings and cores, Elders et al. (1980) have confirmed the existence in the reservoir of a systematic sequence of temperaturedependent hydrothermal minerals (Figure 4). These are formed by progressive dehydration, decarbonation, and exchange reactions. Minor variations in mineral assemblages in different parts of the systems were observed. These are due to differences in permeability, $\mathrm{pCO}_{2}$ and in some cases to localized episodic temperature fluctuations.

The thermal metamorphism of organic particles (phytoclasts) found in Cerro Prieto sedimentary 


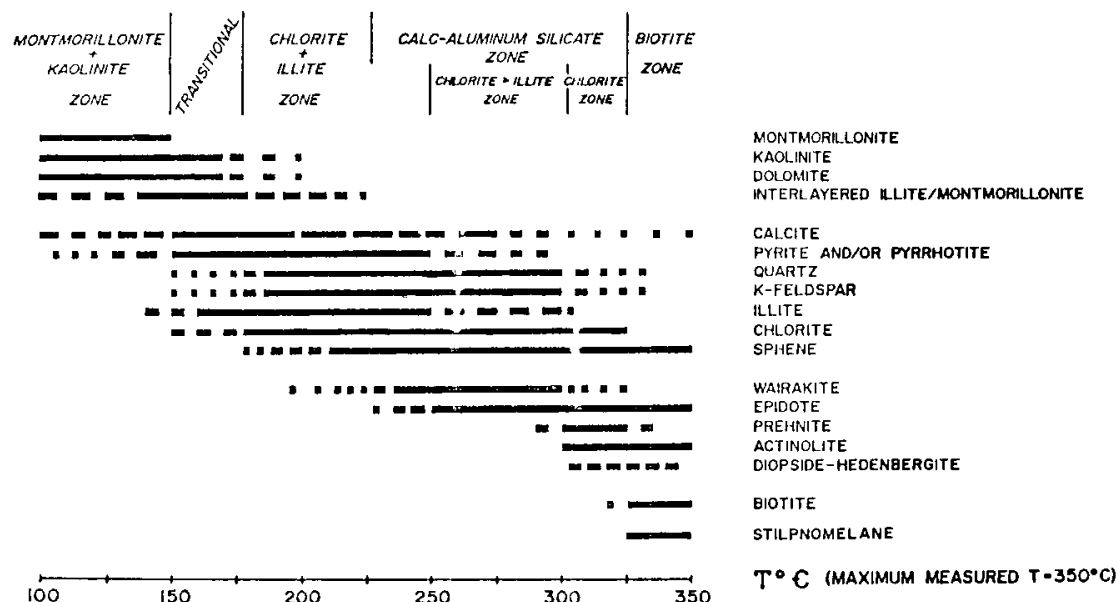

Figure 4. Mineral zonation in Cerro Prieto sandstones (from E1ders et al., 1980).

(XBL 804-9162)

rocks indicate that the measured temperatures in the deeper portions of the geothermal wells are equilibrium reservoir temperatures (Elders et al., 1980).

Paleomagnetic studies of rocks from the Cerro Prieto volcano suggested that it originated about 110,000 years B.P., and that volcanism continued intermittently until about 10,000 years ago (de Boer, 1979).

\section{Geophysics}

During $1979 \mathrm{CFE}$ and LBL and their contractors continued surface geophysical surveys throughout the area. LBL concentrated its efforts on improving the structural model of the field and using resistivity, gravity, and seismicity to monitor changes due to fluid production. On the other hand, CFE extended exploration surveys to other potentially promising areas in the Mexicali Valley.

Based on independent dipole-dipole dc resistivity and magnetotelluric surveys performed and interpreted by LBL, the reservoir rocks currently exploited show up as more resistive ( $4 \mathrm{ohm}-\mathrm{m})$ than the surrounding rock $(\sim 1.5 \mathrm{ohm}-\mathrm{m})$. Although this is contrary to the widely held theory that hot reservoir rocks will appear as low resistivity zones, a correlation between surface resistivity data and borehole geologic data shows that the higher resistivities can be accounted for by hydrothermal metamorphism that has reduced the porosity of the mud and shale units (Wilt et al., 1979; Goubau et al., 1979). Surface measurements have also provided subsurface information that may help CFE in planning step-out drilling.

A repeat precision gravity survey at monuments over and around the field was made in 1979 (Grannell et al., 1979). Two-thirds of the station observations have an estimated error less than 9 gal, sufficient to permit detection of mass changes taking place within $2 \mathrm{~km}$ of the surface. To within the accuracy of the 1978 and 1979 sets of measurements, no mass changes are evident. This suggests that over the 2-year period the circulation system remained in approximate dynamic equilibrium.

\section{Geochemistry}

Based on chemical and isotopic studies of the Cerro Prieto brines, Truesdell et al. (1979) conclude that the fluids derive from a mixture of partially evaporated sea water and Colorado River waters, which were extensively altered compositionally by high-temperature reactions involving the reservoir rocks (Figure 5). Their results also have shown that exploitation of the field has greatly changed the pressure, temperature, state, and chemistry of the aquifer fluids.

A geochemical study of the different surface manifestations in the Cerro Prieto field (Elders et al., 1980) suggests: (1) there is a close relationship between the hot springs in the area and the deep geothermal reservoir, and (2) there has been a change in the spring's chemical characteristics since 1968 in response to the large-scale fluid extraction from the field.

\section{Subsidence}

Last year the first-order leveling and precise horizontal-control networks established in 1978 were surveyed for the second time. The comparison of the measurements from the first and second vertical surveys indicated localized vertical subsidence and uplifts in the area, ranging from $-28.0 \mathrm{~mm}$ to +33.0 mu (García and Mendéz, 1979).

Trilateration surveys indicated that horizontal ground-surface movement was also occurring (Figure $6)$. The portion of the local net covering the geothermal production zone showed a northwest-southeast contraction that may be as great as $31 \mu$ strain/yr. Movements in the area surrounding the production 


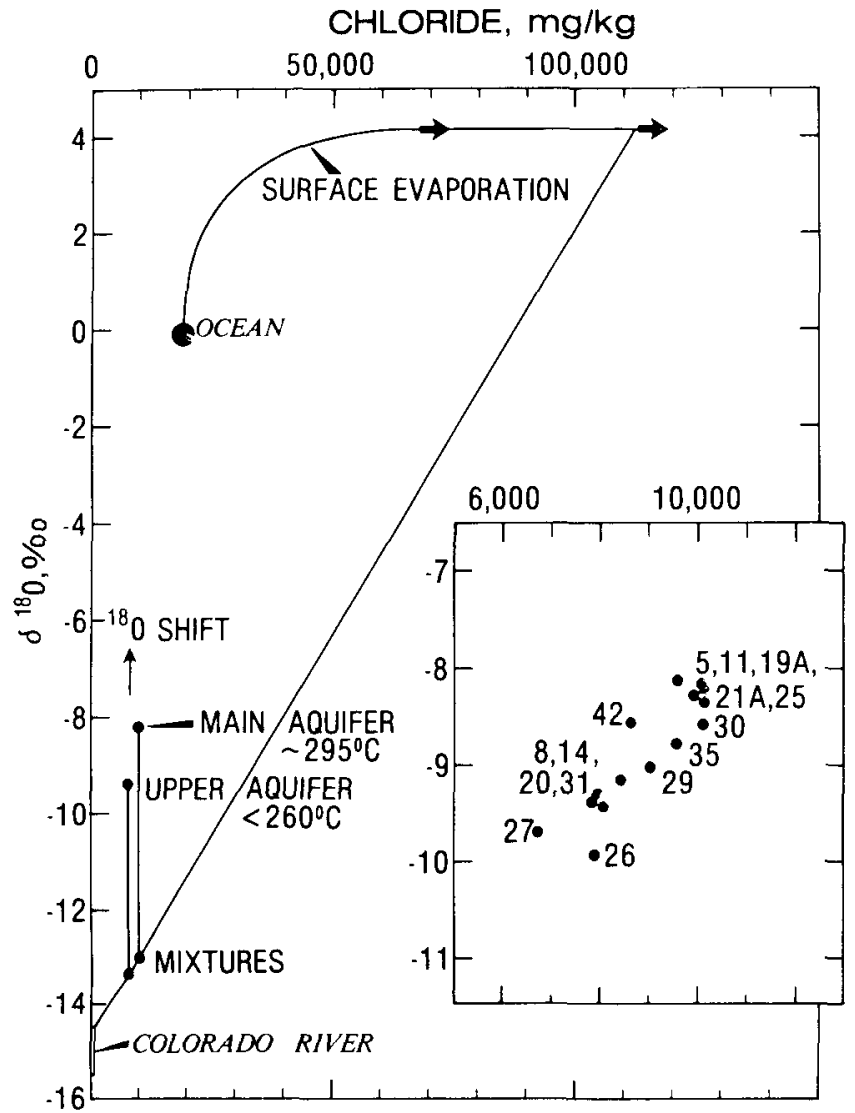

Figure 5. Isotopic composition and chloride content of Cerro Prieto reservoir, Colorado River and ocean waters, showing the effect of surface evaporation, mixture, and high temperature reactions (from Truesde11 et al., 1979).

(XBL 804-9163)

zone are small and show a northeast-southwest extension of about $0.7 \mu$ strain/yr. The regional net resurvey showed a small expansion on all axes with a maximum of about $0.7 \mu \mathrm{strain} / \mathrm{yr}$ in a northeastsouthwest direction (Massey, 1979).

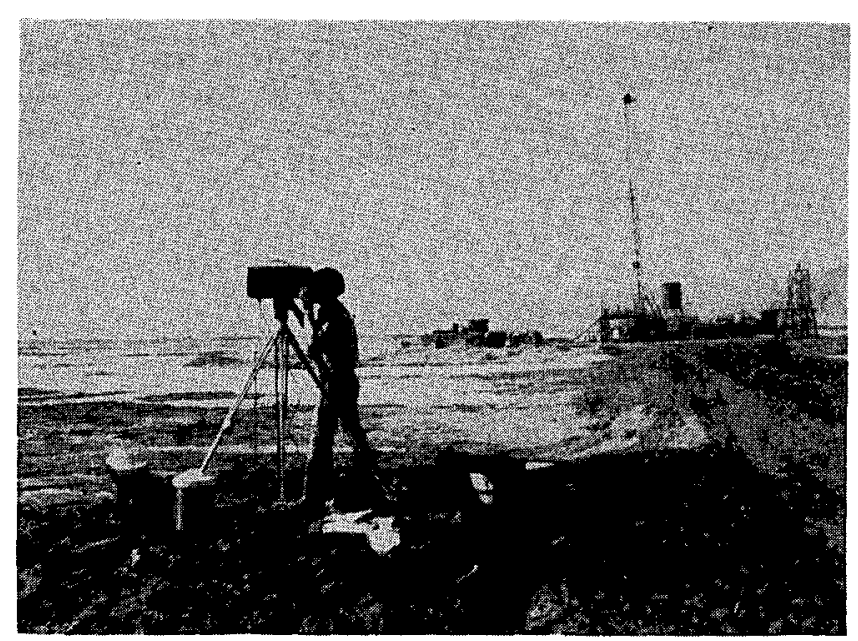

Figure 6. Electronic distance measurement equipment being used at a horizontal control station of the local network (USGS photograph).

(BBC 784-4885)

\section{Reservor Engineering}

During fiscal year 1979 LBL advised CFE in their well testing program, performed a number of field tests, and assisted in interpreting the data obtained. The results from two-rate flow and interference tests confirmed that permeability of the reservoir is on the order of tens of millidarcies.

LBL carried out a two-rate flow test in one of the wells using a downhole tool modified by Sandia Laboratories (Figure 7). The test demonstrated that the modified high-temperature tools could operate at temperatures of up to $340^{\circ} \mathrm{C}$ for $12-\mathrm{hr}$ periods. The maximum downhole time seems to be determined by the failure of the O-rings, and not of the clocks (Alonso et a1., 1979).

Physical and mechanical properties of cores continued to be determined under high temperature and pressure conditions (Abou-Sayed and Schatz, 1979). Simplified models of the field were used to determine its boundary condition and recharge rates and to simulate its behavior during production and injection.

\section{$\underline{\text { Reinjection }}$}

In August 1979 CFE began reinjection of untreated $165^{\circ} \mathrm{C}$ brines into well $\mathrm{M}-9$. The test is being carefully monitored. Downhole measurements in M-9 are periodically carried out. Pressure and temperature of neighboring producing wells are being monitored to detect any changes resulting from the test.

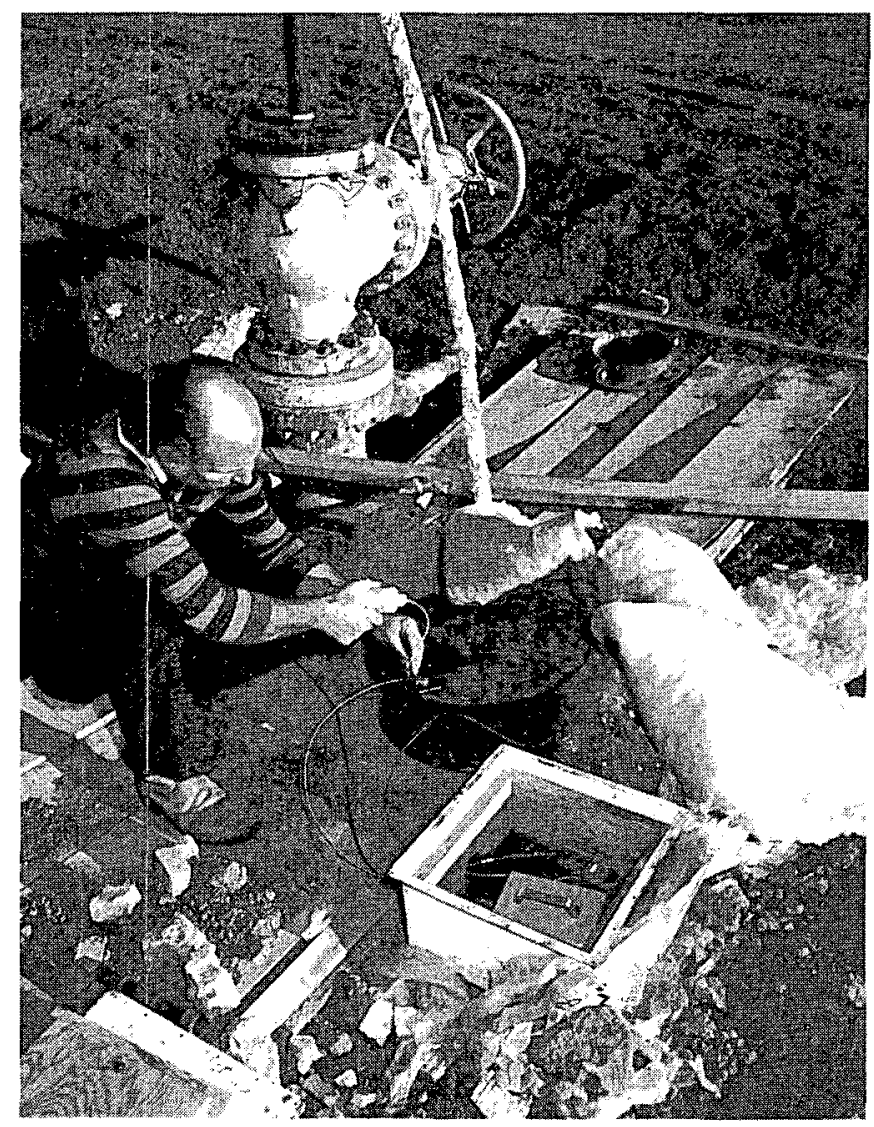

Figure 7. Technician checking instrumentation during a well test.

(BBC 782-2269) 
Because a 30 MW low-pressure turbine will be on line in 1982 , large amounts of $100^{\circ} \mathrm{C}$ brines supersaturated with silica will then be available for reinjection. To avoid major problems in the pipes and reservoir, the excess silica will have to be eliminated before reinjection.

In support of these future reinjection operations under low temperature conditions, Weres et al. (1980) carried out laboratory experiments and theoretical calculations to evaluate different brine treatment processes. They found that part of the dissolved silica quickly polymerizes to form suspended colloidal silica. This colloidal silica will flocculate and settle rapidly by raising the $\mathrm{pH}$ and stirring the brine. The theoretical equilibrium calculations indicated that the increase of $\mathrm{pH}$ of the brine to remove silica might cause some precipitation of carbonates. If this occurs the problem could be eliminated at reasonable cost.

Mexico has begun pilot plant-scale tests to determine the isothermal $\left(\sim 100^{\circ} \mathrm{C}\right)$ rate of silica polymerization for different $\mathrm{pH}$ values. Also, sedimentation tests with and without flocculants are being conducted.

\section{Conferences}

During this fiscal year no symposium open to the general public was held. However, a number of internal planning and technical meetings between Mexican and U.S. scientists and engineers were organized to discuss the latest results and future directions of the coorperative program.

The proceedings of the first symposium, in Spanish and English, were issued as an LBL report (Lawrence Berkeley Laboratory, 1978) and will be published in a special issue of the journal Geothermics.

\section{PLANNED ACTIVITIES FOR FISCAL YEAR 1980}

LBL will continue to coordinate the U.S. activitites at Cerro Prieto under the CFE/DOE cooperative program. Discussions will be held between DOE/ LBL and CFE to extend the present agreement to one of the geothermal areas of central Mexico, possibly Los Azufres field in the state of Michoacan.

The geological model of the Cerro Prieto field will be updated in 1 ight of new data from wells, field surveys, and laboratory work, which will be carried out during the next year. The interpretation of well logs, analysis of cores, and drill cuttings will continue.

The dipole-dipole and precision gravity networks will be resurveyed for the third time to maintain the monitoring activities within the production area. Additional magnetotelluric measurements will be carried out. The induced seismicity array will be refurbished by the installation of improved downhole geophones.

The geochemical model to explain the different processes occurring in the reservoir as well as to determine its evolution and recharge will be developed further based on the analysis of reservoir rocks and fluids.
The regional and local horizontal networks will be resurveyed to monitor crustal deformations related to tectonic and man-made activities.

Improved high-temperature downhole tools will be used in well tests to gather additional data on the characteristics of individual wells and of the different geothermal aquifers. The numerical simulation of field behavior will continue at an accelerated pace in view of the need to estimate the long-term capacity of the field and to predict the effects on the reservoir of large-scale reinjection of waste brines.

Internal technical meetings with DOE and CFE will be held periodically to review results and plan future activities. On October 17-19, 1979, the Second Symposium on the Cerro Prieto Geothermal Field was held in Mexicali. Preparations for the Third Symposium (San Francisco, March 1981) will begin during this fiscal year.

\section{REFERENCES CITED}

Abou-Sayed, A., and Schatz, J. F., 1979. Physical and mechanical properties of cores from the Cerro Prieto geothermal field, in Abstracts, Second Symposium on the Cerro Prieto Geothermal Field. Mexicali, Comisión Federal de Electricidad.

Alonso E., H., Domínguez A., B., Lippmann, M. J., Molinar C., R., Schroeder, R. E., and Witherspoon, P. A., 1979. Update of reservoir engineering activities at Cerro Prieto. Berkeley, Lawrence Berkeley Laboratory, LBL-10209.

de Boer, J., 1979. Paleomagnetic dating of the Cerro Prieto volcano, in Abstracts, Second Symposium on the Cerro Prieto Geothermal Field. Mexicali, Comisión Federal de Electricidad.

Elders, W. A., Hoagland, J. R., Vallette, J. N., Williams, A., Barker, C., and Collier, P., 1980. A comprehensive study of samples from geothermal reservoirs: petrology and geochemistry of subsurface and surface samples from the Cerro Prieto geothermal field, Baja California, Mexico. University of California at Riverside (report in press).

Hernández G., J. L., 1979. Algunas precisiones en torno a la Unidad 5. Boletín Instituto Investigaciones Eléctricas, v. 3, no. 10, p. $7-10$.

Hurtado, R., Díaz, R., Mercado, S., Garibaldi, F., Cortéz, C., and Fausto, J. J., 1979. Brine treatment for reinjection and reinjection tests without treatment, in Abstracts, Second Symposium on the Cerro Prieto geothermal field. Mexicali, Comisión Federal de Electricidad.

García, J. R., and Mendéz, V. P., 1979. Firstorder leveling surveys at Cerro Prieto, in Abstracts, Second Symposium on the Cerro Prieto geothermal field. Mexicali, Comisión Federal de Electricidad.

Goubau, W. M., Stark, M., Gamble, T. D., Goldstein, N. E., and Miracky, R., 1979. Magnetotelluric studies at Cerro Prieto, in Abstracts, Second Symposium on the Cerro Prieto Geothermal Field. Mexicali, Comisión Federal de Electricidad.

Grannel1, R. B., Tarman, D. W., Aronstam, P., Clover, R. C., Leggewie, R. M., Eppink, J., and Kroll, R., 1979. Precision gravity 
measurements in the Cerro Prieto geothermal area, in Abstracts, Second Symposium on the Cerro Prieto Geothermal Field. Mexicali, Comisión Federal de Electricidad.

Lawrence Berkeley Laboratory, 1978. Proceedings, First Symposium on the Cerro Prieto Geothermal Field, Baja California, Mexico, September 20-22, 1978, San Diego, California. Berkeley, Lawrence Berkeley Laboratory, LBL-7098.

Lyons, D. J., and van de Kamp, P. C., 1980. Subsurface geological and geophysical study of the Cerro Prieto geothermal field. Berkeley, Lawrence Berkeley Laboratory, LBL-10540.

Mañon M., A. and Guiza L., J., 1979. E1 proyecto de optimización del aprovechamiento de fluidos geotérmicos en opinión de dos expertos. Boletín Instituto Investigaciones Eléctricas, v. 3, no. 4, p. 22 .

Massey, B. L., 1979. Measured crustal strain, Cerro Prieto geothermal field, Baja California, Mexico, in Abstracts, Second Symposium on the Cerro Prieto Geothermal Field. Mexicali, Comisión Federal de Electricidad.

Truesde11, A. H., Nehring, N. L., Thompson, J. M., Coplen, T. B., DesMarais, D. J., Janik, C. J., and Meh1, D. C., 1979. Geochemical studies of the Cerro Prieto reservoir fluid, in Abstracts, Second Symposium on the Cerro Prieto Geothermal Field. Mexicali, Comisión Federal de Electricidad.

Vonder Haar, S, and Howard, J. H., 1979. Intersecting faults and sandstone stratigraphy at the Cerro Prieto geothermal field, in Abstracts, Second Symposium on the Cerro Prieto Geothermal Field. Mexicali, Comisión Federal de Electricidad.

Weres, O., Tsao, L., and Iglesias, E., 1980. Chemistry of silica in Cerro Prieto brines. Berkeley, Lawrence Berkeley Laboratory, LBL-10166.

Wilt, M. J. and Goldstein, N. E., 1979. Resistivity monitoring at Cerro Prieto, in Abstracts, Second Symposium on the Cerro Prieto Geothermal Field. Mexicali, Comisión Federal de Electricidad.

Witherspoon, P. A., Alonso E., H., Lippmann, M. J., Mañon M., A., and Wollenberg, H. A., 1978. Mexican-American Cooperative Program at the Cerro Prieto geothermal field. Berkeley, Lawrence Berkeley Laboratory, LBL-7095.

\section{REGIONAL GEOLOGIC SETTING OF THE CERRO PRIETO GEOTHERMAL FIELD}

\section{S. P. Vonder Haar and J. H. Howard}

\section{INTRODUCTION}

A synthesis of geological information on the Salton Trough from the Salton Sea region south to the Upper Gulf of California was completed during the past fiscal year.

Satellite photography and field research established important relationships between a probable deep heat source, fluid migration, and magnitude of the geothermal fields (Vonder Haar and Puente $C$. , 1979a; Meidav and Howard, 1979). Our understanding of regional volcanism and subsurface stratigraphy was enhanced by paleomagnetic and micropaleontology studies. Merging of concepts on San Andreas type wrench faulting with oceanic transform fault theory (Vonder Haar and Puente C., 1979b) provided insight into the apparently significant role of northeastsouthwest trending cross-faults in geothermal fields in the Salton Trough, including Cerro Prieto.

\section{THE YEAR'S ACTIVITIES}

The wedge-shaped region termed the Salton Trough extends from the Salton Sea to the uppermost Gulf of California (Figure 1) and is noted for recent volcanism, strike-slip faulting and geothermal fields. This region is bounded on the east by the poorly defined Craton Margin Lineament (see Figure 2) and the Sierra Pinacate volcanics. On the west, the San Felipe basin-bounding fault zone and the combined E1sinore/San Jacinto fault zones form a sharp boundary. Slicing through the trough are the Cerro Prieto fault, the Imperial fault and still other faults. Faults in the trough are best conceived of as hybrid types having features of both San Andreas style wrench faults and oceanic transform faults. Earlier ideas of passive pullapart basins or transform faults that leak magma (Elders et al., 1972) have been refined.

Fault blocks between the Cerro Prieto and Imperial faults appear to be 1 to $4 \mathrm{~km}$ on a side. oblique intersections of northeast-southwest trending fault shear zones with these two major faults

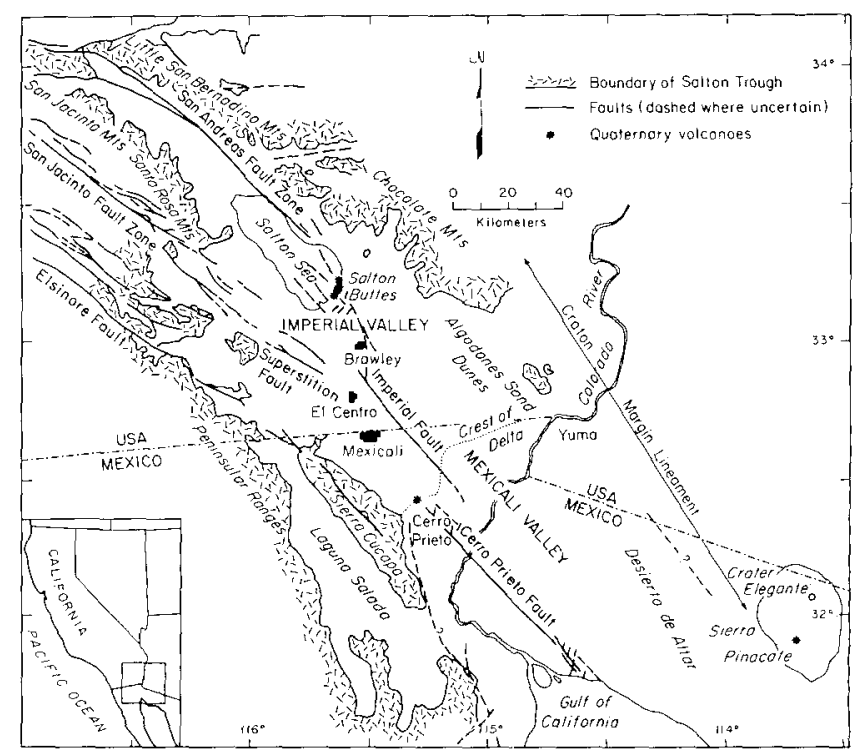

Figure 1. Regional geology of the Cerro Prieto geothermal field showing major faults and sites of paleomagnetic studies (see Vonder Haar, Noble, and Puente C., 1979).
(XBL 801-6718) 


\section{SALTON TROUGH FAULTING}

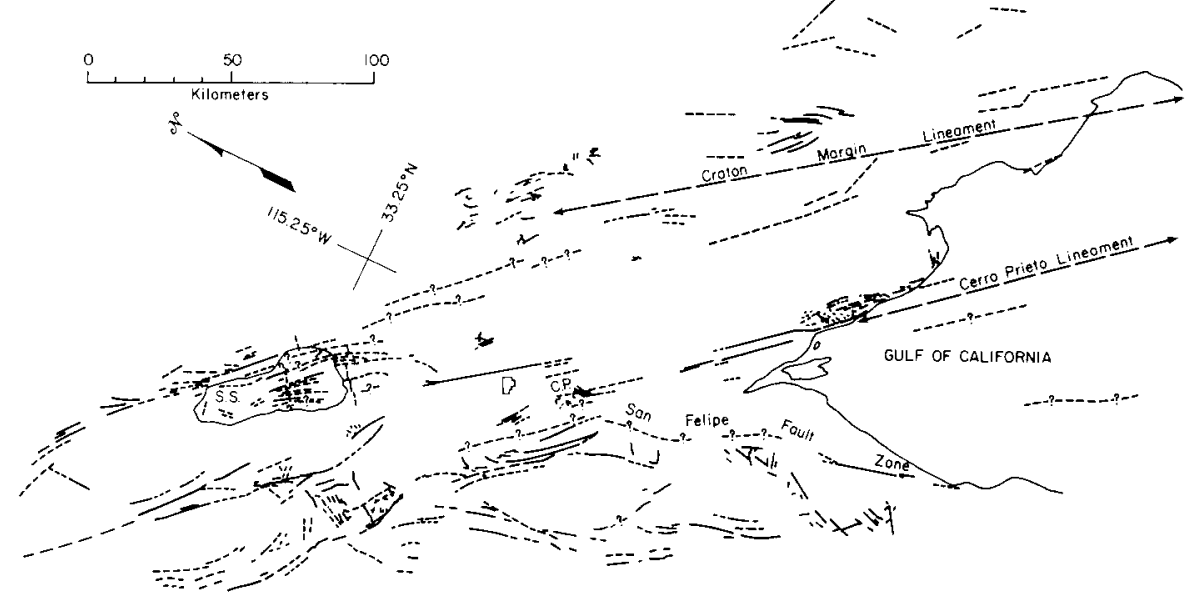

Figure 2. Compilation of faults in the Salton Tough showing the Cerro Prieto Lineament as a major hybrid transform fault zone. Note the prevalent and long northwest-southeast trending faults with much shorter intersecting faults of northeast-southwest trends. Faults indicated by lines, dashed where discontinuous or subsurface; ? indicates uncertain location. Critical data evaluation from published work; S.S. indicates Salton Sea; C.P. is the Cerro Prieto geothermal area (from Vonder Haar and Puente C., 1979a).

indicate sites for the most productive wells. In addition, these cross-cutting northeast-southwest faults help move the convective fluid flow away from the deep penetrating hybrid transform faults. Thus the areal extent of the rapid recharge zone is increased.

of major importance to the regional stratigraphy was the discovery of a mid-Tertiary (approximately $15 \mathrm{~m} . \mathrm{y}$. old) foraminifer Cassigerinella chipolensis (Figure 3 ). This planktonic marine

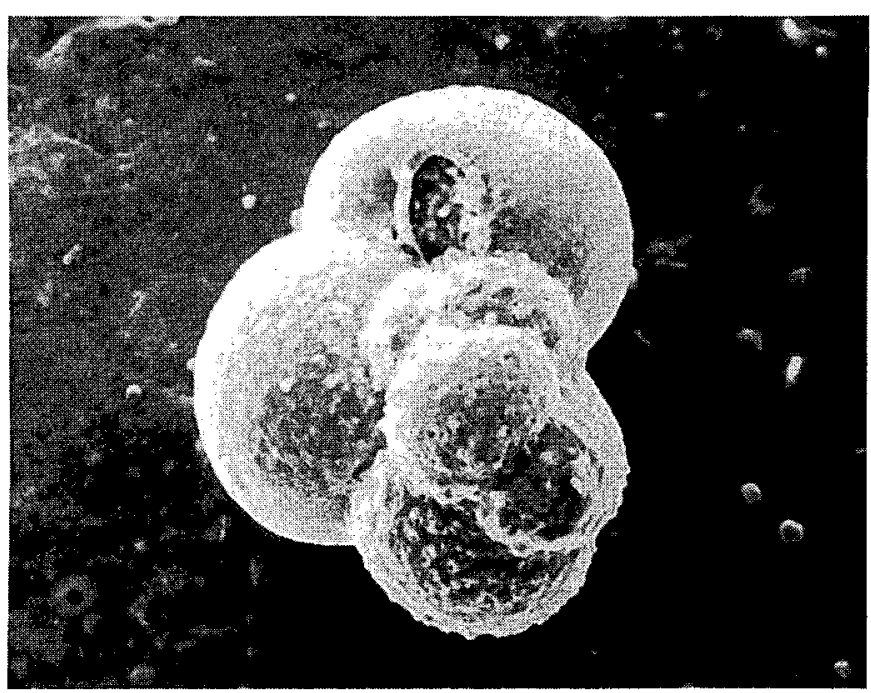

Figure 3. Cassigerinella chipolensis; a midTertiary planktonic microfossil found in Cerro Prieto geothermal well cuttings (see Cotton and Vonder Haar, 1979). Scanning electron microphotograph provided by J. L. Lamb, Exxon Production Research; actual diameter of the microfossil is $0.7 \mathrm{~mm}$.

(XBB 790-13447) microfossil was found in well cuttings from the Cerro Prieto geothermal field. These specimens are not laboratory contaminates and have not been found in the drilling mud (Cotton and Vonder Haar, 1980). If the presence of Cassigerinella chipolensis is confirmed, the current conceptualization of the opening of the Gulf of California after mid-Tertiary, on 1 y 11 million years ago, and the California Pacific coast mid-Tertiary history will need to be revised.

Timing of geologic events in the region and the variation in volcanism were clarified by paleomagnetic studies. Figure 4 illustrates polar excursion paths and data for the Salton Buttes, Crater Elegante, and Cerro Prieto. Deviating thermomagnetic directions in volcanism representing the second and fifth or sixth pulse of volcanism suggest that Cerro Prieto originated approximately 110,000 years B.P. and continued to be active intermittently until about 10,000 years ago (de Boer and Vonder Haar, 1980). The Crater Elegante, Salton Buttes, and Cerro Prieto poles differ enough to support the conclusion that volcanic activity throughout the trough was not contemporaneous.

Analogs to the Cerro Prieto region were investigated in relation to both early rifting phases (see Vonder Haar and Howard, 1978) and to transform faulting. In addition to the Gulf of California basin studies (Lonsdale and Lawver, 1979), the insitu structural observations along Transform fault " $\mathrm{A}$ " in the FAMOUS area of the Mid-Atlantic ridge provided clear insights into tectonism (see Figure 5). Geophysical studies and well drilling in the Cerro Prieto region furnished a model that compared favorably with these analogs if the increased de1taic sedimentation rate and thickening continental basement near Cerro Prieto are considered. 


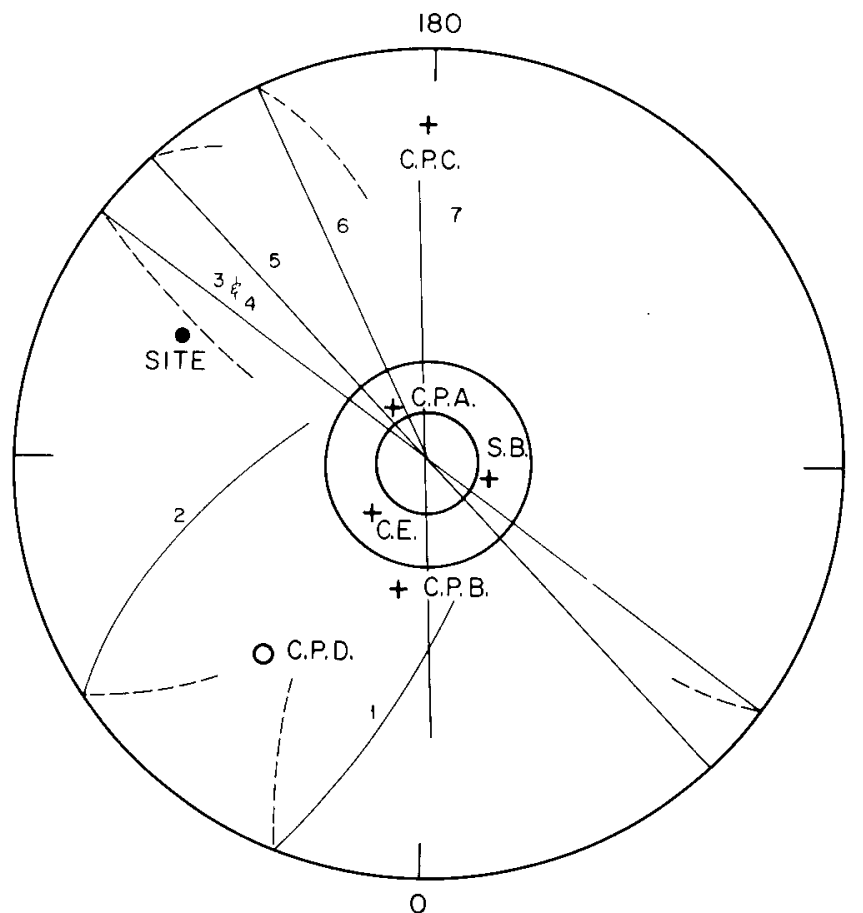

Figure 4. Polar paths for major magnetic excursions in the Brunhes period: (1) Gothenburg $(\sim 10,000$ years B.P.), (2) Starno ( 12.000 years B.P.), (3) Lake Mungo, (4) Laschamp, (5) Lake Bitwa, (6 and 7) Blake $(119,000$ to 108,000 years B.P.); with the virtual geomagnetic poles for Cerro Prieto (CPA, CPB, CPC, CPD), Salton Buttes (SB), and Crater Elegante (CE). CPD represents a pole in the southern hemisphere--a magnetic reversal.

(XBL 7912-13474)

\section{TRANSFORM FAULT "A"}

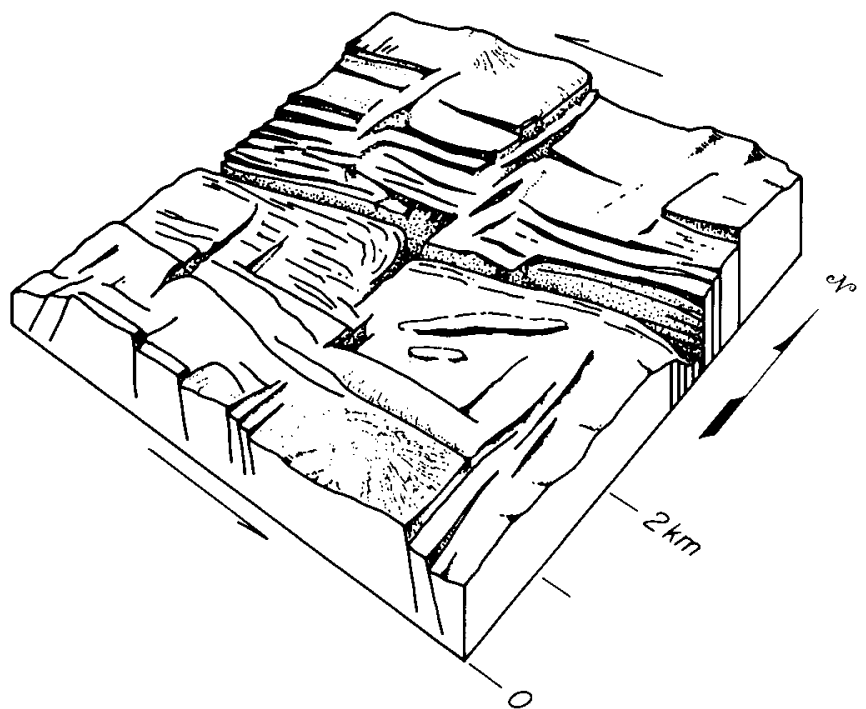

Figure 5. Interpretive block diagram of Transform fault " $A$ " in the Mid-Atlantic Ridge showing structural domains. The ramps, cross-faults and 200m-wide active zone of strike-slip movement within a 4-km-wide fault trough suggest the possible complexity of faulting along the Cerro Prieto and Imperial faults and within the producing geothermal fields (after Choukroune et al., 1978).(XBL 797-7583)

\section{PLANNED ACTIVITIES}

During the coming fiscal year, work on the neotectonism and regional stratigraphy is planned. In particular we will study the Sierra Cucapa, only $10 \mathrm{~km}$ west of the Cerro Prieto geothermal zone, for fracture density and fracture styles around the normal and strike-slip faults. This will aid in studies of the production zone at 2 to $3.5 \mathrm{~km}$ depth at the Cerro Prieto field. Heat flux and detailed faulting at the southern end of the Imperial fault are not nearly as well understood as at the northern terminus of the Cerro Prieto fault. Geophysical data that reach across the Salton Trough would be most useful. Micropaleontology of key outcrop and subsurface wells should prove as exciting and beneficial as the initial work on Cerro Prieto well samples.

\section{REFERENCES CITED}

Choukroune, P., Francheteau, J., and Le Pichon, X., 1978. In situ structural observations along Transform Fault A in the FAMOUS area, MidAtlantic Ridge. Geol. Soc. Amer. Bul1., v. 89, P. 1013-1029.

Cotton, M. L., and Vonder Haar, S., 1980. Microfossils from Cerro Prieto geothermal wells, Baja, California, Mexico. Berkeley, Lawrence Berkeley Laboratory, LBL-10303.

de Boer, J., and Vonder Haar, S., 1980. Paleomagnetism of the Quaternary Cerro Prieto, Crater Elegante, and Salton Buttes volcanic cones in the northern Gulf of California rhombochasm. Berkeley, Lawrence Berkeley Laboratory, (in prep.).

Elders, W. A., Rex, R. W., Meidav, T., Robinson, P. T., and Biehler, S., 1972. Crustal spreading in southern California: Science, v. 178, no. 4056, p. $15-24$.

Lonsdale, P., and Lawver, L. A., submitted 1979. Submersible study of immature plate boundary zones in the Gulf of California. Geol. Soc. Amer. Bull., 8 p.

Meidav, T. and Howard, J. H., 1979. An update of tectonics and geothermal resource magnitude of the Salton Sea geothermal resource. Transactions, v. 3, Geothermal Resources Council Annual Meeting, 24-27 September 1979, Reno, Nevada, p. 445-448.

Vonder Haar, S. and Howard, J. H., 1978. Geology and geothermal resources of the Salton Trough California in relation to rift zone tectonics; International Symposium on the Rio Grande Rift, Santa Fe, New Mexico. Program and Abstracts Vo1., p. 97-99.

Vonder Haar, S. and Puente C., I., 1979a. Fault intersections and hybrid transform faults in the southern Salton Trough geothermal area, Baja California, Mexico. Geothermal Resources Council Annual Meeting, 24-27 September 1979, Reno, Nevada, Transactions, v. 3, p. 761-764. , 1979b. Transform faulting related to geothermal energy in Baja California, Mexico. Geol. Soc. Amer. Annual Meeting, San Diego, Nov. 5-8, Abstracts and Programs, v. 11, no. 7 , p. 533 .

Vonder Haar, S., Noble, J. E., and Puente C., I., 1979. Vertical movement along the Cerro Prieto transform fault, Baja California, Mexico--A mechanism for geothermal energy renewa1. Berkeley, Lawrence Berkeley Laboratory, LBL-8905. 


\title{
SUBSURFACE GEOLOGY OF THE CERRO PRIETO GEOTHERMAL FIELD
}

\author{
S. P. Vonder Haar, J. Noble, M. T. O’Brien, and J. H. Howard
}

\section{INTRODUCT ION}

A subsurface evaluation of the Cerro Prieto geothermal field was undertaken to furnish information for use in reservoir simulation models. Structure, stratigraphy, hydrothermal alteration and reservoir properties were studied. Data used included well logs, well cuttings and cores, and surface geophysical surveys. Detailed information from reports by Elders et al. (1979), and Lyons and van de Kamp (1980), were integrated into ongoing Cerro Prieto geothermal research at LBL. The approach taken in this summary and the concepts developed for Cerro Prieto are applicable to geothermal exploration and reservoir development in other regions.

\section{THIS YEAR'S ACTIVITIES}

Structural features at Cerro Prieto are dominated by a major northeast-southwest strike slip fault zone termed the Cerro Prieto Fault (Vonder Haar and Puente, C., 1980) and cross-cutting north-northeast to south-southwest faults. Figure 1 illustrates these faults based on revised interpretations of well 1 log correlations, 1 inear surface features, thermal spring locations, seismic reflection and refraction profiles, and gravity and magnetic maps. Faulting is complex in terms of the history of episodic fault movements. Only dip-slip displacement can be recognized, whereas there may also be a significant lateral component.

A variety of subsurface cross sections have been compiled. One useful style is based on lithofacies analysis (Figure 2) of mechanical well logs in conjunction with cutting and core (Figure 3 ) descriptions. Based on lithofacies analysis and geochemical data it was possible to delineate densification and hydrothermally altered zones and temperature-sensitive hydrothermal mineral horizons

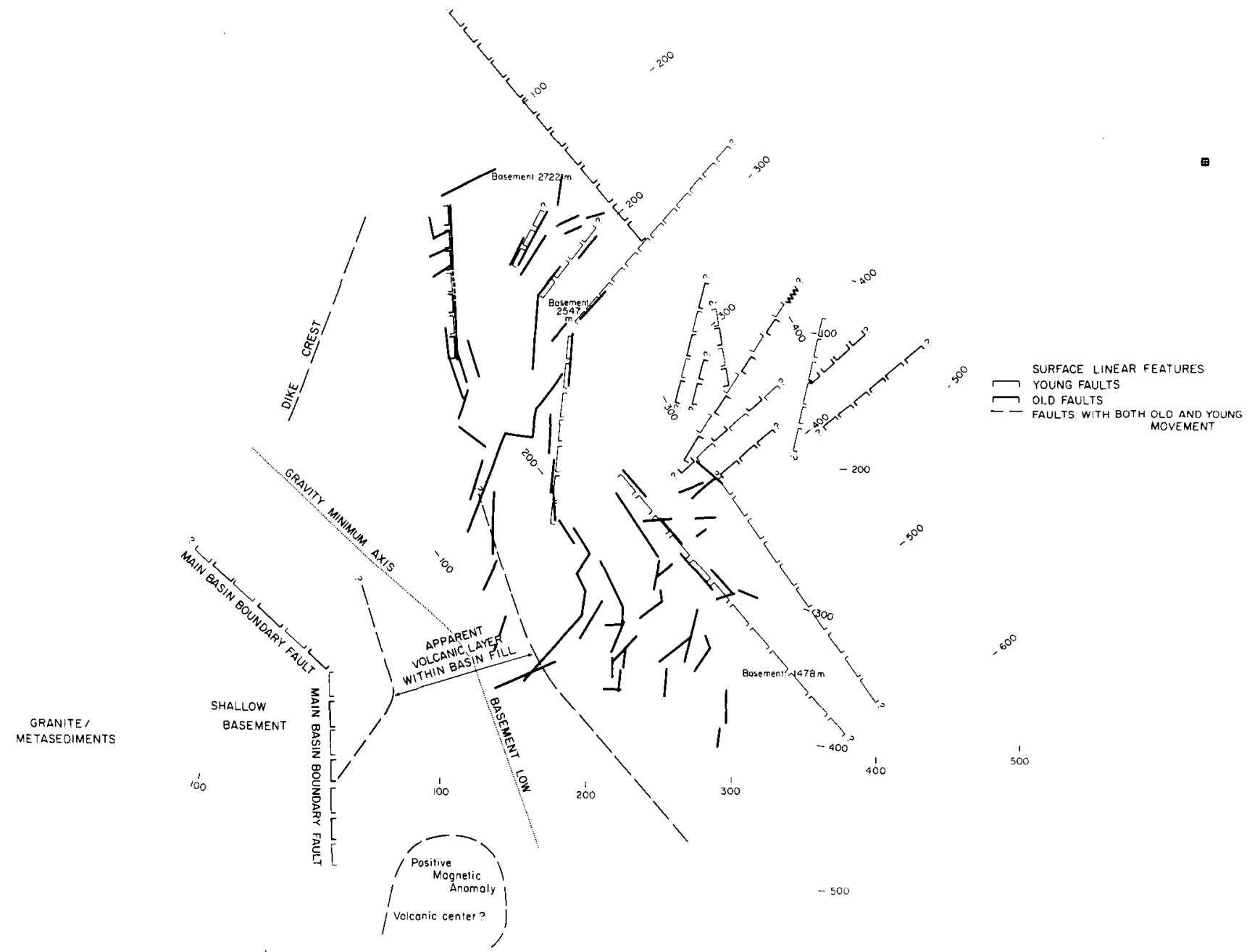

Figure 1. Index map for the Cerro Prieto geothermal field showing wells, faulting, seismic reflection lines and geologic cross sections.

(XBL 801-6753) 


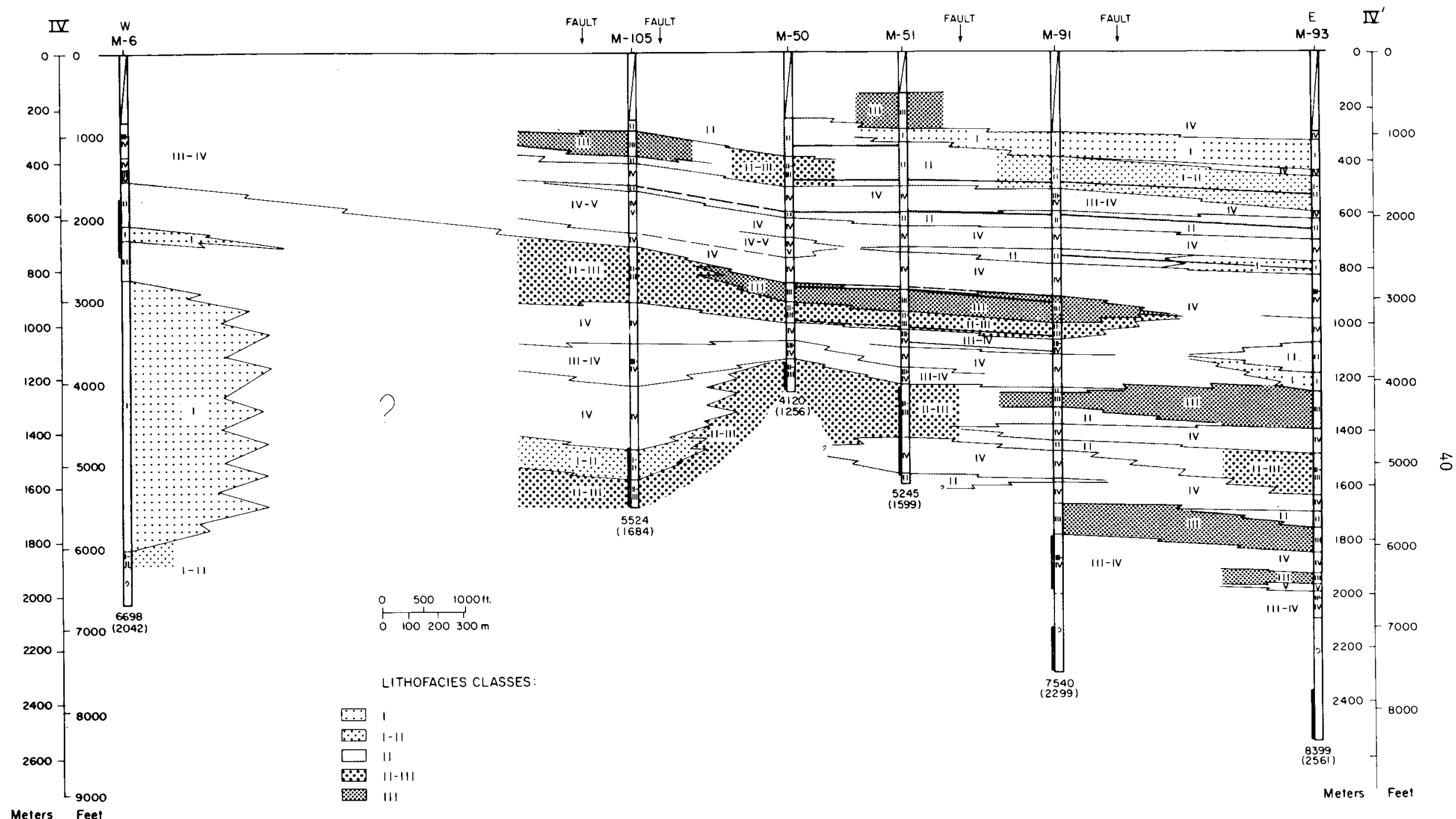

Figure 2. Lithofacies cross-section IV-IV' spanning the southern portion of the geothermal field. Correla grading down to class $\mathrm{v}$, which is predominantly siltstones and shales (see Lyons and van de Kamp, 1979). (XBL 801-6731A) 
41

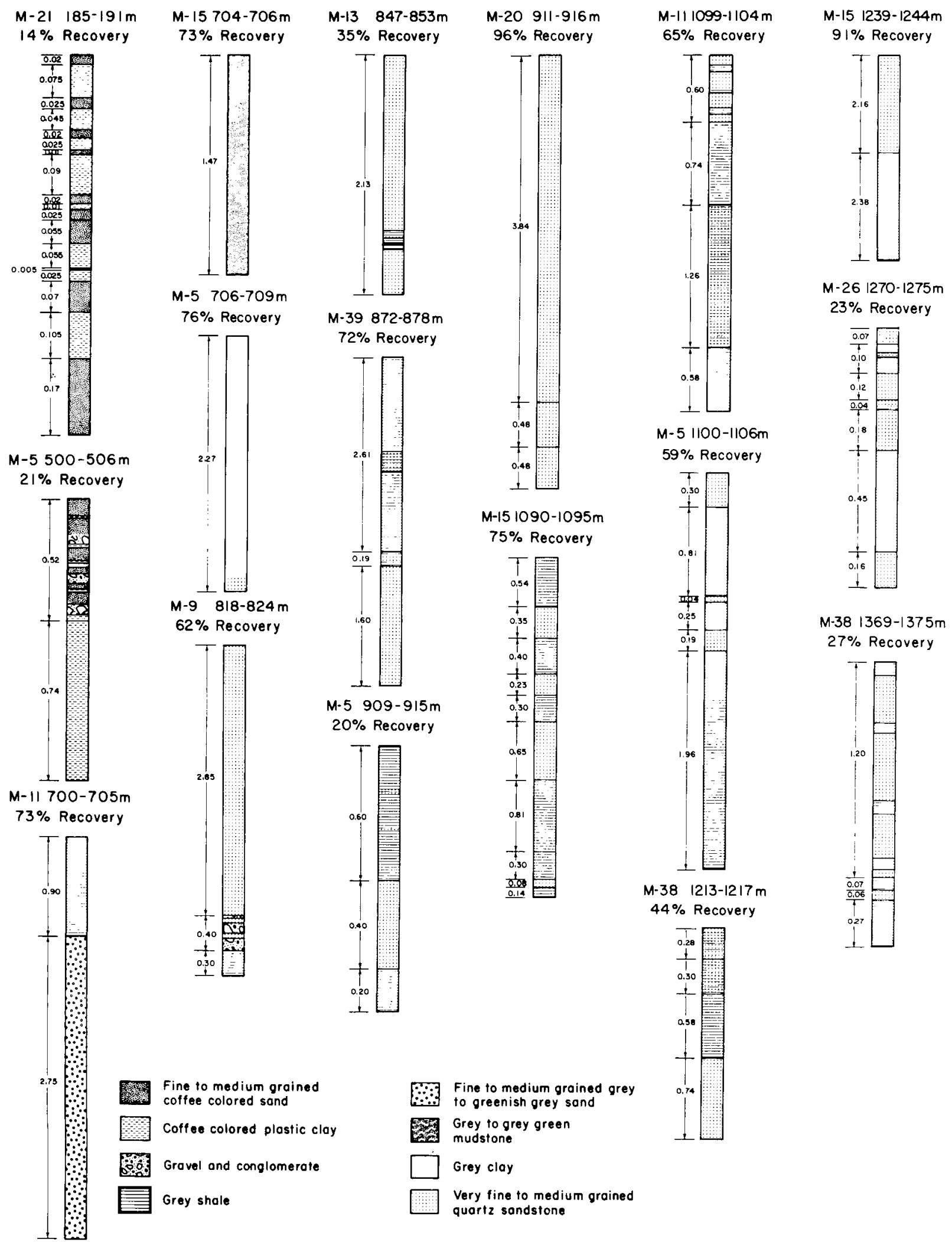

Figure 3. Summary of rock types recovered by coring from Cerro Prieto geothermal wells. Note the abundance of deltaic sandstone and the transition near $700 \mathrm{~m}$ depth from sediment to hydrothermally altered rock. Numbers next to the cores, such as 0.62 , indicate the length in meters of core pieces recovered.

(XBL 7910-13058) 
(Figure 4) in order to estimate reservoir temperature and flow characteristics. Contour maps of reservoir properties such as resistivity (Figure 5) are available for use in documenting somewhat subtle shifts in sediment type, porosity and thus fluid flow within the reservoir area.

Studies of the cores and cuttings confirmed the presence of microfossils in portions of the field, as shown in Table 1 (Cotton and Vonder Haar, 1979). In addition to being useful paleoenvironmental indicators, these carbonate and silica fossils substantiate our alteration hypothesis of localized and selective removal of sediments within the densified reservoir units. Secondary porosity is commonplace. Porosity shifts are also apparent in density and porosity versus depth plots as shown in Figure 6. Dramatic visual confirmation of porosity and permeability clogging, using scanning electron microscopy, (Figure 7) has been related to both the $x$-ray diffraction work and the downhole mechanical properties.

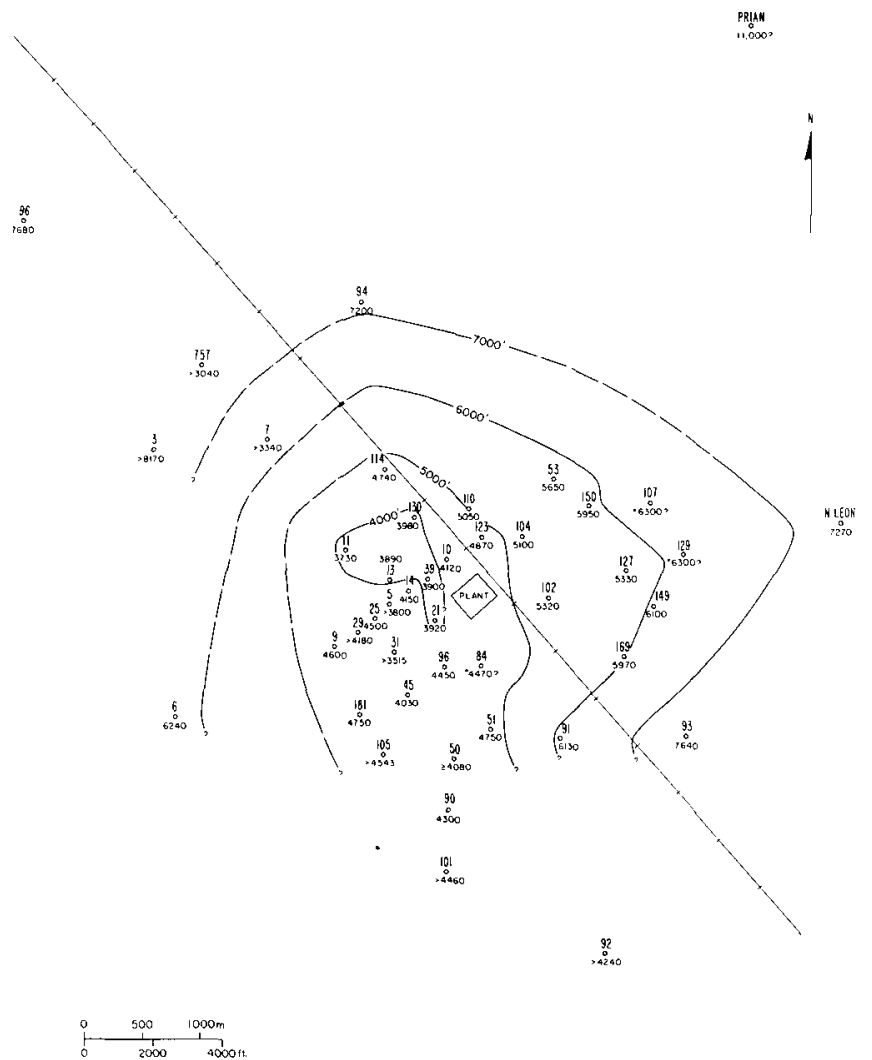

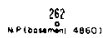

Figure 5. Three-dimensional computer presentation of a capping type domal surface in the Cerro Prieto geothermal field. This surface represents the mean depth of the unconsolidated sediment to rock contact (Puente C. and de la Peña L., 1980); and the top of the metamorphic zone based on hydrothermal mineral alterations (data from Elders et a1., 1979).

(XBL $803-6851$ )
Mean of $A / B$ and Top of Metomorphic Zone

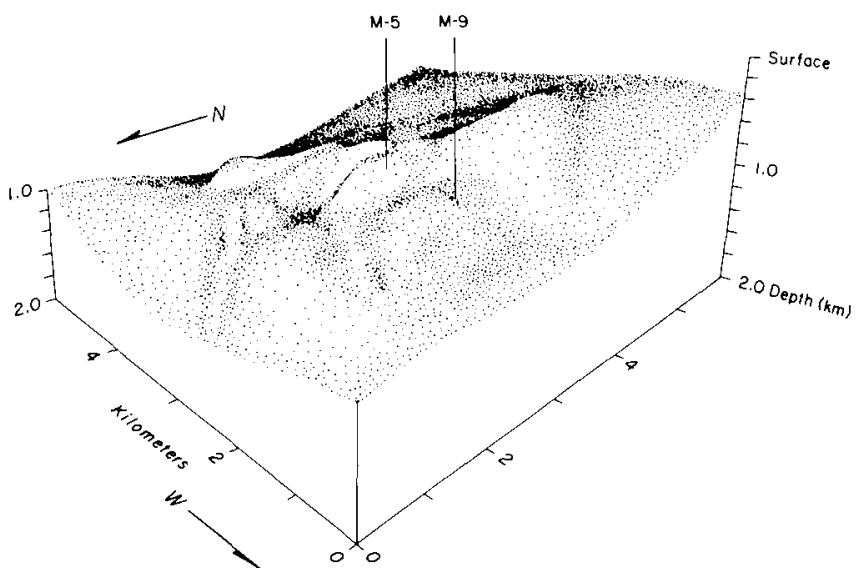

Figure 4. Map of the depth below which shale resistivities exceed 5 ohm-m (top of high-resistivity shales). Contours are in feet.

(XBL 801-6723)

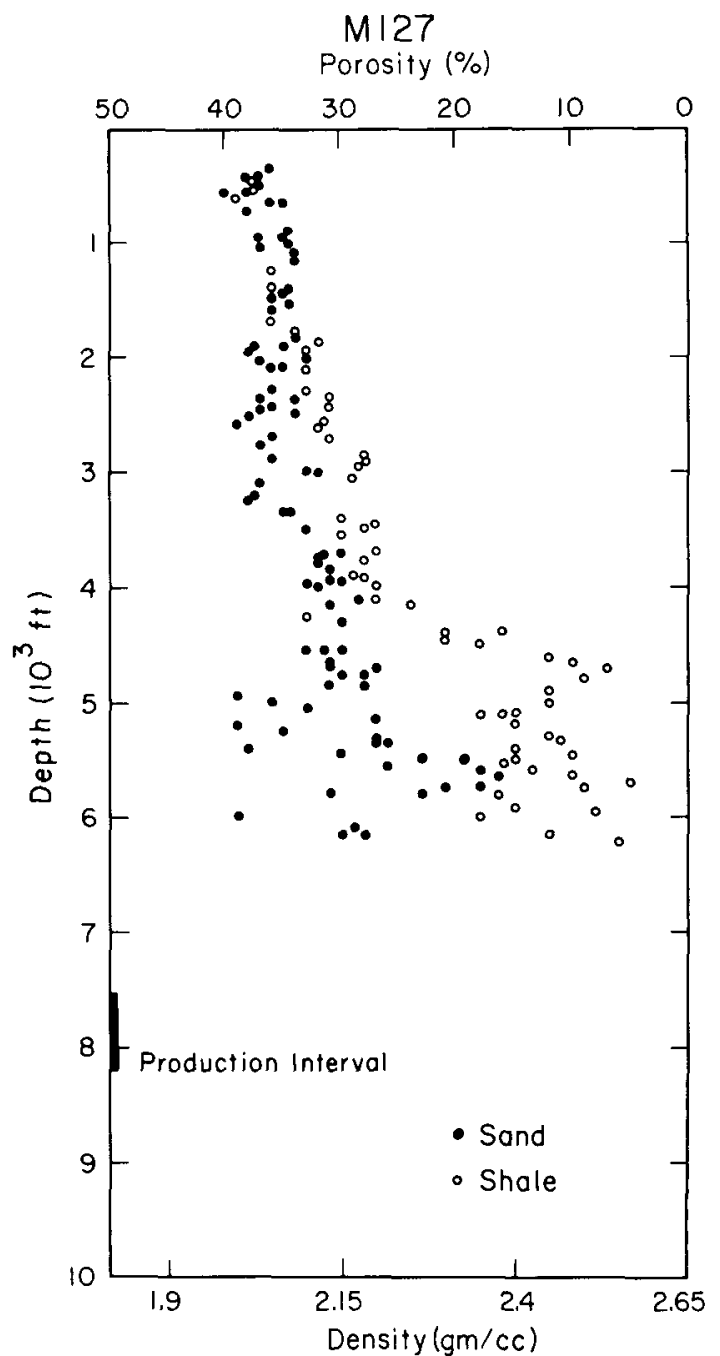

Figure 6. Plot of porosity and density versus depth for well M-127, determined from well logs. Some sandstone porosities in the altered zone at depth are even higher than those above the A/B boundary. These higher porosity sandstones interbedded with metamorphosed, low density shales imply secondary porosity that contributes to the reservoir zone.

(XBL 802-6769) 


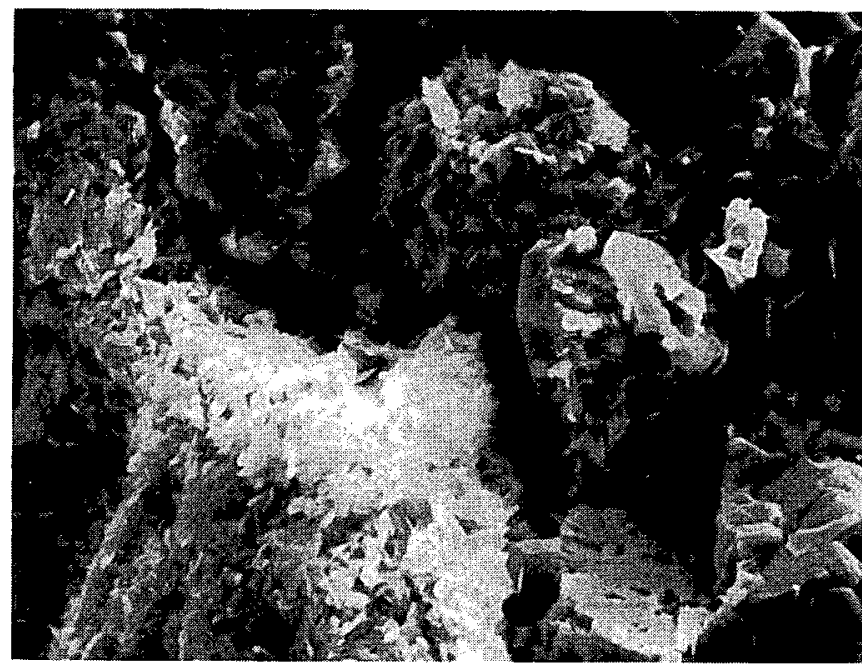

Figure 7. Scanning electron microphotograph of a core chip from well M-38 at $1372 \mathrm{~m}$ below the surface; field of view across the photograph is $100 \mu \mathrm{m}$ $(=0.1 \mathrm{~mm})$. This sample lies within the zone of the first occurrence of prehnite $\left(280^{\circ} \mathrm{C}\right)$ defined by Elders et al. (1979). Note the variety of claylike minerals, leached crystal faces and new crystal faces.

(XBB 797-9451)

\section{PLANNED ACTIVITIES}

In fiscal year 1980 , we will clarify geological reservoir features of the Cerro Prieto geothermal field by comparing them with geophysical data and regional groundwater flow concepts. In particular we will relate the role of secondary porosity and deeper fracture flow in metamorphosed deltaic rocks to transmissivity and storativity. A geologic model will be confirmed and tested for prediction of reservoir behavior and production characteristics.

\section{SECONDARY POROSITY STUDIES}

Secondary sandstone porosity extends the depth range for effective sandstone porosity far below the depth limit for effective primary porosity. Generation and primary migration of geofluids occurs mainly below the range of effective primary porosity. The path of primary migration and the site of accumulation of geofluids are, therefore, commonly controlled by the distribution of secondary porosity.

The reservoir aspects of fields producing from secondary sandstone porosity more closely resemble carbonate reservoirs than fields with primary sandstone porosity. The distribution of secondary porosity in a sandstone formation may not show a direct relationship with depositional lithofacies or burial history and can be difficult to predict with conventional subsurface methods. However, detailed geologic and petrologic analysis of the factors that control the occurrence of secondary porosity often greatly enhance the understanding and prediction of its distribution. Sandstone reservoirs with secondary porosity have special problems but they also offer special opportunities for both the explorationist and the exploitationist. It is necessary, firstly, to recognize the secondary nature of the porosity of these reservoirs; secondly, to interpret controls and timing of the origin of their porosity; thirdly, to evaluate any factors that may have played a role in preserving this porosity; and fourthly, to survey the existing pore geometry in order to optimize the methods and economics of finding and recovering geofluids.

The detailed analyses of the petrological attributes of secondary porosity will require the use of advanced analytical techniques, such as cathode luminescence petrography, scanning electron microscopy, pore cast examination, microprobe analysis, and stable isotope analysis. In many sandstones, an amount of important information will be obtained simply by careful and methodical use of conventional petrographic microscopy.

The results of these detailed analyses will be integrated into the geologic model of the Cerro Prieto geothermal field.

\section{REFERENCES}

Cotton, M. L., and Vonder Haar, S., 1979. Microfossils from Cerro Prieto geothermal wells, Baja California, Mexico. Berkeley, Lawrence Berkeley Laboratory, LBL-10303.

Elders, W. A., Hoagland, J. R., Williams, A., Barker, C., Valette, J. N., and Collier, P., 1979. A study of Cerro Prieto geothermal we11 samples. University of California Riverside Publication (final report in preparation).

Lyons, D. J., and van de Kamp, P. C., 1980. Subsurface geological and geophysical study of the Cerro Prieto geothermal field. Berkeley, Lawrence Berkeley Laboratory, LBL-10540.

Vonder Haar, S. P., and Puente, C., I., 1980. Fault intersection and hybrid transform faults in the Southern Salton Trough geothermal area, Baja California, Mexico. Trans. Geothermal Resources Council, Annual Meeting, v. 3, 24-27 September, 1979, Reno, Nevada, p. 761-764.

Puente C., I. and de la Peña L., 1979. Geological model of the Cerro Prieto geothermal field, in Proceedings of the Second Symposium on the Cerro Prieto geothermal field. Mexicali, Comisión Federal de Electricidad. 


\title{
NUMERICAL MODELING STUDIES OF THE CERRO PRIETO RESERVOIR
}

\author{
M. J. Lippmann and K. P. Goyal
}

\section{INTRODUCTION}

The Cerro Prieto geothermal field is presently producing $150 \mathrm{MW}$ of electric power. In April 1979 the capacity of the power plant was doubled (from 75 to $150 \mathrm{MW}$ ) as two new units came into operation. Consequently, the fluid production rate has increased from about 2800 to 4200 tonnes per hour. Bermejo et a1. (1979) estimate that about $1.2 \times 10^{8}$ tonnes of steam-brine mixture has been extracted from the field as of late 1978 .

Improved estimates of the total capacity of the field will be essential in studying the feasibility of further developments of the area.

A realistic geohydrological model is of fundamental importance in estimating the capacity and longevity of the Cerro Prieto field. A number of papers presented at the Second Symposium of the Cerro Prieto Field (October 17-19, 1979, Mexicali, Baja California, Mexico) discussed the various efforts under way to establish the dimensions, structure and stratigraphy of the field, the properties and interconnection between the various aquifers, and the circulation of fluid and heat within the geothermal system and across its boundaries.

\section{ACTIVITIES IN FISCAL YEAR 1979}

During this year the aim of the modeling studies on the Cerro Prieto field were to determine its preproduction recharge and discharge conditions. As a first step, a simplified geological model of the system was developed on the basis of the available data. Then, the heat and mass flow through this model were calculated numerically using a computer program. The location, temperature and strength of the reservoir recharge and discharge areas, the thermal and hydraulic boundaries of the model, and the properties of the different materials were varied in an attempt to reproduce the preproduction temperatures given by Mercado (1976), and Elders et al. (1978). No efforts were made to match early reservoir pressures since pre-1973 pressure data are only available for few wells in the central part of the field.

The sources and sinks identified by this study could also be used for simulating the behavior of the field after 1973. However, their characteristics would change due to large-scale production. The mass inflow from the sources into the reservoir is expected to increase significantly in this open system and a decrease is anticipated at the sinks due to exploitation. In addition, areas surrounding the producing reservoir are also expected to drain (cold or hot) fluids in response to the changes in the pressure distribution in the field.

\section{Relevant Work}

Knowledge about the recharge and discharge characteristics of the field is essential to predict its future behavior. Based on data from recent

and earlier studies, zones of recharge and directions of flow of the recharged fluid may be inferred. Unfortunately not all the data point to exactly the same zones and directions.

On the other hand, no precise locations at depth are available for the zones where some of the fluid and heat transported across the geothermal reservoir find their way to the surface. It is safe to say that heat is conducted through the caprock, and that fluids, and heat carried by convection, are discharged to the surface along the main fault zones in the area.

Using well temperatures, pressures, enthalpy, flow data and geothermochemical correlations of the fluids discharged by the wells, Mercado (1976) developed a hydrogeological model of the Cerro Prieto area. He postulated that: (1) hot fluids ascending in the eastern and central zones of the field flow toward the west, (2) the heat source is located in the eastern and deeper part of the field, (3) the reservoir is recharged mainly from the west (in the area of alluvial fans of the Sierra Cucapa) and also to some extent from the east by the underflow of the Colorado River water. Figures 1 and 2 show the preproduction temperature distributions in the field along two different cross-sections (Mercado, 1976).

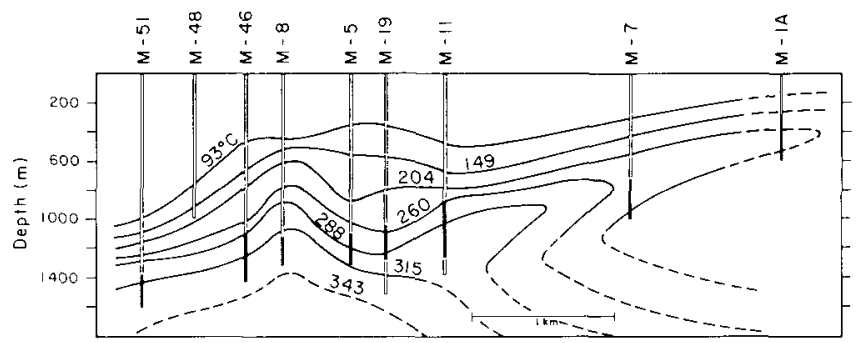

Figure I. Preproduction temperature distribution in the reservoir along a southeast-northwest crosssection (adapted from Mercado, 1976).

(XBL 804-7028)

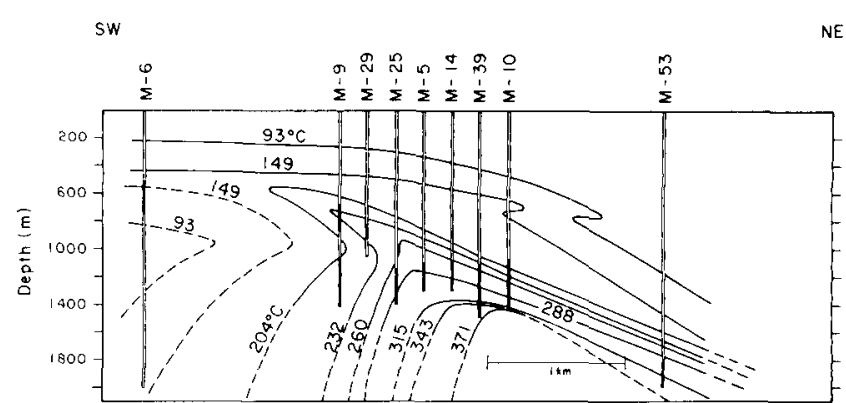

Figure 2. Preproduction temperature distribution in the reservoir along a southwest-northeast crosssection (adapted from Mercado, 1976).

(XBL 804-7027) 
According to Truesdell et al. (1979) the comparison of measured deuterium contents of the Cerro Prieto geothermal waters and the interpolated composition of cold Mexicali Valley ground waters suggest that the recharge to the system could have occurred along a narrow zone running from Mexicali on the north, passing just west of the field and curving northeast to the Mesa Arenosa on the east. This recharge from the west agrees with part of Mercado's (1976) model.

Corwin et al. (1979) correlated the dipolar self-potential anomaly detected in the Cerro Prieto area with geothermal activity. They concluded that the surface anomaly could be the result of a vertical fault or fracture zone along which a vertical component of fluid or heat flow exists. Based on these data the hot water upflow zone is distributed along an approximately north-south area passing near wel1 $\mathrm{M}-48$.

Elders et al. (1978) recognized a number of regularly distributed mineral zones in the field by examining cores and drill cuttings. They developed maps indicating depths to the first occurrence of some temperature diagnostic minerals. The minera1 distributions suggest that the hottest fluids rose along a north-south trending zone passing near well M-105. This zone is displaced toward the west with respect to the one inferred from the self-potential study (Corwin et al, 1979).

The isotopic and mineralogic data represent the preproduction condition of the system, that is before 1973 when large scale exploitation of the field began.

\section{Numerical Computer Program and Methodology}

The numerical computer code CCC developed at Lawrence Berkeley Laboratory was used in these studies. The program solves the heat and mass flow equations for liquid saturated media. Details on the Integrated Finite Difference Method, and on the explicit-implicit iterative procedure used in this program, are given elsewhere (Edwards, 1972; Narasimhan and Witherspoon, 1976; Lippmann et a1., 1977).

In all cases the numerical computations were run until a steady-state pressure and temperature distribution was obtained in the simulated system. The computed temperatures were then compared with Mercado's (1976) temperature distributions (Figures 1 and 2).

Using these comparisons as a guide, the characteristics of the sources, sinks, and boundary conditions were modified to improve the match. The changes were not arbitrarily made but were based on available geological and reservoir engineering information.

A number of different models were used to reproduce Mercado's preproduction temperature distributions. Only the results of two of the cases studied will be discussed here. As will be shown, it was not possible to reach good agreements. We suspect that the simplified geological model and boundary conditions used in the simulations were responsible for some of the poor matches obtained.
Recent studies (Lyons and Van de Kamp, 1980) indicate that the lithology of the field is quite complex, with lithofacies changes controlling largely the fluid flow within the system.

\section{Geological Model}

Using the information available in mid-1979, a simplified geological model of Cerro Prieto was developed for use in simulations. The faults believed to be bounding and intersecting the area initially developed by CFE (Cerro Prieto I) are shown on Figure 3 . Based on these data, the region modeled to reproduce the preproduction conditions of the field was restricted to the area indicated on Figure 4.

Basically, the 1ithologic column introduced by Abril and Noble (1979) was incorporated in the model (Figure 5). According to them in this area the column may be subdivided into three units. The upper one (Unit A) consists of unconsolidated sediments, the middle one (Unit B) of consolidated materials, and the lower one (Unit C) of granodioritic and metamorphic rocks. Unit $A$ acts as the leaky caprock of the geothermal system, while Unit $C$ constitutes its impermeable bedrock. Unit B, overlying the basement formed by alternating sandstone and shale layers, can be divided into five major subunits.

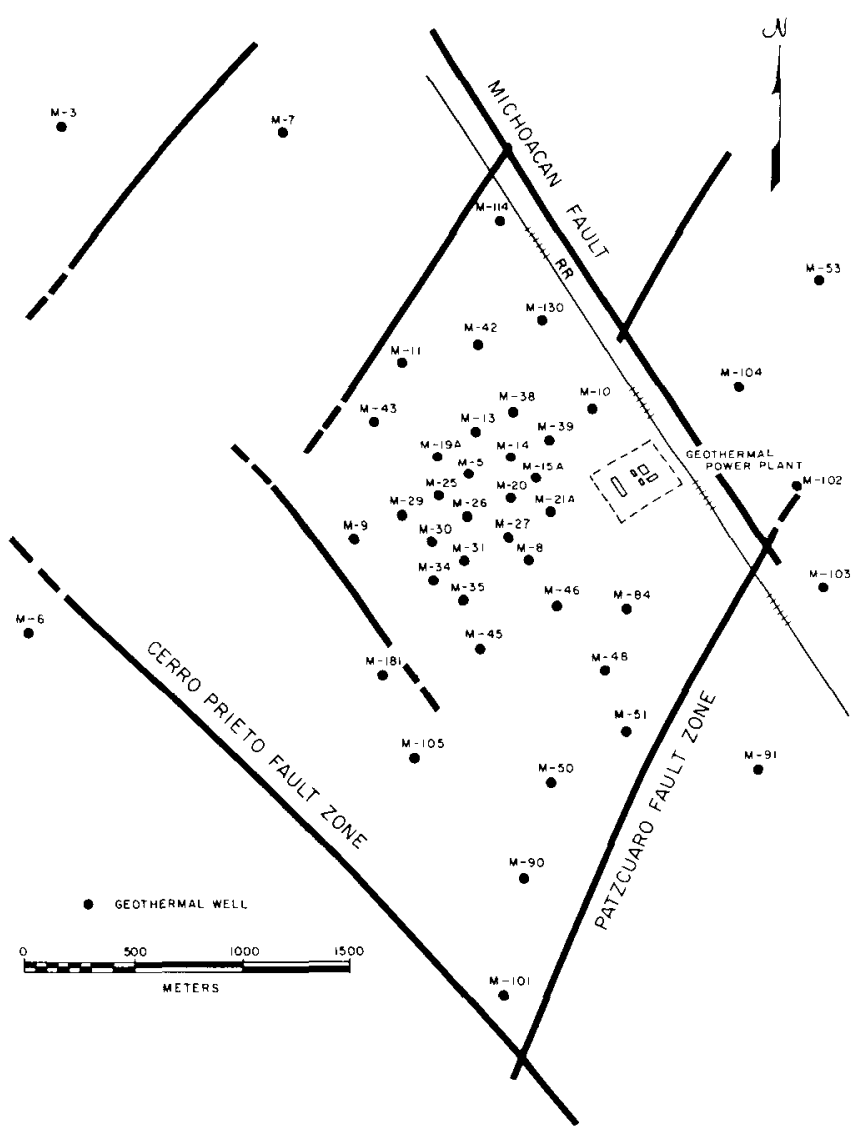

Figure 3. Fault map for the area initially developed at Cerro Prieto (from Vonder Haar and Howard, 1980).
(XBL 804-7025) 


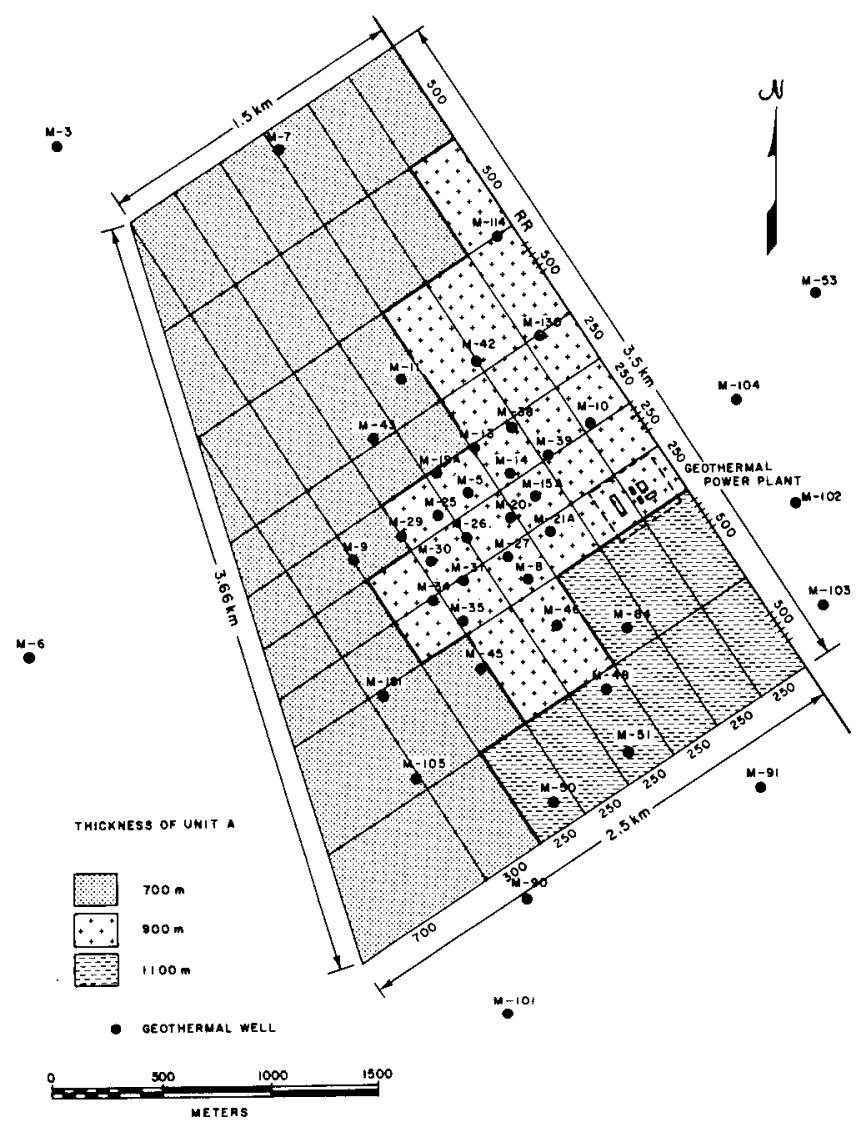

Figure 4. Plan view of the area modeled and mesh used. Contrasting hatchings correspond to different thicknesses of Unit A (unconsolidated sediments).

(XBL 799-11561)
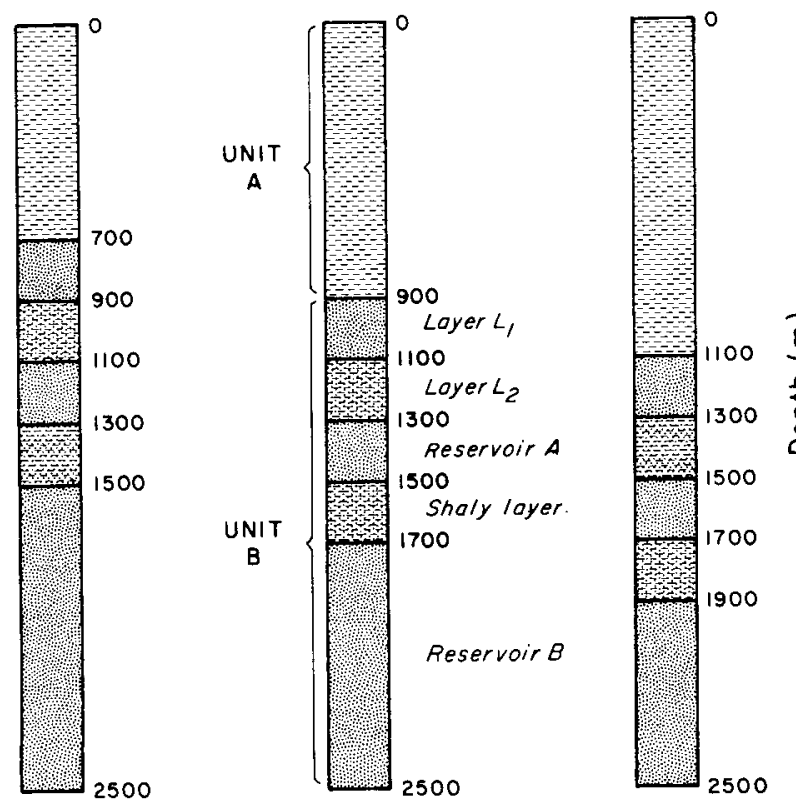

Figure 5. Basic lithologic columns used in the model for the areas with different Unit A thicknesses (see Figure 4).
The top layer $L_{1}$ consists of sandstone lenses and shales. Below Layer $\mathrm{L}_{1}$ is Layer $\mathrm{L}_{2}$, which is characterized by rocks with high content of carbonate cement. The underlying sandy strata, separated by a shaly layer, are the main geothermal reservoirs $A$ and $B$ at Cerro Prieto.

The total thickness of the sedimentary column varies within the Cerro Prieto field. The depth to the block-faulted basement increases significantly towards the east (Fonseca and Razo, 1980). For simulation purposes the top of the bedrock was assumed to be at a constant depth of $2500 \mathrm{~m}$ throughout the modeled area.

An isopach map of Unit A, based on data provided by CFE, is given in Figure 6 . For the simulations the variable thickness of this unit was modeled as shown in Figure 4. By assuming constant thicknesses for the different subunits of Unit B, three basic lithologic columns were used in the model (Figure 5). It is believed (A. Mañon, personal communication) that in the central part of the Cerro Prieto I area there is preferential fluid movement in a northeastsouthwest direction due to presence of more permeable facies or highly fractured rocks. This feature was incorporated in the model as discussed below.

\section{Mesh Used in the Simulations}

The three-dimensional region studied was subdivided into 560 nodes (or elements). The vertical column, $2500 \mathrm{~m}$ thick, was subdivided into

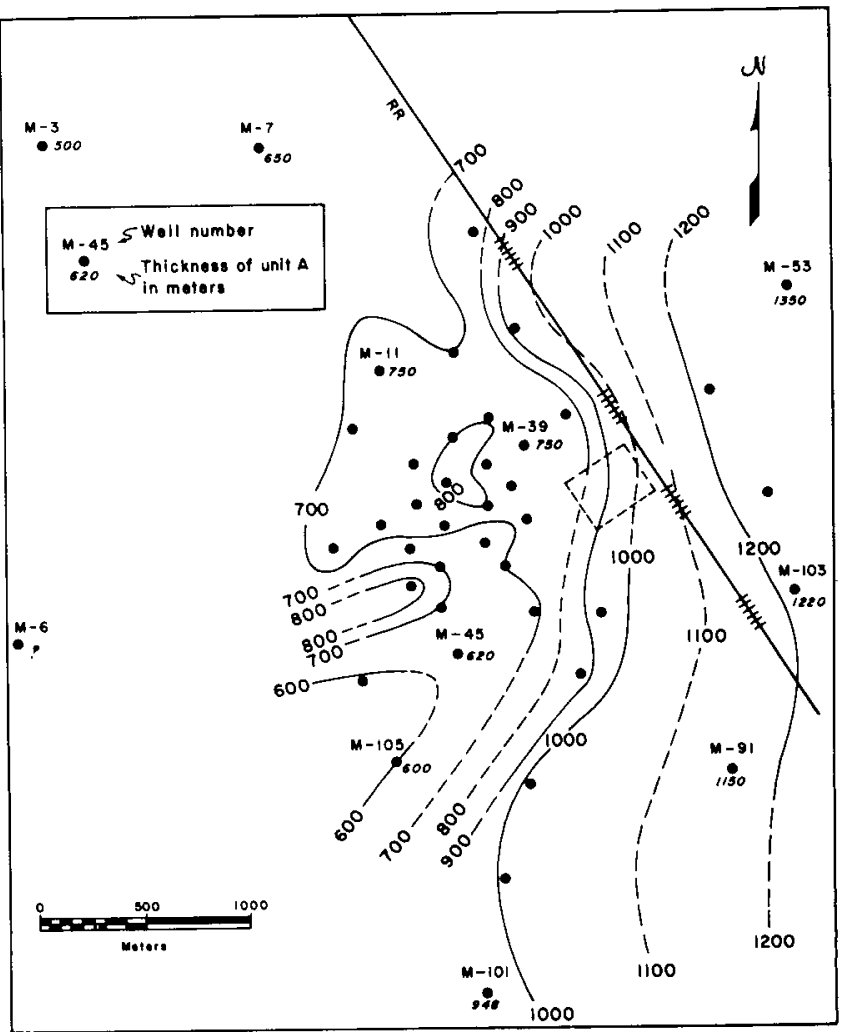

Figure 6. Unit A isopach map. 
8 horizontal levels (each having 70 nodes). The lowest level ( 100 leve 1 ) is $600 \mathrm{~m}$ thick, above it the 200 to 700 levels each $200 \mathrm{~m}$ thick, and the upper level ( 800 level) is $700 \mathrm{~m}$ thick. The different thicknesses were needed to account for the different lithologic columns used in the model (Figure 5).

Figure 7 depicts the numbering used for the nodes in the 400 level, a similar numbering scheme was used in the other levels. In this three-digit system, the first digit represents the level, while the number of the node is represented by the other two. Thus, node 818 lies in the 800-level layer and is vertically above nodes $118,218,318,418$, 518,618 , and 718 . In the horizontal plane, its shape is exactly the same as that of node 418 . Figure 7 shows the northeast-southwest trending high permeability area, representing a coarser facies or a fractured zone in the field. The higher permeable material was restricted to the 400 level only.

\section{Boundary and Initial Conditions}

Boundary conditions that have to be specified in the model are: (1) type of boundaries whether open or closed to heat and mass flow, (2) tempera-

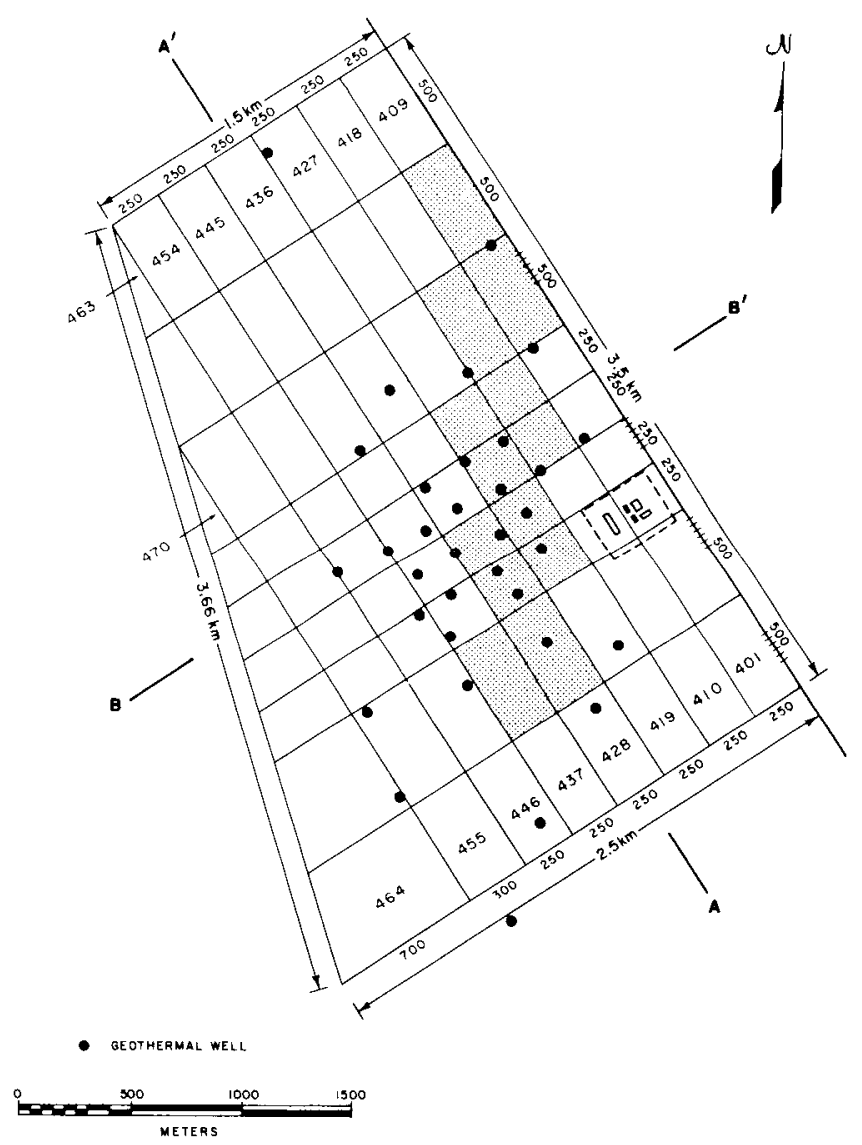

Figure 7. Plan view of the mesh used in the computations. Hatched area indicates an area of higher permeability in the 400 level ( $1400 \mathrm{~m}$ depth). Node numbering for the 400 level, and the location of the $A-A^{\prime}$ and $B-B^{\prime}$ cross-sections are also shown.

(XBL 799-11558A) tures and pressures at the boundaries, (3) location and strength of sources and sinks, and (4) temperature of fluid entering the system.

In the various modeis developed for the Cerro Prieto I area most of these conditions were varied to study their effect on the preproduction temperature distributions. However, in both cases discussed here we made the following assumptions. (1) The inflow and outflow of fluids into and from the region were modeled by placing sources and sinks in some nodes located at the boundaries (i.e., near geologic faults). (2) All vertical boundaries were closed to heat flow. (3) The top and bottom boundaries were held at constant temperatures. The top surface was assumed to be at $25^{\circ} \mathrm{C}$; the bottom at $150^{\circ} \mathrm{C}$. (4) The total mass flow rate across the model (from the sources towards the sinks) was arbitrarily assumed to be $2.95 \times 10^{7}$ $\mathrm{kg} / \mathrm{day}$. This rate is about 2.15 times the preproduction discharge of the surface manifestations in the area as reported by Mercado (1968). We considered that before 1973 a significant fraction of the heat and mass inflow into the geothermal field rose to the surface mainly through the fault zones.

Hydrostatic pressure and 1 inear temperaturedepth distribution were used as initial conditions for the system.

\section{Fluid and Rock Properties}

We assumed that (1) the fluid in the system was liquid and had constant properties, and (2) the properties of the solid matrix are isotropic and constant.

For the fluid, we used pure water properties at $250^{\circ} \mathrm{C}$. The solid matrix properties are given in Table 1 and are representative of the different lithologies included in the model.

No temperature or pressure dependency of the properties was used to reduce the cost of computations, because we felt that this simplification would not significantly affect the computed steady state temperature distributions. We planned to include temperature and pressure dependencies once an acceptable match between computed and Mercado (1976) temperatures was obtained.

Mode1 1

In model 1 and in the one discussed later, we considered that the recharge and discharge areas were closely associated with the bounding faults. We assumed the inflow of fluids into the system to be distributed as follows (Table 2):

1. $22 \%$ of the total mass recharge is at $350^{\circ} \mathrm{C}$. The sources are located in the lower part of Reservoir B ( 100 level), near the intersection of the Michoacán and Pátzcuaro faults (Figure 3 ).

2. $61 \%$ of the recharge comes from colder water sources located in the upper part of Reservoir $\mathrm{B}$ (levels 200 and 300 , at $208^{\circ} \mathrm{C}$ and $188^{\circ} \mathrm{C}$, respectively), near the southwest region of the system, along the Cerro Prieto fault zone. 
Table 1. Properties used for the solid matrix.

\begin{tabular}{lccccc}
\hline Material & $\begin{array}{c}\text { Density } \\
\left(\mathrm{kg} / \mathrm{m}^{3}\right)\end{array}$ & $\begin{array}{c}\text { Heat } \\
\text { capacity } \\
\left(\mathrm{J} / \mathrm{kg} \cdot{ }^{\circ} \mathrm{C}\right)\end{array}$ & $\begin{array}{c}\text { Thermal cond. } \\
\left(\mathrm{J} / \mathrm{m} \cdot \mathrm{day} \cdot{ }^{\circ} \mathrm{C}\right)\end{array}$ & $\begin{array}{c}\text { Intrinsic } \\
\text { permeability } \\
(\mathrm{md})\end{array}$ & Porosity \\
\hline Unit A & 2500 & 935 & $1.92 \times 10^{5}$ & $10^{-3}$ & 0.20 \\
Layer L 1 & 2650 & 825 & $2.8 \times 10^{5}$ & 20 & 0.10 \\
Layer L 2 & 2700 & 860 & $1.85 \times 10^{5}$ & 5 & 0.10 \\
Reservoir A & 2650 & 825 & $2.8 \times 10^{5}$ & 50 & 0.10 \\
Shaly layer & 2700 & 860 & $1.85 \times 10^{5}$ & 5 & 0.10 \\
Reservoir B & 2650 & 825 & $2.8 \times 10^{5}$ & 80 & 0.10 \\
$\begin{array}{l}\text { Highly } \\
\text { permeable }\end{array}$ & 2650 & 825 & $2.8 \times 10^{5}$ & 100 & 0.10 \\
\hline
\end{tabular}

Table 2. Model 1, locations and characteristics of sources and sinks.

\section{SOURCES}

\begin{tabular}{lcc} 
Node & $\begin{array}{c}\text { Mass flow rate } \\
(\mathrm{kg} / \text { day })\end{array}$ & $\begin{array}{c}\text { Temperature } \\
\left({ }^{\circ} \mathrm{C}\right)\end{array}$ \\
\hline 101 & $2.5 \times 10^{6}$ & 350 \\
110 & $2.5 \times 10^{6}$ & 350 \\
119 & $1.5 \times 10^{6}$ & 350 \\
264 & $2.5 \times 10^{6}$ & 208 \\
265 & $2.5 \times 10^{6}$ & 208 \\
266 & $1.5 \times 10^{6}$ & 208 \\
267 & $1.5 \times 10^{6}$ & 208 \\
268 & $1.0 \times 10^{6}$ & 208 \\
364 & $2.5 \times 10^{6}$ & 188 \\
365 & $2.5 \times 10^{6}$ & 188 \\
366 & $1.5 \times 10^{6}$ & 188 \\
367 & $1.5 \times 10^{6}$ & 188 \\
368 & $1.0 \times 10^{6}$ & 258 \\
608 & $5.0 \times 10^{6}$ &
\end{tabular}

SINKS

Node Mass flow rate Node Mass flow rate (kg/day) (kg/day)

\begin{tabular}{llll}
\hline 527 & $1.00 \times 10^{6}$ & 727 & $1.00 \times 10^{6}$ \\
536 & $1.00 \times 10^{6}$ & 736 & $1.00 \times 10^{6}$ \\
545 & $1.00 \times 10^{6}$ & 745 & $1.00 \times 10^{6}$ \\
554 & $1.00 \times 10^{6}$ & 754 & $1.00 \times 10^{6}$ \\
562 & $2.00 \times 10^{6}$ & 762 & $2.00 \times 10^{6}$ \\
563 & $0.50 \times 10^{6}$ & 763 & $0.50 \times 10^{6}$ \\
564 & $3.50 \times 10^{6}$ & 764 & $3.50 \times 10^{6}$ \\
565 & $2.75 \times 10^{6}$ & 765 & $2.75 \times 10^{6}$ \\
566 & $2.00 \times 10^{6}$ & 766 & $2.00 \times 10^{6}$ \\
\hline
\end{tabular}

3. $17 \%$ of inflow of fluid is concentrated at the intersection of the Michoacan fault and a northeast-southwest trending fault (Figure 3). The $250^{\circ} \mathrm{C}$ source (node 608 ) is located in Layer $\mathrm{L}_{1}$.

The sinks where the fluids leave the system were distributed around its northwest and southwest corners, near the intersection of the Cerro Prieto fault and northeast-southwest trending faults. The discharge occurs through Layers $\mathrm{L}_{1}$ and $\mathrm{L}_{2}$, at levels 700 and 500 respectively. The sinks were arranged in a manner approximately similar to the surface distribution of the geothermal. manifestations in the area given by Mercado (1968).

The bottom of the model (2500-m depth) was considered to be a constant temperature boundary at $150^{\circ} \mathrm{C}$. This low value was used to duplicate the temperatures of the regions away from the hot recharge zones. Around the inflow zones the temperatures near the bottom of the model will be reflecting those of the recharge fluids and not that of the boundary.

The computed steady-state temperatures are described by various temperature distribution maps. The effect of sources and lower permeability layers on the fluid flow can be established by analyzing the isotherms at different depths. The hotter waters entering the system at the deeper levels move in response to the pressure distribution resulting from the sources and sinks located in the model; it tends to move around the less permeable layers.

The isotherms at $1000 \mathrm{~m}(600$ leve 1$)$ and $1400 \mathrm{~m}$ (400 leve1) are given in Figures 8 and 9, respectively. In Figure 8 the $250^{\circ} \mathrm{C}$ isotherm in the northeast part reflects the effect of the source in node 608. The high temperatures in the southcentral part of the system are caused by the hot 


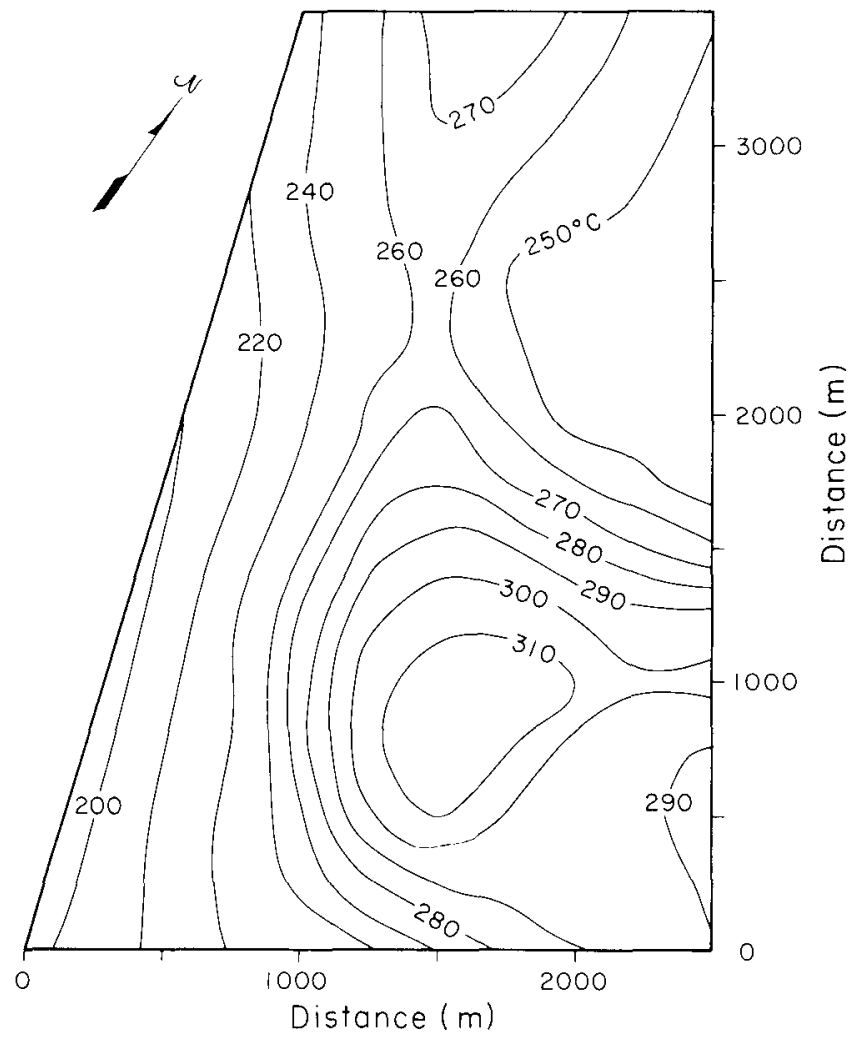

Figure 8. Mode1 1. Isotherms at the 600-leve1 (1000-m depth). water rising from beneath. In Figure 9, the isotherms in the southeast corner indicate the movement and cooling of the water as it flows away from the $350^{\circ} \mathrm{C}$ sources. The $190^{\circ} \mathrm{C}$ isotherm toward the west shows the influence of $188^{\circ} \mathrm{C}$ sources located in the 300 level; the $260^{\circ} \mathrm{C}$ isotherm towards the northeast shows that of $250^{\circ} \mathrm{C}$ sources in the 600 level.

The calculated temperatures along the sections $A-A^{\prime}$ and $B-B^{\prime}$ are shown in Figures 10 and 11 . These plots, when compared with the temperatures given in Figures 1 and 2 , indicate that in the southeast-northwest section, the computed temperatures are higher everywhere except in the area near the center of Figure 10. In this region the temperatures seem to be dominated by the strength and temperatures of the sources located at the southeast corner of the field. A comparison of Figures 2 and 11 indicates that the temperatures match favorably near well $\mathrm{M}-9$ and in the central part of the field. Generally the calculated temperatures are higher than those of Mercado.

Mode1 2

To obtain a better match, the sources in the 100-level were displaced toward the southwest corner of the system, the 200-1eve1 sources were taken out, and their flow rates were added to those at the 100 level. The temperature of the sources at the 300 and 600 levels were changed to $200^{\circ} \mathrm{C}$ (Table 3). The sinks in this model were assumed to be equal to those in Model 1 (Table 2). The temperature of the lower boundary was again fixed at $150^{\circ} \mathrm{C}$.

Isotherms at $1000-$ and 1400-m depths ( 600 and 400 levels) are given in Figures 12 and 13 . Temperatures have changed with respect to those of Figures 8 and 9 in response to the change of source characteristics.

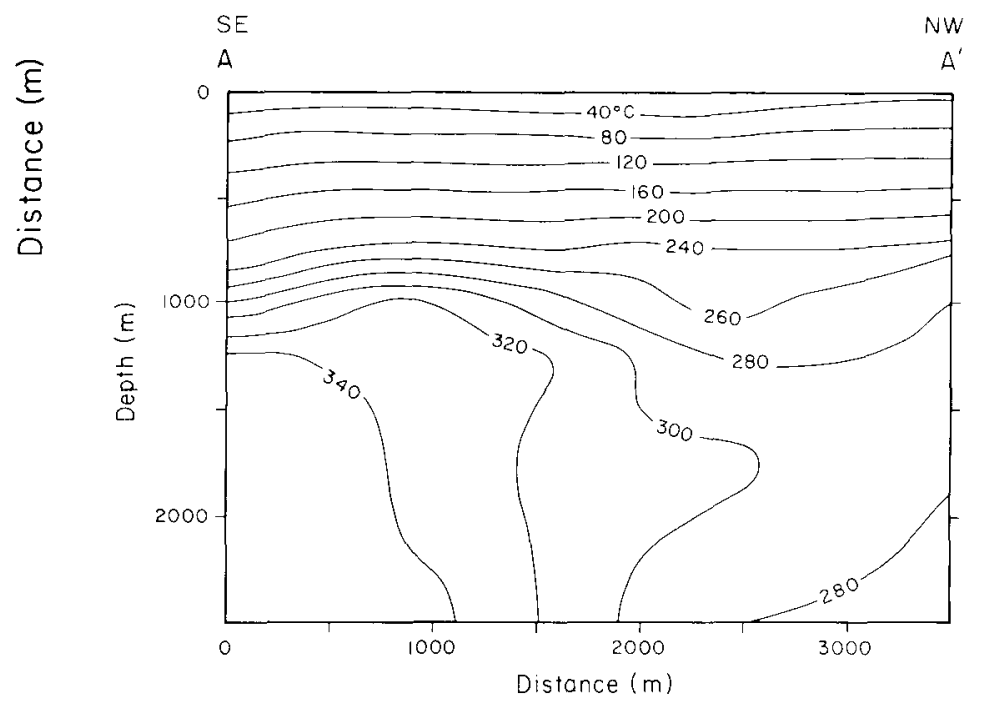

Figure 10. Model 1. Temperature distribution

along the $A-A^{\prime}$ cross-section. (XBL 804-7037)
Figure 9. Model 1. Isotherms at the 400-level (1400-m depth).
(XBL 804-7034) 


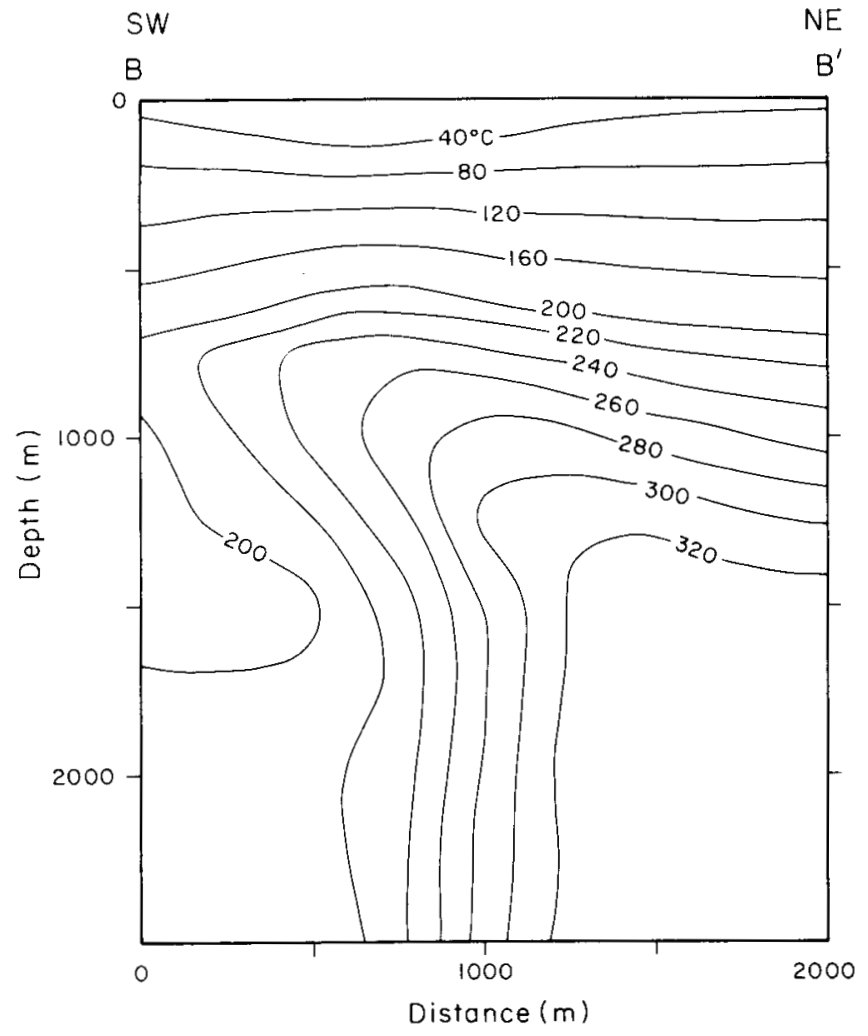

Figure 11. Mode1 1. Temperature distribution along the $B-B^{\prime}$ cross-section. (XBL 804-7032)

Isotherms along section $A_{-} A^{\prime}$ are shown in Figure 14. A comparison with Figure 1 indicates that the calculated temperatures at well M-8 are close to Mercado's. Temperatures in the central part of Figure 14 also match favorably those in Figure 1. The calculated temperatures are sligthly higher in the southeastern part of the field.

Isotherms along section $B-B^{\prime}$ are shown in Figure 15 .

Table 3. Model 2, location and characteristics of sources.

\begin{tabular}{lcr}
\hline Node & $\begin{array}{c}\text { Mass } \mathrm{flow} \text { rate } \\
(\mathrm{kg} / \text { day })\end{array}$ & $\begin{array}{c}\text { Temperature } \\
\left({ }^{\circ} \mathrm{C}\right)\end{array}$ \\
\hline 128 & $2.5 \times 10^{6}$ & 350 \\
137 & $3.0 \times 10^{6}$ & 350 \\
146 & $3.0 \times 10^{6}$ & 350 \\
155 & $3.0 \times 10^{6}$ & 350 \\
164 & $2.5 \times 10^{6}$ & 350 \\
165 & $1.5 \times 10^{6}$ & 350 \\
364 & $2.5 \times 10^{6}$ & 200 \\
365 & $2.5 \times 10^{6}$ & 200 \\
366 & $1.5 \times 10^{6}$ & 200 \\
367 & $1.5 \times 10^{6}$ & 200 \\
368 & $1.0 \times 10^{6}$ & 200 \\
608 & $5.0 \times 10^{6}$ & - \\
\hline
\end{tabular}

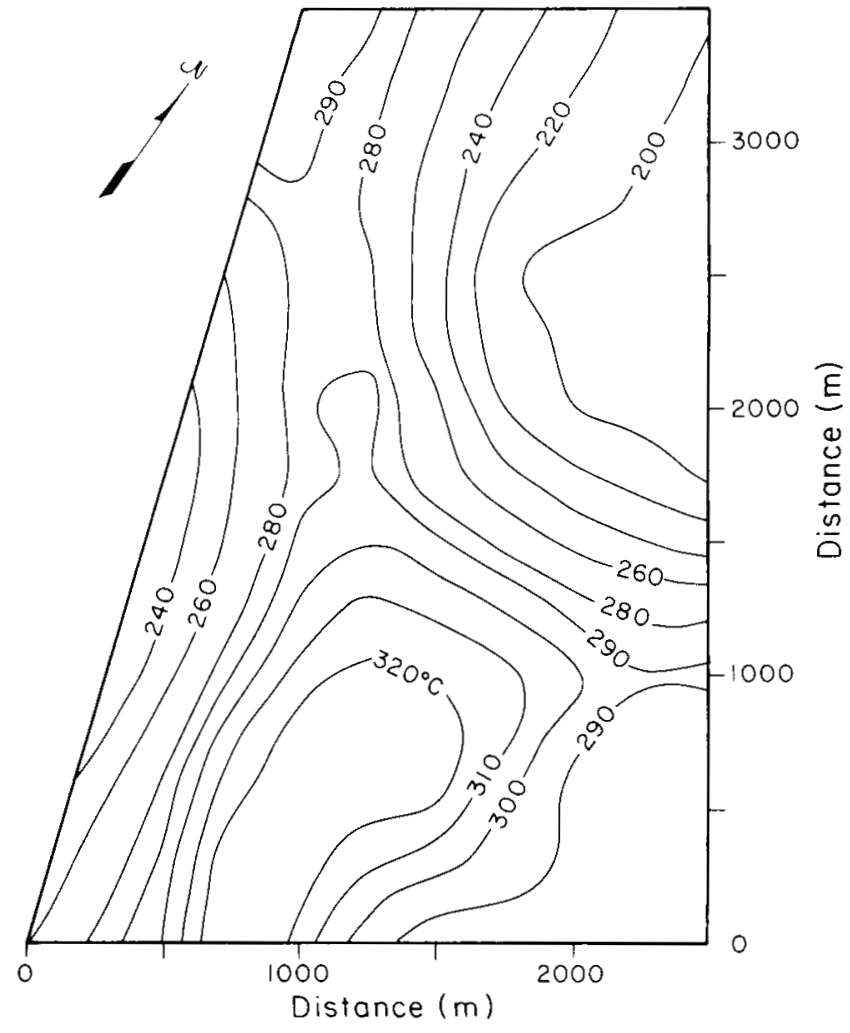

Figure 12. Mode1 2. Isotherms at the 600 leve1 (1000-m depth).

(XBL 804-7035)

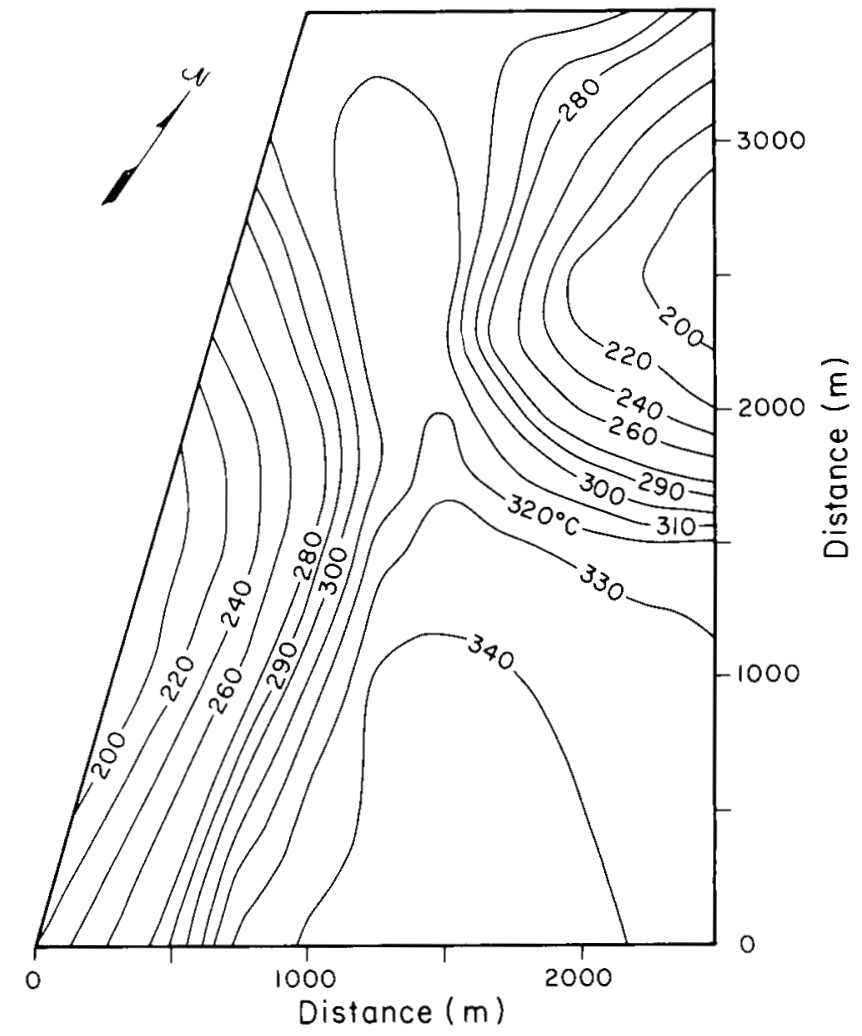

Figure 13. Mode1 2. Isotherms at the 400 level (1400-m depth). 


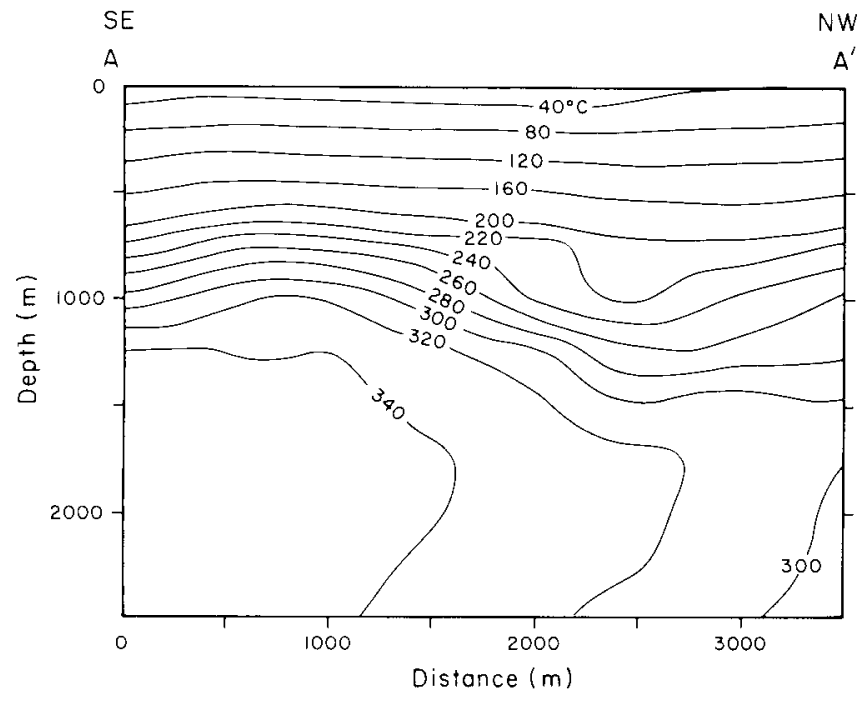

Figure 14. Mode1 2. Temperature distribution along the A-A' cross section. (XBL 804-7030)

A comparison of these temperatures with those in Figure 2 shows that the calculated temperatures are, in general, higher than the preproduction temperatures given by Mercado (1976).

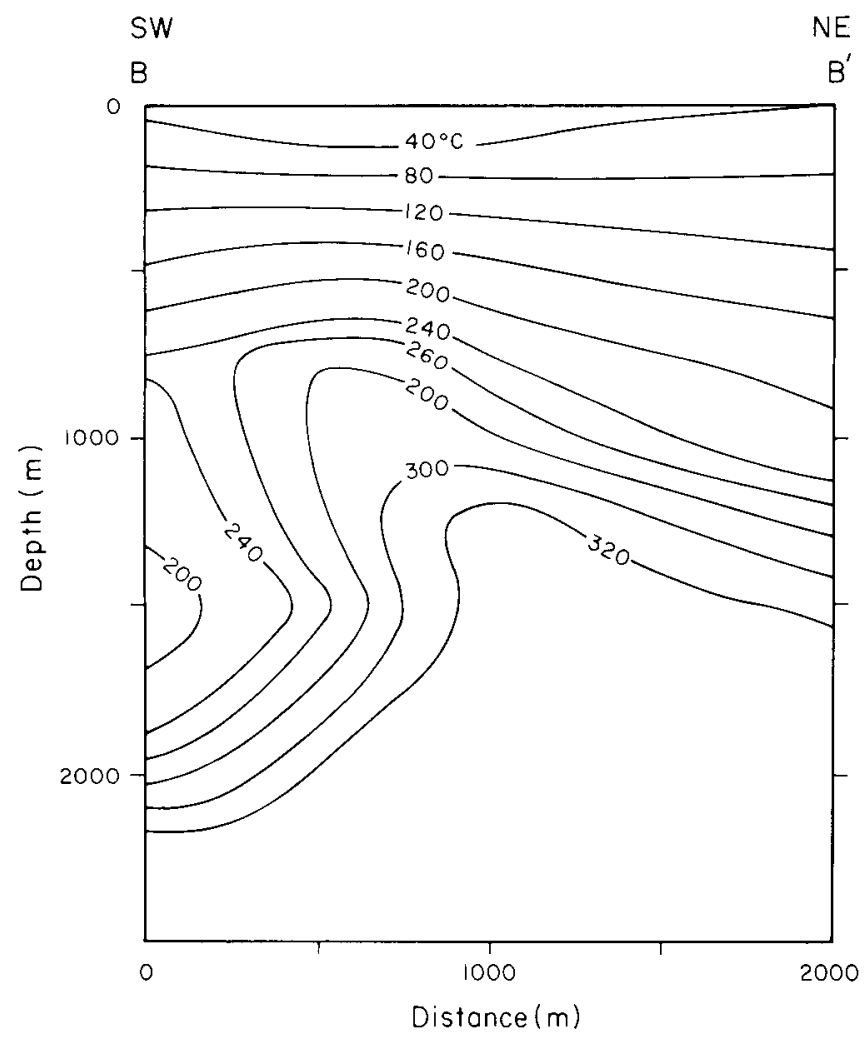

Figure 15. Mode1 2. Temperature distribution along the $B-B^{\prime}$ cross section. (XBL 804-7029)

\section{PLANNED ACTIVITIES FOR FISCAL YEAR 1980}

In order to establish the preproduction recharge and flow characteristics of the Cerro Prieto field, more temperature and early pressure data will be obtained. The geological model of the field to be used in the computations will be modified based on new information expected to become available during fiscal year 1980 .

A three-stage program in reservoir modeling of the field response to large-scale fluid production (started in 1973) will be initiated. It will begin with the simulation of the initial production area, working up to a simulation of the entire known Cerro Prieto geothermal field.

\section{REFERENCES CITED}

Abril G., A., and Noble, J. E., 1979, Geophysical we11-log correlations along various crosssections of the Cerro Prieto geothermal field, in Proceedings, First Symposium on the Cerro Prieto geothermal field, Baja California, Mexico, September 1978. Berkeley, Lawrence Berkeley Laboratory, LBL-7098, p. 41-48.

Bermejo M., F., Cortéz A., C., and Aragón A., A., 1979. Physical and thermodynamic changes observed in the Cerro Prieto geothermal reservoir, in Proceedings, First Symposium on the Cerro Prieto geothermal field, Baja California, Mexico, September 1978. Berkeley, Lawrence Berkeley Laboratory, LBL-7098, p. 300-332.

Corwin, R. F., Morrison, H. F., Díaz, C. S., and Rodríguez B., J., 1979. Self-potential studies at the Cerro Prieto geothermal field, in Proceedings, First Symposium on the Cerro Prieto geothermal field, Baja California, Mexico, September 1978. Berkeley, Lawrence Berkeley Laboratory, LBL-7098, p. 204-210.

Edwards, A. L., 1972. TRUMP: A computer program for transient and steady state temperature distribution in multidimensional systems. Livermore, Lawrence Livermore Laboratory, UCRL-14754, Rev. 3.

Elders, W. A., Hoagland, J. R., Olson, E. R., McDowe11, S. D. and Collier, P., 1978. A comprehensive study of samples from geothermal reservoirs: Petrology and light stable isotope geochemistry of twenty-three wells in the Cerro Prieto geothermal field, Baja California, Mexico. Riverside, University of California, UCR/IGPP-78/26.

Fonseca L., H., and Razo M., A., 1980. Gravimetric magnetometric and seismic reflection studies at the Cerro Prieto geothermal field, in Proceedings, Second Symposium on the Cerro Prieto Geothermal Field, Baja California, Mexico, October 1979. Mexicali, Comisión Federal de Electricidad (in preparation).

Lippmann, M. J., Tsang, C. F., and Witherspoon, P. A., 1977. Analysis of the response of geothermal reservoirs under injection and production procedures: Dallas, Society of Petroleum Engineers, SPE-6537.

Lyons, D. J., and van de Kamp, P. C., 1980. Subsurface geological and geophysical study of the Cerro Prieto geothermal field: Berkeley, Lawrence Berkeley Laboratory, LBL-10540.

Mercado G., S., 1968. Localización de zonas de máxima actividad hidrotermal por medio de 
proporciones químicas, campo geotérmico de Cerro Prieto B. C.: Presented at the III Congreso Mexicano de química pura y aplicada March 21-23, 1968, Guadalajara, México. , 1976. Movement of geothermal fluids and temperature distribution in the Cerro Prieto geothermal field, Baja California, Mexico, in Proceedings, Second United Nations Symposium on the Development and Use of Geothermal Resources, May 1975: Washington, D.C., U.S. Government Printing Office, v. 1, p. 487-494.

Narasimhan, T. N., and Witherspoon, P. A., 1976. An integrated finite difference method for analyzing fluid flow in porous media: Water
Resources Research, v. 12, no. 1, p. 57-64.

Truesdel1, A. H., Rye, R. O., Pearson, F. J., Jr. Olson, E. R., Nehring, N. L., Huebner, M. A., and Coplen, T. B., 1979. Preliminary isotopic studies of fluids from the Cerro Prieto geothermal field, in Proceedings, First Symposium on the Cerro Prieto geothermal field, Baja California, Mexico, September 1978; Berkeley, Lawrence Berkeley Laboratory, LBL-7098, p. 95-99.

Vonder Haar, S., and Howard, J. H., 1980. Intersecting faults and sandstone stratigraphy at the Cerro Prieto geothermal field. Berkeley, Lawrence Berkeley Laboratory, LBL-9546.

\title{
SIMULATION OF REINJECTION AT CERRO PRIETO USING AN IDEALIZED TWO- RESERVOIR GEOLOGICAL MODEL
}

\author{
C. F. Tsang, D. C. Mangold, and M. J. Lippmann
}

\section{INTRODUCTION}

Most of the papers published on the hydrodynamic and thermal effects of reinjection in geothermal fields assume a single reservoir with uniform transmissivity and storativity. However, there is evidence that the Cerro Prieto geothermal field is a two-reservoir system and that each reservoir has different hydraulic properties (Abril and Noble, 1979). Since the case of two-reservoir fields has not been adequately studied, the present research attempts to analyze the thermohydrological response of this kind of geothermal system to various alternative schemes of reinjection. Parameters relevant to the Cerro Prieto system are used so that the results will be useful in the planning of future reinjection operations at this field.

\section{ACTIVITIES IN FISCAL YEAR 1979}

In the present analysis LBL computer program CCC (Lippmann et a1., 1977) is used, which is capable of modeling the complex geological and boundary conditions of a geothermal system. CCC a1so simulates the major physical factors involved in the movement of the injected waters: (1) forced convective flow between the production and injection areas; (2) heat exchange among injected water, rock matrix, and native waters; (3) density-buoyancy effects, and (4) influence of temperature-dependent viscosity on fluid flow. But the problems associated with the chemistry of the fluids and the porous media, such as injectibility of the wells, injected/native groundwater compatibility, and water-rock interactions, will not be covered here. These matters are addressed in a number of other papers at the second Cerro Prieto symposium.

\section{Reinjection Modeling}

In any type of modeling study we may distinguish two broad categories: special studies and detailed simulations. In the case of reinjection, special studies investigate particular topics of interest, such as optimal injection well patterns and the effects of temperature-dependent properties (e.g. Tsang et a1., 1979). On the other hand, detailed simulation studies are appropriate only after a realistic geologic model of the system (i.e. its geometry, physical properties, boundary and initial conditions) is developed. In this general framework, we address a special study of reinjection operations in a geothermal field. The study is concerned with the peculiarities of carrying out this type of operation in a system consisting of two separate reservoirs. One particular purpose for employing in this research a simpler idealized model is to begin to determine the best strategies for reinjection so that they can be tested later in more realistic simulations.

\section{Two-Reservoir Systems}

1. Single Well Model. The simplified radially symmetric two-reservoir model used for this case with its initial temperature distribution is shown in Figure 1. The reservoir hydraulic and thermal properties are displayed in Table l. These data are all taken from an earlier simulation study of Cerro Prieto (Lippmann et al., 1979). Note from the table that the permeability in the lower aquifer is 80 md whereas in the upper aquifer it is $50 \mathrm{md}$. The intervening layer has a permeability of $0.5 \mathrm{md}$, which is two orders of magnitude smaller, but still not negligible. For simplicity, the aquifers are assumed to be uniformly $100 \mathrm{~m}$ thick and the intervening layer is $50 \mathrm{~m}$ thick.

a. Pressure effects (production only). In this series of simulations a constant production rate of $1000 \mathrm{~m}^{3} / \mathrm{hr}$ is assumed (approximately $40 \%$ of the 1978 production rate at Cerro Prieto). The injection rate is at $500 \mathrm{~m}^{3} / \mathrm{hr}$, one-half of the production rate. Three different boundary conditions were employed to study pressure effects during production.

The open boundary case corresponds to an aquifer of large radial extent, with a constant potential boundary simulating "full" recharge conditions $2.3 \mathrm{~km}$ away from the well. The semi-open boundary case had a leaky flow barrier at the same distance 


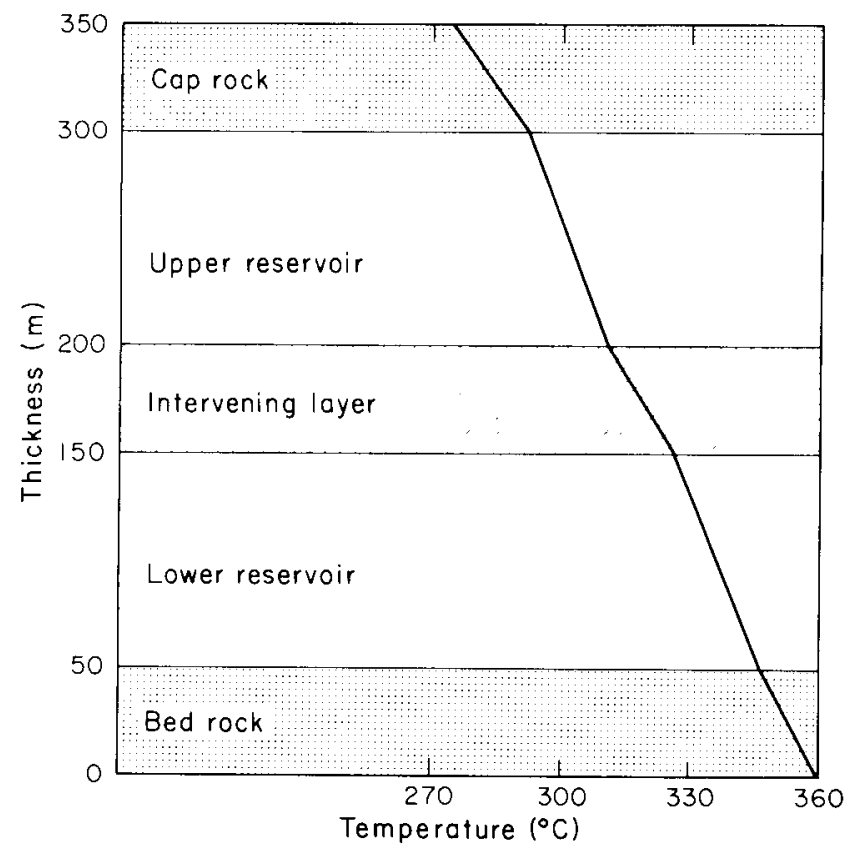

Figure 1. Cross section of the two-reservoir model used and its initial temperature profile.

(XBL 803-6829) to simulate "partial" recharge. The closed boundary case was used as a limiting case, with no recharge through the barrier. The letters A, B, and $C$ on Table 2 are the locations where temperature and pressure were determined as the upper aquifer was produced: A is near the well in the upper aquifer, and $B$ and $C$ are $100 \mathrm{~m}$ away from the well in the upper and lower aquifers, respectively.

The results of the simulations for 5 and 10 years are displayed in Table 2 . In comparing pressure reductions for the upper and lower aquifers at either 5 or 10 years, the results show maximum differences of only $13 \%$ after 5 years, and $10 \%$ after 10 years. This demonstrates considerable hydraulic communication through the intervening layer. The results also show the effect of boundary conditions.

b. Temperature effects (injection). In Figures 2 and 3 the temperature fronts are indicated for injection into the upper and lower aquifer after 10 years, respectively. The open boundary or "full" recharge condition was employed. In the upper aquifer case the thermal front has begun to penetrate through the intervening layer due to the downward flow of the higher-density-injected cold water. In the lower aquifer case there is some dispersion of the thermal front within the aquifer, but with little effect on the intervening layer. This is encouraging, because it shows that thermal fronts do not easily migrate through the intervening layer.

Table 1. Material properties used in the singlewell and doublet simulations.

\begin{tabular}{|c|c|c|c|c|}
\hline Property & $\begin{array}{c}\text { Lower } \\
\text { reservoir }\end{array}$ & $\begin{array}{l}\text { Intervening } \\
\text { layer }\end{array}$ & $\begin{array}{c}\text { Upper } \\
\text { reservoir }\end{array}$ & $\begin{array}{l}\text { Bedrock/ } \\
\text { Caprock }\end{array}$ \\
\hline $\begin{array}{l}\text { Intrinsic } \\
\text { perneability } \\
\text { (nd) }\end{array}$ & 80 & 0.5 & 50 & 0.005 \\
\hline Porosity & 0.22 & 0.40 & 0.20 & 0.40 \\
\hline $\begin{array}{l}\text { Specific } \\
\text { storage }\left(\mathrm{n}^{-1}\right)\end{array}$ & $10^{-4}$ & $1.6 \times 10^{-3}$ & $10^{-4}$ & $1.6 \times 10^{-3}$ \\
\hline $\begin{array}{l}\text { Thernal } \\
\text { coriductivity } \\
\left(\mathrm{cal} / \mathrm{sec} \cdot \mathrm{cr}^{\circ} \mathrm{C}\right)\end{array}$ & $10 \times 10^{-3}$ & $7.5 \times 10^{-3}$ & $10 \times 10^{-3}$ & $6.0 \times 10^{-3}$ \\
\hline $\begin{array}{l}\text { Heat } \\
\text { capacity } \\
\left.\text { (cal } / \mathrm{g}^{\circ} \mathrm{C}\right)\end{array}$ & 0.250 & 0.230 & 0.250 & 0.230 \\
\hline
\end{tabular}


Table 2. Pressure drawdowns for the single well production simulations.

\begin{tabular}{|c|c|c|}
\hline \multirow[t]{2}{*}{ Case } & \multicolumn{2}{|c|}{ Pressure drawdowns (psi) } \\
\hline & 1 to & to $10 \mathrm{yrs}$ \\
\hline \multicolumn{3}{|l|}{ At Point A } \\
\hline open & 36 & 40 \\
\hline Semi-open & 38 & 61 \\
\hline Closed & 39 & 64 \\
\hline \multicolumn{3}{|l|}{ At Point B } \\
\hline Open & 36 & 40 \\
\hline Semi-open & 38 & 61 \\
\hline Closed & 39 & 64 \\
\hline \multicolumn{3}{|l|}{ At Point $C$} \\
\hline Open & 32 & 36 \\
\hline Semi-open & 33 & 58 \\
\hline Closed & 35 & 61 \\
\hline
\end{tabular}

The box below the thermal front diagrams in Figures 2 and 3 records pressure changes in the upper and lower aquifers, respectively, at radial distances of $500 \mathrm{~m}$ and $1000 \mathrm{~m}$. These pressures agree with the results of the production tests mentioned above. Despite the much lower permeability of the intervening layer, pressures are readily transmitted through it from the injected reservoir to the other reservoir. This indicates that reinjection may be useful to maintain overall reservoir pressures even through an intervening layer which inhibits or slows down thermal fronts, thereby prolonging the useful life of a geothermal field.

Injection into upper aquifer after 10 years

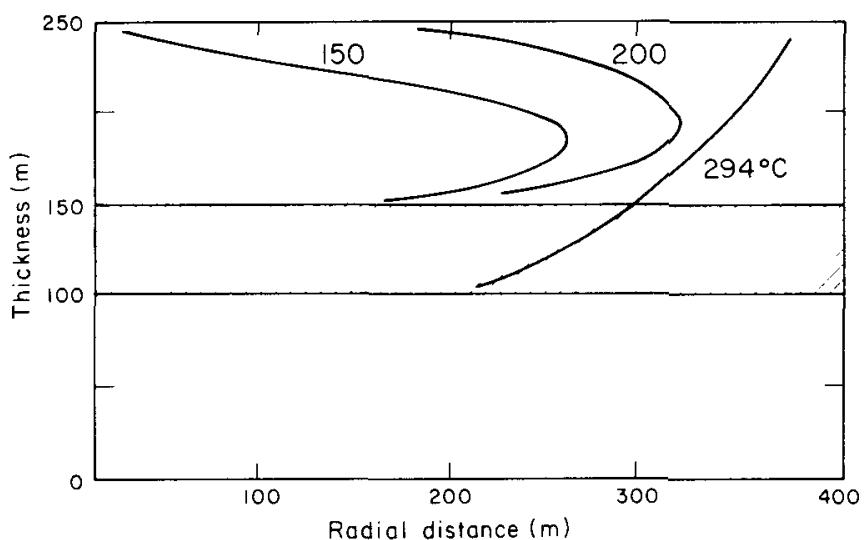

Pressure increase ( $p$ i) measured at

\begin{tabular}{|c|cc|}
\hline Aquifer & $500 \mathrm{~m}$ & $1000 \mathrm{~m}$ \\
\hline Upper & 54 & 19 \\
Lower & 33 & 22 \\
\hline
\end{tabular}

Figure 2. Isotherms and pressure changes simulated for 10 years of single-well injection into the upper reservoir.

(XBL 803-6833)
Injection into lower aquifer after 10 years

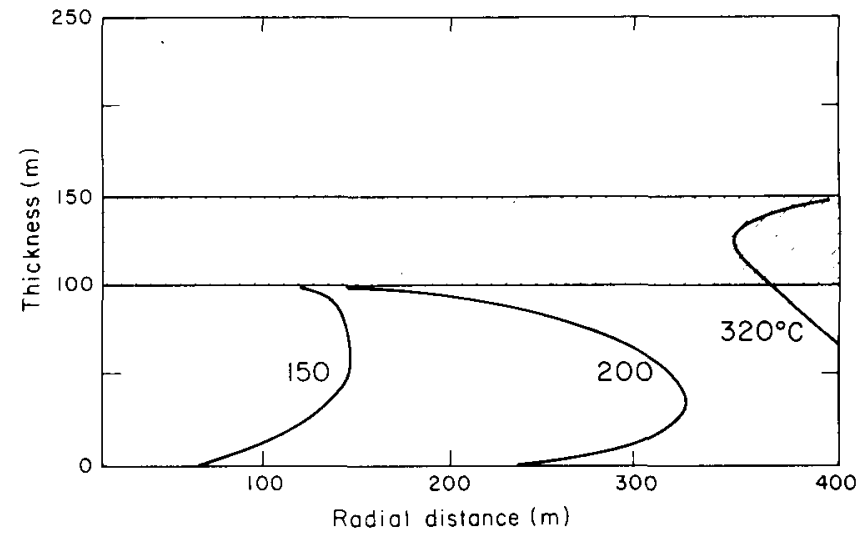

Pressure increase (psi) measured a†

\begin{tabular}{|c|cc|}
\hline Aquifer & $500 \mathrm{~m}$ & $1000 \mathrm{~m}$ \\
\hline Upper & 16 & 9 \\
Lower & 54 & 28 \\
\hline
\end{tabular}

Figure 3. Isotherms and pressure changes simulated for 10 years of single-well injection into the lower reservoir.

(XBL 803-6835)

2. Doublet Mode1. As a further development in modeling reinjection, the slightly more realistic case of a simultaneous system of production and injection was simulated. Figure 4 illustrates the mesh for a two-layer doublet system which is produced from the upper reservoir at the rate of $2000 \mathrm{~m}^{3} / \mathrm{hr}$ and is injected with $150^{\circ} \mathrm{C}$ water at the rate of $1000 \mathrm{~m}^{3} / \mathrm{hr}$ into either the upper or lower reservoir. The three-dimensional mesh makes use of symmetry along the 1 ine connecting the production and injection wells, but otherwise it is similar to

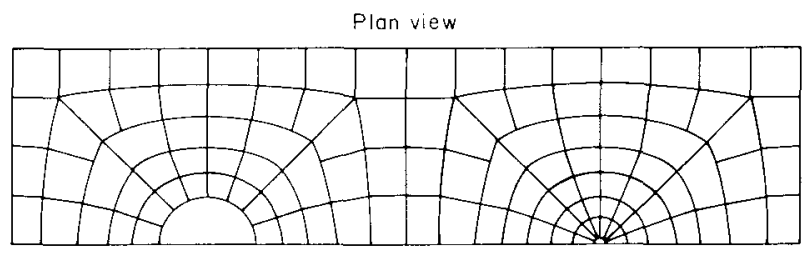

$$
1
$$

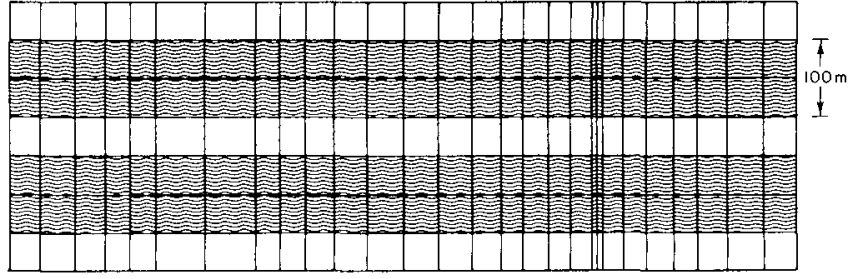

Cross section view

Figure 4. P1an and cross section views of the doublet mesh.

(XBL 803-6844) 
the single well model, with the same seven layers, thickness and reservoir properties. The simulated area is $4 \mathrm{~km}$ by $1 \mathrm{~km}$, with a $2 \mathrm{~km}$ spacing between production and injection wells, surrounded by a closed boundary.

The outcomes of the simulations at 10 years are displayed in Figures 5 and 6 for injection into the upper and lower reservoirs, respectively. The upper panel shows the temperature fronts for the upper reservoir, the middle one is a cross section view with the intervening layer shaded, while the lower panel shows the temperature fronts for the lower reservoir. (In examining the contours recall that the upper and lower reservoirs are at different temperatures initially.) The results are similar to the single-well case.

The pressure response is given in Table 3. Pressures are shown as the differences between the pressure changes resulting from simultaneous production and injection, and those due to production only. The results indicate that the overall increase in presssure from injection is on the order of $100 \mathrm{psi}$ at $1 \mathrm{~km}$ from the production well. Again, as in the single well model, there appears to be very good pressure communication through the intervening layer, because the reservoirs without injection have pressures which are within $10-15 \%$ of those of the reservoirs with injection. The lower pressure at the producing well for the upper injection case appears to be caused by the thermal effects described below.

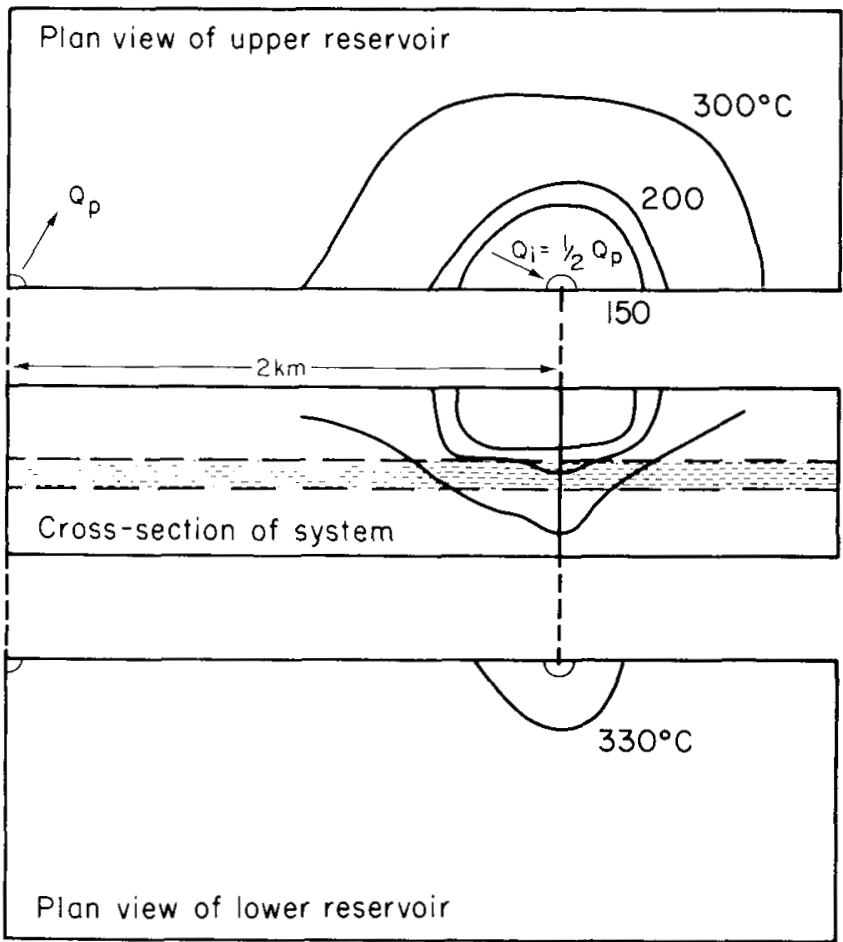

Figure 5. Isotherms simulated for 10 years of doublet injection into the lower reservoir.

(XBL 803-6826)

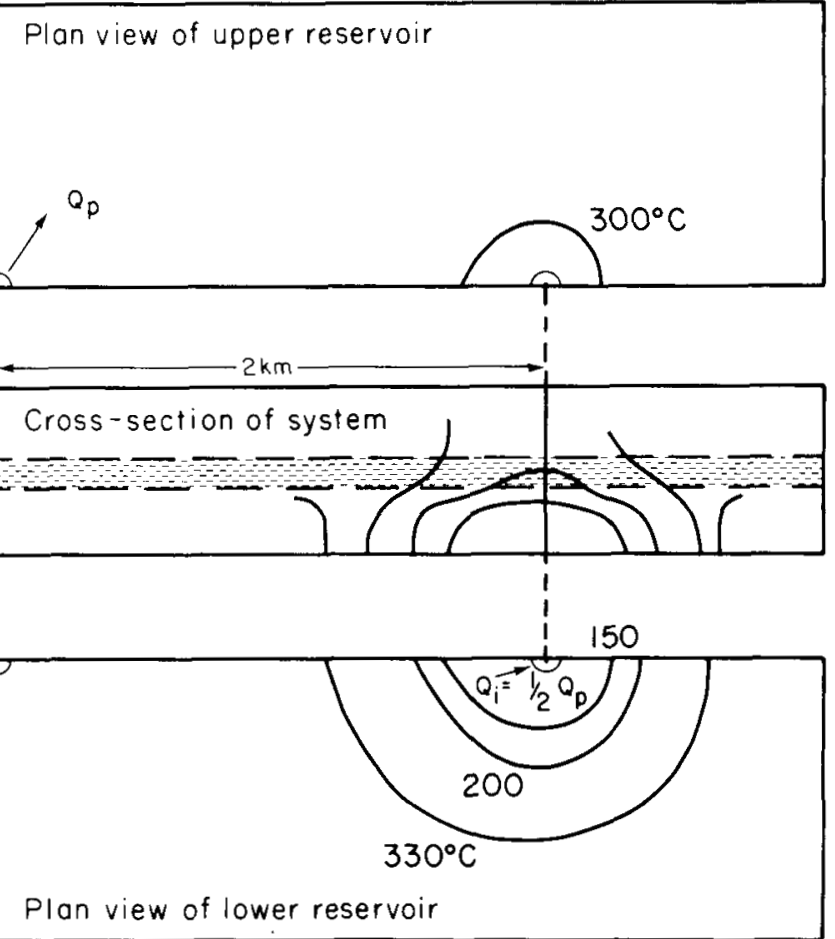

Figure 6. Isotherms simulated for 10 years of doublet injection into the upper reservoir.

(XBL 803-6828)

Table 3. Pressure changes for doublet injection simulations after 10 years.*

\begin{tabular}{|c|c|c|c|c|}
\hline \multirow{3}{*}{$\begin{array}{l}\text { Cases } \\
(\mathrm{psi})\end{array}$} & \multicolumn{2}{|c|}{$\begin{array}{c}\text { At production } \\
\text { we } 11\end{array}$} & \multicolumn{2}{|c|}{$\begin{array}{l}1 \mathrm{~km} \text { from } \\
\text { prod well }\end{array}$} \\
\hline & Upper & Lower & Upper & Lower \\
\hline & \multicolumn{2}{|c|}{ Reservoir } & \multicolumn{2}{|c|}{ Reservoir } \\
\hline Upper injection & 78 & 80 & 132 & 120 \\
\hline Lower injection & 81 & 88 & 120 & 138 \\
\hline $\begin{array}{l}\text { Lower injection } \\
\text { (intervening } \\
\text { layer perneabil- } \\
\text { ity }=5 \mathrm{md} \text { ) }\end{array}$ & 226 & -3 & 148 & 116 \\
\hline
\end{tabular}

* $P_{i, p}-P_{p}$ (psi) where $P_{i, p}=$ change in pressure in the case of simultaneous injection and production; and $P_{p}=$ change in pressure in the case of production only. 
The pressure response for the upper injection case over the 10-year period is shown in Figure 7 . The pressure profile between the production area and the injection well displays a transition region between the injected $150^{\circ} \mathrm{C}$ water and the surrounding $302^{\circ} \mathrm{C}$ water. In this region, the viscosity changes significantly due to fluid temperature differences (a ratio of nearly 2:1), producing a moving thermal barrier which can be responsible for larger than usual pressure declines in well test analysis (Mangold et al., 1979). The accompanying graph in Figure 8 suggests the influence of this effect on pressure response in a comparison between the cases of upper and lower injection. After 10 years of injection into the upper reservoir, the production well area actually has a lower pressure than the lower injection case, probably due to the thermally produced viscosity barrier in the upper aquifer. For injection into the lower reservoir, the pressures in the upper aquifer are not as affected by such a barrier since it is restricted to the lower aquifer. Such results indicate that a combination of viscosity and buoyancy effects are needed in order to adequately describe the physical processes of reinjection, especially in a two-reservoir system. These matters will be the subject of a further investigation.

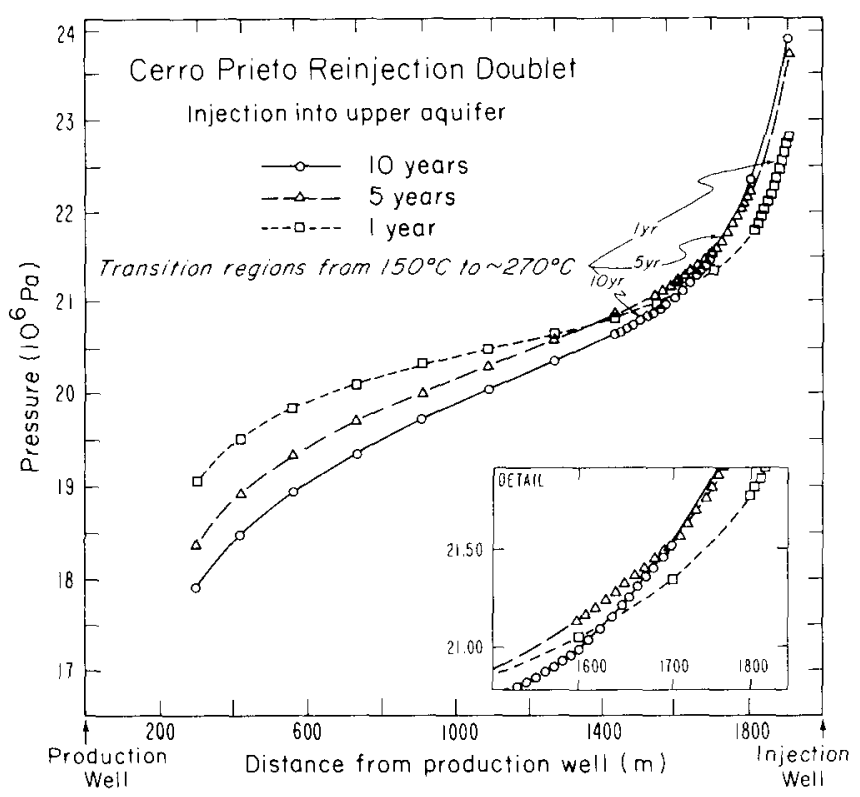

Figure 7. Radial pressure distribution simulated for 1,5 , and 10 years of doublet injection into the upper reservoir, showing the transition region between hot and cold waters.

(XBL 803-6832)
Thus the doublet model further confirms that in a more realistic model of a two-reservoir system, reinjection will be useful to maintain reservoir pressure while restricting the thermal front to the neighborhood of the injection area.

\section{Cerro Prieto Reinjection Doublet}

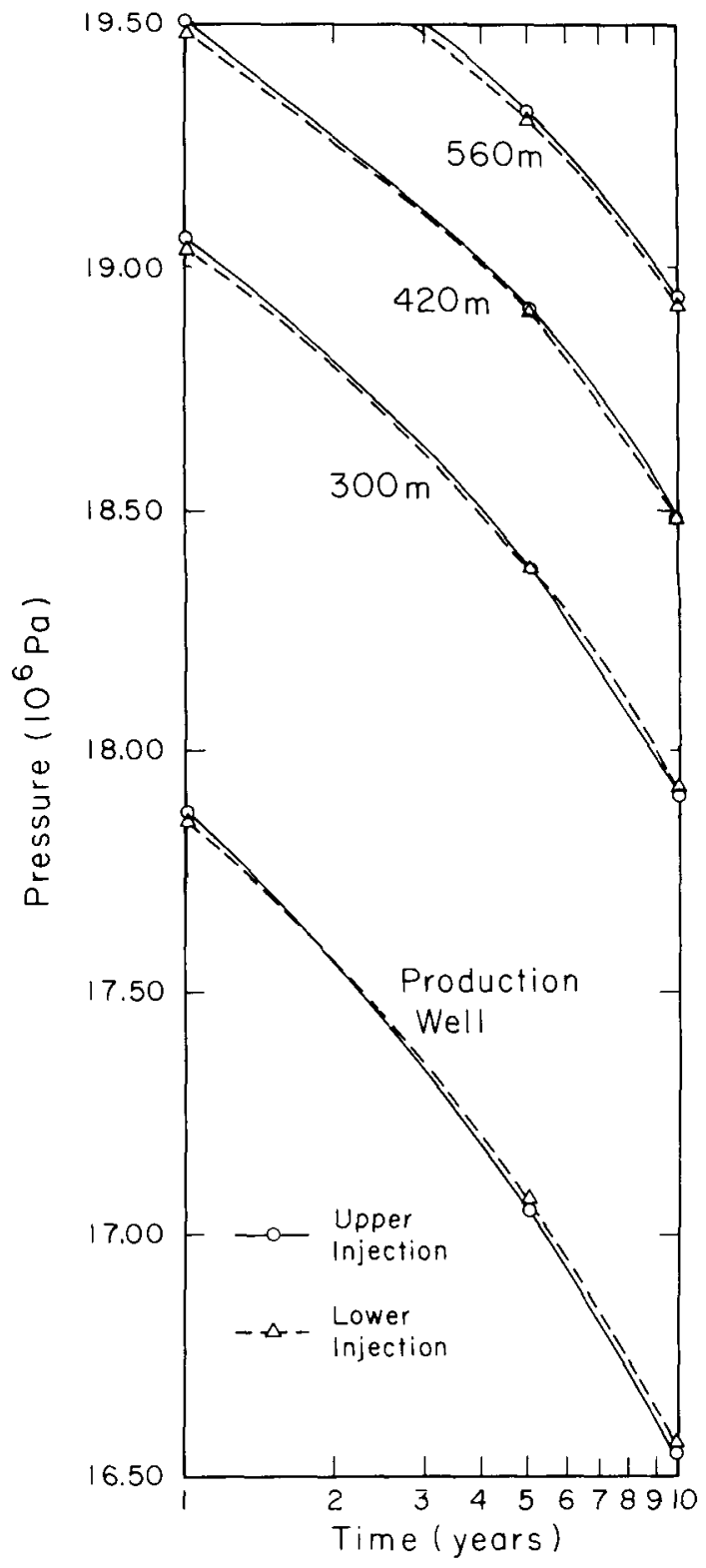

Figure 8. Pressure changes near the production area simulated for 1,5 , and 10 years of doublet injection into the upper and lower reservoirs.

(XBL 803-6836) 


\section{CONCLUS ION}

In this paper we have introduced an idealized two-reservoir model to explore some of the effects of reinjection in a geothermal field. For both the single-wel1 model and the doublet model the results indicate that reservoir pressures will be adequately maintained even when an intervening layer of low permeability is present. The same intervening layer may nevertheless be an effective barrier to the movement of cold fronts, due to the action of gravity and viscosity on the flow of denser colder waters. This shows promise for developing reinjection strategies which can be tested on more detailed simulation models for specific sites such as the Cerro Prieto field.

\section{PLANS FOR FISCAL YEAR 1980}

In further research we hope to conduct a sensitivity analysis on some of the main parameters used in this study, especially permeability. Clearly, there is also a need to study the flow of the colder water toward the production well for a longer period of time than 10 years. Such matters as simulation of permeability anisotropy and optimum well spacing for injection may have to wait until detailed geological models become available. Idealized models like the ones employed in this study, however, are useful for suggesting practical reinjection operation strategies for optimizing the development of geothermal energy resources.

\section{REFERENCES CITED}

Abril G., A. and Noble, J. E., 1979. Geophysical well-log correlations along various cross

\section{RESISTIVITY STUDIES AT CERRO PRIETO}

\author{
M. J. Wilt and N. E. Goldstein
}

\section{INTRODUCTION}

In 1978 Lawrence Berkeley Laboratory, in cooperation with Comision Federal de Electricidad, began a program of dipole-dipole resistivity studies at the Cerro Prieto geothermal field (Wilt et a1., 1979). Dipole-dipole resistivity measurements were conducted in 1978 and 1979 along two long east-west survey lines; one ( $E-E^{\prime}$ ) crossing the central part of the production area near the power plant, and the other ( $D-D^{\prime}$ ) passing about $4 \mathrm{~km}$ north of the plant and immediately south of sections of the Cerro Prieto Geothermal Field, in Proceedings, First Symposium on the Cerro Prieto Geothermal Field, Baja California, Mexico, September, 1978. Berkeley, Lawrence Berkeley Laboratory, LBL-7098, p. 41-48.

Lippmann, M. J., Bodvarsson, G. S., Witherspoon, P. A., and Rivera R., J., 1979. Preliminary simulation studies related to the Cerro Prieto Field, in Proceedings, First Symposium on the Cerro Prieto Geothermal Field, Baja California, Mexico, September, 1978. Berkeley, Lawrence Berkeley Laboratory, LBL-7098, p. 375-387.

Lippmann, M. J., Tsang, C. F., and Witherspoon, P. A., 1977. Analysis of the response of geothermal reservoirs under injection and production procedures. SPE 6537, presented at the 47 th Annual California Regional Meeting SPE-AIME, Bakersfield, California, April 1977.

Mangold, D. C., Tsang, C. F., Lippmann, M. J., and Witherspoon, P. A., 1979. A study of thermal effects in well test analysis. SPE-8232, presented at the 54th Annual Fall Technical Conference SPE-AIME, Las Vegas, Nevada, September 1979. Berkeley, Lawrence Berkeley Laboratory, LBL-9769.

Tsang, C. F., Bodvarsson, G. S., Lippmann, M. J., and Rivera R., J., 1979. Some aspects of the response of geothermal reservoirs to brine reinjection with application to the Cerro Prieto Field, in Proceedings, First Symposium on the Cerro Prieto Geothermal Field, Baja California, Mexico, September, 1978. Berkeley, Lawrence Berkeley Laboratory, LBL-7098, p. 396-403. the Cerro Prieto volcano (Figure 1). The utmost care was taken to achieve the best accuracy obtainable with the available instrumentation.

The goals of this project are to determine how well the boundaries of the geothermal field can be defined with surface resistivity measurements, and to determine if changes in reservoir conditions due to production (e.g. formation of a vapor zone, changes in porosity at the periphery of the reservoir) may be monitored by means of accurate surface resistivity measurements. 


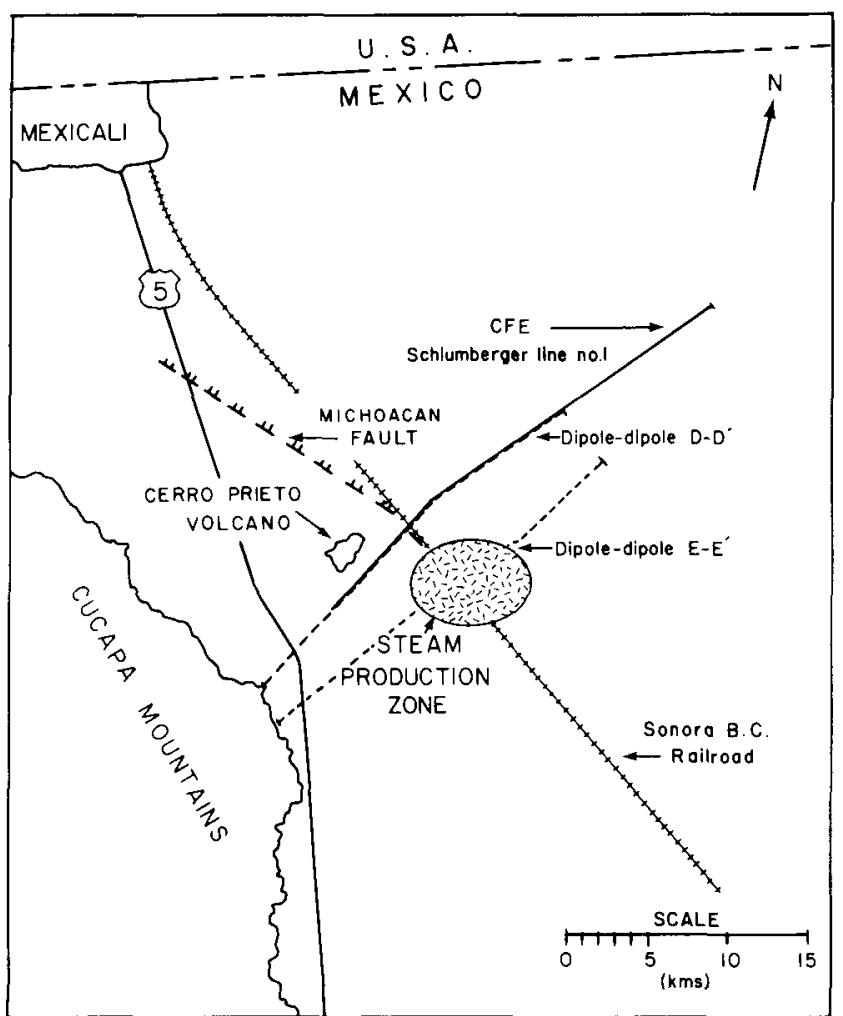

Figure 1. Project location map, LBL resistivity project.

(XBL 788-1632)

\section{PROGRESS IN FISCAL YEAR 1979}

In fiscal year 1979 , line E-E' was remeasured with 1-km dipoles but at significantly greater accuracy than in 1978 to provide better modeling constraints and to establish a reliable baseline for future observations of resistivity changes (Wilt et al., 1980). The LBL 25-kW motor generator was used as the power source both years, but greater accuracy was achieved in 1979 because of superior receiver instrumentation, mechanical improvements to the power source, and the experience gained from the previous year.

Measurements on line $E-E^{\prime}$ were extended $4 \mathrm{~km}$ farther eastward and the maximum transmitter receiver separations were increased from $N=6$ to $\mathrm{N}=8$, thereby yielding a greater depth of exploration. In addition, telluric profile measurements were made along line E-E' to test the applicability of this relatively fast and inexpensive method for resolving subsurface structure.

The expanded and more accurate results were used to develop an improved two-dimensional resistivity cross-section for line E-E' (Figures 2 and 3 ). New model perturbation studies were performed to identify points of maximum 1 ikely interest; i.e., those measurement points where reservoir changes might be most easily recognized, and to examine the magnitude of resistivity change for several possible reservoir changes. An analysis of measurement errors was done with the 1978 and 1979 data and the two sets were compared to see (1) if new measurements (1979) fall within the predicted errors and (2) if data accuracy is sufficient to isolate any changes in reservoir conditions.

Telluric data taken in 1979 were analyzed, and errors were evaluated to determine if it is possible to use this method for resistivity monitoring.

\section{Results of Dipole-Dipole Studies}

The following is a summary of some of our findings:

1. The dipole-dipole data gathering technique was improved in 1979 to where estimated measurement errors are less than $3 \%$ for most points. This is sufficient accuracy to observe changes in resistivity that may occur over a short time interval due to reservoir dynamics associated with production.

2. Further resistivity modeling has better defined the resistivity structure of the eastern part of the field. The model suggests that the resistive body associated with the producing zone (Figure 3) dips eastward at 30 to 50 degrees to a depth of greater than $2.0 \mathrm{~km}$. A narrow, steeply dipping conductive zone lies immediately east of the resistive body and may correspond to a zone of recharge or faulting (Lyons et a1., 1980).

3. The resistivity modeling suggests a deep source of fluid beyond the eastern part of the field. This is shown as the $4.0 \mathrm{ohm}-\mathrm{m}$ layer at 2.5 to $3.0 \mathrm{~km}$ depth. There is also some evidence that this deep zone is in hydrologic communication with existing shallower production (Elders et al., 1979).

4. Model perturbation studies show that apparent resistivity changes due to model variations normally occur as banded or grouped points of anomalous apparent resistivities. The signature of such models (Figure 4) may allow detection and identification of changes in the presence of noise. The study also helped define an "area of interest" of 60 measurement points particularly associated with changes in the reservoir formation.

5. Interpretation of telluric profile measurements done over line E-E' yields a significant amount of reconnaissance information about the field. Because of inherent measurement uncertainty, however, the method seems unsuitable for monitoring purposes. 
E- E' | km OBSERVED DATA (1979)

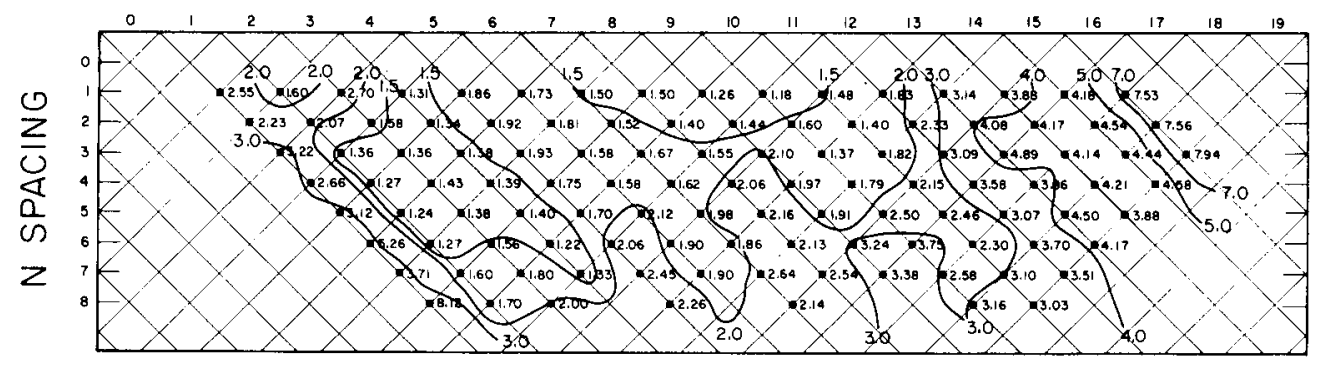

E-E' I km CALCULATED DATA

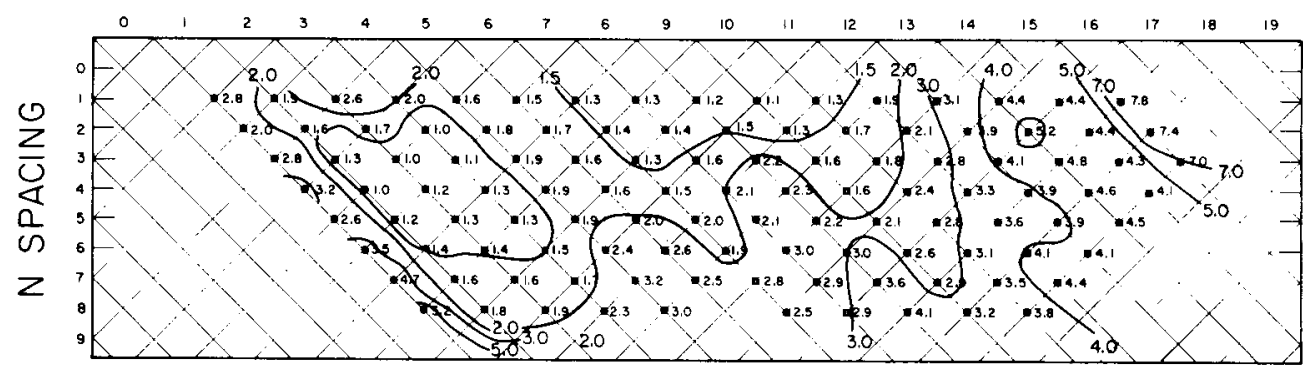

2 D RESISTIVITY MODEL

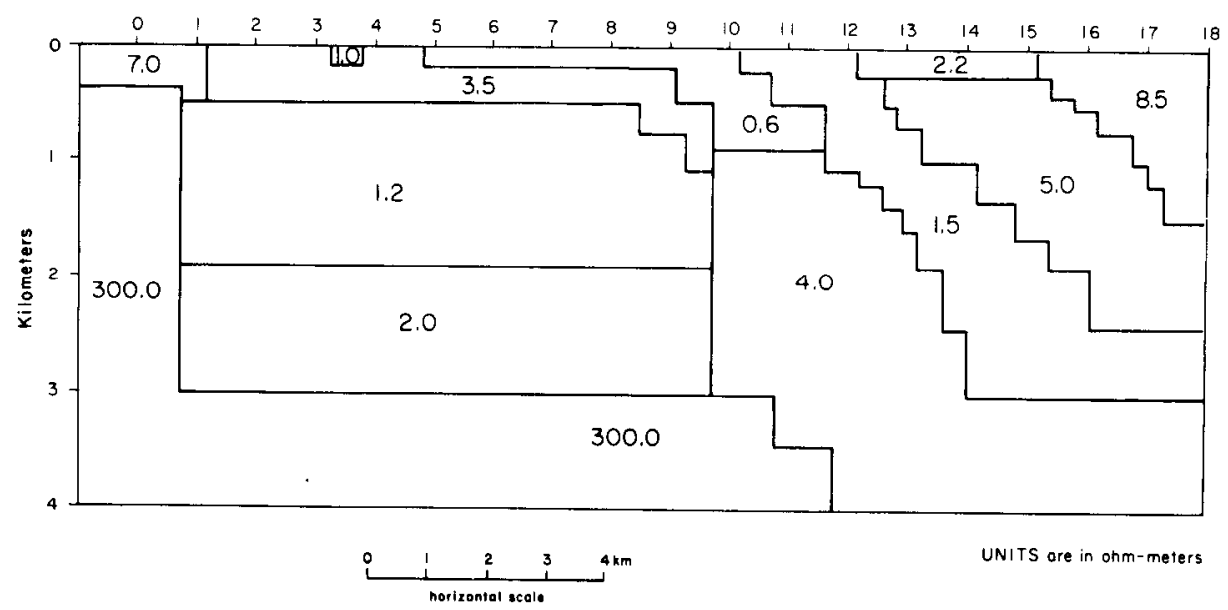

Figure 2. Dipole-dipole resistivity profile, line E-E', 1979: observed data, calculated data, and two-dimensional resistivity model.

(XBL 7910-13040A) 
Section E-E' Resistivity

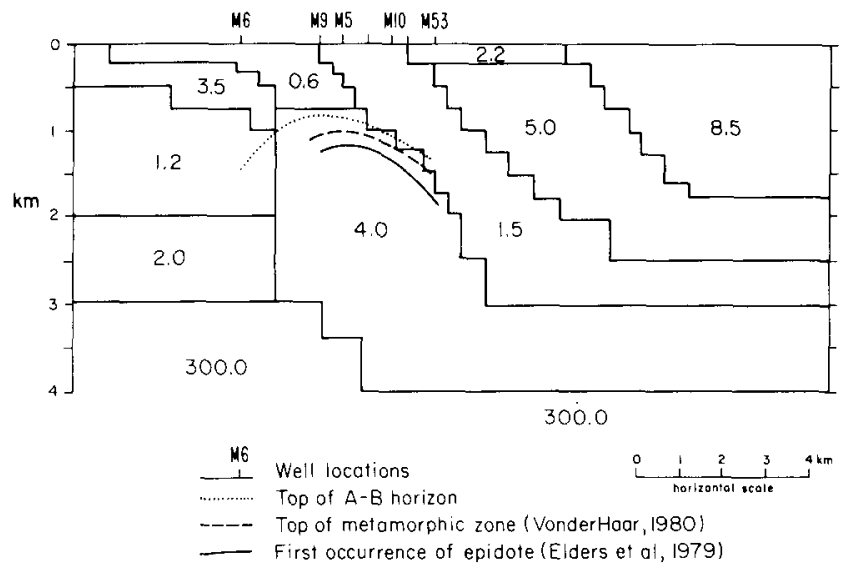

Figure 3. Expanded two-dimensional resistivity model showing well locations and plots of the consolidated-unconsolidated sediment interface, the top of the metamorphic zone, and the first occurrence of the metamorphic mineral epidote.

(XBL 801-6761)
PLANS FOR FISCAL YEAR 1980

In fiscal year 1980 line E-E' will be remeasured to an accuracy of $3 \%$ or better for all points. In addition, a detailed analysis will be performed on observed changes in apparent resistivity with emphasis on those 60 points most closely associated with the reservoir. Further model perturbation studies will be performed and some three-dimensional computer models will be calculated that account for the rapid changes in resistivity near the edges of the field that were observed with magnetotelluric measurements (Gamble et al., 1979). These threedimensional models will be of use in constructing more realistic perturbation models.

In the hope of futher improving the accuracy of our measurements two changes will be made to the recording system: (1) a telluric monitor will be added for direct telluric noise cancellation, and (2) a multichannel signal processor will be used for improved signal averaging and filtering. For larger transmitter-receiver separations telluric noise is often greater than the signal and this noise must be effectively cancelled to achieve the

\section{Model Perturbation Case 1-Cold Water Influx}
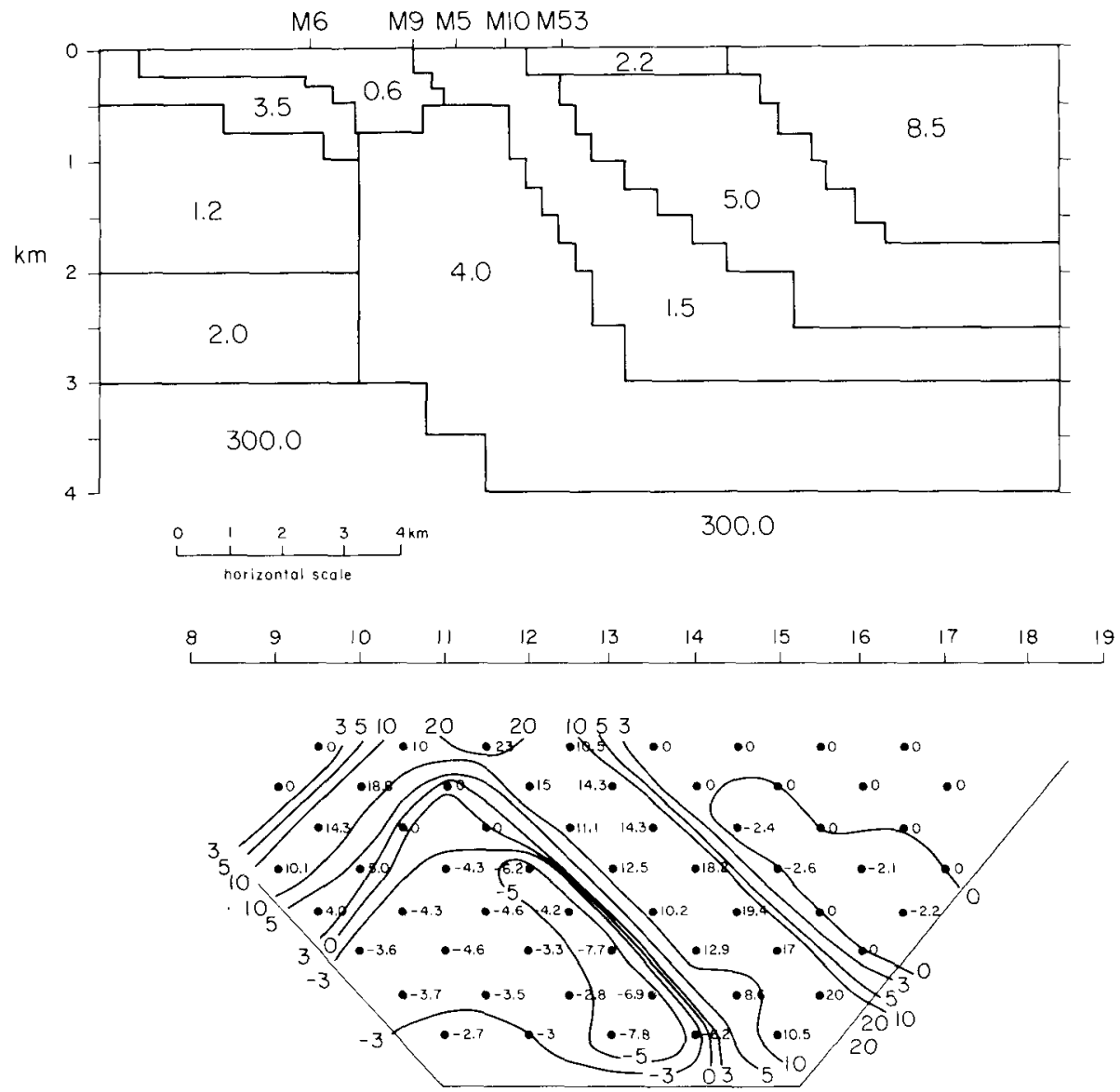

Percent variation

Figure 4. Model perturbation study to simulate the effect of cold water influx into the upper portion of the reservoir (compare model with Figure 3). Percent variations are differences between the calculated data from Figure 2 and the calculated data from the perturbed mode1. (XBL 801-6759) 
required accuracy. This can be done either by subtracting it directly from recordings or by averaging many cycles of data, assuming that the telluric noise will average to zero; we intend to do both.

For noise removal a telluric monitor will be placed 10-15 miles away from the dipole-dipole line so that no transmitted signal is contained in remote signals. The monitor will consist of an electric dipole, amplifiers and filters, and a radio transmitter to telemeter data to the recording van. The remote signal is then adjusted in amplitude, inverted, and added to the local tellurics, to reach a null signal. The transmitter is then switched on and data is taken in a normal manner.

Automatic signal averaging for noise reduction will be done with the new multichannel, microprocessor-controlled wave analyzer originally designed for use with an electromagnetic system. Its flexible design permits its use as a general geophysical receiver (Morrison et al., 1978). The addition of this instrument will allow superior filtering of noise, adjustable cycle averaging to a maximum of over 2000 cycles, and harmonic analysis of transmitted square waves. Since this receiver has six channels it will allow us to increase survey speed by making several measurements simultaneously.

\section{REFERENCES CITED}

E1ders, W. A., and Hoagland, J. R., 1979. Studies of water/rock interaction in the Cerro Prieto geothermal field, Baja California, Mexico, in
Abstracts, Second Symposium on the Cerro Prieto Geothermal Field, Baja California, Mexico: Mexicali, Comisión Federal de Electricidad.

Gamble, T. D., Goubau, W. M., Goldstein, N. E., Miracky, R., Stark, M., and Clark, J., 1980. Magnetotelluric studies at Cerro Prieto, in Proceedings, Second Symposium on the Cerro Prieto Geothermal Field, Baja California, Mexico, October 1979. Mexicali, Comisión Federal de Electricidad.

Lyons, D. J., van de Kamp, P., Vonder Haar, S., Noble, J., and Howard, J. H., 1980. Subsurface stratigraphy at the Cerro Prieto geothermal field, in Proceedings, Second Symposium on the Cerro Prieto Geothermal Field, Baja California, Mexico, October 1979. Mexicali, Comisión Federal de Electricidad.

Morrison, H. F., Goldstein, N. E., Hoversten, M., Oppliger, G., and Riveros, C., 1979. Description field test and data analysis of a controlled source EM system (EM-60). Berkeley, Lawrence Berkeley Laboratory, LBL-7088.

Wi1t, M., Goldstein, N. E., and Razo, M. A., 1979. LBL resistivity studies at Cerro Preito, in Proceedings, First Symposium on the Cerro Prieto Geothermal Field, Baja California, Mexico, September 1978. Berkeley, Lawrence Berkeley Laboratory, LBL-7098, p. 179-188.

Wilt, M., and Goldstein, N. E., 1980. Resistivity monitoring at Cerro Prieto, in Proceedings, Second Symposium on the Cerro Prieto Geothermal Field, Baja California, Mexico, October 1979. Mexicali, Comisión Federal de Electricidad.

\title{
MAGNETOTELLURIC STUDIES AT CERRO PRIETO
}

\author{
T. D. Gamble, W. M. Goubau, R. Miracky, J. Clarke, and N. E. Goldstein
}

\section{INTRODUCTION}

Seventeen magnetotelluric soundings have been performed near the current geothermal production zone at Cerro Prieto, Mexico. These measurements indicate, among other things, a zone of relatively high resistivity enclosing the region of current brine producion. This narrow zone plunges at a shallow angle to the south-southeast. The threedimensional nature of this resistive body, combined with the long range influence of the high resistivity Cucapa Mountain Range and other regional features, makes a rigorous quantitative evaluation impractical. Nonetheless, the qualitative picture is clear; and a rough model drawn from crude quantitative considerations has been shown to be in good agreement with dipole-dipole resistivity measurements and well log data from the area. The relatively high resistivity is apparently due to hydrothermal metamorphism of the sediments by geothermal activity, with an attendant loss of porosity, in a zone of faulting parallel to the regional strike, about $15^{\circ}$ west of north.

\section{PROGRESS IN FISCAL YEAR 1979}

Figure 1 is a map of the sites of the magnetotelluric soundings performed in 1978 and 1979.
They form three lines: D to the north of the plant, $E$ parallel to $D$ through the present production

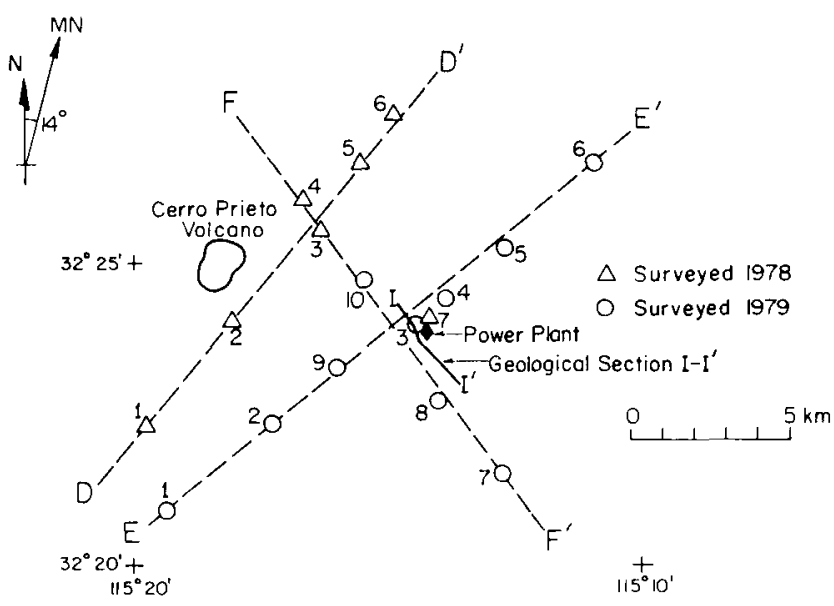

Figure 1. Location of magnetotelluric stations at Cerro Prieto, Baja California.
(XBL 791-12866) 
field, and $F$ also through the present field but perpendicular to the others and parallel to the geologic strike. Al1 the measurements were made using the remote reference technique (Gamble 1978; Gamble et a1. 1979a,b,c,d; Gamble, 1980). The Sierra Cucapa range is about $10 \mathrm{~km}$ to the west of Cerro Prieto; and the southern extension of the Imperial Valley fault lies about $12 \mathrm{~km}$ to the east, both sub-parallel to line $F$.

Magnetotelluric measurements can determine two response functions of the earth. One is the tipper, $\vec{T}$, which relates the vertical to the horizontal components of the magnetic field by $\mathrm{H}_{2}=$ $\vec{T} \cdot \vec{H}$. The second is the impedance tensor $Z$, which relates the horizontal components of the electric field to the horizontal components of the magnetic field by $\vec{E}=Z \vec{H}$. $Z$ is usually described by the apparent resistivity, which is the resistivity of a homogeneous earth that would give the same ratio of electric to magnetic field powers as is observed at a given frequency. This apparent resistivity is proportional to the squared magnitude of the offdiagonal components of $\underset{\widetilde{Z}}{Z}$. For the real, inhomogeneous earth, resistivity is a function of frequency. Apparent resistivity and tipper information are often conveniently represented in pseudosection form, where the lateral axis specifies the position along a survey line and the vertical scale is the logarithm of the period. The depth of penetration of the electromagnetic waves is roughly proportional to the square root of the period, so the vertical axis corresponds very roughly to logarithmic depth.

We present a small sample of the pseudosections of the data from these soundings. Figure 2 is a pseudosection of the tipper magnitude for current going across the strike, for line F. There is a very large maximum at station 3 , just north of the power plant, at periods of about 1 second. The tipper indicates lateral changes in resistivity, so this pseudosection indicates a large north-south gradient of resistivity just north of the plant. The phase of the tipper (not shown) indicates that the more resistive material is to the south. Figure 3 is a pseudosection of the apparent resistivity for the same line, $F$, and current direction, across the regional strike. Here we see more directly a region of higher resistivity to the south indicated by an area of high apparent resistivity, greater than $3 \mathrm{ohm}-\mathrm{m}$, south of station 3 . The contour of 3 ohm-m apparent resistivity closes at longer periods, but this does not mean that the actual resistivity decreases at the greatest depths. Rather, we are seeing the influence of the resistive barrier of the Cucapa granites to the west. This barrier blocks off the current at great depths, causing a lower apparent resistivity for the longer periods.

Because of lateral resistivity changes in geologically complex areas, we rarely encounter data that can be quantitatively interpreted in terms of a simple one-dimensional (i.e., horizontally layered) earth. The only station for which the measurements appear consistent with a one-dimensional model over most of the frequency range is station 6 on line $E$, the station farthest from the Cucapas. We used a program developed by Oldenburg (1979) to invert the data from this sounding. The results are shown in Figure 4. The crosses indicate the

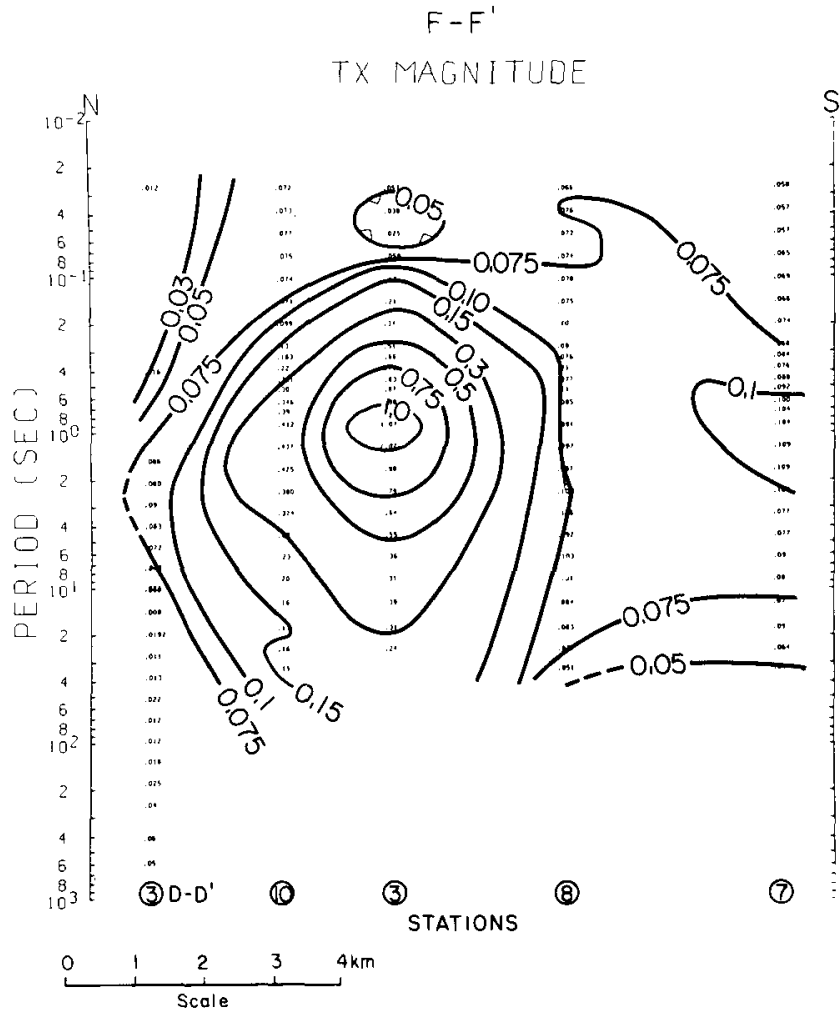

Figure 2. Observed tipper magnitude for line $F-F^{\prime}$, current perpendicular to regional geologic strike.

(XBL 799-11504)

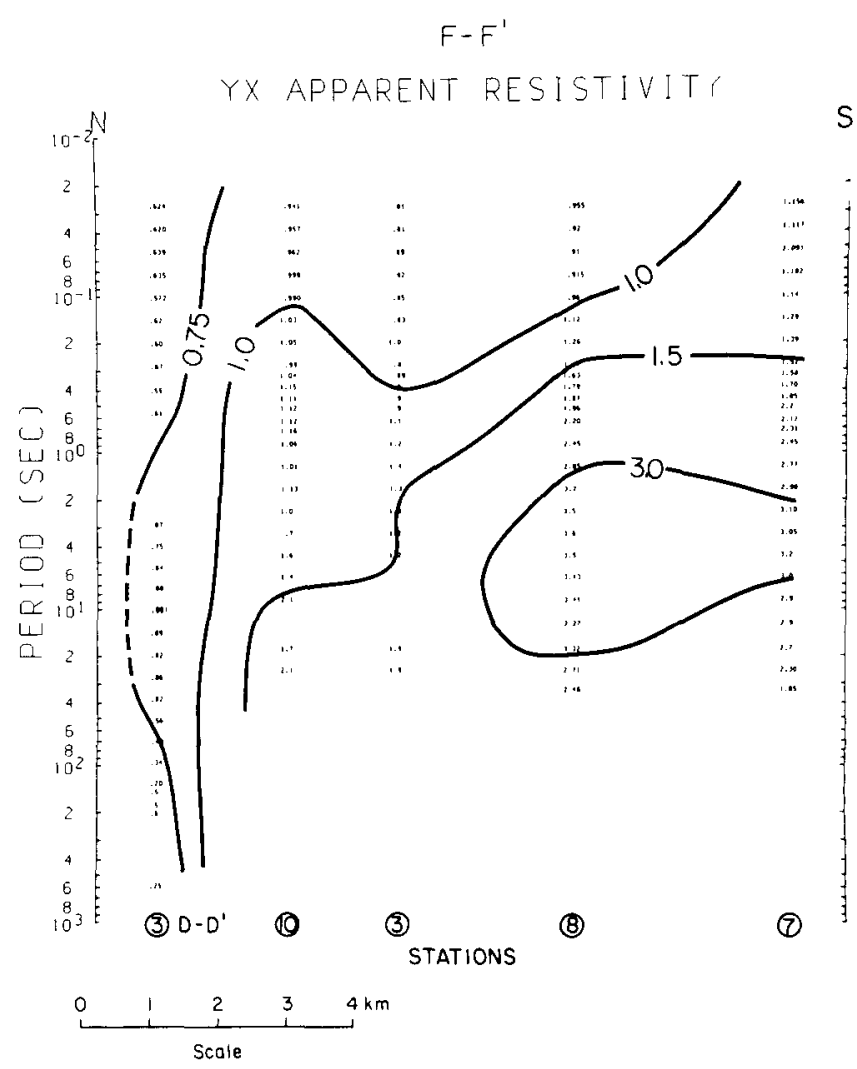

Figure 3. Apparent resistivity pseudosection along line $F-F^{\prime}$, current perpendicular to regional geologic strike.
(XBL 799-11507) 
63

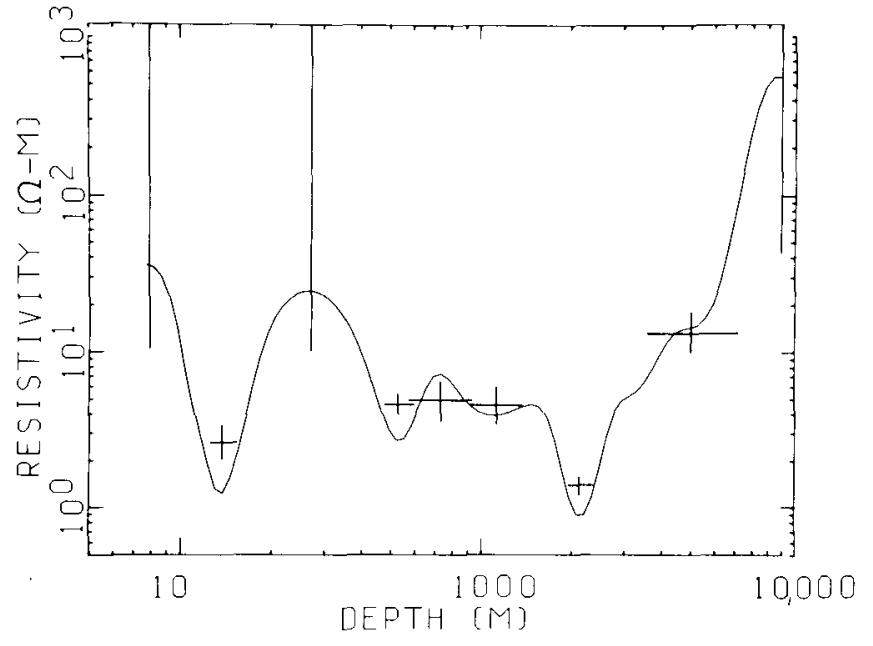

Figure 4. One-dimensional inversion results for station 5, line E-E'; electric field parallel to regional strike (crosses explained in text).

(XBL 7910-12330A)

resolution of the sounding. The vertical bars indicate a range of depths over which the resistivity was average, whereas the horizontal bars indicate the standard deviation of this average resistivity due to the uncertainty of the measurements. Between depths of 200 and $2000 \mathrm{~m}$, resistivities tend to decrease, a consequence of water salinity changing from nearly fresh at the surface (Colorado River water) to fossil sea water trapped in the deeper sediments. The low resistivity anomaly ( $1 \mathrm{ohm}-\mathrm{m}$ ) between 1.9 and $2.5 \mathrm{~km}$ depth, could be caused by a combination of high temperature and high salinity. Results from well Neuvo Leone $I$ in the general area confirm this condition.

The soundings along line $\mathrm{D}$ are relatively consistent with a two-dimensional earth; i.e., there is no indication of a large lateral change in resistivity in the strike direction. Therefore, we have attempted to match the observed pseudosections to those for a two-dimensional model. A preliminary model, which was included in the 1978 annual report, roughly matched the long period data from this line (Gamble et al., 1979b). This model has been refined to obtain a much better match to al1 the measurements. This subsurface resistivity along line $D$ is presented in Figure 5. To illustrate how well the model satisfies the data, Figure 6 shows a comparison of calculated and observed apparent resistivity pseudosections. Although Figure 6 portrays only the case for current perpendicular to strike (the TE mode), the model also satisfies current perpendicular to strike (the TM mode). For this particular line, agreement between model and observed results is particularly good. The values of resistivity were found for the blocks shown in Figure 5.

The 41 ohm-m block at the western end of line $D$ is included to account for the conduction paths within the Cucapa mountains above the level of the plain. Also, relatively resistive rocks were required east of station 6 to help fit the data. Thus we had to introduce a rather artificial 25 ohm-m block of undetermined depth extent beyond the

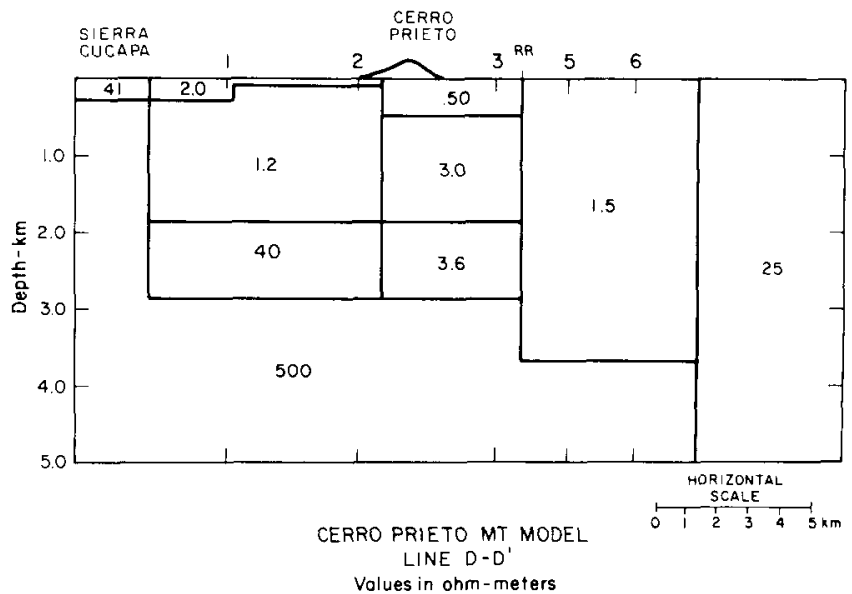

Figure 5. Two-dimensional interpretation of resistivity fitting the magnetotelluric results at stations along line $D-D^{\prime}$.

(XBL 796-7534A).

eastern end of the 1 ine. The low resistivity surface $z$ one in the middle of the line is well resolved, and is coincident with the geothermal surface manifestations near the Cerro Prieto volcano. The measurements are consistent with 1.7 or 1.8 ohm-m resistivity from 0.5 to $3.0 \mathrm{~km}$ depth below stations 3,5 , and 6 , although a slightly better match is obtained with the values of 3.0 and 3.6 ohm-m below station 3 , as shown. This more resistive zone, bounded approximately by the Cerro Prieto fault on the west and the Michoacan fault on the east, is better defined by means of dipole-dipole resistivity than by $\mathrm{MT}$. The zone corresponds to a region of hydrothermal metamorphism and reduced porosity as determined from a study of well cuttings (Elders et a1., 1979).

Because of the large lateral changes of resistivity in the regional strike direction over the field, indicated earlier by Figures 2 and 3 , we have not attempted to match these soundings to a two-dimensional model. Instead, we have conceptualized a rough three-dimensional model based on a qualitative consideration of all relevant pseudosections. Sections of this model along lines $\mathrm{E}$ and F, plotted to a logarithmic depth scale, are shown in Figures 7 and 8 , respectively. The resistive body in the vicinity of the power plant presents a large cross section along line $F$ but only a relatively small one along line $E$. It is not connected to the resistive zone near the surface to the east on line $E$ and does not extend any farther south than the southernmost station on line $\mathrm{F}$. It comes within $500 \mathrm{~m}$ of the surface in the region of the power plant and plunges at a shallow angle to the south. We have no stations distributed across strike near the middle of this resistive zone, so we cannot determine its width, although it appears narrow. It could be a single vertical dike-1ike body of resistive material, a number of such narrow bodies, or a zone of anisotropic conductivity, more conductive along strike.

Dipole-dipole resistivity measurements have been performed along 1 ines $D$ and $E$. The models developed from these measurements are in close agreement along those lines with rough model from 


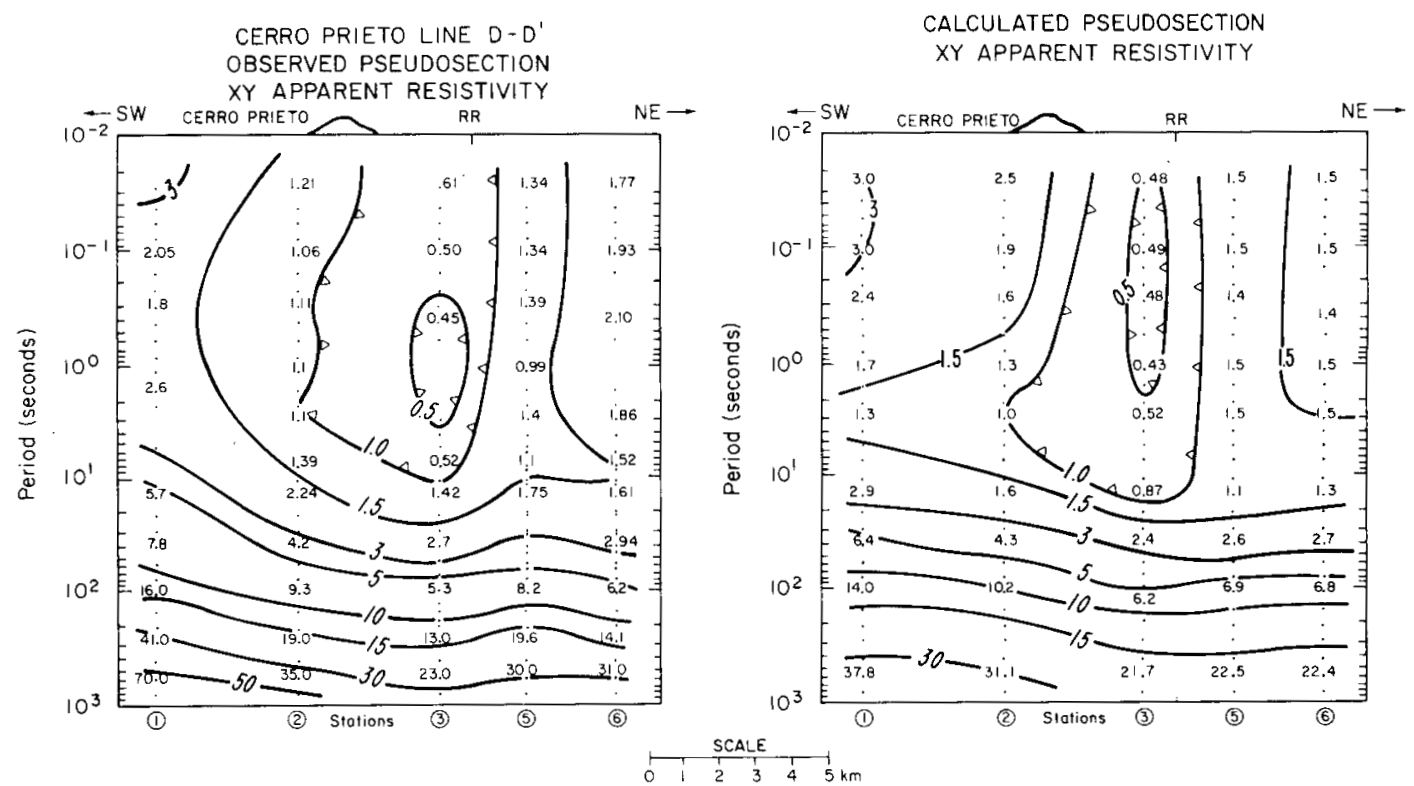

Figure 6. Observed and calculated apparent resistivity pseudosections, 1ine D-D', current paralle1 to geologic strike.

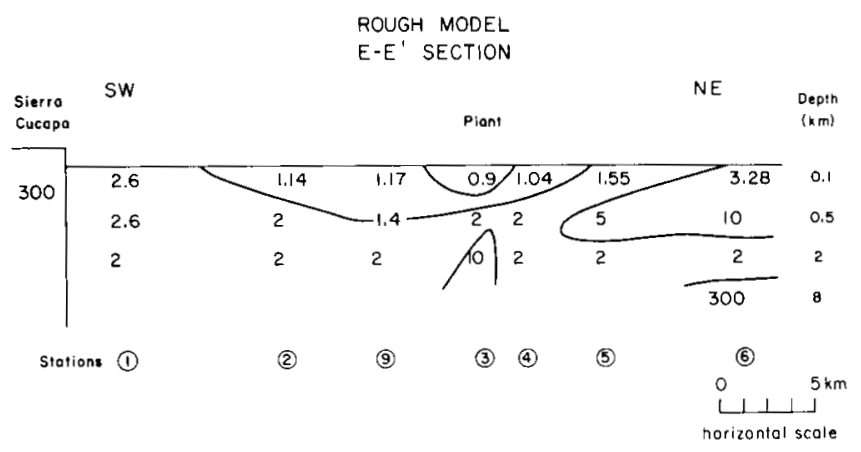

Figure 7. Semi-quantitative estimate of subsurface resistivity distribution along line $E-E^{\prime}$, vertical scale logarithmic.

(XBL 799-1150A)

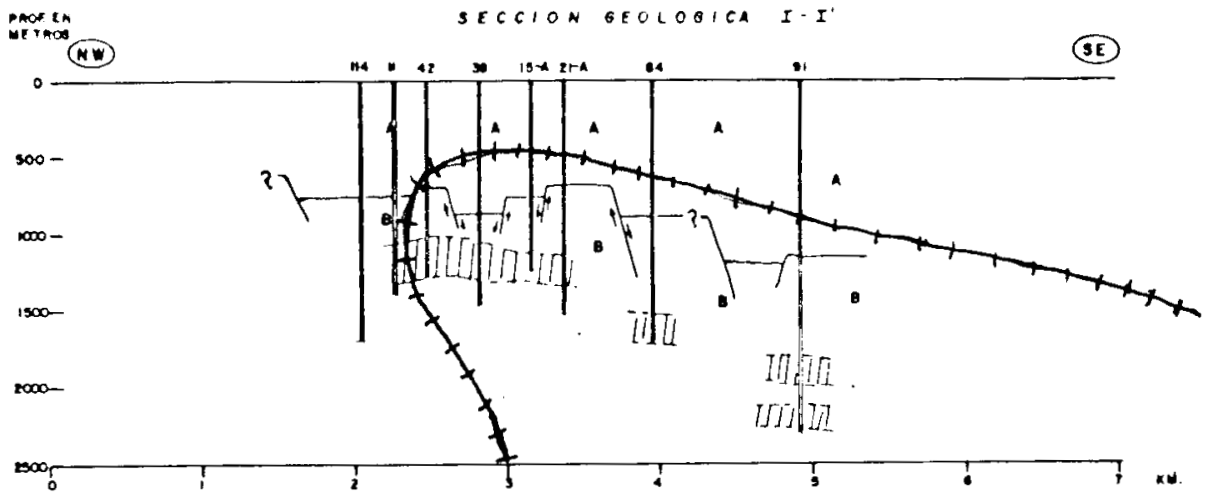

Figure 8. Approximate relationship between the dipping resistive zone and subsurface geology. 
the magnetotelluric measurements (Wilt and Goldstein, 1979). In fact the match between the measured and calculated responses for the dc resistivity mode has been signficantly improved by the inclusion of features from the "rough" magnetotelluric model into the dipole-dipole model.

Except where the resistive zone is shallowest, north of the power plant, the top of the zone corresponds well to the first occurrence of significant hydrothermal alteration as determined from well samples. Very little mineralogical data are available from wells to the north, but what is available does not show any sharp increase in the depth to the altered zone. We are reminded that the bulk resistivity properties as measured from the surface are determined by many factors, such as the grain of fracturing in fault zones. They all must be included to explain the resistivity structure; and we do not have any really satisfactory explanation of the lateral change of resistivity to the north.

It is 1ikely that the history of geothermal activity at Cerro Prieto has included phases of induration of the sediments by hydrothermal solutions interrupted by faulting and fracturing that opened new paths for hydrothermal solutions and provided convective pathways for dissolution and resulting secondary porosity of the sandstones (Lyons, 1979, personal communication.). However, the gross features of the structure in the current production zone can be explained most simply in terms of hydrothermal alteration of the sediments by geothermal fluids emanating from a source at depth about $4 \mathrm{~km}$ to the south-southeast of the pressent plant and flowing along the general regional strike in a zone of faulting to the north-northwest. A well of great capacity has been recently completed about $3 \mathrm{~km}$ to the southeast of the plant, supporting this picture.

The conductive layer at $2 \mathrm{~km}$ depth to the east may indicate that the circulation system now extends to this region and that recharge to the production zone may also be coming from reservoir rocks underlying the central portion of the Mexicali Valley.

\section{PLANNED ACTIVITIES FOR 1980}

We plan to add another line of stations parallel to lines $D$ and $E$, about $4 \mathrm{~km}$ south of the plant, over the apparent root of the resistive zone. We hope this line will yield significant information about the hydrothermal flow around the source of the heat.

A more fundamental objective is to improve interpretation of magnetotelluric measurements.
At present there is no program that can calculate the responses that would be observed for our rough mode1. Magnetotelluric measurements can be performed to almost arbitrary accuracy with the use of a remote reference; but the promise of magnetotellurics will not be fulfilled until some quantitative means is developed for direct approximate inversion of the measurements to determine the conductivity structure of the ground in complex situtations.

\section{REFERENCES CITED}

Elders, W. A., Hoagland, J. R., McDowel1, S. E., and Cobo, R. J., 1979. Hydrothermal mineral zones in the geothermal reservoir of Cerro Prieto, in Proceedings, First Symposium on the Cerro Prieto Geothermal Field, Baja California, Mexico, September 1978. Berkeley, Lawrence Berkeley Laboratory, LBL-7098, p. $68-75$.

Gamble, T. D., 1978. Remote reference magnetote1lurics with SQUID (Ph.D. dissertation). Berkeley, Lawrence Berkeley Laboratory, LBL-8062.

Gamble, T. D., Goubau, W. M. Goldstein, N. E., and Clarke, J., 1979a. Referenced magnetotellurics at Cerro Prieto, in Proceedings of the First Symposium on the Cerro Prieto Geothermal Field, Baja California, Mexico: Berkeley, Lawrence Berkeley Laboratory, LBL-7098.

1979b. Magnetotelluric survey at Cerro Prieto, in Earth Sciences Division Annual Report $1 \overline{978}$. Berkeley, Lawrence Berkeley Laboratory, LBL-8648, p. 41-42.

Gamble, T. D., Goubau, W. M., and Clarke, J., 1979c. Magnetotellurics with a remote magnetic reference. Geophysics, v. 44, no. 1, p. 53-68. , 1979d. Error analysis for remote reference magnetotellurics. Geophysics, v. 44 , no. 5 , p. 959-968.

Gamble, T. D. Goubau, W. M., Goldstein, N. E., Miracky, R., Stark, M. and Clarke, J., October 1980. Magnetotelluric studies at Cerro Prieto, in Proceedings, Second Symposium on the Cerro Prieto Geothermal Field, Baja California, Mexico, October 1979. Mexicali, Comisión Federal de Electricidad.

Oldenburg, D. W., 1979. One dimensional inversion of natural source magnetotelluric observations. Geophysics, v. 44, no. 7, p. 1218-1244.

Wilt, M., and Goldstein, N. E., 1979. Resistivity monitoring at Cerro Prieto, in Proceedings, Second Symposium on the Cerro Prieto Geothermal Field, Baja California, Mexico, October 1979. Mexicali, Comisión Federal de Electricidad. 


\title{
PRECISION GRAVITY STUDIES AT THE CERRO PRIETO GEOTHERMAL FIELD
}

R. B. Grannell, ${ }^{*}$ D. W. Tarman, $†$ R. C. Clover ${ }^{*}$ R. M. Leggewie, ${ }^{*}$ P. S. Aronstam, ${ }^{*}$

R. C. Kroll, * and J. Eppink $\dagger$

From January to March 1979,60 permanent gravity stations in the Cerro Prieto geothermal field were reoccupied for the collection of data, a year after their initial occupation in early 1978 (Chase et al., 1978; Grannell et a1., 1979). For the collection of both data sets, each station was occupied four times and was replicated four times at an individual occupation, for a total of 16 readings. Two LaCoste and Romberg G-model gravity meters were used. In a looping technique, individual stations were surveyed between two base station occupations, taken up to five hours apart. This procedure allowed identification of tares and partial removal of instrumental drift.

The data were reduced to observed gravity values using meter calibrations and the appropriate corrections for both earth tides and instrumental drift. The station values were then referred to a bedrock base, presumed stable and nonsubsiding over short time intervals, (several years). This base is located on granitic rocks in the Sierra Cucupa, west of the geothermal field.

A comparison of reduced data from the two periods shows no significant gravity changes in that interval. This result is consistent with the results of first- and second-order leveling carried out by CFE within and adjacent to the Cerro Prieto geothermal field. The possible reasons for lack of gravity changes are fourfold: (1) insufficient time at the current rate of production to produce measurable changes; (2) local recharge to offset mass losses; (3) drawdown in an area not covered by the gravity survey (possible to the west); and (4) changes too small to be detected at the current level of precision ( 10 to $17 \mu$ gals).

\section{REFERENCES CITED}

Chase, D. S., Clover, R. C., Granne1, R. B., Leggewie, R. M., Eppink, J., Tarman, D. W., and Goldstein, N. E., 1979. Precision gravity studies at Cerro Prieto, in Proceedings, First Symposium on the Cerro Prieto Geothermal Field, Baja California, Mexico, September 1978. Berkeley, Lawrence Berkeley Laboratory, LBL-7098, p. 249-256.

Granne 11, R. B., Tarman, D. W., Aronstam, P., Clover, R. C., Leggewie, R. M., Eppink, J., and Kroll, R., 1979. Precision gravity measurements in the Cerro Prieto geothermal area, in Abstracts, Second Symposium on the Cerro Prieto Geothermal Field, Baja California, Mexico. Mexicali, Comision Federal de Electricidad, p. 37-39.

\footnotetext{
*California State University, Long Beach

tCalifornia State Polytechnic University, San Luis Obispo
}

\section{GEOTHERMAL RESERVOIR ENGINEERING MANAGEMENT PROGRAM: DEVELOPMENTS IN FISCAL 1979}

\author{
J. H. Howard and W. J. Schwarz
}

\section{INTRODUCTION}

Fiscal year 1979 was the third year of LBL's responsibility for the Geothermal Reservoir Engineering Management Program (GREMP) on behalf of the U. S. Department of Energy, Division of Geothermal Energy. The concept behind this program is explained in Lawrence Berkeley Laboratory report LBL-7000. Its history since 1977 is summarized in Earth Science Division Annual Reports of 1977 and 1978 .

Fiscal 1979 was marked by the conclusion of a number of contracts supported by the program and by relative decline in the number of new contracts when compared with 1978. Overall, the GREMP program has shown typical signs of growth and maturity: fiscal 1977 was devoted largely to planning and getting the program initiated; fiscal year 1978 was characterized by an appreciable amount of new contracting; and fiscal year 1979 was devoted to the conclusion of many contracts and a call for serious review and possible redirection and reorganization of the effort.

ACTIVITIES IN FISCAL YEAR 1979

Administrative Highlights

New contracts were let in fiscal year 1979 for work on tracers in geothermal reservoirs (with Vetter Research) and for work on declines of geothermal well production (with $\mathrm{E}$. Zais and Associates). Contracts with Princeton University, University of California at Riverside, and Stanford University, which started under the NSF-RANN program, were continued.

From its start at LBL through this fiscal year, 23 distinguishable research projects have been addressed through the efforts of 14 institutions. This work is summarized in Figure 1, which shows the relationship of these various projects to the overall GREMP plan. Table 1 gives a brief statement of explanation of each of these projects. 


\section{SUMMARY OF PROJECTS RELATIVE TO ORIGINAL PLAN 는}

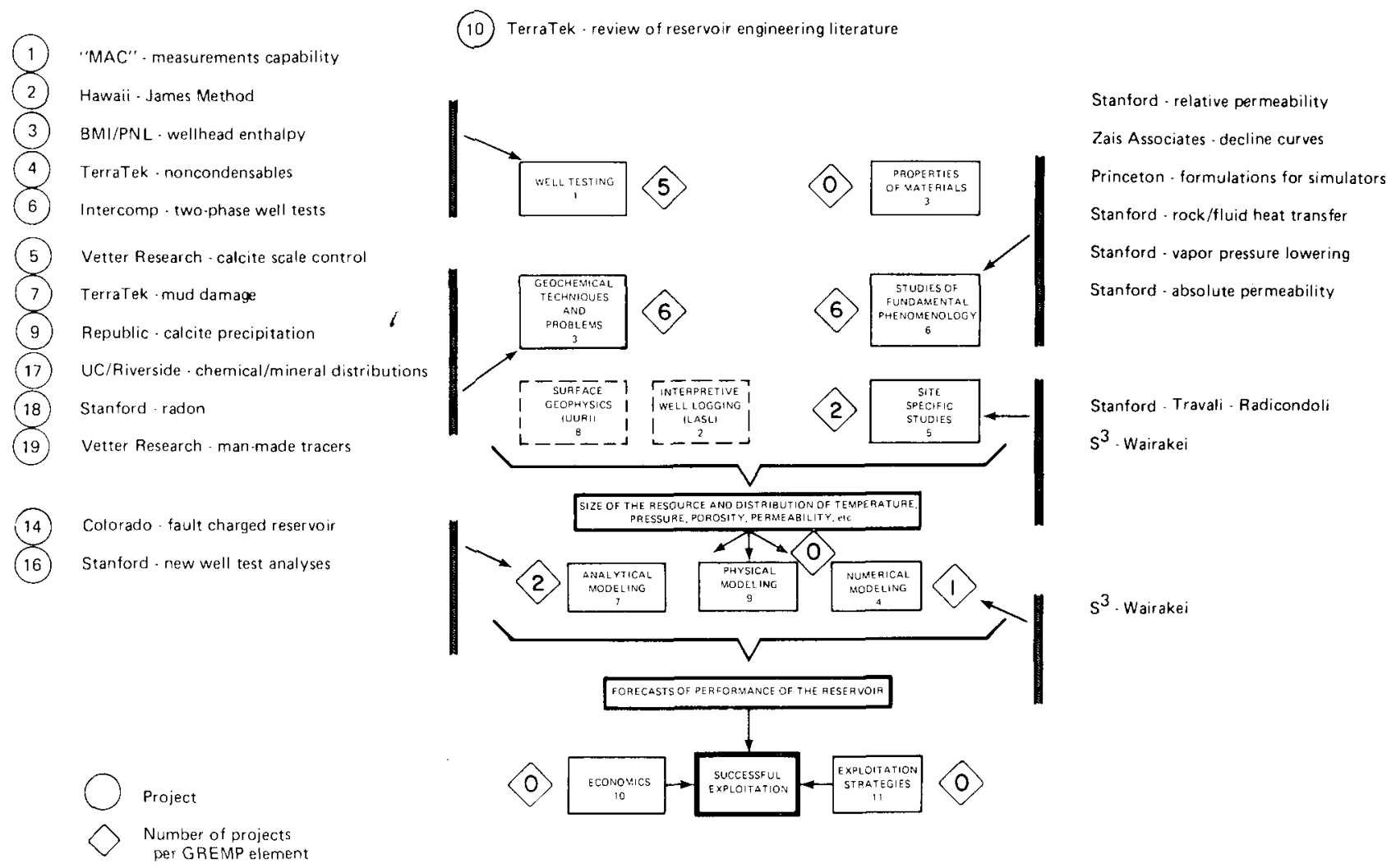

Figure 1. Summary of projects with respect to elements of original GREMP plan.

(XBL 7911-13434)

The GREMP publication series, which was started in fiscal year 1978 was continued and now includes six publications with two more of the series in press (as of January 1980).

The newsletter "News from GREMP" was continued through fiscal year 1979 and now includes six issues. This series has set a good precedent for communication of technical results (with an active mailing list of 600), and has encouraged the issuing of similar series for other programs like GREMP.

Certain areas of work have yet to be addressed by the program. These include, economics and exploitation strategies. Generally, projects-notdone are a consequence of recommended low priority for support by the Review Task Force for GREMP and due to fund limitations.

\section{Technical and Scientific Progress}

Technical work addressed to date through GREMP is summarized in Figure 1 and Table 1 . Attention is called to the projects completed (marked with an asterisk), and to publications about those works. Space does not permit even a short statement on the progress for each project during fiscal year
1979. However, noted below are three achievements of special interest.

1. TerraTek instrument development for measurement of noncondensables on a real-time basis. This instrument has been successfully field tested and is now at the stage of being perfected for practical use. Several companies have expressed interest in its purchase or lease when it is available commercially.

2. UC/Riverside work on petrology of Cerro Prieto geothermal field. The significance of minerals, as an index of temperature in the field, has been sufficiently well established that the minerals seen in cuttings have been used as a basis for decisions to abandon or to deepen a well. This achievement is particularly noteworthy inasmuch as the motive for investigation was an improvement in understanding of metamorphosis in geothermal reservoirs, a fundamental scientific question.

3. Vetter Research (and Repub1ic Geothermal Incorporated) on use of a chemical additive to control calcite precipitation. Calcite fouling is a serious practical problem in the production of geothermal fluids and this research defined the circumstances under which an additive DEQUEST 2060 can virtually eliminate calcite precipitation. 
TaDle 1. Summary of Geothermal Reservoir Engineering projects supported by USDOE/DGE through Lawrence Berkeley Laboratory.

\begin{tabular}{|c|c|c|c|}
\hline IU\# & Brief project name & Contractor & Brief summary of work \\
\hline 1. & $\begin{array}{l}\text { Status of reservoir } \\
\text { related measurements* }\end{array}$ & $\begin{array}{l}\text { Measurement } \\
\text { Analysis } \\
\text { Corp. }\end{array}$ & $\begin{array}{l}\text { A comprehensive appraisal of measurement needs and instrumentation for geo- } \\
\text { thermal applications has been completed, indicating that commercially avail- } \\
\text { able technology and instrumentation exists in principle for all wellhead and } \\
\text { process plant measurement requirements, except two-phase flow (Lamers, 1979). }\end{array}$ \\
\hline$\angle$. & $\begin{array}{l}\text { Theoretical basis } \\
\text { for James method }\end{array}$ & $\begin{array}{l}\text { University } \\
\text { of Hawait }\end{array}$ & $\begin{array}{l}\text { The purpose of this project is to understand the theoretical basis of James } \\
\text { empirical method for estimating mass flow and enthalpy (Cheng, 1979). }\end{array}$ \\
\hline 3. & $\begin{array}{l}\text { Measurement of } \\
\text { enthalpy at } \\
\text { wellhead* }\end{array}$ & $\begin{array}{l}\text { Battelle } \\
\text { Pacific } \\
\text { Northwest } \\
\text { Laboratory }\end{array}$ & $\begin{array}{l}\text { Several calorimetry methods for measuring geothermal wel lhead enthalpies were } \\
\text { reviewed. A mixing tee condenser was recommended for use when cooling water } \\
\text { is available. When not, a mult iphase tank was recommended. Work on engineer- } \\
\text { ing drawings of a sampling system and a mixing tee condenser (Cliff et al., } \\
\text { 1979a) have been prepared (Cliff et al., 1979b). }\end{array}$ \\
\hline 4. & $\begin{array}{l}\text { Weasurements of } \\
\text { noncondensible } \\
\text { yases at wellhead }\end{array}$ & TerraTek & $\begin{array}{l}\text { Engineering design construction and testing of a device with the capability } \\
\text { to monitor noncondensible gas concentrations continuously in geothermal dis- } \\
\text { charges has been completed (Harrison et al., 1979). }\end{array}$ \\
\hline b. & $\begin{array}{l}\text { Control of calcite } \\
\text { precipitation by } \\
\text { adaitives* }\end{array}$ & $\begin{array}{l}\text { Vetter } \\
\text { Research }\end{array}$ & $\begin{array}{l}\text { Scale inhibitor tests performed at Republic Geothermal Inc., East Mesa wel is } \\
\text { have shown that Dequest can economically el iminate calcite precipitation in } \\
\text { the discharge flow stream (vetter, 1979). }\end{array}$ \\
\hline o. & $\begin{array}{l}\text { Anaiys is of well } \\
\text { tests of two-phase } \\
\text { reservoir }\end{array}$ & Intercomp & $\begin{array}{l}\text { Favorable comparison of Intercomp's proprietary geothermal wel Ibore and reser- } \\
\text { voir simulators with the experimental and numerical results from three other } \\
\text { models has been completed. Data on two-phase well tests have been assembled } \\
\text { for analysis (Aydelotte and Taylor, 1979) and the Hawai ian well HCP-4 has } \\
\text { been studied. }\end{array}$ \\
\hline 7. & $\begin{array}{l}\text { Formation damage } \\
\text { of drilling mud }\end{array}$ & TerraTek & $\begin{array}{l}\text { Laboratory simulation of drilling mud damage to geothermal reservoir rocks } \\
\text { has been initiated. Parameters to be considered are pressure, temperature, } \\
\text { reservoir fluid chemistry, mud composition, and time (Butters, 1979). }\end{array}$ \\
\hline$d$. & $\begin{array}{l}\text { Relative permeability } \\
\text { of steam and water }\end{array}$ & $\begin{array}{l}\text { Stanford } \\
\text { University }\end{array}$ & Relative permeability data have been collected by Counsil (1978). \\
\hline$y$. & $\begin{array}{l}\text { Calcite formation } \\
\text { oy inappropriate } \\
\text { production } \\
\text { practices }\end{array}$ & $\begin{array}{l}\text { Republic } \\
\text { Geothermal, } \\
\text { Inc. }\end{array}$ & $\begin{array}{l}\text { Carbonate-rich geothermal brine is being passed through containers of granular } \\
\text { materials in order to evaluate the mechanism and rate of calcite precipita- } \\
\text { tion within the pore space. The ultimate practical purpose of the activity } \\
\text { is to plan better remedial "acid jobs" on calcite-fouled geothermal wells } \\
\text { (Michaels, 1979). }\end{array}$ \\
\hline IU. & $\begin{array}{l}\text { Literature review } \\
\text { of reservoir } \\
\text { explaitation* }\end{array}$ & TerraTek & $\begin{array}{l}\text { An annotated bibliography covering reservoir modeling, exploitation strategies, } \\
\text { and interpretation of production trends has been prepared (Harrison and } \\
\text { Randall, 1979). }\end{array}$ \\
\hline 11. & $\begin{array}{l}\text { Stuay of the } \\
\text { Travali Kadicondoli } \\
\text { yeothermal areas in } \\
\text { Italy }\end{array}$ & $\begin{array}{l}\text { Stanford } \\
\text { University }\end{array}$ & $\begin{array}{l}\text { Geology and pressure-production history of Serrazzano reservoir have been } \\
\text { reviewed. Bottomhole temperatures and pressures have been calculated from } \\
\text { wellhead measurements. Areal distribution of pressure has been mapped for } \\
\text { seven different times spanning the last } 15 \text { years. A conceptual model of } \\
\text { Travali Radicondoli geothermal field was developed on the basis of the avail- } \\
\text { able field data (Miller et al., 1978). }\end{array}$ \\
\hline 12. & $\begin{array}{l}\text { Uata collection } \\
\text { for the wairekei } \\
\text { field, New Zealand* }\end{array}$ & $\begin{array}{l}\text { Systems, } \\
\text { Science and } \\
\text { Software }\end{array}$ & $\begin{array}{l}\text { A1) geological, geochemical, geophysical, and wellbore data from January, } 1953 \\
\text { to December, } 1976 \text { has been collected and synthesized (Pritchett et al., } 1978 \text { ). }\end{array}$ \\
\hline 13. & $\begin{array}{l}\text { Simulation of past } \\
\text { and future perfor- } \\
\text { Inance at wairakei, }\end{array}$ & $\begin{array}{l}\text { Systens, } \\
\text { Science and } \\
\text { Software }\end{array}$ & $\begin{array}{l}\text { With the data collected and synthesized (\$12 above), an attempt is under way to } \\
\text { match the pressure, enthalpy and subsidence history during past production of } \\
\text { the wairakei, New Zealand, field (Pritchett et al., 1979). }\end{array}$ \\
\hline 14. & $\begin{array}{l}\text { Prototype of a fault- } \\
\text { cnaryed geothermal } \\
\text { reservoir* }\end{array}$ & $\begin{array}{l}\text { University } \\
\text { of Colorado }\end{array}$ & $\begin{array}{l}\text { A physical, viable, mathematical model of an unexploited geothermal system has } \\
\text { been constructed in terms of a fault zone controlled charging of a reservoir } \\
\text { (Kassoy and Goyal, 1979). }\end{array}$ \\
\hline 15. & $\begin{array}{l}\text { Keview of decline } \\
\text { curves appropriate to } \\
\text { geothermal reservoirs }\end{array}$ & $\begin{array}{l}\text { E. Zais and } \\
\text { Associates }\end{array}$ & $\begin{array}{l}\text { The purpose of this project is to review decline curve procedures used in the } \\
\text { petroleum industry, detemine which procedures are applicable to geotherma? } \\
\text { systems, and establish a theoretical basis for applicability. }\end{array}$ \\
\hline 10. & $\begin{array}{l}\text { New analytical we } 17 \\
\text { test methods for } \\
\text { geotnernal reservoirs }\end{array}$ & $\begin{array}{l}\text { Stanford } \\
\text { University }\end{array}$ & $\begin{array}{l}\text { The utility of parallelipiped models has been investigated (Ramey et al., } \\
\text { 1978). }\end{array}$ \\
\hline 17. & $\begin{array}{l}\text { Studies of mineral } \\
\text { facies and stable iso- } \\
\text { topes and their rela- } \\
\text { tions to geothermal } \\
\text { reservoirs }\end{array}$ & $\begin{array}{l}\text { University } \\
\text { of California, } \\
\text { Riverside }\end{array}$ & $\begin{array}{l}\text { Cuttings and core samples, obtained from the six wells drilled during the year } \\
\text {, } 1977 \text { were studied and interpreted to define the current temperatures in the } \\
\text { field (Elders et al., 1978). }\end{array}$ \\
\hline 18. & $\begin{array}{l}\text { understanding the sig- } \\
\text { nificance of radon in } \\
\text { yeotherma? reservoirs. }\end{array}$ & $\begin{array}{l}\text { Stanford } \\
\text { University }\end{array}$ & $\begin{array}{l}\text { The variation of radon associated with geothermal reservoir production has been } \\
\text { analyzed and interpreted for several reservoirs throughout the world (Kruger } \\
\text { et al., 1978). }\end{array}$ \\
\hline 19. & $\begin{array}{l}\text { Studies of the use of } \\
\text { tracers in geothermal } \\
\text { reservoirs }\end{array}$ & $\begin{array}{l}\text { Vetter } \\
\text { Research }\end{array}$ & $\begin{array}{l}\text { A program of literature review and laboratory evaluation of tracers suitable } \\
\text { for use in geothermal reservoirs has been initiated. }\end{array}$ \\
\hline 20. & $\begin{array}{l}\text { Study of Dasic formu- } \\
\text { lation of simulation } \\
\text { of geothermal reser- } \\
\text { voirs. }\end{array}$ & $\begin{array}{l}\text { Princeton } \\
\text { University }\end{array}$ & $\begin{array}{l}\text { Multiphase flow equations have been derived for a deformable porous medium. } \\
\text { Equations for heat and mass transfer in a fractured reservoir have also been } \\
\text { formulated. A computer code BIFEPS (Block Interactive Finite Element Pro- } \\
\text { cessed Scheme) has been developed to solve nonlinear transient problems with } \\
\text { one or two governing equations in two or three dimensions. (Pinder et al., 1978). }\end{array}$ \\
\hline 21. & $\begin{array}{l}\text { Studies of heat trans- } \\
\text { fer from rock to fluid }\end{array}$ & $\begin{array}{l}\text { Stanford } \\
\text { University }\end{array}$ & $\begin{array}{l}\text { Heat flow from rock to water has been studied as a function of a number of } \\
\text { parameters including the size of rock fragments (Kruger et a1., 1979). }\end{array}$ \\
\hline ¿2. & $\begin{array}{l}\text { Vapor pressure lower- } \\
\text { ing phenomena of geo- } \\
\text { thermal fluids }\end{array}$ & $\begin{array}{l}\text { Stanford } \\
\text { University }\end{array}$ & $\begin{array}{l}\text { The project demonstrated that vapor pressure may be lowered as a consequence } \\
\text { of a number of chemical and petrophysical parameters (Miller et al., 1979). } \\
\text { parameters (Miller et al., 1979). }\end{array}$ \\
\hline$\angle 3$. & $\begin{array}{l}\text { ADsolute permeability } \\
\text { of geothermal fluids }\end{array}$ & $\begin{array}{l}\text { Stanford } \\
\text { University }\end{array}$ & $\begin{array}{l}\text { The effects of temperature and chemical composition of the rock types on rela- } \\
\text { tive permeability has been investigated (Miller et al., 1978). }\end{array}$ \\
\hline
\end{tabular}

* Project coinpleted. 
It should also be noted that the Fifth Annual Stanford Geothermal Reservoir Engineering Workshop was held. This workshop is of special significance to GREMP. To some extent, it measures the existence and viability of a geothermal reservoir engineering professional working community and also reveals the extent to which students (tomorrow's geothermal reservoir engineers) are entering the community. These concerns are a part of the GREMP program, and judging from the workshop, it would be fair to say that the community is alive and well, and that an adequate number of students are entering the community.

Activities Planned for Fiscal Year 1980

Several changes are planned for the GREMP program in fiscal year 1980 . It is anticipated that primary responsibility for administering the program will begin a transfer to DOE/SAN. A major revision of the plans for GREMP is ecpected to take place. From a technical point of view the following activities are expected to receive emphasis, as budgets allow:

1. Evaluating the basic validity of computerized reservoir simulators and the effectiveness with which they can be applied to specific reservoirs (to be handled by DOE/SAN)

2. Evaluating techniques of measurement of twophase mass flow

3. Relating well cuttings and core to porosity and permeability.

In addition, of course, projects under contract should continue in force to their successful conclusion.

\section{REFERENCES CITED}

Cliff, W. C., Apley, W. J., and Creer, J. M., 1979. Evaluation of potential geothermal wellhead flow sampling and calorimetry methods. Berkeley, Lawrence Berkeley Laboratory, LBL-9248, GREMP-7.

Elders, W. A., Hoagland, J. R., Olson, E. R., McDowe11, S. D., and Collier, P., 1978. A comprehensive study of samples from geothermal reservoirs. Riverside, University of California, UCR/IGPP-78/26 (also LBL-9088, GREMP-4).

Harrison, Roger, and Randa11, Georgia, 1979. Annotated research bibliography for geothermal reservoir engineering. Berkeley, Lawrence Berkeley Laboratory, LBL-8664, GREMP 1 .

Kassoy, D. R., and Goyal, K. P., 1979. Modeling heat and mass transfer at the Mesa anomaly, Imperial Valley, California. Berkeley, Lawrence Berkeley Laboratory, LBL-8784, GREMP-3.

Lamers, Michael D., 1979. An appraisal of measurement methods for geothermal well system parameters. Berkeley, Lawrence Berkeley Laboratory, LBL-9090, GREMP-6.

Lawrence Berkeley Laboratory, Earth Sciences Division, 1977. Geothermal reservoir engineering management program plan (GREMP plan). Berkeley, Lawrence Berkeley Laboratory, LBL-7000, $135 \mathrm{p}$.

Lawrence Berkeley Laboratory, 1978. Earth Sciences Division annual report 1978 . Berkeley, Lawrence Berkeley Laboratory, LBL-8648, $251 \mathrm{p}$.

Pritchett, J. W., Rice, L. F., and Garg, S. K., 1978. Summary of reservoit engineering data: Wairakei geothermal field. Berkeley, Lawrence Berkeley Laboratory, LBL-8669, GREMP-2.

Vetter, O. J., 1979. Scale inhibitor tests at East Mesa. Berkeley, Lawrence Berkeley Laboratory, LBL-9089, GREMP-5.

\section{EVALUATION OF CITY WELL 1, KLAMATH FALLS, OREGON}

\section{S. M. Benson, C. B. Goranson, and R. C. Schroeder}

\section{ABSTRACT}

A city-wide geothermal space heating project is currently under development at Klamath Falls, Oregon. The first phase of the project will require two production we1ls. Geothermally heated water will be used to heat 14 city, county, state, and federal buildings. At peak load the heating system will require approximately $750 \mathrm{gpm}$ of $200^{\circ} \mathrm{F}$ (or greater) geothermal brine.

The first production well was spudded on August 29, 1979. During drilling a major lost circulation zone was encountered between 340 and $360 \mathrm{ft}$ depth. At this time the well was cleaned, reamed, cased to $300 \mathrm{ft}$, and then pump tested. The well was pumped for a total of $15-1 / 2 \mathrm{hr}$. A maximum flow rate of $680 \mathrm{gpm}$, with $77 \mathrm{ft}$ of drawdown, was held constant for 7-1/2 hr. Discharge temperature was approximately $218^{\circ} \mathrm{F}$.
Three observation wells were monitored to determine the impact of producing large quantities of brine on the many private geothermal wells already in use for space heating. Preliminary indications are that the water level decline in the area will be small ( 2 to $3 \mathrm{ft}$ ). However, further testing is recommended to determine the effects of reservoir heterogeneity on the water level decline.

\section{INTRODUCTION}

A city-wide geothermal space heating project is currently under development at Klamath Falls, Oregon. Phase I of the project involves drilling two production wells, constructing a pipeline to transport the geothermal brine, designing a heatexchanger system, and retrofitting 14 city, county, state, and federal buildings to use geothermally heated water. A flow rate of approximately 750 $\mathrm{gpm}$ of $200^{\circ} \mathrm{F}$ brine is required to meet the maximum heat load for Phase I of the project. 
The first of two production wells was spudded on August 21, 1979. The selection of the drill site was based on several factors: proximity to the most active thermal region, availability of land, and distance from the existing private geothermal wells already in use. As part of the overall resource delineation study, lithologic logs from roughly 40 wells have been collected and examined. From these, two likely production zones have been identified. The first is at a depth of $200 \mathrm{ft}$, and the second is at a depth of $750 \mathrm{ft}$. While drilling the first well, a lost circulation $z$ one was encountered between 340 and $360 \mathrm{ft}$. At this time, the well was reamed to $17-1 / 2$ in. A 12-in. casing was then set at $300 \mathrm{ft}$. The well was pump tested for a total of $15-1 / 2 \mathrm{hr}$.

The purpose of the pump-test was twofold. First, the flow rate, well drawdown, and the wel1head production temperature was measured to determine the feasibility of using this aquifier as the production zone for Phase I of the district heating project. It was also necessary to measure the impact of producing large quantities of fluid from this zone on the many private geothermal we11s in the area. If excessive drawdown of the surrounding wells took place, it would not be possible to use this aquifer as a producing zone for the project. A short term interference test $(8 \mathrm{hr})$ was run in conjunction with a productivity test to determine inter-well communication and, if possible, to predict the effect of sustained production on the surrounding wells. The results of the tests will be discussed here.

\section{WELL COMPLETION AND LITHOLOGY}

A summary of the drilling rate, lost circulation zones, and lithology for City Wel1-1 is shown in Table 1. As is typical of the wells in this area, a sequence of roughly $250 \mathrm{ft}$ of lacustrine and volcanic sediments overlie larger units of black, grey and "red" basalts. Several substantial lost circulation zones were encountered, one at about $195 \mathrm{ft}$ and a second at $350 \mathrm{ft}$. The first occurred in a brown shale, and the second in an altered reddish basalt previously identified as a potential producing aquifer. When the second zone was encountered, the well was reamed to 17-1/2 in. and a 12-in. casing was cemented from ground leve 1 down to $300 \mathrm{ft}$. From 300 to $360 \mathrm{ft}$ the well was left uncased.

\section{WELL TEST DESIGN}

The well test was designed with three primary objectives:

1. To determine if the shallow aquifier is suitable as a production zone for Phase I of the district heating program.

2. To obtain a more comprehensive model of the hydrogeology of the Klamath Falls KGRA (Known Geothermal Resource).

3. To assist in obtaining a data base to be used in establishing a resource management program.
To accomplish these objectives, a productivity test and a short term interference test were performed simultaneously. In this paper we will discuss the results of this test insofar, as they pertain to the development of the district heating project.

Several factors must be taken into account in determining if the shallow aquifer is a suitable production zone for Phase I of the district heating program. First, flowing wellhead temperatures must be greater than $200^{\circ} \mathrm{F}$ to satisfy the heat-exchanger design specifications. A flow rate of $350 \mathrm{gpm}$ with less than $250 \mathrm{ft}$ of drawdown in the well must be obtained (one-half the required total flow rate based on peak load demands.) Finally, there must be a negligible impact (both thermal and hydrologic) on the many private geo-thermal wells in use for space heating, domestic hot water, and industrial processing.

\section{PRODUCTION TEST RESULTS}

For the production test, City We11-1 was pumped for a total of $15-1 / 2 \mathrm{hr}$. Table 2 summarizes the pumping time, flow rate, flowing wellhead temperature, and drawdown. During the test, a maximum pumping rate of approximately $680 \mathrm{gpm}$ with $77 \mathrm{ft}$ of drawdown was held constant for $7-1 / 2 \mathrm{hr}$. Discharge temperatures measured at this time varied between 217 and $219^{\circ} \mathrm{F}$. The small drawdown at this rate far exceeded estimates for the shallow aquifer production capacity.

The water level in the pumped well was measured using an electric probe. The primary flow rate measuring device used was an orifice plate with a bourdon tube pressure gauge on the upstream side of the orifice. Because the brine flashed downstream of the orifice, the accuracy of the measured flow rate is poor. However, other methods were also used to estimate the flow rates, and those values were in close agreement with those obtained from the orifice measurement. The estimated flow rates are probably not accurate to better than $15 \%$ of the stated value. Higher flow rates could have been obtained with a deeper pump setting if the surface equipment (discharge pipe, pump platform, pump packing) had been more suitable (water well pumping equipment was used). Wellhead temperatures were measured continuously upstream from the orifice using an RTD probe. These values are believed to be accurate to $\pm 0.2^{\circ} \mathrm{F}$.

\section{INTERFERENCE TESTING}

Three observation wells were used to monitor the impact of pumping large volumes of fluid from City Wel1-1. Figure 1 shows the location of these wells. Two of the wells, the Head Well and the Adamcheck Well, are in an area where a large number of geothermal wells are currently in use. The monitor wells are completed in a similar manner and to similar depths as the many existing wells in this area. These monitor wells will most likely reflect the behavior in other existing wells.

In Figure 2 the well completion and well 1ithology are shown for each well. As shown in 
TABLE 1 QRILLING AND COMPLETION HISTORY OF CITY WELL

KLAMATH FALLS CITY WELL 1

SPUD DATE AND TIME - AUGUST 21, 1979, 1640 HOURS

COMPLETION DATE - SEPTEMBER 17, 1979

CASING RECORD - 300 FT OF 12 IN BLANK CASING

\begin{tabular}{|c|c|c|c|c|c|c|}
\hline $\begin{array}{l}\text { DEPTH- } \\
\text { FT }\end{array}$ & $\begin{array}{l}\text { DRILLING } \\
\text { RATE FT/HR }\end{array}$ & MUD $_{0}{ }_{C}^{T E M P}$ & $\begin{array}{l}\text { MUD L } \\
\text { WARM }\end{array}$ & $\begin{array}{l}\text { LOSSES } \\
\text { ENTRY }\end{array}$ & $\begin{array}{l}\text { LITHOLOGIC } \\
\text { COLUMN }\end{array}$ & SAMPLE DESCRIPTION--PRELIMINARY \\
\hline & & & & & & $0-2 \mathrm{FT}-\mathrm{TOD}$ SOIL \\
\hline 10 & 50 & $\cdots$ & & -- & & 2-20 FT - DIATOMITE, WHITE, SILICA FILLED \\
\hline 20 & 50 & -- & & - & & 20-47FT - DIATOMITE, WHITE \\
\hline 30 & 60 & 16 & & $-\infty$ & & 47-66 FT - DIATOMITE, SOME GREY SHALE \\
\hline 40 & 60 & 16 & & -- & & \\
\hline 50 & 50 & 17 & & -- & & \\
\hline 60 & 18 & 20 & & -- & & 66-93 FT - GREY SHALE AND CLAY \\
\hline 70 & 17 & 21 & & -- & & \\
\hline 80 & 17 & 23 & & -- & & \\
\hline 90 & 17 & 24 & & - & & 93-104 FT - BLACK SHALEE \\
\hline 100 & 17 & 26 & & -- & & \\
\hline 110 & 30 & 29 & & -- & & 104-116 FT - GREY SHALE \\
\hline 120 & 40 & 30 & & - & & \\
\hline 130 & 40 & 32 & & -- & & 116-147 FT - BROWN SHALE AND CLAY \\
\hline 140 & 40 & 34 & & -- & & \\
\hline 150 & 40 & 35 & & -- & & 147-152 FT - GREY SHALE AND CLAY \\
\hline 160 & 40 & 36 & - WARM & M WATER & & 152-160 FT - BROWN SHALE AND GREY TUFF \\
\hline 170 & 30 & 39 & ENTR & RY $160-17$ & OFT & 160-170 FT - GREY TUFF AND SHALE \\
\hline 180 & 25 & 37 & - WARM & M WATER & & \\
\hline 190 & 30 & 41 & ENTRY & २Y $178-185$ & & 170-198 FT - BROWN SHALE \\
\hline 195 & 20 & 40 & - SUBST & STANT I AL & & \\
\hline 200 & 20 & 29 & MUD L & LOSS-195 F & & 198-243 FT - BLUE AND GREY SHALE \\
\hline 210 & 20 & 29 & & & & \\
\hline 220 & 20 & 29 & $-\operatorname{LOSIN}$ & ING MUD & & \\
\hline 230 & 20 & 30 & $195-2$ & $-245 \mathrm{FT}$ & & $\begin{array}{l}\text { 243-253 FT - STREAN DEPOSIT OVERLYING BLAC } \\
\text { BASALT, CONSIDERABLE 'BLUE' }\end{array}$ \\
\hline 240 & 5 & 31 & & & & QUJARTZ VEINING \\
\hline 250 & 3 & 31 & - LOST & CIRCULATI & & 253-276 FT - GREY EASALT-SOFT \\
\hline 260 & 3 & 31 & AT 24 & $248 \mathrm{FT}$ & & \\
\hline 265 & 10 & 31 & & & & 276-279 FT - GREY BASALT-HARD \\
\hline 270 & 10 & 32 & - CONTI & IINUOUS & & \\
\hline 280 & 15 & 36 & SLOW & $\checkmark$ LOSS CF $M$ & & 279-235 FT - R:EDDISH1 BRO!IN BASALT \\
\hline 285 & 5 & 35 & - LOST & CIRCULATI & & . \\
\hline 290 & 3 & 39 & $292-2$ & $-298 \mathrm{FT}$ & & 285-341 FT - HARD GREY BASALT AND CLAY \\
\hline 300 & 2 & 37 & $-\operatorname{LOSIN}$ & ING MUD & & \\
\hline 310 & 3 & & & & & \\
\hline 320 & 3 & & & & & \\
\hline 330 & 3 & & & & & \\
\hline 340 & 2 & $\begin{array}{l}\text { MUD TEMP } \\
\text { INCREASING }\end{array}$ & $\begin{array}{r}-\operatorname{LOSIN} \\
340^{-}\end{array}$ & $\begin{array}{l}\text { NG MUD } \\
-360 \mathrm{FT}\end{array}$ & & $341 \mathrm{FT}$ - END OF HARD BASALT \\
\hline 350 & 20 & & & & & 341-360 FT - RED BASALT \\
\hline 360 & 20 & & & & & \\
\hline
\end{tabular}


TABLE 2 SUMMARY OF PRODUCTION TEST (CITY WELL 1 )

\begin{tabular}{|cc|c|c|c|c|}
\hline \multicolumn{1}{|c|}{ TIME } & FLOWRATE & TEMPERATURE & $\begin{array}{c}\text { PUMPING } \\
\text { LEVEL }\end{array}$ & DRAWDOWN \\
\hline 5 & $\mathrm{HRS}$ & $260 \mathrm{GPM}$ & $212^{\circ} \mathrm{F}$ & $11 \mathrm{FT}$ & $35 \mathrm{FT}$ \\
$2 \mathrm{HRS}$ & $480 \mathrm{GPM}$ & $215^{\circ} \mathrm{F}$ & $115 \mathrm{FT}$ & $39 \mathrm{FT}$ \\
1 & HRS & $550 \mathrm{GPM}$ & $217^{\circ} \mathrm{F}$ & $125 \mathrm{FT}$ & $49 \mathrm{FT}$ \\
$7.5 \mathrm{HRS}$ & $680 \mathrm{GPM}$ & $217-219^{\circ} \mathrm{F}$ & $153 \mathrm{FT}$ & $77 \mathrm{FT}$ \\
\hline
\end{tabular}

STATIC WATER LEVEL

$\sim 76 \mathrm{FT}$

WELL DEPTH

$\sim 360 \mathrm{FT}$

CASING SIZE

12 IN

OPEN INTERVAL

$300-350 \mathrm{FT}$

PUMP SETTING

200 FT $(5$ IN. COLUMN,

8 IN. BOWLS)

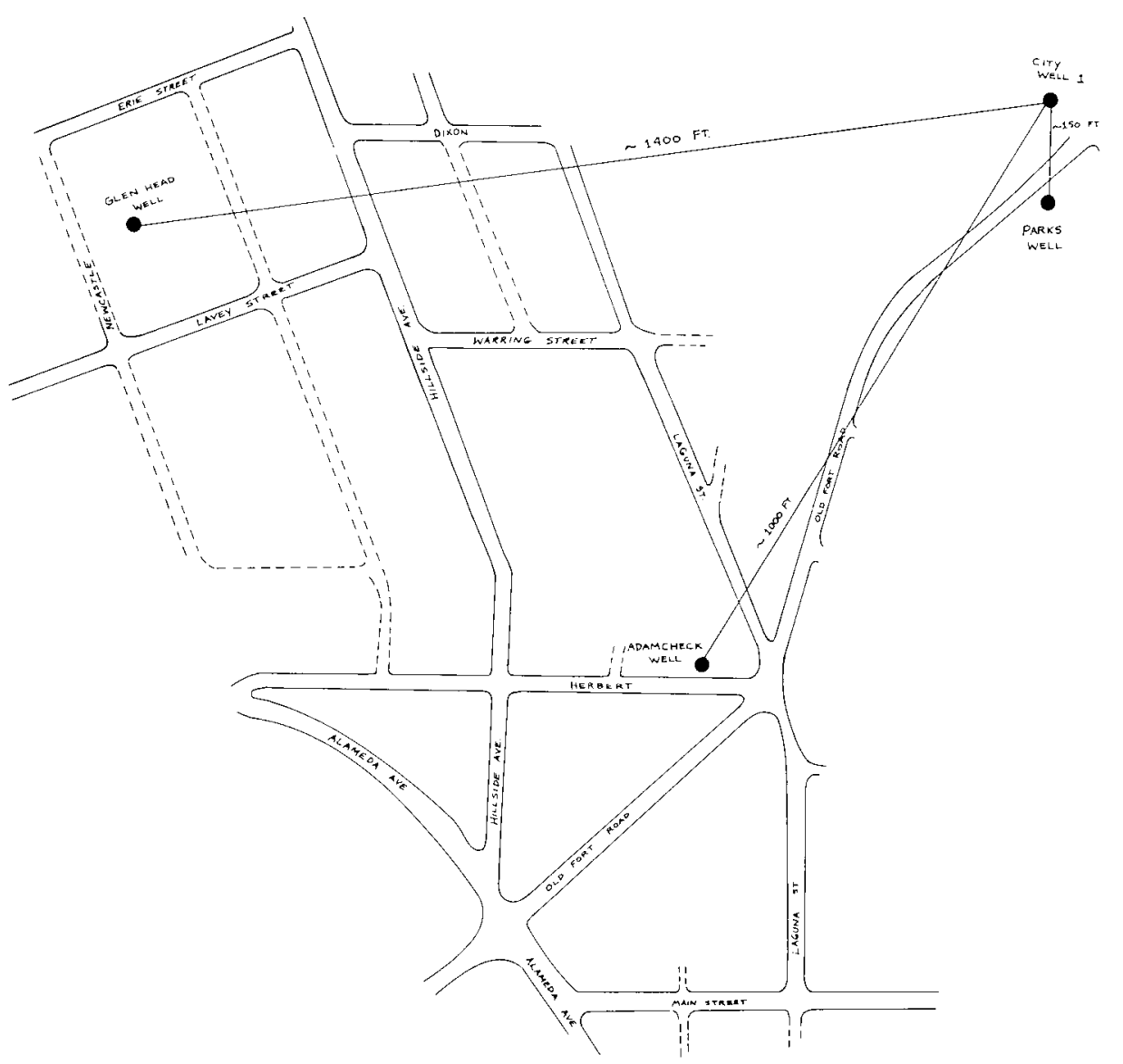

Figure 1. Locations of monitor wells and City We11-1.

(XBL 802-8113) 


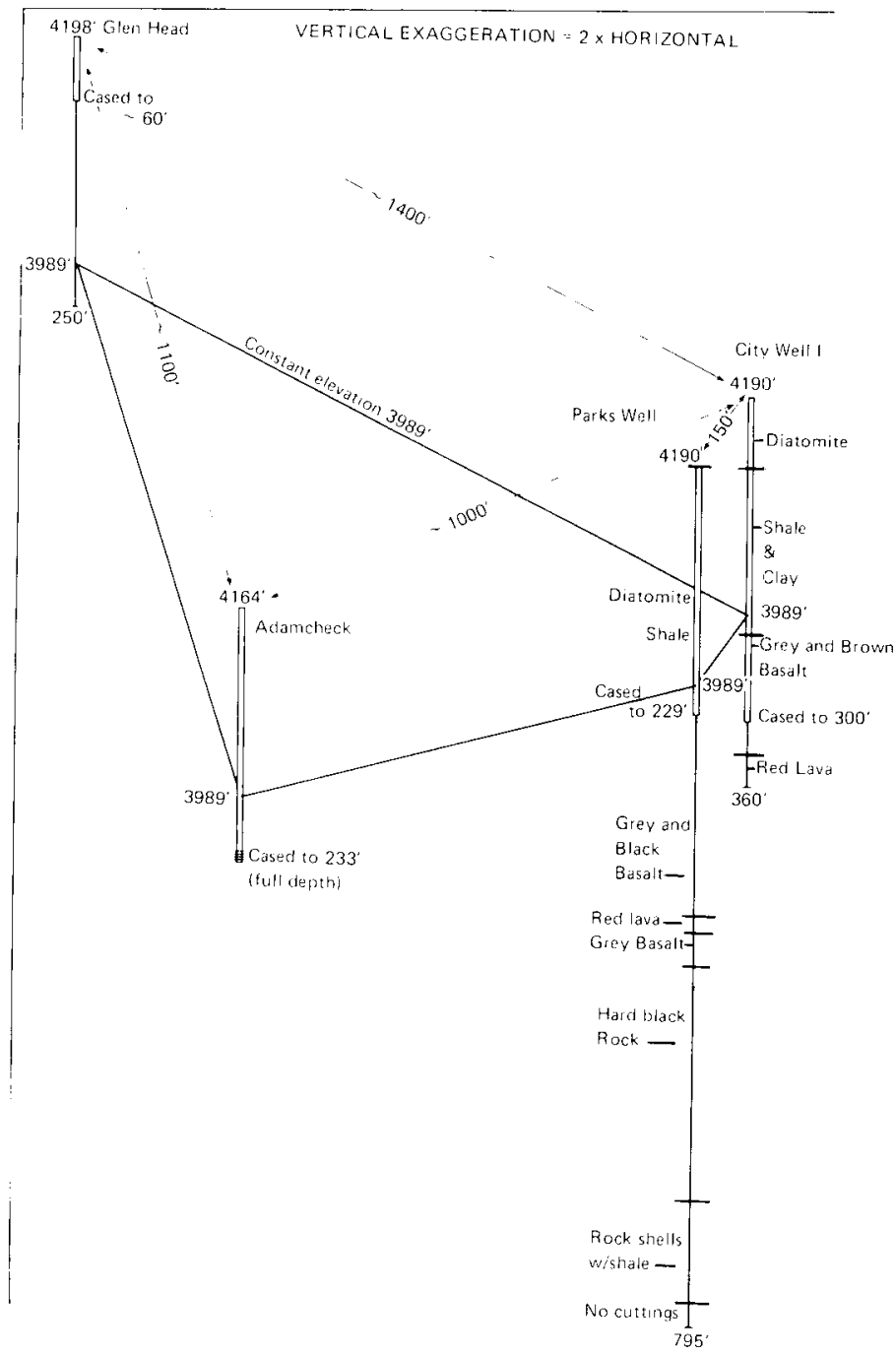

Figure 2. Fence diagram of monitor wells and City We11-1.

(XBL 801-6744)

the figure, two of the wells, Head and Adamcheck, are shallower than the city well. The lithologic logs from these wells are not available at this time. Well logs from several surrounding wells indicate that these two wells penetrate approximately $200 \mathrm{ft}$ of lacustrine sediments, which are underlain by a highly permeable volcanic tuff or pumice. It is doubtful that these wells penetrate the red basalt strata, which is the production zone for the city well. The difficulties encountered in correlating individual strata from one well to another indicate complex faulting in the area (or lake bed sediments deposited in a tectonically active area). The Parks Well is open to the same reservoir interval as the city well. However, correlation on individual strata between the two wells is not obvious.

\section{INTERFERENCE MONITORING EQUIPMENT}

Water levels in the Adamcheck Well and the Head Well were monitored using Leopold-Stevens continuous-recording water level devices. Changes in water level of $1 / 2$ in. can be easily resolved. Background data were obtained from these wells for several months before the test. At the onset of the cold season in September, a decline of the water levels took place at a similar rate in all of the monitor wells. The water level was dropping at a rate of approximately $3 \mathrm{ft} / \mathrm{mo}$. when the pump test began. Figure 3 shows the water level data obtained during the interference test.

Water level changes in the Parks Well were measured using a downhole Paro-Scientific pressure transducer. The transducer measures changes of water level by measuring the weight of the column of water above it. The instrument has a resolution of approximately 0.01 psi (better than $1 / 2$ in.). Pressure data are recorded automatically at specified time intervals ranging from $1 \mathrm{sec}$ to $2 \mathrm{hr}$. For this test, data points were recorded at $10-\mathrm{sec}$ intervals each time the pump was turned on or off and at 2-min intervals when water level changes occurred less rapidly. Table 3 summarizes the instrumentation and the location of the wells used in the test. Figure 4 shows the data obtained from the Parks Well during the interference test.

\section{INTERFERENCE TEST ANALYSIS}

The rapid drop in water levels at the onset of production from City Well-l indicates a high degree of hydrologic reservoir continuity. Response time at the Parks Well (150 ft) was less than $10 \mathrm{sec}$ after the pump was turned on. At the other two observation wells, response time was short but difficult to measure because of the non-digital time display. Interference tests can be used to determine the reservoir parameters that control reservoir drawdown. Together with an accurate hydrogeologic model of the reservoir, these parameters can be combined to predict how the system will respond to pumping (and/or injection) with any arbitrary flow rate schedule and well configuration.

Interference test data are usually analyzed using a simplified reservoir model. The model assumed in this analysis was that on which the Theis solution is based. This model assumes the production well fully penetrates an isothermal, isotropic, homogeneous, porous medium of infinite

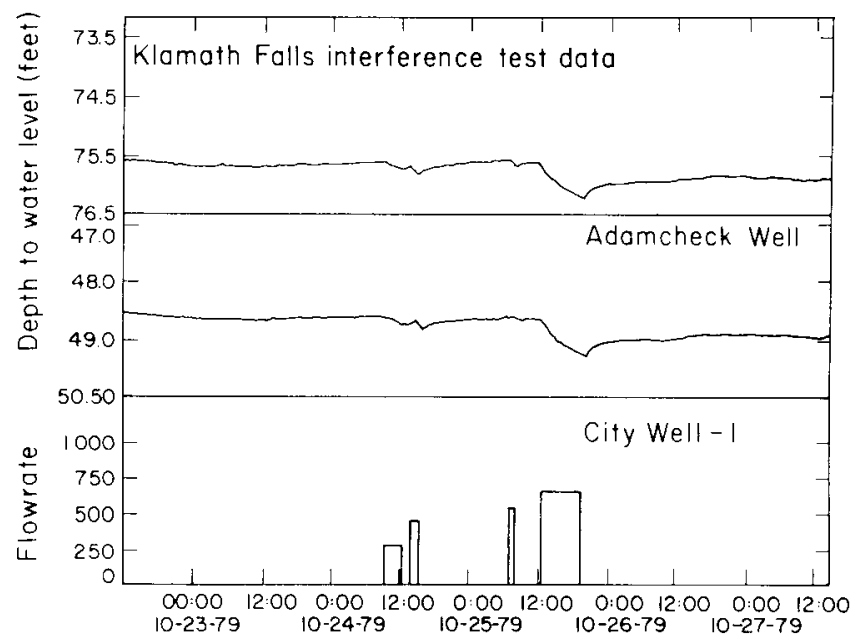

Figure 3. Interference test data from the Head Well and the Adamcheck Well. 


\begin{tabular}{|c|c|c|c|c|c|}
\hline WELL & LOCATION & $\begin{array}{l}\text { DISTANCE TO } \\
\text { CITY WELL } 1\end{array}$ & INSTRUMENTATION & $\begin{array}{l}\text { DRAWDOWN } \\
71 / 2 \mathrm{HR} \\
680 \text { GPM }\end{array}$ & $\begin{array}{l}\text { AFTER } \\
\text { S }\end{array}$ \\
\hline PARKS & OLD FORT RD. & $180 \mathrm{FT}$ & $\begin{array}{l}\text { DOWNHOLE PRESSURE } \\
\text { TRANSDUCER }\end{array}$ & 1.2 & FT \\
\hline $\begin{array}{l}\text { ADAM- } \\
\text { CHECK }\end{array}$ & $\begin{array}{l}\text { HERBERT } \varepsilon \\
\text { LAGUNA ST. }\end{array}$ & $1000 \mathrm{FT}$ & $\begin{array}{l}\text { CONT INUOUS } \\
\text { WATER LEVEL } \\
\text { RECORDER }\end{array}$ & 7 & IN \\
\hline HEAD & NEWCASTLE & $1420 \mathrm{FT}$ & $\begin{array}{l}\text { CONT INUDUS } \\
\text { WATER LEVEL } \\
\text { RECORDER }\end{array}$ & 7 & IN \\
\hline
\end{tabular}

areal extent and constant thickness. The data from the Adamcheck Well and the Head Well are shown matched to the Theis curve in Figures 5 and 6 respectively. The match of the data is acceptable for these small measured drawdowns. The transmissivity values calculated range from $1.4 \times 10^{7}$ to $1.5 \times 10^{7} \mathrm{md}-\mathrm{ft} / \mathrm{cp}$ and the storativity values range from $2.4 \times 10^{-3}$ to $7.8 \times 10^{-3} \mathrm{ft} / \mathrm{psi}$. The data begin departing from the Theis curve toward the end of the test, indicating that some sort of hydrologic boundary or reservoir heterogeneity may be affecting the reservoir response. Another explanation for the departure from the Theis curve is that the reservoir water level trend recorded before the test is affecting the drawdown.

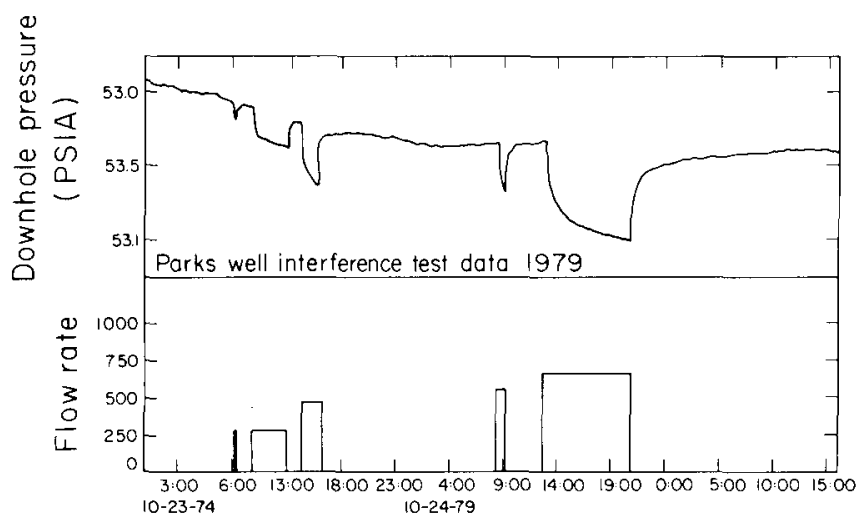

Figure 4. Interference data from Parks Well. (XBL 801-132)
A nonlinear least-squares matching program developed at LBL was then used to determine if an impermeable reservoir boundary was affecting the drawdown at the observation wells. The program uses the method of images to locate reservoir boundaries. The matches obtained from the computer analysis are shown in Figures 7,8 , and 9. Two of the wells, the Adancheck Well and the Parks We11, suggest that an impermeable boundary may be affecting the data. The location of this boundary, however, is nonunique. A longer test with a constant background pressure is necessary to determine both the existence and location of a boundary. Table 4 summarizes the results obtained from the computer analysis.

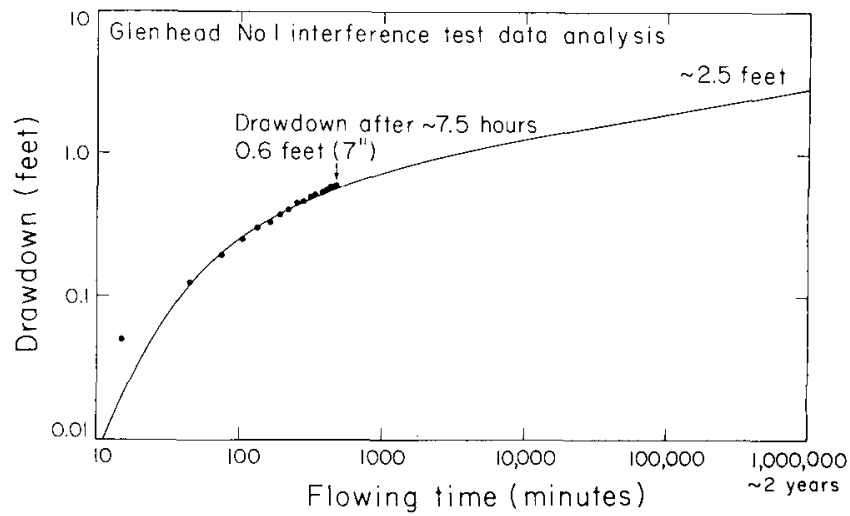

Figure 5. Theis curve match of interference test data from the Head Well.

(XBL 801-134) 


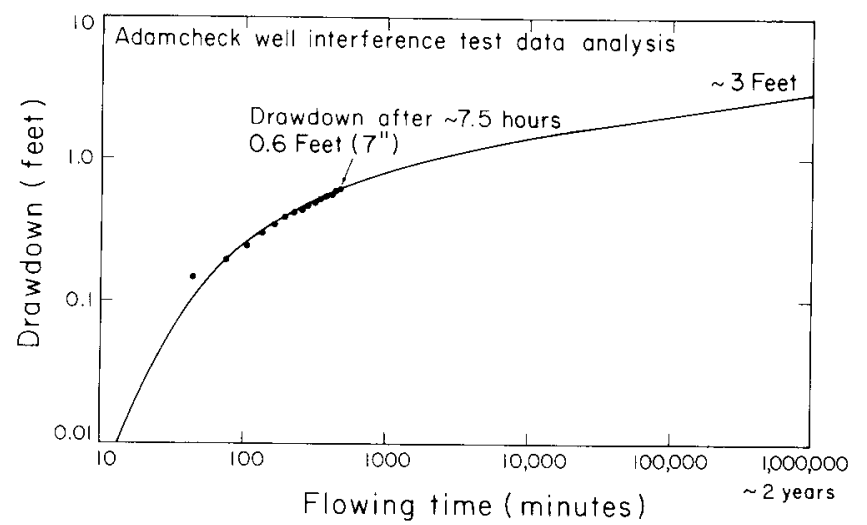

Figure 6. Theis curve match of the Adamcheck well interference data.

(XBL 801-133)

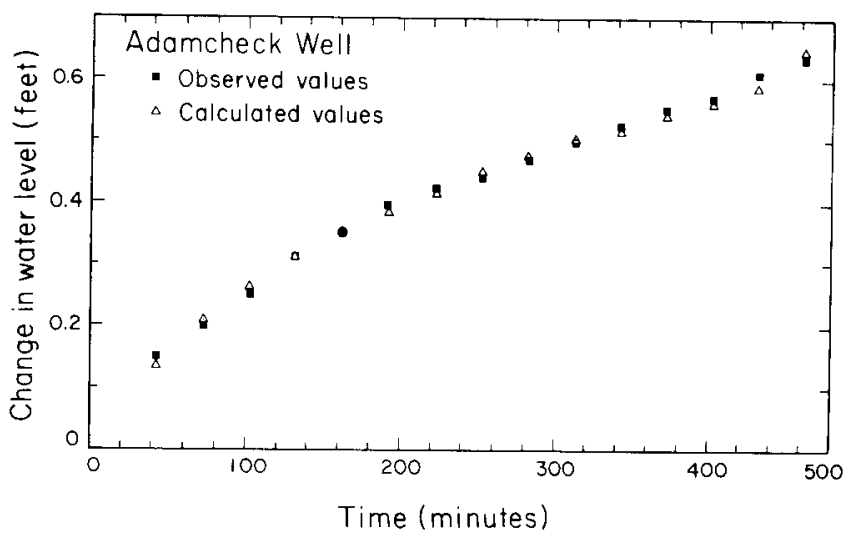

Figure 7. Computer match of the Adamcheck Well interference data.

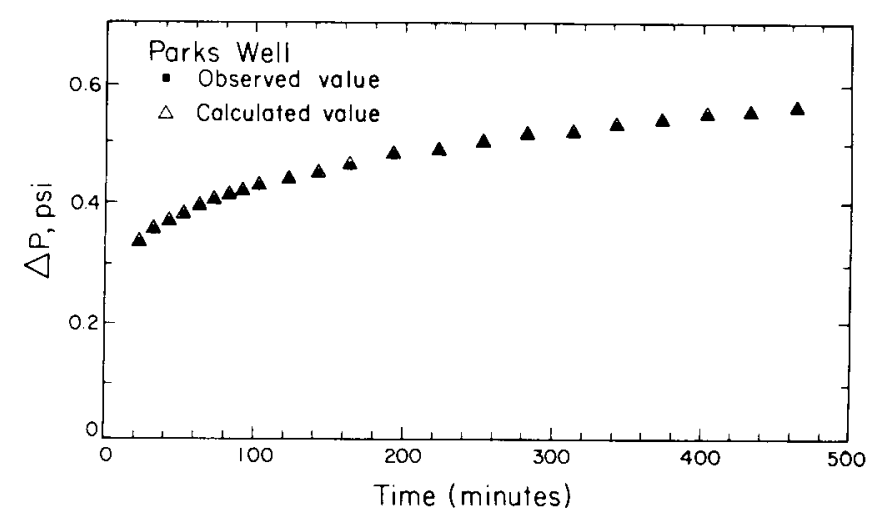

Figure 8. Computer match of the Parks Well interference test data.

(XBL 801-137)

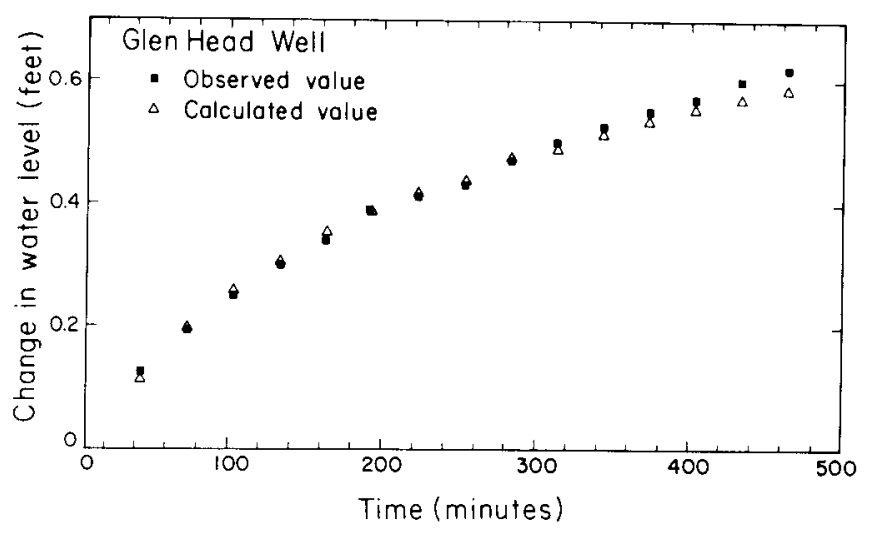

Figure 9. Computer match of the Head Well interference test data.

(XBL 801-136)

TABLE 4 COMPUTER MATCH OF WELL DATA

\begin{tabular}{|c|c|c|c|c|}
\hline WELL & $\begin{array}{l}\text { DISTANCE TO } \\
\text { CITY WELL-1 }\end{array}$ & $\begin{array}{c}\mathrm{KH} / \mu \\
(M D \cdot F T / C P)\end{array}$ & $\begin{array}{l}\phi \mathrm{CH} \\
(\mathrm{FT} / \mathrm{PSI})\end{array}$ & $\begin{array}{l}\text { DISTANCE TO } \\
\text { BOUNDARY }\end{array}$ \\
\hline ADAMCHECK & $1000 \mathrm{FT}$ & $2.6 \cdot 10^{7}$ & $1.1 \cdot 10^{-3}$ & 2280 \\
\hline GLEN HEAD & $1400 \mathrm{FT}$ & $1.7 \cdot 10^{7}$ & $1.4 \cdot 10^{-3}$ & \\
\hline PARKS & $200 \mathrm{FT}$ & $3.3 \cdot 10^{7}$ & $9.1 \cdot 10^{-4}$ & 4300 \\
\hline
\end{tabular}


Figure 10 shows a $\log \Delta S$ vs $\log t / r^{2}$ plot for all of the observation wells. If the reservoir model discussed above was accurate, the data should plot as one curve. The discrepancy could be caused by any of several factors: reservoir heterogeneity, fractures, reservoir boundaries, partial penetration, dual porosity and so on. To accurately discern the cause of the discrepancy, an interference test of longer duration would be necessary.

The values obtained from the analysis indicate that the shallow reservoir permeability is very high. Assuming an aquifer thickness of $40 \mathrm{ft}$, and a viscosity value of $0.3 \mathrm{cp}\left(220^{\circ} \mathrm{F}\right.$ water $)$, the calculated permeability value is approximately 100 darcies. The porosity value extracted from the storativity value $(\phi \mathrm{cH})$ using a compressibility of $5 \times 10^{-5} \mathrm{psi}^{-1}$ is approximately 0.5 . This is anomalously high, indicating that the values used for the compressibility and reservoir thickness are uncertain.

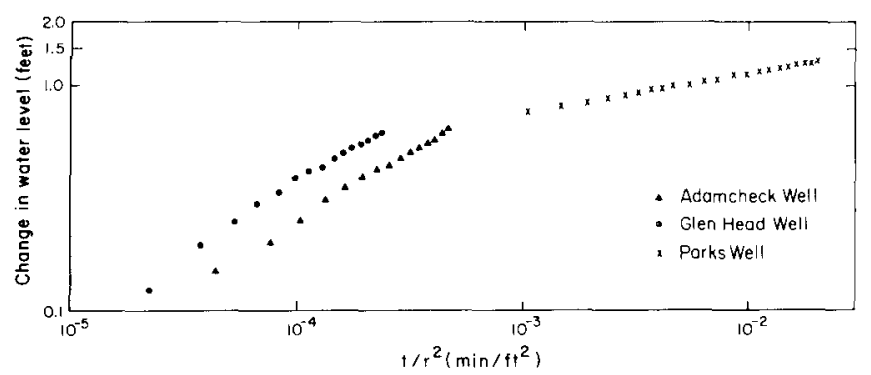

Figure 10. Log $\Delta s$ vs $\log \left(\Delta t / r^{2}\right)$ plot of the interference test data. (XBL 801-6747)

\section{CONCLUSIONS}

The tests of the Klamath City We11 非 1 show that the shallow test aquifer is capable of sustained production of at least $680 \mathrm{gpm}$ at a temperature of about $218^{\circ} \mathrm{F}$. Rapid water level changes in the surrounding wells indicate a high degree of hydrodynamic reservoir continuity through several distinct lighologic units. This would indicate that a fracture network may be controlling fluid movement in the reservoir. Calculated transmissivity values from the interference test indicate a permeability of approximately 100 darcies. When the pressure behavior over the 8-hr interference test are extrapolated to several years, drawdowns of 2 to $3 \mathrm{ft}$ are predicted at a sustained production rate of $680 \mathrm{gpm}$. However, the data show a departure from the Theis curve match near the end of the test interval. This departure could imply greater drawdowns than predicted by these tests. At present no unique explanation $c$ an be given to account for this departure. To accurately predict the effects of sustained production over the lifetime of this project a longer test must be conducted to determine the effects of reservoir heterogeneity on the water level decline in sur-rounding wells. Present indications, from reservoir testing at the Klamath Falls, are that this system has a very promising potential for development of a largescale district heating project.

\section{ACKNOWLEDGEMENTS}

We would like to thank G. Parks, G. Head, C. Adamscheck, and T. Fillmore for allowing us to use their wells in previous and subsequent reservoir tests at Klamath Falls. We also thank John Lund, Paul Lienau, and Gene Culver from Oregon Institute of Technology Geo-Heat Utilization Center for their help in obtaining information on the Klamath Falls resource. Finally, we would like to thank Harold Derrah, Assistant City Manager of Klamath Falls, for his patience and help.

\title{
EVALUATION OF THE SUSANVILLE, CALIFORNIA, GEOTHERMAL RESOURCE, 1979
}

\author{
S. M. Benson, C. B. Goranson, J. P. Haney, and R. C. Schroeder
}

\section{INTRODUCTION}

The Susanville geothermal anomaly is located in northeast California. The presence of several shallow hot-water wells and a natural hot spring initially identified in this area as a prospective candidate for the development of geothermal energy. Increased fossil fuel cost and the high price of transporting liquified natural gas to the area stimulated interest in developing the resource for a city-wide space-heating program. Since late 1978 , the U.S. Bureau of Reclamation and Lawrence Berkeley Laboratory's Earth Sciences Division have collaborated on a geothermal resource evaluation project at Susanville, California. As part of this project, 12 exploratory temperature gradient holes were drilled, subsurface geologic and geophysical data were analyzed, and a well test was conducted.

The town of Susanville lies at the intersection of three major geologic regimes, the Sierra Nevada Range to the southwest, the Modoc Plateau to the northwest, and the Basin and Range Province which extends into Nevada (Rudser, 1978; U.S. Bureau of Reclamation, 1976a,b,c). Subsurface geology is characterized by interbedded basalt flow, agglomerates, and alluvial conglomerates. Subsurface and surface geologic structure indicate extensive block faulting, with the dominant trend in a northwesterly direction. Subsurface temperature contours indicate the occurrence of the geothermal anomaly is fault related. 


\section{WELLS IN THE CITY OF SUSANVILLE}

Six geothermal wells had been drilled in Susanville before the $1970 \mathrm{~s}$. These wells had been used for heating a greenhouse, space heating, and heating a swimming pool. Because these wells (Naef we11, LDS Church we11, Roosevelt Swimming Pool, and Davis well) were drilled long ago little detailed information on well lithology, temperature, completion, and total depth is available.

The U.S. Bureau of Reclamation has drilled 12 exploratory wells and five shallow temperature gradient holes. The locations of the twelve exploratory wells are shown in Figure 1. Well sites were chosen in an attempt to define the areal extent of the geothermal anomaly. Depths of the well ranged from 135 to $640 \mathrm{~m}$. Well diameters were 6 in. and were completed with a 2-in. sealed casing. Two of the wells, Suzy-4 and Suzy-6, were completed with 4-in. and 6-in. casings, respectively. The total depths, casing size, and completion schedule are shown in Figures 2 and 3 .

Detailed interpretation of the formation lithology and geophysical bore logs have been completed. Several distinct units, probably offset by faults, have been identified. All of the wells, however, penetrated a sequence of basalt, mud-flow and ashflow agglomerates. Several of the wells on the southern portion of the anomaly penetrate alluvial conglomerates. The contact zones between the basalt layers and the conglomerates have been identified as the major geothermal production zones. The agglomerate and the conglomerates may also contribute to the geothermal production.

\section{TEMPERATURE DISTRIBUTION}

Temperature profiles obtained from the wells are shown in Figures 4, 5, and 6 . Several of the wells in the southwest portion of the anomaly dis-

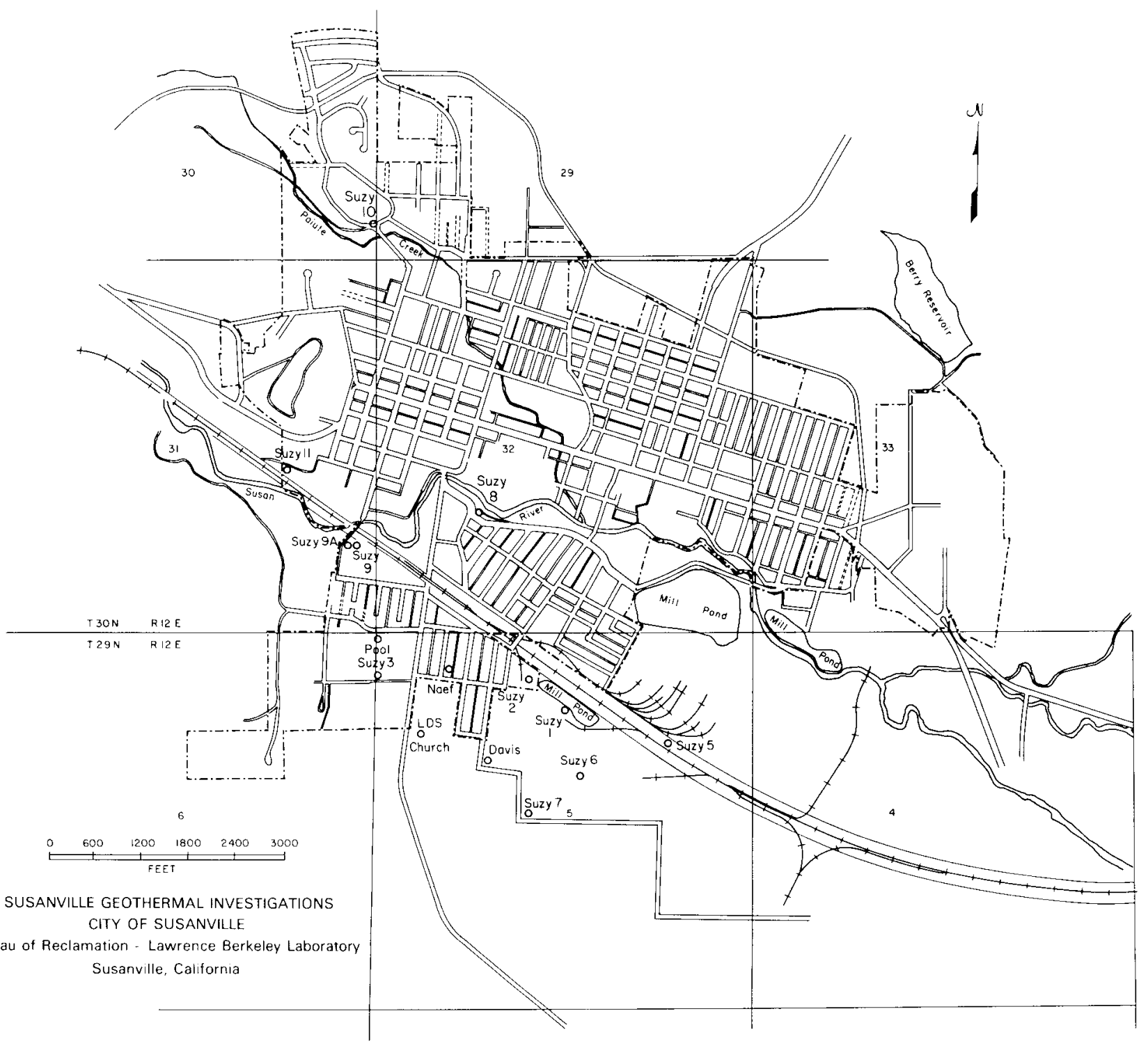

Figure 1. Geothermal well locations in Susanville, California. (XBL 801-6767) 


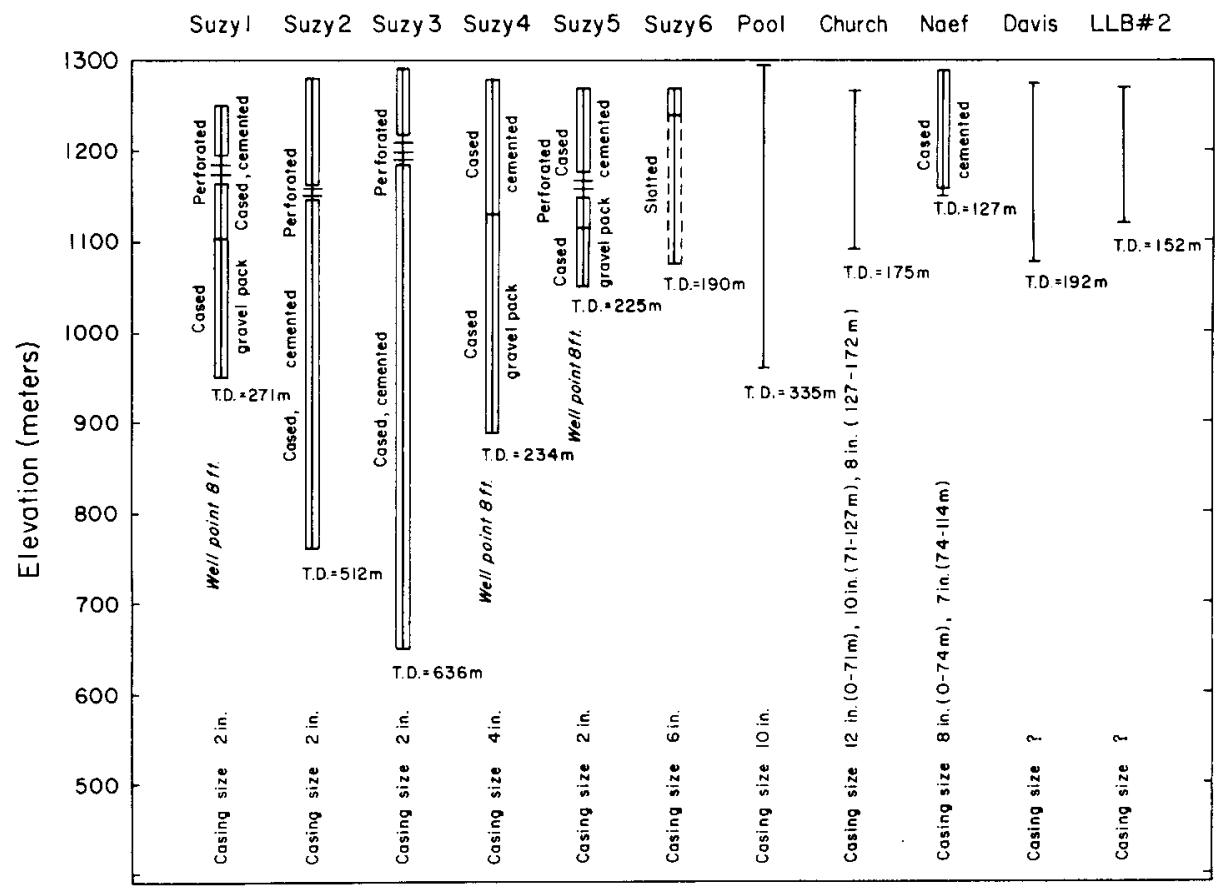

Figure 2. Completion record of the wells in Susanville, California.

(XBL 795-7442)

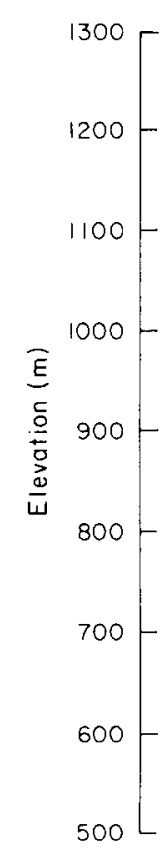

Suzy7 Suzy 8 Suzy 9 Suzy9a Suzy 10 Suzy 11
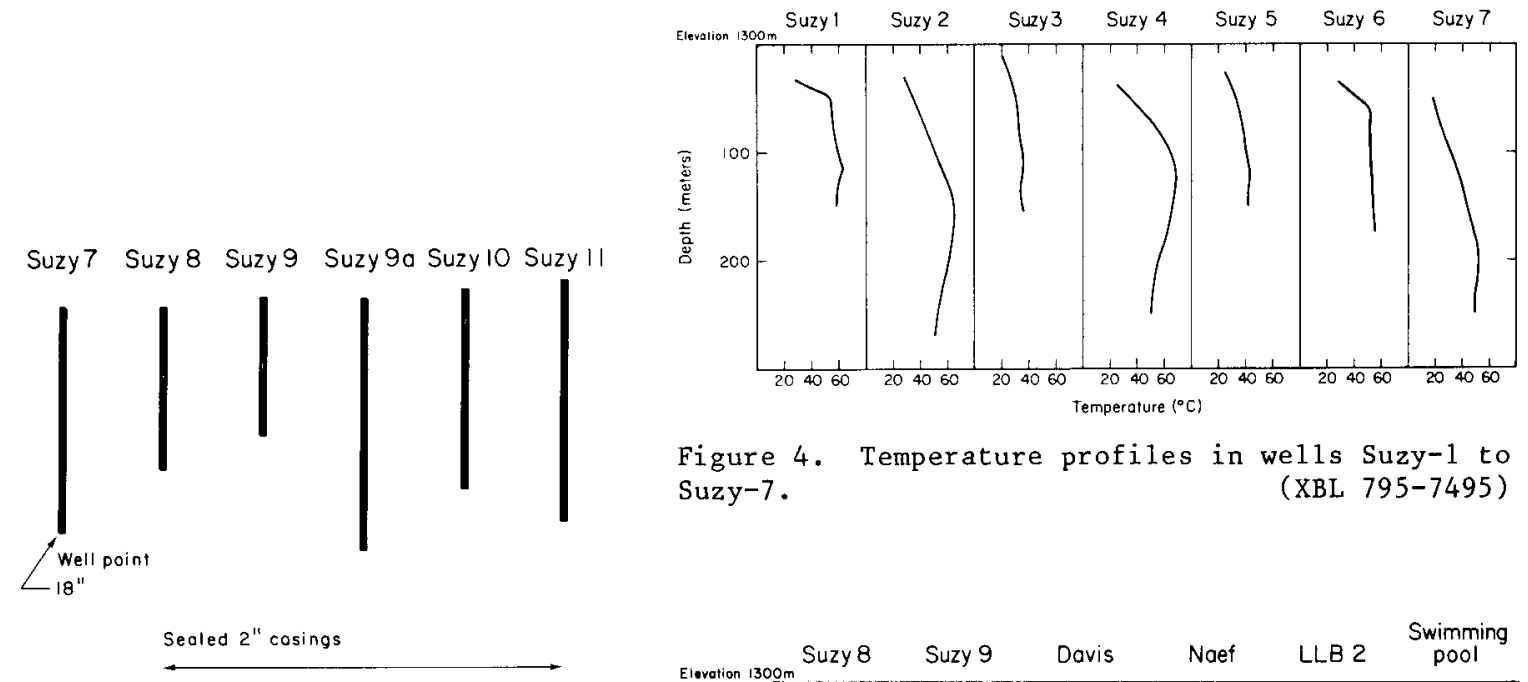

Figure 4. Temperature profiles in wells Suzy-1 to Suzy-7.

(XBL 795-7495)

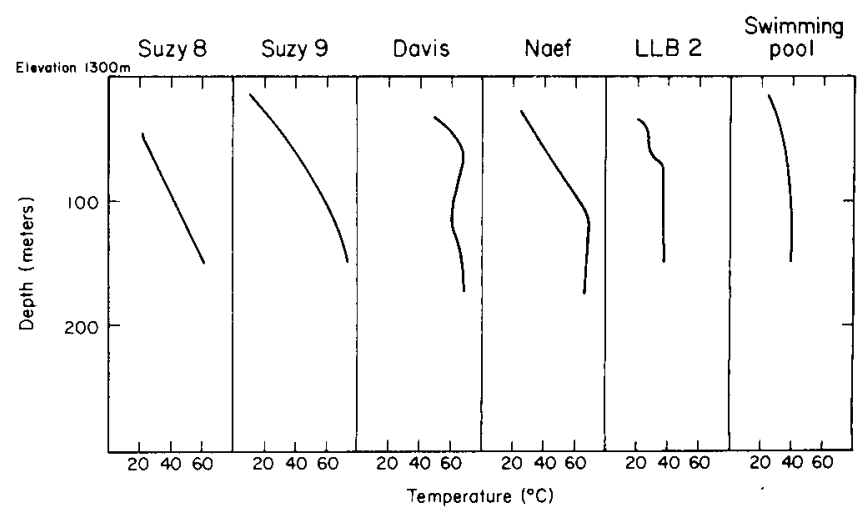

Figure 3. We1l completions of Suzy-7 through Suzy11 , Susanville, California.

(XBL 7912-13485)

Figure 5. Temperature profiles for wells Suzy-8, Suzy-9 and several older wells in Susanville, California. (XBL 795-7496) 


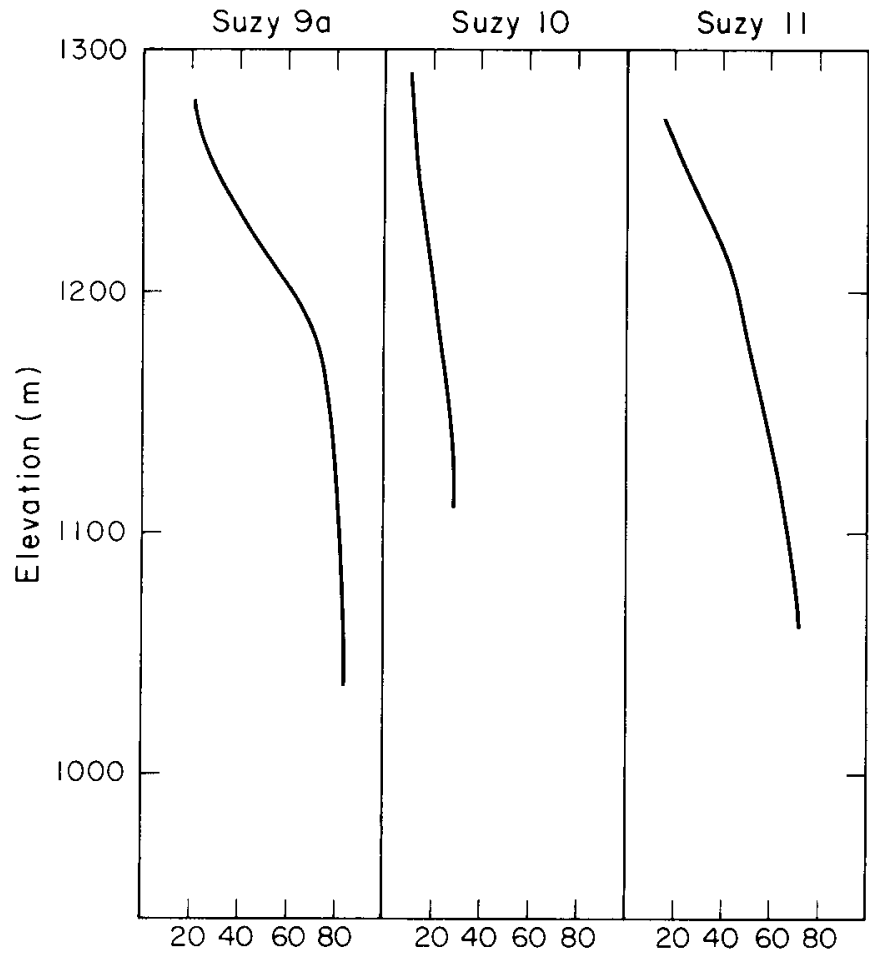

Figure 6. Temperature profiles for Suzy-9a through Suzy-11.

(XBL 7912-13486) play temperature reversals with depth. The temperature reversals take place at depths between 100 and $150 \mathrm{~m}$. The reversals nearly coincide with the contact zones between the basalt and the conglomerate, which is further evidence that the producing aquifer(s) occur at the contact zones in those wells. Maximum temperatures range from $35^{\circ} \mathrm{C}$ to $70^{\circ} \mathrm{C}$. The hottest wells are Suzy-9 and Suzy-9a. No temperature reversals take place, indicating the possibility of higher temperatures with depth. However, the productivity of this section of the reservoir is unknown. Further testing in this area will indicate the productivity of these highertemperature zones.

Temperature contours at $50 \mathrm{~m}$ (1250-m elevation) and $100 \mathrm{~m}$ (1200-m elevation) are shown in Figures 7 and 8 . The contours are asymmetrically shaped around a northwest-trending axis. The anomaly is sharply bounded to the west, indicating a hydrologic or geologic discontinuity (e.g., a fault or fracture zone). To the south, east, and north, the thermal anomaly gradually abates. Analysis of cores and geophysical data suggests cooler groundwater from saturated strata are mixing with geothermal fluids in these areas. The asymmetrically shaped thermal anomaly and the noticeable temperature reversals in the southern portion of the field suggest heated fluids are upwelling along a northwest-trending fault. They are then dispersed into the reservoir along the most permeable strata. In the southern portion of the anomaly, the basaltconglomerate interface appears to be the most permeable.

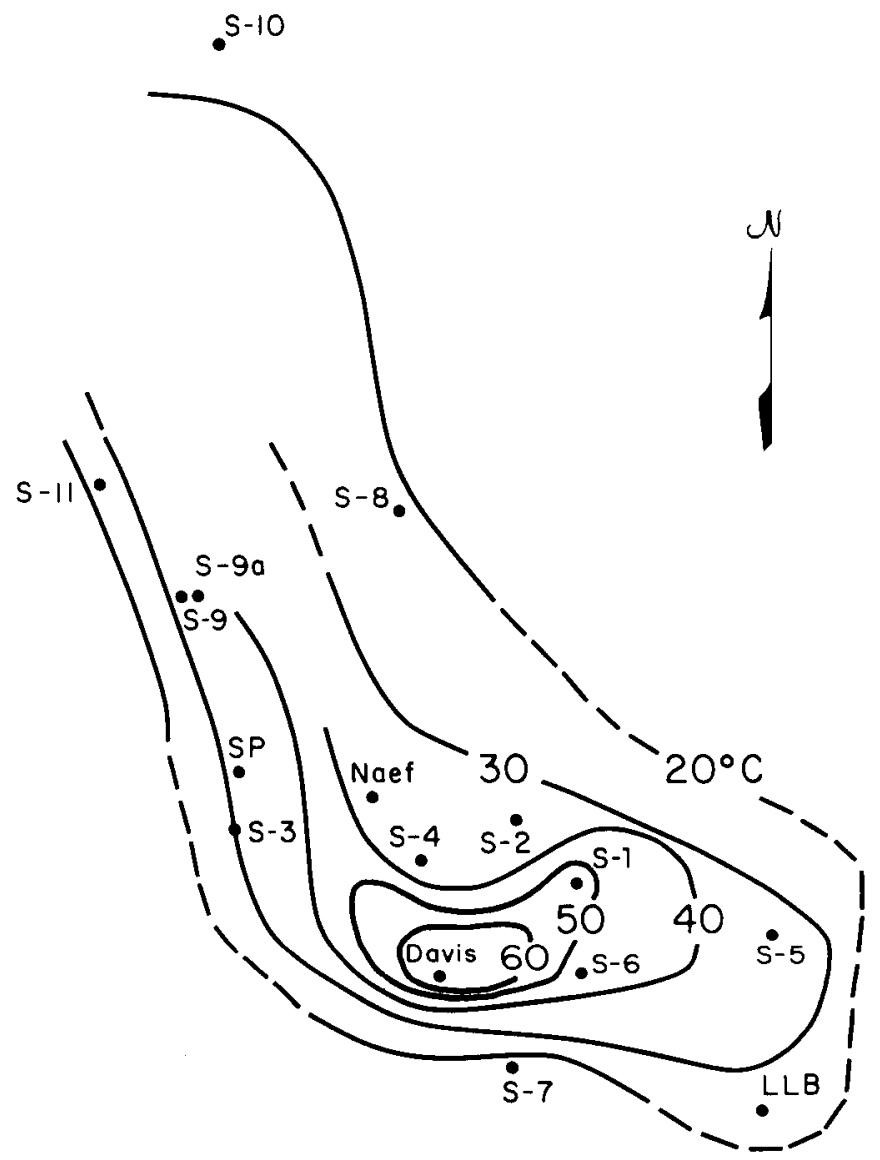

Figure 7. Temperature contours at $50 \mathrm{~m}$ below ground level. 
$5-10$

$20^{\circ}$

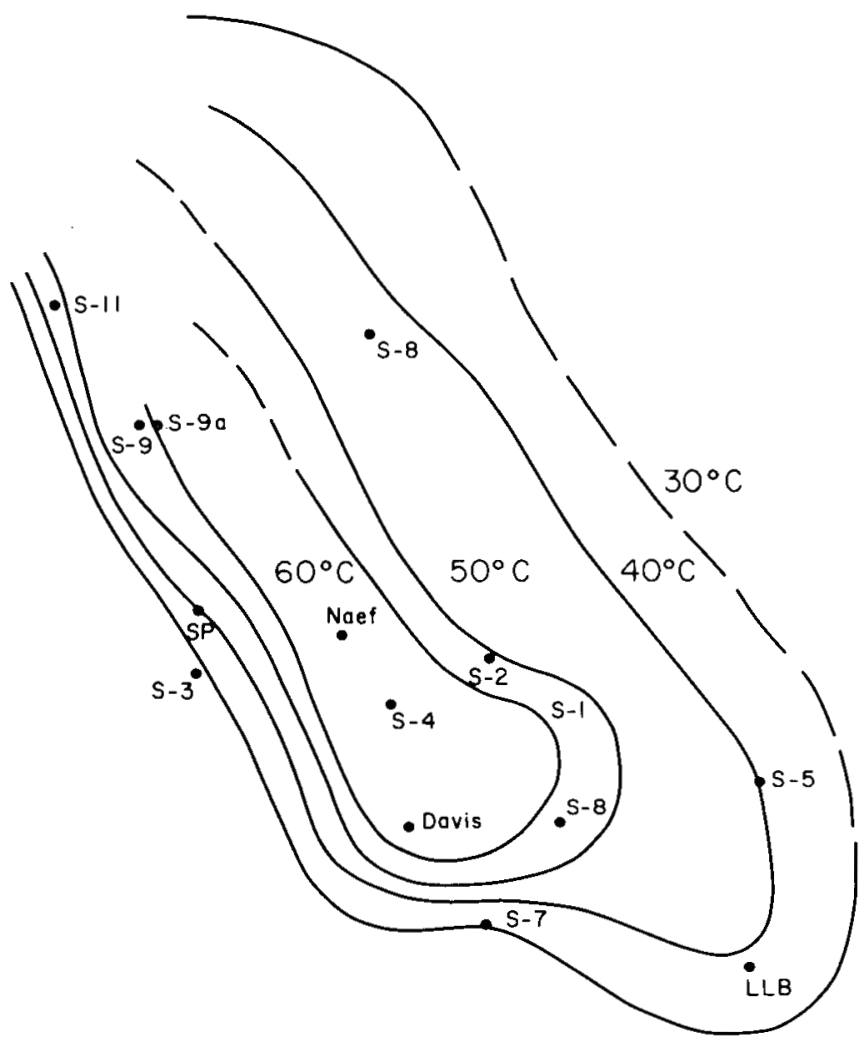

Figure 8. Temperature profiles at $100 \mathrm{~m}$ below ground level.

(XBL 7912-13487)

\section{RESERVOIR TESTING}

A well test was conducted by LBL in December 1978 and January 1979. During this test two wells were pumped, the Davis well and the Roosevelt swimming pool well. Water level changes in eight observation wells and one production well were monitored. Table 1 summarizes the instrumentation and wells used. The test consisted of four segments. The first segment consisted of obtaining background data before pumping the Davis well. However, due to the extremely cold weather the LDS Church well was produced for space heating. To avoid or minimize any transients associated with the church well flow, the rate was held constant at approximately $90 \mathrm{gpm}$ throughout the background data collection period and the subsequent pumping of the Davis well. The second segment of the test consisted of pumping the Davis well at a rate of $250 \mathrm{gpm}$ for a period of 9 days. The well was then shut in and the build-up was observed. Several days after the Davis well was shut in, the LDS Church we11 was shut in for $12 \mathrm{hr}$, then pumped again for several days; shut in for $12 \mathrm{hr}$ and then pumped continuously for the duration of the test. During the last segment of the test the Roosevelt swimming pool well was pumped at a rate of $\sim 275 \mathrm{gpm}$ for three days and then shut in.

The magnitude of drawdowns at the observation we $11 \mathrm{~s}$ in this test were from 0.3 to $1.5 \mathrm{~m}(0.4$ to $2.4 \mathrm{psi}$ ). The wells with $2-\mathrm{in}$. casing were instrumented with nitrogen-filled tubing (Suzy-1, Suzy-2, Suzy-3, and Suzy-5). We1 1 Suzy-4 was instrumented with a downhole Paro-scientific pressure transducer, LLB-2 was instrumented with a Hewlett Packard downhole transducer. The Naef well, was instrumented with a continuously recording water-level gauge. Water-level data (and pressure data) obtained during the test for the Naef we11, Davis wel1, Suzy-3, Suzy-4 and Lassen Lumber and Box are shown in Figures 9-13.

Several months of background data at the Naef well were obtained before the test by the U.S. Bureau of Reclamation. Figure 14 shows the daily fluctuations of $\pm 0.2 \mathrm{ft}$ superimposed on larger magnitude fluctuations throughout the summer months. Particularly curious is the water level build-up that took place over several weeks in the early fall. At the present time the cause is unknown. However, several possible explanations exist. If rainfall were particularly heavy during this period, influx of this water from either overlying sediments or the river could cause this behavior. Or, the cessation of irrigation after the summer months could cause a pressure build-up in the reservoir. Both of these possibilities are highly speculative, but pressure data do indicate that the reservoir is effected by external sources.

The sharp peaks and valleys in the data starting at the beginning of September are caused by production at the LDS Church well. An expanded section of these data, shown in Figure 15 , reveals three build-ups and drawdowns corresponding to the Church well being shut in for several hours and then pumped again. Analysis of these data returned a transmissivity value of $3.6 \times 10^{6} \mathrm{md}-\mathrm{ft} / \mathrm{cp}$ and a storativity value of $2.3 \times 10^{-4} \mathrm{ft} / \mathrm{psi}$. The best match of the data obtained indicated the pressure response was influenced by an impermeable reservoir boundary. The location of this barrier cannot be established with one observation wel1. The best match obtained between calculated and observed pressures is shown in Figure 16.

Those wells instrumented with nitrogen-filled tubing (Suzy-1, Suzy-2, Suzy-3, and Suzy-5) were strongly affected by daily temperature and atmospheric pressure changes. This noise obscured both the initial pressure and the drawdown (if any) caused by the production wel1(s). These data are not considered to be suitable for analysis. The data obtained at Suzy-4 and at the Lassen Lumber and Box wells illustrate drawdowns of $2 \mathrm{psi}$ and 0.5 psi, respectively. Both of these wells show two peculiar features as compared with other wells (see Figures 9, 12, and 13). First, they both show a gradual pressure decrease several days before the Davis well was shut in. Second, they both displayed a pressure build-up before shutting in the Davis we11. For this reason, the data from these wells are not suitable for complete analysis.

Because both of these wells incurred a drawdown due to the Davis well production it can be 
Table 1. Summary of instrumentation and wells used in Susanville, California well tests.

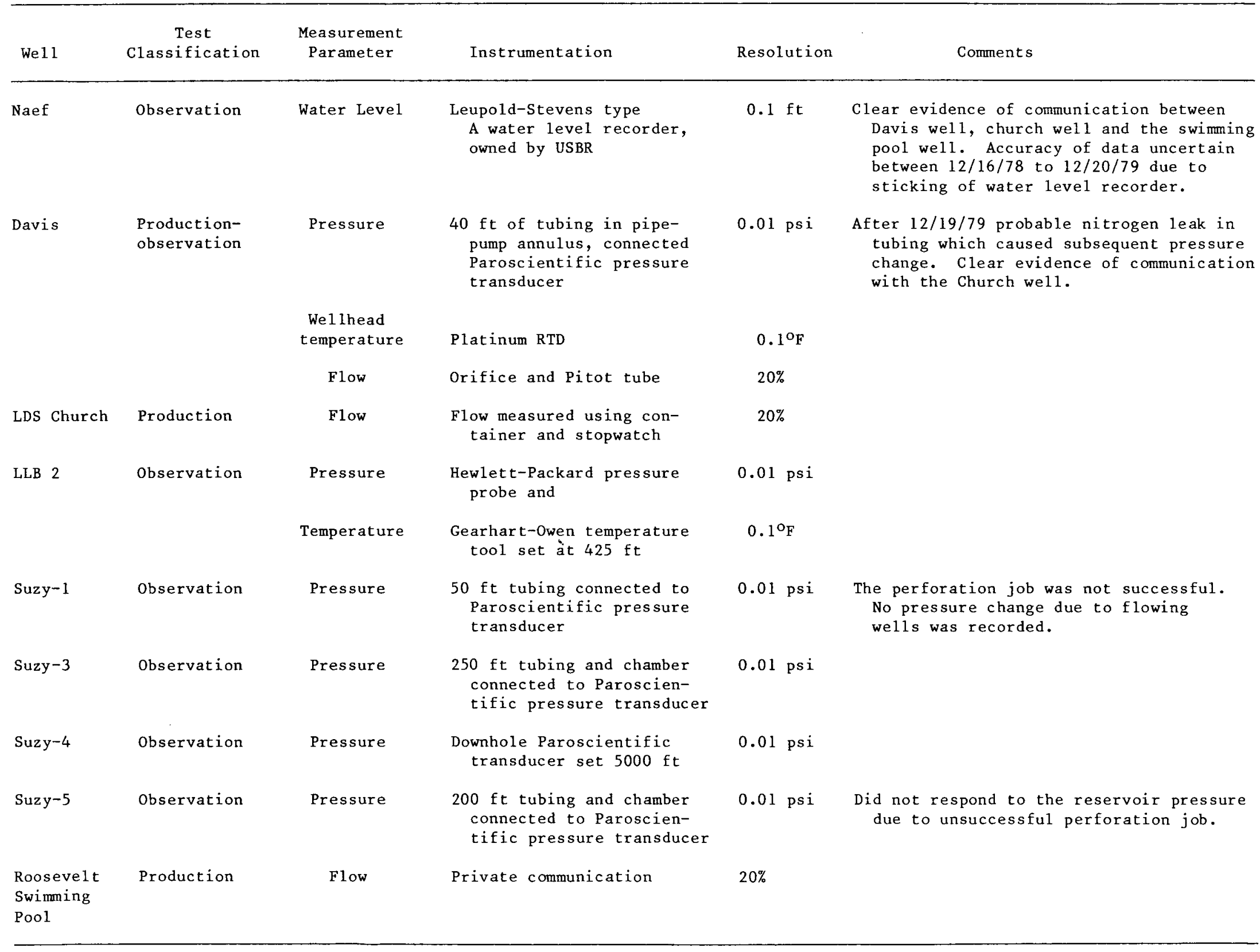




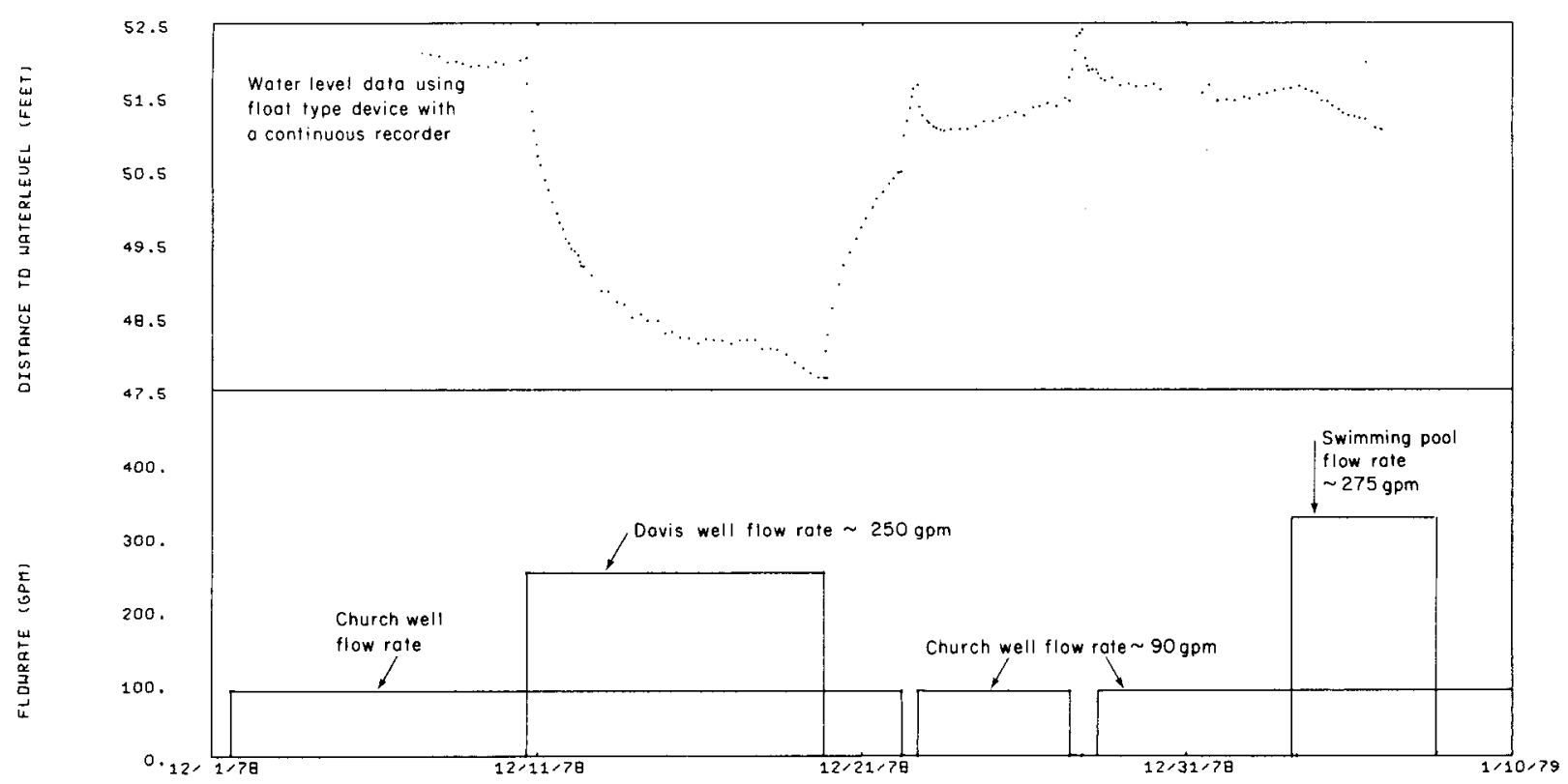

Figure 9. Naef well interference data. (XBL 795-7441)

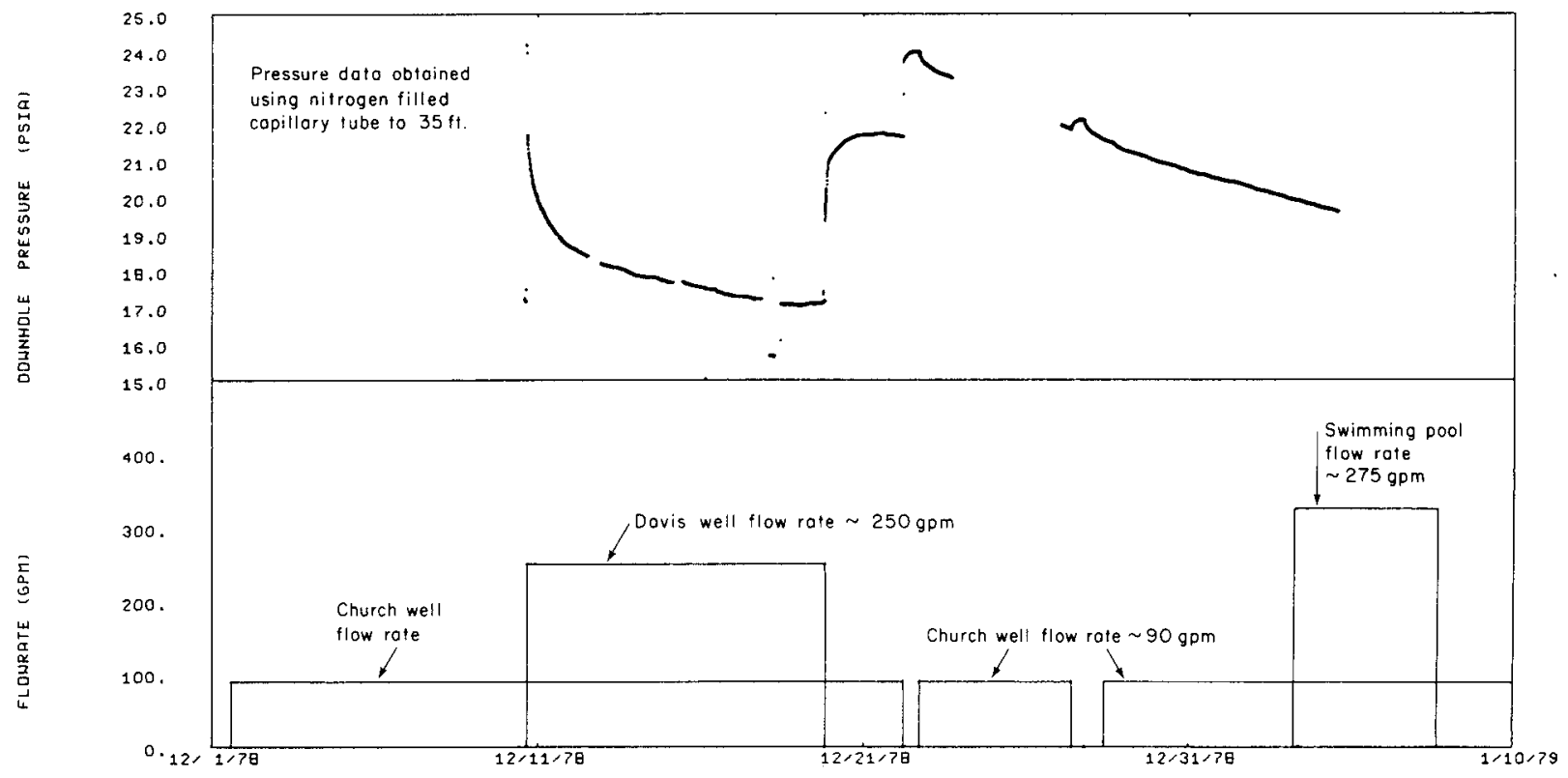

Figure 10. Davis wel1 production data.

(XBL 795-7439) 


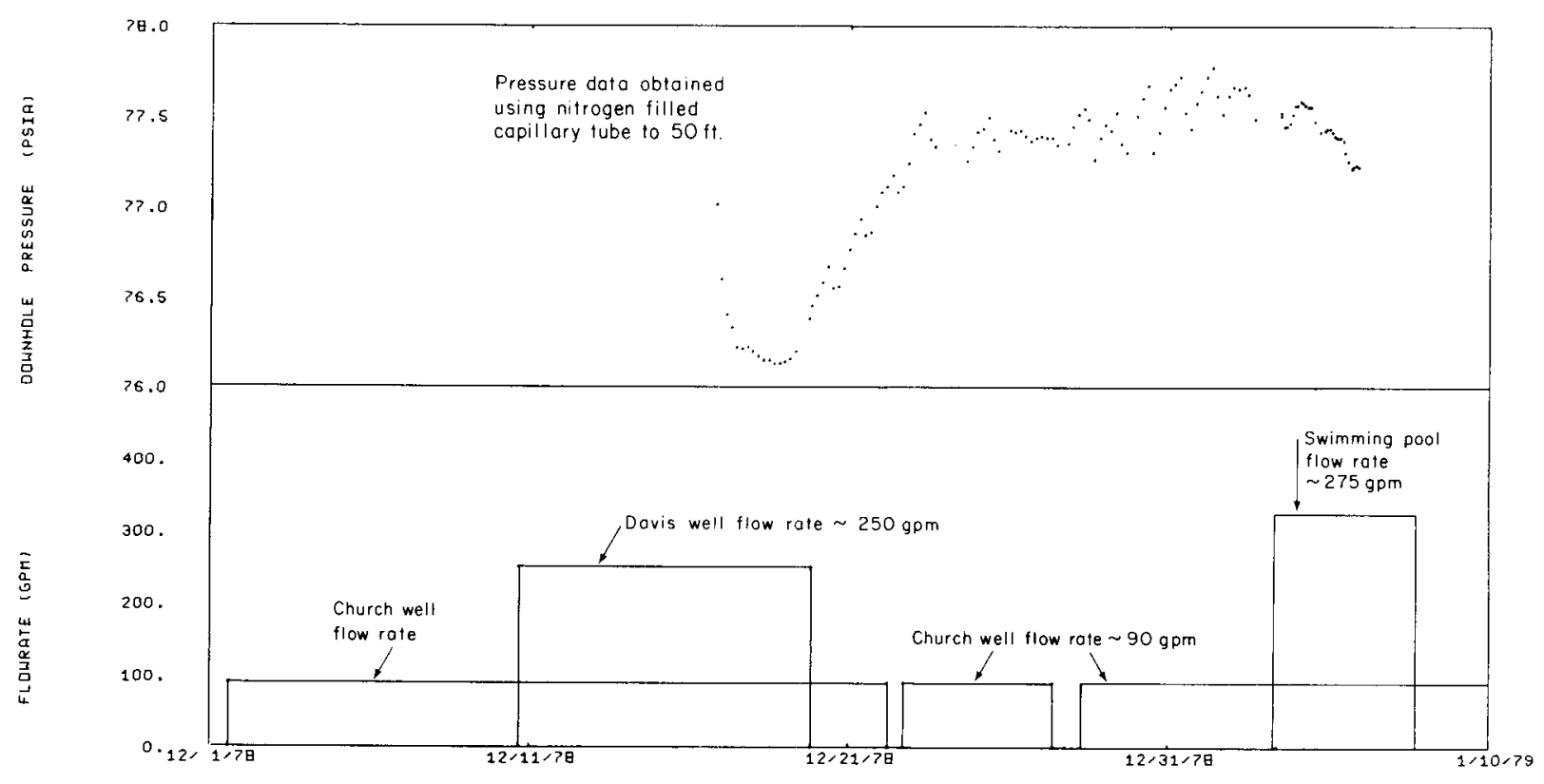

Figure 11. Suzy-3 interference data.

(XBL 795-7438)

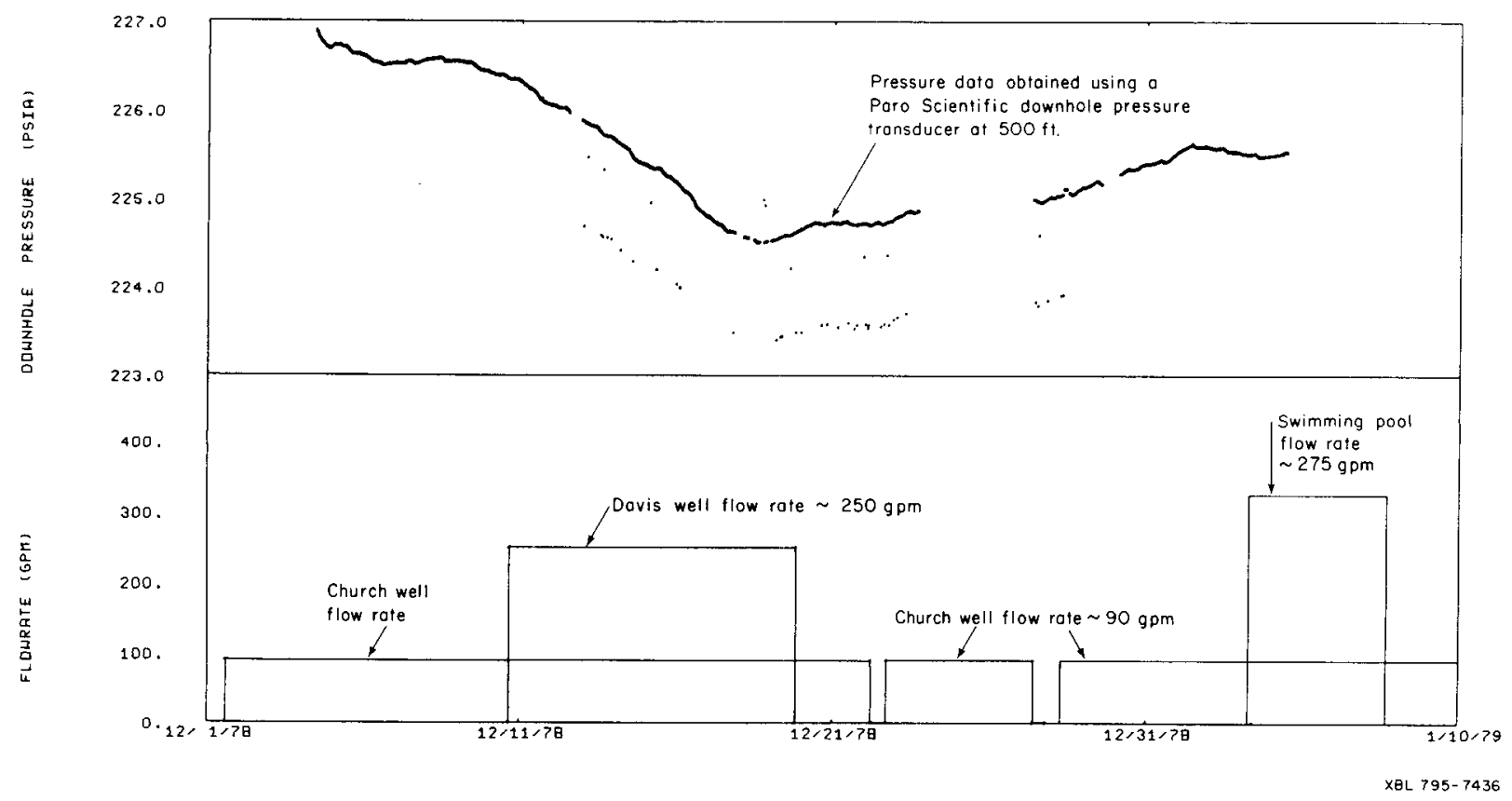

Figure 12. Suzy-4 interference data. (XBL 795-7436) 
84

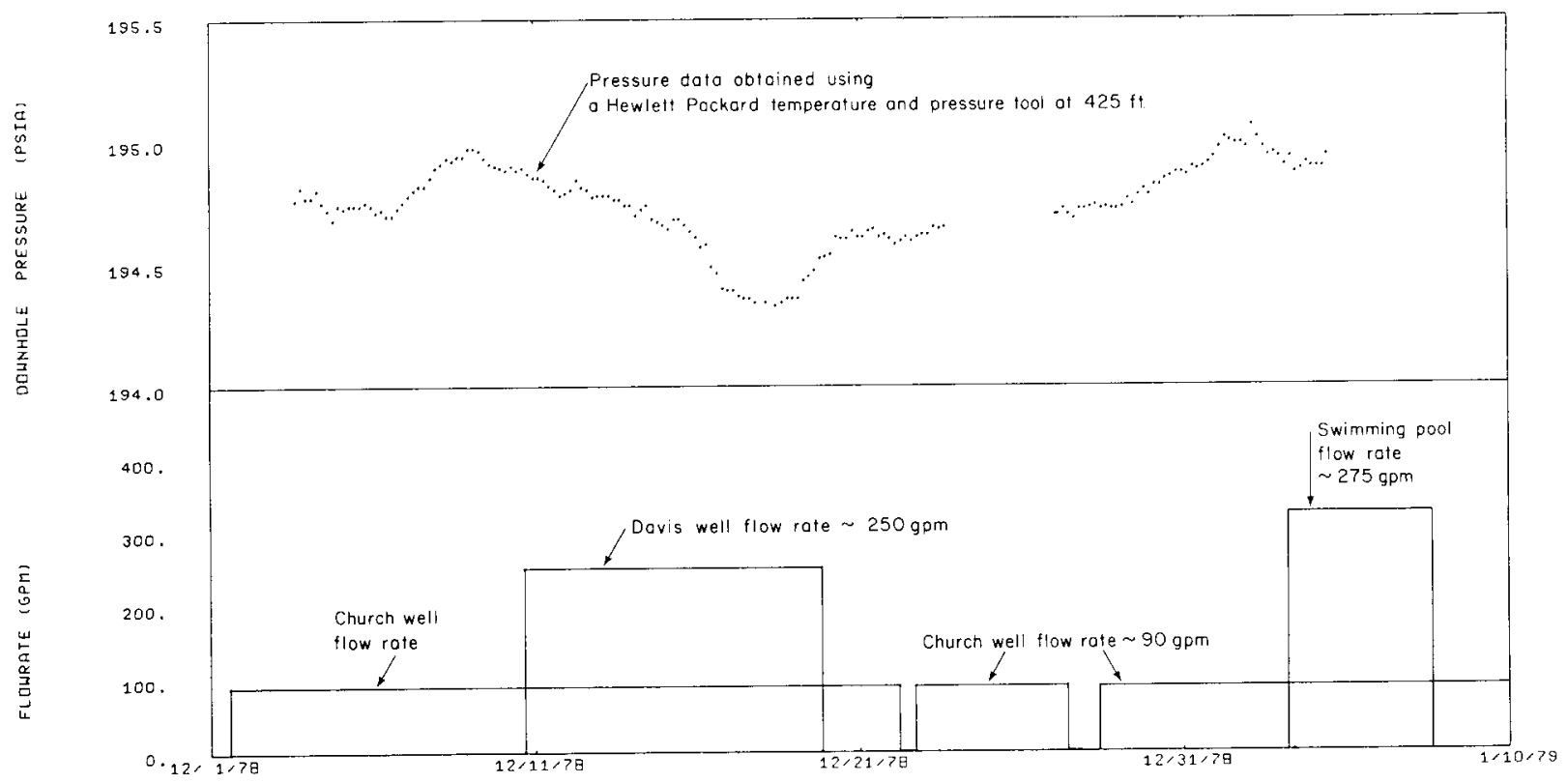

Figure 13. LLB-2 interference data. (XBL 795-7440)

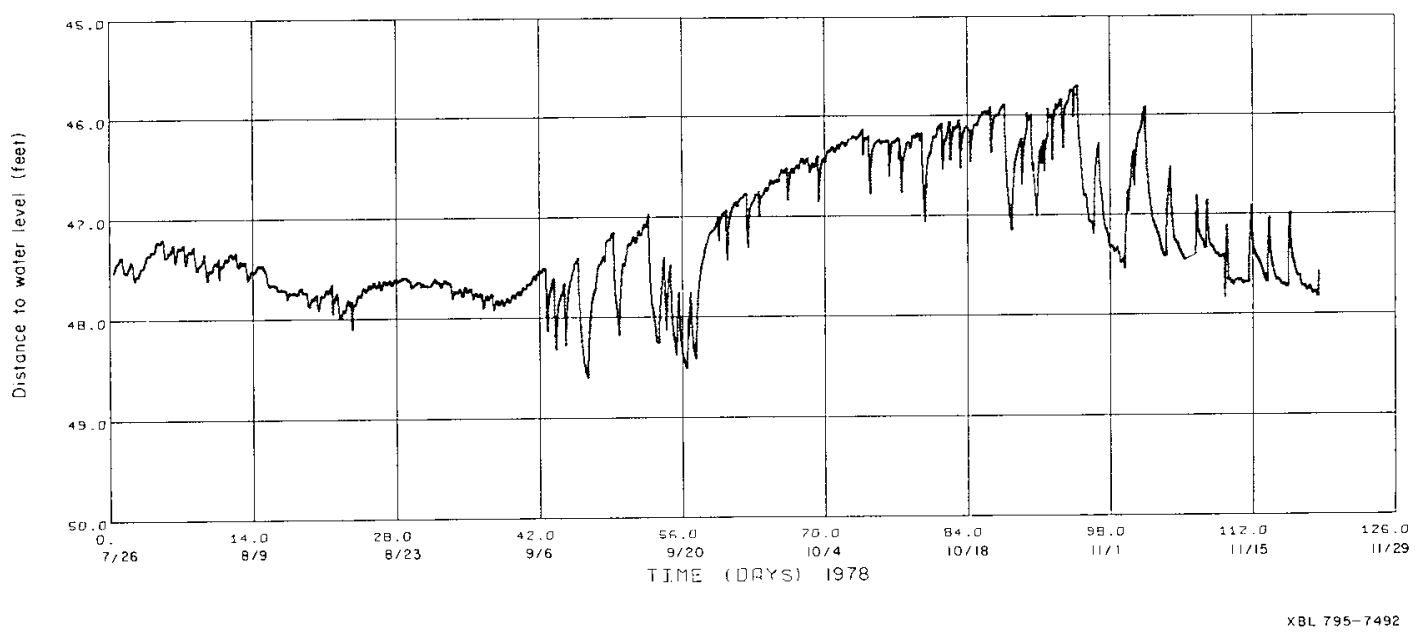

Figure 14. Naef well pre-test data. (XBL 795-7492) 


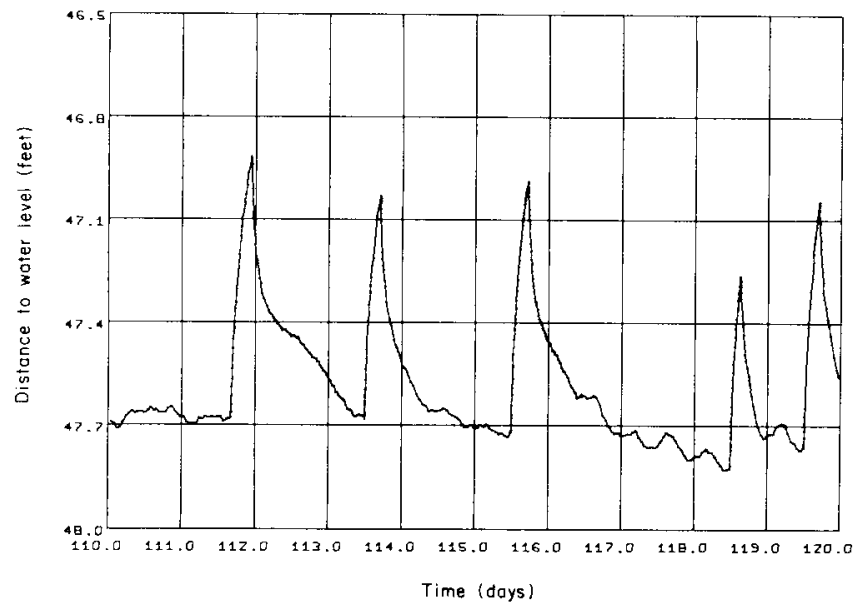

Figure 15. Expanded section of the Naef well pretest data showing five build-up and drawdowns caused by the church well production.

(XBL 795-7493)

inferred that the pressure is affected by the Davis well production and by an external source: e.g., atmospheric pressure, ambient temperature, or an influx of fluids to the reservoir from some unknown source(s) such as local precipitation or melting snow.

Match of calculated and observed values

for pre-test drawdown of Noef due to production of the Church Well

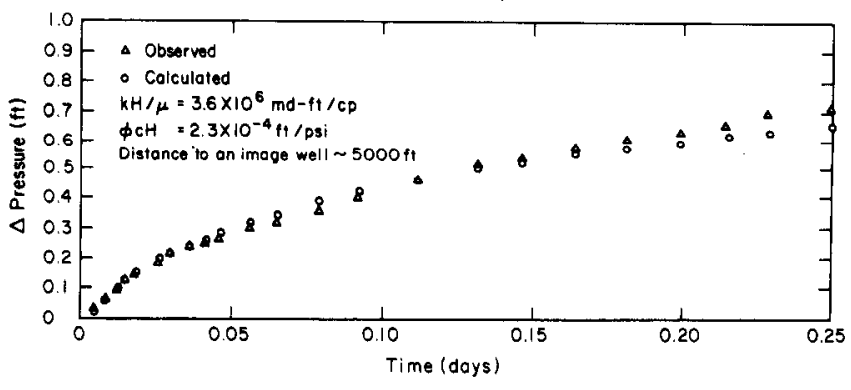

Figure 16. Match of calculated and observed drawdowns at the Naef well due to the church we11 production.

(XBL 796-7508)

\section{WELL TEST DATA ANALYSIS}

Pressure data obtained from an observation well that is affected by the production of more than one well or by variable flow rates requires computer-assisted analysis methods. A non1inear least-squares computer-matching program developed at LBL was used to analyze observation water level data from the Naef well (McEdwards and Tsang, 1977). The program employs the line source solution (Theis), which calculates pressure drawdowns assuming an isotropic, isothermal, homogeneous porous medium of constant thickness. The production wel1 is modeled as a line source that fully penetrates the reservoir. The program can also be used to search for vertical reservoir boundaries (impermeable or constant potential). Vertical boundaries are modeled using the method of images.

The interference data from the Naef well were first analyzed using the production data from all three producing wells (Church, Davis, and Roosevelt swimming pool wells). This analysis revealed that an acceptable match of the pressure data could not be obtained with one set of reservoir parameters $(\mathrm{kH} / \mu, \phi \mathrm{cH}$, geometry). For this reason, the data were analyzed in two parts. The drawdown at the Naef well caused by the Davis well was analyzed assuming that the production of the Church well had no pressure transients associated with it during the Davis well production. An instrument malfunction at the Naef well made only the first six days of data analyzable. Analysis yields a $\mathrm{kh} / \mathrm{\mu}$ values of $2.3 \times 10^{6} \mathrm{md}-\mathrm{ft} / \mathrm{cp}$ and $\phi \mathrm{cH}$ of $7.2 \times 10^{-4} \mathrm{ft} / \mathrm{psi}$. Figure 17 shows the best match obtained between the observed and calculated response. The best match of observed and calculated values indicate the pressure response was influenced by an impermeable boundary.

Pressure and discharge temperature data at the Davis well were obtained for the duration of the test. However, due to instrumentation problems only data from the drawdown (12/10/78 to $12 / 19 / 78)$ is considered reliable. These data were analyzed by the Miller-Dyes-Hutchinson (semi-log) technique (Earlougher, 1977). The data are shown plotted on semi- $\log$ paper in Figure 18. After the first several hundred minutes the data fall on a single straight line indicating that no boundary is influencing the pressure response. The calculated transmissivity is $7.3 \times 10^{5} \mathrm{mid}-\mathrm{ft} / \mathrm{cp}$. The discharge temperature stabilized at $59^{\circ} \mathrm{C}$.

Table 2 summarizes the reservoir parameters obtained from analysis of the well test data. The relatively high transmissivity values and low storativity values are indicative of a fracture dominated producing aquifer. 


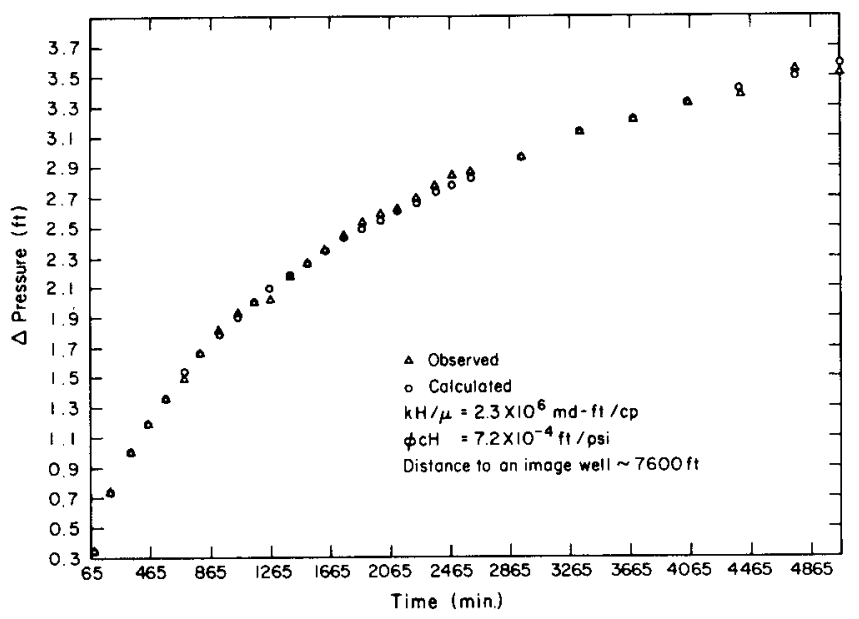

Figure 17. Match of calculated and observed values for the drawdown at the Naef well due to production of the Davis well.

(XBL 796-7507)

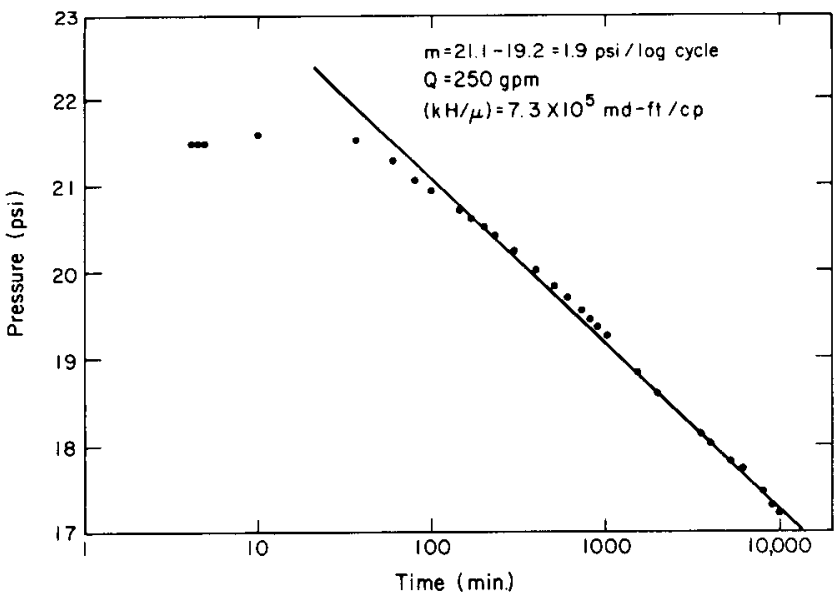

Figure 18. Semi-log plot of the drawdown data from the Davis well.
CONCLUS ION

The occurrence of the Susanville geothermal resource appears to be fault related. Temperature contours and temperature profiles suggest that heated fluids are upwelling on a northwest-trending fault. The heated fluids are then dispersed into the reservoir along the highly permeable (fracture) agglomerate-basalt interface. The geothermal anomaly is larger in lateral extent than was first estimated. However, studies show that the portion of the resource that is above $40^{\circ} \mathrm{C}$ is partially confined both laterally and vertically. The areal confinement is on three sides of the northwest. The vertical confinement appears to be related to the presence of fractures at the agglomerate(conglomerate-) basalt interface in the southwest portion of the anomaly.

Well tests show a high lateral permeability associated with the fractured basalt-agglomerate interface. Porosity values are low, supporting evidence of a fracture-dominated producing aquifer. Drilling in the northwestern portion of the anomaly has encountered fluids of higher temperatures than Eound in the southern portion of the geothermal anomaly. Further well testing will be required to determine the productivity of the higher temperature fluids in this area of the anomaly.

\section{ACKNOWLEDGMENT}

We would like to thank Wes Davis and D. Naef for use of their wells during testing in the Susanville area. We are also thankful to Lyle Tomlin and Dick Richardson from the U.S. Department of the Interior, Bureau of Reclamation, Mid-Pacific Region, for their help in obtaining reservoir information at Susanville. The information obtained from J. Jesky and C. Richardson of the City of Susanville is also acknowledged.

\section{REFERENCES CITED}

Earlougher, R. C., 1977. Advances in well test analysis. Dallas, Society of Petroleum Engineers, monograph, v. 5.

McEdwards, D. G., and Tsang, C. F., 1977. Variable rate multiple well testing analysis, in Proceedings, Invitational Well Testing symposium.

Table 2. Reservoir parameters obtained from analysis of well test data.

\begin{tabular}{clccl}
\hline $\begin{array}{c}\text { Observation } \\
\text { Well }\end{array}$ & $\begin{array}{c}\text { Pumped } \\
\text { Well }\end{array}$ & $\begin{array}{c}\mathrm{kh} / \mu \\
(\mathrm{md}-\mathrm{ft} / \mathrm{cp})\end{array}$ & $\begin{array}{c}\phi \mathrm{ch} \\
(\mathrm{ft} / \mathrm{psi})\end{array}$ & $\begin{array}{c}\text { Indication of } \\
\text { reservoir boundaries }\end{array}$ \\
\hline Naef & Church & $3.6 \times 10^{6}$ & $2.3 \times 10^{-4}$ & Barrier boundary \\
Naef & Davis & $2.3 \times 10^{6}$ & $7.2 \times 10^{-4}$ & Barrier boundary \\
Naef & $\begin{array}{c}\text { Roosevelt } \\
\text { Swimming } \\
\text { Pool }\end{array}$ & $3.4 \times 10^{6}$ & $3.9 \times 10^{-2}$ & None \\
Davis & Davis & $4.3 \times 10^{5}$ & Not obtained & None \\
\hline
\end{tabular}


Berkeley, Lawrence Berkeley Laboratory, LBL-7027, p. 92-99.

Rudser, R. J., 1978. The geology and geothermal potential of Susanville, Lassen County, California (M.S. thesis). Davis, University of California.

U.S. Bureau of Reclamation, 1976a. Susanville geothermal investigations: special report 1976. Sacramento, U.S. Bureau of Reclamation, Mid-Pacific Region.

, 1976b. Susanville geothermal investigations: Supplemental technical data: special report 1976. Sacramento, U.S. Bureau of Reclamation, Mid-Pacific Region.

\section{RECENT MODIFICATIONS OF THE NUMERICAL CODE CCC}

\section{G. S. Bodvarsson, M. J. Lippmann, and T. N. Narasimhan}

\section{INTRODUCTION}

The numerical code CCC (convection, conduction and consolidation) developed at LBL, solves the energy and mass balance equations and the one-dimensional consolidation for liquid water flow in porous media. The program can be used to simulate one-, two-, or three-dimensional heterogeneous, isotropic, nonisothermal saturated systems. The thermal and hydraulic properties of the water and rock matrix can be temperature or pressure dependent. The program, which was based on programs SCHAFF (Sorey, 1975) and TRUST (Narasimhan, 1975), employs an integrated finite-difference method to discretize the flow regime, and to define the numerical formulation (Edwards, 1972; Narasimhan and Witherspoon, 1976).

The earlier version of CCC (Lippmann et al., 1977) solved the mass and energy equation alternatively by interlacing them in time (leap-frogging method), as shown schematica11y in Figure 1 . The flow equation solves for the pressure and the Darcy velocities, assuming that the temperature-dependent properties remain constant. The energy equation is then solved for the temperature changes, assuming that the Darcy velocity and the pressure-dependent properties remain constant. Because the pressure generally changes much faster than the temperature, much smaller time steps had to be taken in the flow cycles than in the energy cycles for accurate simulation of the pressure behavior.

There were two key factors behind the decision to modify CCC. In the approach employed by the older version, some very important coupling terms between the energy and the mass equations were neglected. In addition, the temperature- and pressure-dependent (nonlinear) parameters were not accurately evaluated during the course of the simulation.

\section{FLOW CYCLES}

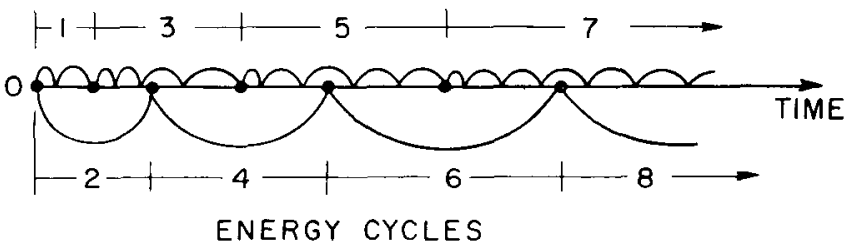

Figure 1. Interlacing of flow and energy calculation.

(XBL 7611-7862)
In the modified version of CCC, developed during fiscal year 1979, the two basic balance equations are solved simultaneously using an efficient sparse solver (Duff, 1977). This approach allows all coupling terms to be taken into account and the temperature or pressure dependent coefficients to be accurately evaluated during each time step. Furthermore, the modified version allows much larger time steps to be taken, resulting in a drastic reduction in the simulation costs.

In this report we will give the formulation of the governing equation enabling direct solution by the sparse solver. The assumptions employed in the formulation will be discussed and the solution technique briefly described. Finally, some validation examples will be given, and the advantages of the new formulation listed.

\section{ACTIVITIES IN FISCAL YEAR 1979}

\section{Governing Equations}

The governing equations for nonisothermal flow of slightly compressible fluid through porous media are the mass and the energy balance equations. These can be written in integral form as follows:

$\underset{\text { balance }}{\operatorname{mass}} \frac{\partial}{\partial t} \int_{V} \frac{S_{S}}{g} P d V=-\int_{S} \rho \vec{v}_{d} \cdot \vec{n} d S+\int_{V} G_{f} d V$

energy

$$
\begin{aligned}
& \frac{\partial}{\partial t} \int_{V}(\rho c)_{M} T d V=\int_{S} K_{M} \vec{\nabla} T \cdot \vec{n} d S \\
& -\int_{S} \rho c_{F} \delta T \vec{v}_{d} \cdot \vec{n} d S+\int_{V} G_{h} d V
\end{aligned}
$$

In the mass balance equation, the left-hand side (LHS) represents the rate of mass accumulation whereas the terms on the right-hand side (RHS) represent the fluxes into the volume element and the sources within the element. Similarly, the LHS of the energy equation consists of the accumulation term whereas the three terms on the RHS represent conductive and convective heat transfer and the source term, respectively. 
Equations (1) and (2) must be supplemented by an equation of motion and a number of constitutive relations to fully describe the phenomena being considered. For the equation of motion, the validity of Darcy's law is assumed:

$$
\overrightarrow{\mathrm{v}}_{\mathrm{d}}=-\frac{\mathrm{k}}{\mu}(\vec{\nabla} \mathrm{P}-n \rho g)
$$

Constitutive relations must be specified for each of the temperature- or pressure-dependent properties of the fluid and the rock matrix. In the program, these relations have been incorporated either as equations or tabulated values.

\section{Assumptions}

The formulation of the model as described by equations (1) and (2) was based on several assumptions. The most significant ones are:

1. Fluid motion is governed by Darcy's law.

2. The fluid and the rock matrix are in local thermal equilibrium.

3. Work due to the effects of viscous dissipation, acceleration, and compressibility is neglected.

\section{Formulation}

In this section, the governing equations (equations 1 and 2) will be written in matrix form to be readily handled by the sparse solver. Re-writing equation (1) using numerical notation for a node $n$ and adjacent nodes $m$, the equation becomes:

$$
\begin{aligned}
\frac{\left(S_{s} V\right)_{n}}{g} \frac{\Delta P}{\Delta t} & =\sum_{m}\left[\left(\frac{k \rho A}{\mu}\right)_{n, m} \frac{\left(P_{m}-P_{n}\right)}{D_{n, i n}+D_{m, n}}-\left(\frac{k \rho^{2} n A}{\mu}\right)_{n, m} g\right] \\
& +\left(G_{f} V\right)_{n}
\end{aligned}
$$

Adopting an implicit formulation to relax constraints in the time steps results in the following equations:

$$
\begin{aligned}
& \mathrm{P}_{\mathrm{n}}=\mathrm{P}_{\mathrm{n}}^{\mathrm{o}}+\lambda \Delta \mathrm{P}_{\mathrm{n}} \\
& \mathrm{P}_{\mathrm{m}}=\mathrm{P}_{\mathrm{m}}^{\mathrm{o}}+\lambda \Delta \mathrm{P}_{\mathrm{m}}
\end{aligned}
$$

Here $\lambda$ is a weighting factor that is limited to the range 0.5 to 1.0 for unconditionally stable solutions. Substituting (5) and (6) into (4) yields,

$$
\begin{aligned}
\frac{\left(\mathrm{S}_{\mathrm{s}} \mathrm{V}\right)_{\mathrm{n}}}{\mathrm{g}} \frac{\Delta \mathrm{P}}{\Delta \mathrm{t}} & =\sum_{\mathrm{m}}\left[\left(\frac{\mathrm{k} \rho \mathrm{A}}{\mu}\right)_{\mathrm{n}, \mathrm{m}} \frac{\mathrm{P}_{\mathrm{m}}^{\mathrm{O}}+\lambda \Delta \mathrm{P}_{\mathrm{m}}-\mathrm{P}_{\mathrm{n}}^{\mathrm{o}}-\lambda \Delta \mathrm{P}_{\mathrm{n}}}{\mathrm{D}_{\mathrm{n}, \mathrm{m}}+\mathrm{D}_{\mathrm{m}, \mathrm{n}}}\right. \\
& \left.+\left(\frac{k \rho^{2} \eta \mathrm{A}}{\mu}\right)_{n, m} \mathrm{~g}\right]+\left(\mathrm{G}_{\mathrm{f}} \mathrm{V}\right)_{\mathrm{n}}
\end{aligned}
$$

Equation (7) can be written in matrix form as follows:

$$
\begin{aligned}
& {\left[1+\frac{\Delta t g}{\left(S_{s} V\right)_{n}} \sum_{m} \frac{\lambda}{D_{n, m}+D_{m, n}}\left(\frac{k \rho A}{\mu}\right)_{n, m}\right] \Delta P_{n}} \\
& -\left[\frac{\Delta t g}{\left(S_{s} V\right)_{n}} \sum_{m} \frac{\lambda}{D_{n, m}+D_{m, n}}\left(\frac{k \rho A}{\mu}\right)_{n, m}\right] \Delta P_{m} \\
& =\frac{\Delta t g}{\left(S_{s} V\right)_{n}}\left\{\left(G_{f} V\right)_{n}+\sum_{m}\left[\left(\frac{k \rho A}{\mu}\right)_{n, m} \frac{\left(P_{m}^{O}-P_{n}^{o}\right)}{D_{n, m}+D_{m, n}}\right.\right. \\
& \left.\left.-\left(\frac{k \rho^{2} n A}{\mu}\right)_{n, m}^{g}\right]\right\}
\end{aligned}
$$

In terms of the matrix equation $[A][x]=[b]$, the coefficients of the $\Delta \mathrm{P}_{n}$ 's represent the diagonal values of the A matrix, while the coefficients of the $\Delta \mathrm{P}_{\mathrm{m}}$ 's are the off-diagonal values. The RHS of equation (8) gives the values of the known vector $b$.

Similarly, after incorporation of Darcy's law, the energy equation (2) can be written using numerical notation as follows:

$$
\begin{aligned}
& {\left[(\rho c)_{M} V\right]_{n} \frac{\Delta T_{n}}{\Delta t}=\sum_{m}\left[\frac{\left(K_{M}^{A}\right)_{n, m}}{D_{n, m}+D_{m, n}}\left(T_{m}-T_{n}\right)\right.} \\
& \left.+\left(\frac{\rho c_{F}^{A k}}{\mu}\right)_{n, m}\left(T_{n, m}-T_{n}\right)\left(\frac{P_{m}-P_{n}}{D_{n, m}+D_{m, n}}-n \rho g\right)\right]+\left(G_{h} V\right)_{n}
\end{aligned}
$$

In equation (9), $\mathrm{T}_{\mathrm{n}, \mathrm{m}}$ represents the interface temperature between nodes $n$ and $m$, and using upstream weighting, it can be expressed as:

$$
\mathrm{T}_{\mathrm{n}, \mathrm{m}}=a \mathrm{~T}_{\mathrm{n}}+(1-\mathrm{a}) \mathrm{T}_{\mathrm{m}}
$$

In equation (10), a is the upstream weighting factor and it may be varied between 0.5 and 1 . Substitution of (10) into (9) yields

$$
\begin{gathered}
{\left[(\rho \mathrm{c})_{\mathrm{M}} \mathrm{V}\right]_{\mathrm{n}} \frac{\Delta \mathrm{T}_{\mathrm{n}}}{\Delta \mathrm{t}}=\sum_{\mathrm{m}}\left[\frac{\left(\mathrm{K}_{\mathrm{M}}^{\mathrm{A})} \mathrm{n}, \mathrm{m}\right.}{\mathrm{D}_{\mathrm{n}, \mathrm{m}}+\mathrm{D}_{\mathrm{m}, \mathrm{n}}}\left(\mathrm{T}_{\mathrm{m}}-\mathrm{T}_{\mathrm{n}}\right)\right.} \\
\quad+\left(\rho c_{\mathrm{F}} \mathrm{A} \frac{\mathrm{k}}{\mu}\right)_{\mathrm{n}, \mathrm{m}}(1-\mathrm{a})\left(\mathrm{T}_{\mathrm{m}}-\mathrm{T}_{\mathrm{n}}\right) \\
\left.\quad \times\left(\frac{\mathrm{P}_{\mathrm{m}}-\mathrm{P}_{\mathrm{n}}}{\mathrm{D}_{\mathrm{n}, \mathrm{m}}+\mathrm{D}_{\mathrm{m}, \mathrm{n}}}-n \rho \mathrm{g}\right)\right]+\left(\mathrm{G}_{\mathrm{h}} \mathrm{V}\right)_{\mathrm{n}}
\end{gathered}
$$

Again we introduce the implicit formulation:

$$
\mathrm{T}_{\mathrm{n}}=\mathrm{T}_{\mathrm{n}}^{\mathrm{O}}+\lambda \Delta \mathrm{T}_{\mathrm{n}}
$$




$$
\begin{aligned}
& \mathrm{T}_{\mathrm{m}}=\mathrm{T}_{\mathrm{m}}^{\mathrm{O}}+\lambda \Delta \mathrm{T}_{\mathrm{m}} \\
& \mathrm{P}_{\mathrm{n}}=\mathrm{P}_{\mathrm{n}}^{\mathrm{O}}+\lambda \Delta \mathrm{P}_{\mathrm{n}} \\
& \mathrm{P}_{\mathrm{m}}=\mathrm{P}_{\mathrm{m}}^{\mathrm{O}}+\lambda \Delta \mathrm{P}_{\mathrm{m}} \\
& {\left[(\rho c)_{\mathrm{M}} \mathrm{V}\right]_{\mathrm{n}} \frac{\Delta \mathrm{T}_{\mathrm{n}}}{\Delta \mathrm{t}} }=\sum_{\mathrm{m}}\left\{\frac{\left(\mathrm{K}_{\mathrm{M}} \mathrm{A}\right), \mathrm{m}}{\mathrm{D}_{\mathrm{n}, \mathrm{m}}+\mathrm{D}_{\mathrm{m}, \mathrm{n}}}\left[\mathrm{T}_{\mathrm{m}}^{\mathrm{O}}+\lambda \Delta \mathrm{T}_{\mathrm{m}}-\mathrm{T}_{\mathrm{n}}^{\mathrm{O}}-\lambda \Delta \mathrm{T}_{\mathrm{n}}\right]\right. \\
&+\left(\rho \mathrm{c}_{\mathrm{F}} \mathrm{A} \frac{\mathrm{k}}{\mu}\right)_{\mathrm{n}, \mathrm{m}}(1-\mathrm{a})\left[\mathrm{T}_{\mathrm{m}}^{\mathrm{O}}+\lambda \Delta \mathrm{T}_{\mathrm{m}}-\mathrm{T}_{\mathrm{n}}^{\mathrm{O}}-\lambda \Delta \mathrm{T}_{\mathrm{n}}\right] \\
&\left.\times\left[\frac{\mathrm{P}_{\mathrm{m}}^{\mathrm{O}}+\lambda \Delta \mathrm{P}_{\mathrm{m}}-\mathrm{P}_{\mathrm{n}}^{\mathrm{O}}-\lambda \Delta \mathrm{P}_{\mathrm{n}}}{\mathrm{D}_{\mathrm{n}, \mathrm{m}}+\mathrm{D}_{\mathrm{m}, \mathrm{n}}}-\mathrm{n \rho g}\right]\right\}+\left(G_{\mathrm{h}} \mathrm{V}\right)_{\mathrm{n}}
\end{aligned}
$$

If the generation term ( $Q V)$ represents more a sink (fluid produced), it vanishes, but in the case of a source (injection), it becomes

$$
G_{f} \bar{c}_{F}\left[T_{i}-\left(T_{n}^{o}+\lambda \Delta T_{n}\right)\right]
$$

Here $\bar{c}_{F}$ represents the specific heat of the injected fluid. Substitution of (14) into (13) yields:

$$
\begin{aligned}
& {\left[(\rho \mathrm{c})_{M} V\right]_{n} \frac{\Delta T_{n}}{\Delta t}=\sum_{m}\left\{\frac { ( K _ { M } A ) _ { n , m } } { D _ { n , m } + D _ { m , n } } \left(T_{m}^{o}+\lambda \Delta T_{m}\right.\right.} \\
& \left.-T_{n}^{o}-\lambda \Delta T_{n}\right)+\left(\rho c_{F} A \frac{k}{\mu}\right)_{n, m}(1-a)\left[T_{m}^{O}+\lambda \Delta T_{m}\right. \\
& \left.\left.-T_{n}^{o}-\lambda \Delta T_{n}\right]\left[\frac{P_{m}^{o}+\lambda \Delta P_{m}-P_{n}^{o}-\lambda \Delta P_{n}}{D_{n, m}+D_{m, n}^{D}}-n \rho g\right]\right\} \\
& +G_{f} \bar{c}_{F}\left[T_{i}-\left(T_{n}^{O}+\lambda \Delta T_{n}\right)\right]
\end{aligned}
$$

We now proceed and expand neglecting terms involving the products of $\Delta \mathrm{p}$ and $\Delta \mathrm{T}$; the equation becomes

$\left[(\rho c)_{M} v\right]_{n} \frac{\Delta T_{n}}{\Delta t}=\sum_{m}\left\{\frac{\left(K_{M} A\right)}{D_{n, m}+D_{m, n}}\left(T_{m}^{0}+\lambda \Delta T_{m}-T_{n}^{o}-\lambda \Delta T_{n}\right)\right.$

$+\left(\rho c_{F} A \frac{k}{\mu}\right)_{n, m}(1-a)\left[-n \rho g\left(T_{m}^{o}+\lambda \Delta T_{m}-T_{n}^{o}-\lambda \Delta T_{n}\right)\right.$

$+\left(\mathrm{T}_{\mathrm{m}}^{\circ}-\mathrm{T}_{\mathrm{n}}^{\mathrm{o}}\right) \frac{\left(\mathrm{P}_{\mathrm{m}}^{\mathrm{O}}-\mathrm{P}_{\mathrm{n}}^{\mathrm{o}}\right)}{\mathrm{D}_{\mathrm{n}, \mathrm{m}}+\mathrm{D}_{\mathrm{m}, \mathrm{n}}}+\frac{\lambda}{\mathrm{D}_{\mathrm{n}, \mathrm{m}}+\mathrm{D}_{\mathrm{m}, \mathrm{n}}}\left(\Delta \mathrm{T}_{\mathrm{m}}-\Delta \mathrm{T}_{\mathrm{n}}\right)$

$$
\begin{aligned}
& \left.\left.\quad\left(P_{m}^{\circ}-P_{n}^{o}\right)+\frac{\lambda}{D_{n, m}+D_{m, n}}\left(T_{m}^{o}-T_{n}^{\circ}\right)\left(\Delta P_{m}-\Delta P_{n}\right)\right]\right\} \\
& +G_{f} \bar{c}_{F}\left[T_{i}-\left(T_{n}^{\circ}+\lambda \Delta T_{n}\right)\right]
\end{aligned}
$$

$$
\begin{aligned}
& \left\{1+\frac{\Delta t \lambda}{\left[(\rho c)_{M} V\right]_{n}} G_{f} \bar{c}_{F}+\frac{\Delta t \lambda}{(\rho c V)} \sum_{n} \frac{\left(K_{M} A\right) n, m}{D_{n, m}+D_{m, n}}\right. \\
& -\frac{\Delta t \lambda(1-a)}{\left[(\rho c)_{M} V\right]_{n}} \sum_{m}\left(\frac{n \rho^{2} g c_{F} A k}{\mu}\right)_{n, m}+\frac{\Delta t \lambda}{(\rho c V)_{n}} \\
& \left.(1-a) \sum_{m}\left(\frac{\rho c_{F} A k}{\mu}\right)_{n, m} \frac{P_{m}^{O}-P_{n}^{O}}{D_{n, m}+D_{m, n}}\right\} \Delta T_{n} \\
& -\left\{\frac{\Delta t \lambda}{\left[(\rho c)_{M} v\right]_{n}} \sum_{m} \frac{\left(\mathrm{K}_{\mathrm{M}}^{\mathrm{A}}\right)_{\mathrm{n}, \mathrm{m}}}{\mathrm{D}_{\mathrm{n}, \mathrm{m}}+\mathrm{D}_{\mathrm{m}, \mathrm{n}}}-\frac{\Delta t \lambda}{\left[(\rho \mathrm{c})_{\mathrm{m}} \mathrm{V}\right]_{\mathrm{n}}}\right. \\
& \times(1-a) \sum_{m}\left(\frac{n \rho^{2} g c_{F}^{A k}}{\mu}\right)_{n, m}+\frac{\Delta t \lambda}{\left[(\rho c)_{M} v\right]_{n}} \\
& \left.\times(1-a) \sum_{m}\left(\frac{\rho c_{F} A k}{\mu}\right)_{n, m} \frac{P_{m}^{o}-P_{n}^{o}}{D_{n, m}+D_{m, n}}\right\} \Delta T_{m} \\
& +\left[\frac{\Delta t \lambda}{\left[(\rho c)_{M}\right]_{n}}(1-a) \sum_{m}\left(\frac{\rho c_{F} A k}{\mu}\right)_{n, m} \frac{\left(T_{m}^{O}-T_{n}^{O}\right)}{D_{n, m}+D_{m, n}}\right] \Delta P_{n} \\
& -\left[\frac{\Delta t}{\left[(\rho c){ }_{M}\right]_{n}}(1-a) \sum_{m}\left(\frac{\rho C_{F}^{A k}}{\mu}\right)_{n, m} \frac{\left(T_{m}^{o}-T_{n}^{o}\right)}{D_{n, m}+D_{m, n}}\right] \Delta P_{m} \\
& =\frac{\Delta t}{\left[(\rho c){ }_{M}\right]_{n}}\left\{G_{f} \bar{c}_{F}\left(T_{i}-T_{n}^{O}\right)+\sum_{m}\left[\frac{\left(K_{M} A\right) n, m}{D_{n, m}+D_{m}, n}\right.\right. \\
& \times\left(T_{m}^{O}-T_{n}^{o}\right)-(1-a) \sum_{m}\left(\frac{n \rho^{2} g c_{F} A k}{\mu}\right)_{n, m}\left(T_{m}^{O}-T_{n}^{O}\right) \\
& \left.\left.+(1-a) \sum_{m}\left(\frac{\rho C_{F}^{A k}}{\mu}\right)_{n, m} \frac{\left(T_{m}^{O}-T_{n}^{o}\right)\left(P_{m}^{O}-P_{n}^{o}\right)}{D_{n, m}+D_{m, n}}\right]\right\}
\end{aligned}
$$

It can be noted that the unknowns in equation (17) are not only the temperature changes at the nodes but also the pressure changes. The latter were neglected during a time step in the older version of CCC.

For a complete coupling of the mass and the energy equations, equations (6) and (13) can be written in simplified forms as follows: 


$$
\begin{aligned}
& \mathrm{C}_{\mathrm{n}, \mathrm{n}} \Delta \mathrm{P}_{\mathrm{n}}-\mathrm{C}_{\mathrm{n}, \mathrm{m}} \Delta \mathrm{P}_{\mathrm{m}}=\mathrm{b}_{\mathrm{n}} \\
& \mathrm{K}_{i, i} \Delta \mathrm{T}_{\mathrm{n}}-\mathrm{K}_{i, j} \Delta \mathrm{T}_{\mathrm{m}}+\mathrm{K}_{i, \mathrm{n}} \Delta \mathrm{P}_{\mathrm{n}}-\mathrm{K}_{\mathrm{i}, \mathrm{m}} \Delta \mathrm{P}_{\mathrm{m}}=\mathrm{B}_{i}
\end{aligned}
$$

The coefficients in equations (18) and (19) are all nonlinear, i.e., á function of pressure and temperature. These equations are handled by an i.terative procedure to be discussed later. Figure 2 shows the combined equations (8) and (17) expressed in matrix form.

\section{The Solution Technique}

The sets of linear equations (19) and (20) are solved by an efficient direct solver (Duff, 1977). Basically the solver uses LU decomposition and a Gaussian elimination procedure. The matrix of coefficients (the A matrix) is preordered using permutation matrices $\mathrm{Pl}^{1}$ and $\mathrm{Q}^{1}$ such that the resultant matrix is in block lower triangular form. Gaussian elimination is then performed within each diagonal block in order to obtain factorization into the lower triangular $\left(L_{K}\right)$ and the upper triangular $\left(U_{K}\right)$. Finally, the factorization is used to solve the matrix equations.

The flow chart of the modified code is shown in Figure 3. After the input mode has been completed, the program determines the time step to be taken and estimates the values of the nonlinear coefficients based upon anticipated changes in temperature and pressure. Then the values in the $A$ matrix and the $B$ vector are calculated, and the set of linear equations solved by the sparse solver. If the nonlinear coefficients used in the calculations are not accurate enough, the program starts an iterative loop, which terminates when sufficient accuracy has been obtained. Then the program provides output or ends the problem if instructed to do so; otherwise it advances to the next time step.

\section{Validation}

The present code has been validated against a number of analytical solutions. For each case, the new version of CCC gives results identical to or

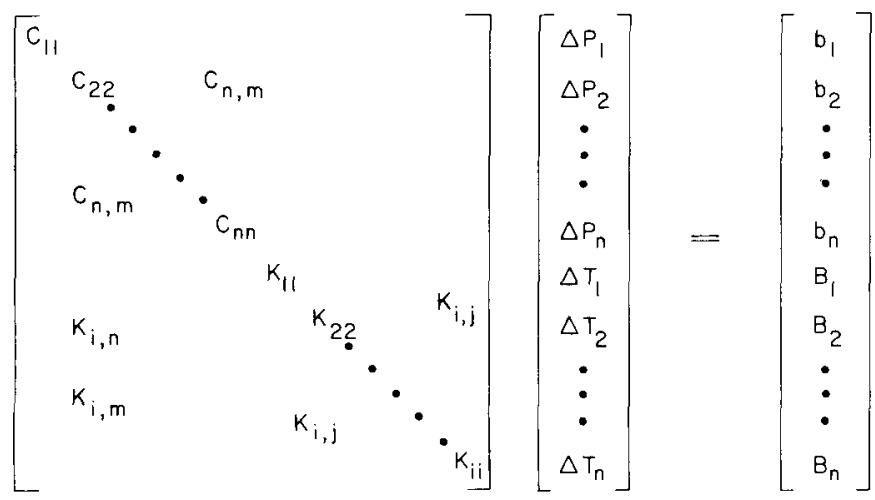

Figure 2. The formulated equations expressed in matrix form.

(XBL 806-7214)

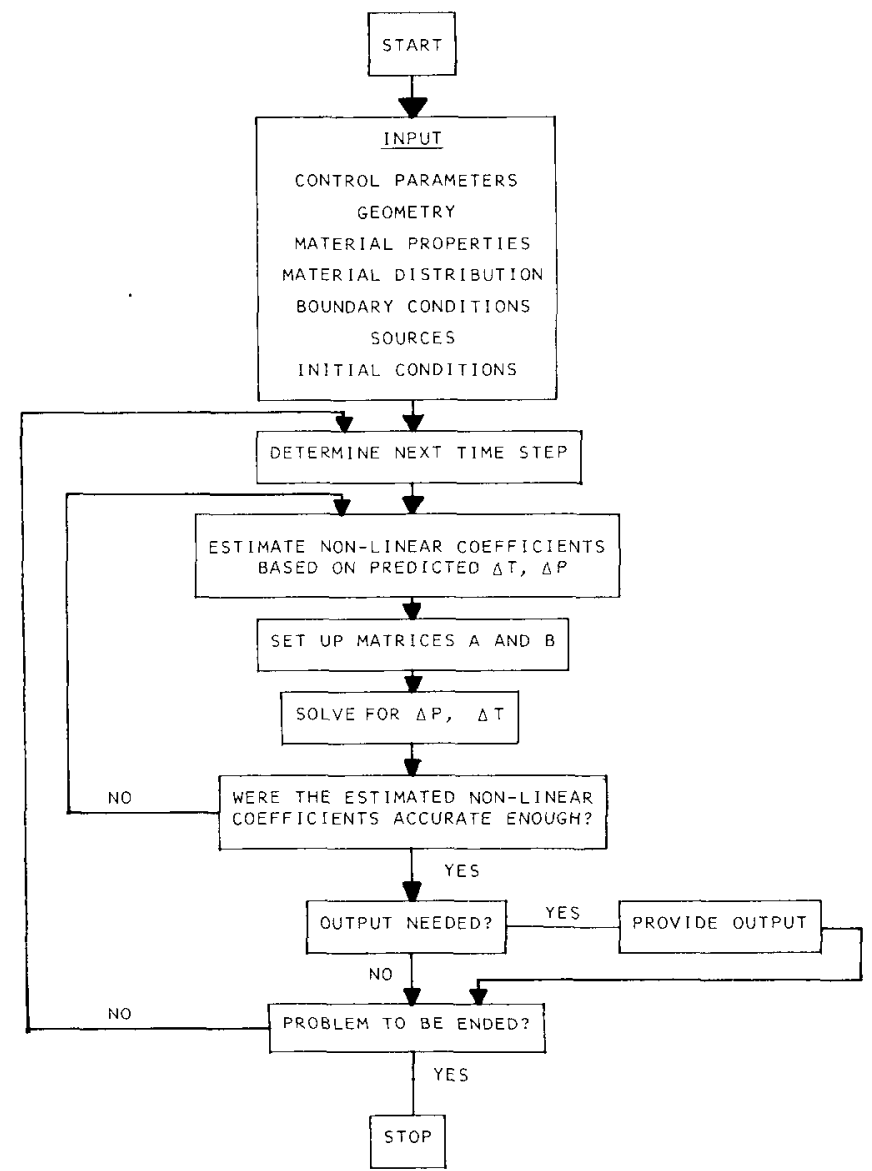

Figure 3. Flow chart for the new version of the computer code CCC

(XBL 806-10532)

better than the old version. For the transientheat/transient-flow case, the new version should give considerably more accurate results than the older one. However, an appropriate analytical solution for comparison is not yet available.

\section{Advantages of the New Formulation}

Some of the main advantages of the new formulation are listed below.

1. The governing equations are solved simultaneously and therefore all of the coupling terms are included.

2. An iterative scheme has been implemented to ensure accurate determination of the nonlinear coefficients.

3. The new code gives as good or better accuracy than the older version for the same time steps. No analytical solution has been found for the transient-flow/transient-heat case, but the new code should give considerably better results than the older one.

4. The direct solution technique allows much larger time steps to be taken and consequently less computational effort is needed. Preliminary comparison between the two versions indicates that the new code is 10 to 100 times more cost efficient than the older one. 
PLANNED ACTIVITIES DURING FISCAL YEAR 1980

During the next fiscal year, the new version will be further improved. We intend to:

1. Establish a better criterion for determining the next time step, and streamline computations when the flow field is under quasi-steady conditions.

2. Incorporate the Newton-Raphson iterative scheme for accurate determination of the nonlinear coefficients.

3. Incorporate in the formulation the thermal expansion of the solid matrix.

\section{REFERENCES CITED}

Duff, I.S., 1977. MA28--a set of FORTRAN subroutines for sparse unsymmetric linear equations. Harwell/oxfordshire, Great Britain, Report AERE-R8730.
Edwards, A.L., 1972. TRUMP: A computer program for transient and steady state temperature distribution in multidimensional systems. Lawrence Livermore Laboratory, UCRL-14754, Rev. 3, 259 p.

Lippmann, M.J., Tsang, C.F., and Witherspoon, P.A., 1977. Analysis of the response of geothermal reservoirs under injection and production procedures. Dallas, Society of Petroleum Engineers, SPE-6537, $15 \mathrm{p}$.

Narasimhan, T.N., 1975. A unified numerical model for saturated-unsaturated groundwater flow (Ph.D. dissertation, Berkeley, University of California), $244 \mathrm{p}$.

Narasimhan, T.N., and Witherspoon, P.A., 1976. An integrated finite-difference method for analyzing fluid flow in porous media. Water Resources Research, v. 12, no. 1, p.57-64.

Sorey, M.L., 1975. Numerical modeling of liquid geothermal systems (Ph.D. dissertation, Berkeley, University of California), $65 \mathrm{p}$.

\title{
DEVELOPMENT OF THE TWO-PHASE RESERVOIR SIMULATION PROGRAM, SHAFT79
}

\author{
K. Pruess, R. C. Schroeder, and P. A. Witherspoon
}

\section{INTRODUCTION}

Over the last year, work on two-phase geothermal reservoir simulation was focused on two areas. First, we made a major effort to increase the efficiency and accuracy of the simulator SHAFT78 through the use of more powerful mathematical and numerical methods. This work has resulted in the completion of a new simulator, called SHAFT79. Second, we applied SHAFT79 to diverse geothermal reservoir problems.

\section{MATHEMATICAL AND NUMERICAL METHODS}

Applications of SHAFT78 had shown that, although it was possible to obtain accurate solutions to difficult problems, including phase transitions, the maximum permissible time steps were severely restricted. For example, in a simulation of the Serrazzano geothermal reservoir (see below) typical time steps were a few hours, and the simulaton required typically $15 \mathrm{sec}$ CPU-time on the CDC-7600 per day of physical time. Computations were so costly and cumbersome that SHAFT78 could only be applied to very simple idealized model problems. SHAFT79 solves the same equations as SHAFT78, but in a much more efficient way. Typical time steps in the Serrazzano simulation with SHAFT79 are 10 to 50 days, with computation times of typically $0.3 \mathrm{sec} C P U-t i m e$ on the CDC- 7600 per day of physical time.

In this section, we shall briefly review the methods used in SHAFT79 as they were developed through step-by-step revisions of SHAFT78. More specific details can be found in the papers by Pruess et al. (1979a,b).

The main shortcoming of SHAFT78 is the oncethrough sequential method used for solving the strongly coupled mass- and energy-transport equations. Our attempt to improve this with an iterative sequential method was unsuccessful. Numerical tests as well as a subsequent analytical derivation showed that the strength of the coupling is such that convergence could only be obtained for small time steps.

The next step was implementation of a completely simultaneous, iterative solution. This in itself did not yet allow longer time steps, because the iterative matrix method used in SHAFT78 for solving the linearized equations requires a diagonally dominant matrix. The off-diagonal matrix elements turn out to be proportional to the time step size $\Delta t$, which restricts the permissible time steps to virtually the same maximum as in the sequential iterative method, above.

Subsequently, the iterative matrix method was replaced with an efficient direct solver as developed by Duff (1977). Duff's program package uses clever storage and pre-ordering procedures combined with LU-decomposition and Gaussian elimination. It is ideally suited for solving non-symmetric matrix equations with random sparcity structure, such as arise in the integrated finite-difference description of fluid and heat flow in porous rock.

The resulting simultaneous iterative solution method with fully implicit time differencing and direct solver permits large time steps. A convenient measure of time-step size is in terms of "throughput," which is defined as ratio of the fluid mass flowing through the surface of an element in one time step to the fluid mass initially in place in that element. Throughputs with SHAFT78 were typically on the order of $10^{-2}$ or smaller, whereas with SHAFT79 throughputs of 10-500 can often be obtained. 
There remains one $f l a w$ in the methodology outlined so far. Namely, the nonlinear equations are replaced in an iterative way with a sequence of 1 inear equations. Convergence occurs when, for a given time step, a set of equivalent linear equations is obtained. This procedure works as long as the nonlinearities are not too severe, but it fails completely for phase transitions. The final step in developing the algorithm of SHAFT79, then, was to implement a Newton/Raphson method for actually solving the nonlinear equations rather than replacing them iteratively with linear ones. With this methodology, SHAFT79 can accurately perform large time steps whether or not phase transitions occur during the time step.

Data inputting and printing of output were also rewritten to accommodate the new computational structure, and to improve usability of the program.

Accuracy of SHAFT79 was verified by comparison with SHAFT78 and with calculations published in the 1 iterature.

\section{APPLICATIONS}

Table 1 gives an overview of the types of systems and processes that have been modeled with SHAFT79. Below are presented results of selected SHAFT79 simulations, which illustrate the range of applications. (Parameters for the individual cases are given in the figure captions.) Relative permeabilities were obtained from Corey's equations, with residual immobile steam saturation $\mathrm{S}_{\mathrm{SC}}$ equal to zero, and residual immobile water saturation $S_{\text {wc }}$ varying between 0.40 and 0.70 .
DEPLETION OF A RESERVOIR WITH SHARP STEAM/WATER INTERFACE

When steam is produced from above a liquid water table, boiling commences near the top of the water zone. This gives rise to a drop in temperature and pressure, whereby a two-phase layer between water and steam zones is established. Water moves upward into the two-phase zone, releasing pressure below the boiling front and advancing it downward (Pruess, 1979b). In the examples studied (see Figure 1), the top of the two-phase zone does not dry up until after the boiling front has reached the bottom of the reservoir. This occurs after 6.4 years for the "high permeability" case (A in Figure 1), and after 9.6 years for the "low permeability" case (B in Figure 1). Vapor saturation at the top of the water table then reaches $46.7 \%$ for case A and $78.9 \%$ for case B. Pressure at the steam/two-phase interface, at a depth of $500 \mathrm{~m}$, declines very slowly during the advancing of the boiling front in case $A$. The reason for this is that the most rapid boiling occurs at the bottom of the two-phase zone. This provides a supply of hotter steam, which flows up from depth and tends to maintain temperature and hence pressure at the top of the two-phase zone. In case $B$ this mechanism for pressure maintenance is much less effective because of the power permeability.

\section{INJECTION OF COLD WATER}

Cold-water injection into a steam reservoir gives rise to a hydrodynamic front and, trailing behind it, a temperature front. In the finitedifference simulation of this process subsequent

Table 1. Simulation studies with SHAFT79.

Geometry $\quad$ Type of problem $\quad$ Simulated processes
$\begin{array}{ll}1-D, \text { rectangular } & \begin{array}{l}\text { Depletion of two-phase geothermal } \\ \text { reservoirs }\end{array}\end{array}$

1-D, cylindrica1 Two-phase flow near wells

2-D, rectangular Krafla geothermal reservoir (Iceland) 4

2-D, cylindrical High-level nuclear waste repository 5

$3-D$, regular

$3-D$, irregular
Two-phase interference test in Cerro Prieto (Mexico)

Serrazzano geothermal reservoir $(\text { Italy })^{3}$
Various production and injection schemes for reservoirs with uniform initial conditions or with sharp steam/water interfaces

Production from two-phase zones; cold water injection into two-phase and superheated steam zones, respectively

Different space and time patterns of production and injection

Long-term evolution of temperatures and pressures near a powerful heat source (in progress)

(in progress)

Detailed field production from 1960 to 1966 


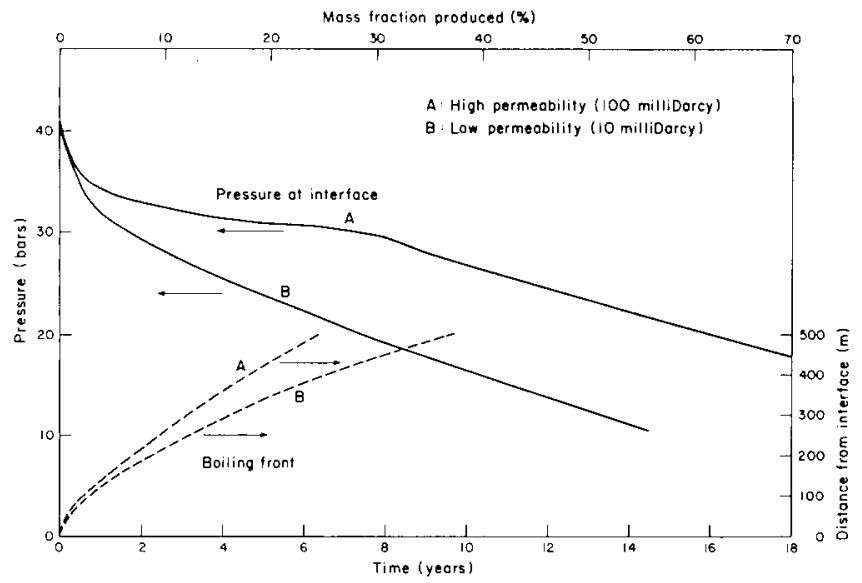

Figure 1. Depletion of a reservoir with sharp steam/water interface. The reservoir is a vertical column of $1 \mathrm{~km}$ depth with a volume of $1 \mathrm{~km}^{3}$ and "no flow" boundaries. For purposes of numerical simulation it is subdivided into 44 horizontal elements. Initially, the bottom half is filled with liquid water, the top half with superheated steam, with temperature $\mathrm{T}=252^{\circ} \mathrm{C}$ and pressures carefully equilibrated under gravity. (Rock parameters: density $=2000 \mathrm{~kg} / \mathrm{m}^{3}$; specific heat $=1232 \mathrm{~J} / \mathrm{kg}{ }^{\circ} \mathrm{C}$; porosity $=10 \%$; residual immobile water saturation $=70 \%$.) Depletion occurs uniformly at the top with a constant rate of $50 \mathrm{~kg} / \mathrm{sec}$. The curves are for a permeability of $10^{-13} \mathrm{~m}^{2}$ (A) and $10^{-14} \mathrm{~m}^{2}$ (B), respectively. Typical time steps in the simulation are $2-5 \times 10^{6} \mathrm{sec}$, corresponding to throughputs of up to 250 .

(XBL 7911-13094)

elements undergo phase transitions from superheated steam to two-phase conditions to subcooled water. Figure 2 shows the fronts at two different times. It is apparent that the fronts are propagated according to the parameter $t / R^{2}$. The volume swept by the temperature front is close to $1 / 4$ of the volume swept by the hydrodynamic front. This reflects the fact that, at a porosity of $20 \%$, the volumetric heat capacity of water is about $1 / 4$ of the volumetric heat capacity of the rock/water mixture.

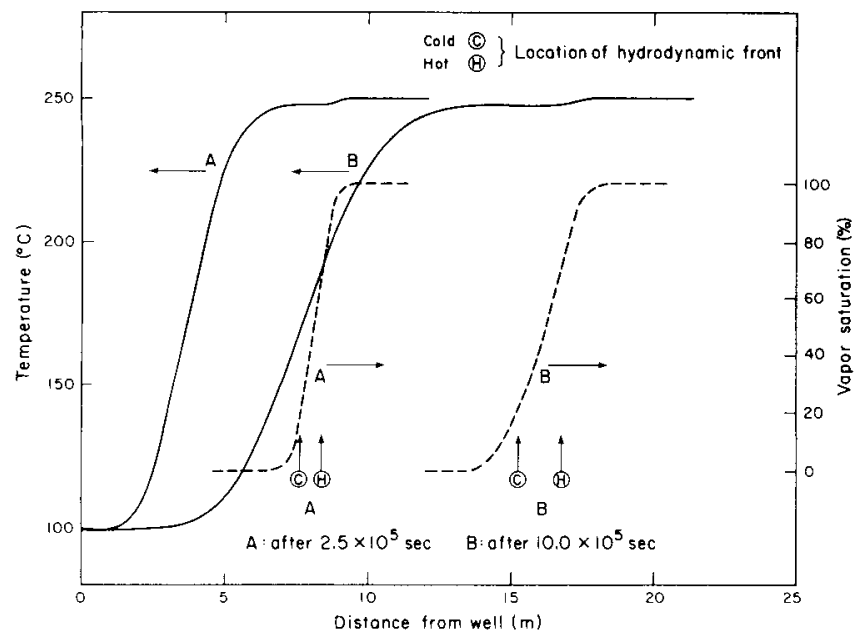

\section{SIMULATION OF KRAFLA FIELD}

Figure 3 shows a vertical two-dimensional grid as used by Jonsson for simulating production and injection at Krafla, Iceland (Jonsson, 1980). The reservoir is initially entirely filled with liquid water close to saturated conditions. Various production and injection schemes were explored in an attempt to optimize injection, i.e., to combine pressure and temperature maintenance during production with minimal sacrifices in terms of decreasing vapor saturation, S. Figure 4 shows typical results. Jonsson finds that deep injection is preferable to shallow injection. Complete problem specifications and discussions of results are given by Jonsson (1980).

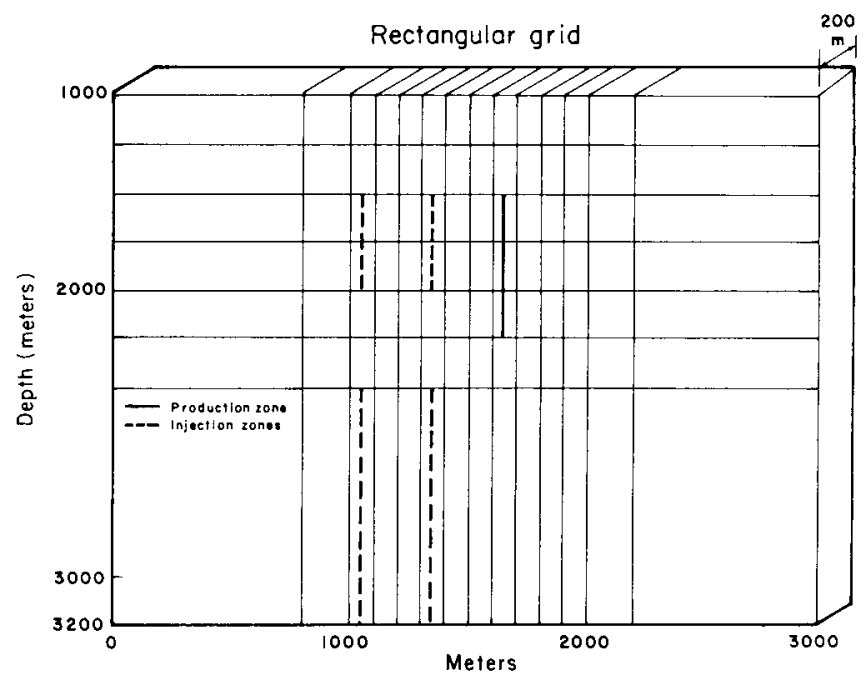

Figure 3. Two-dimensional grid for simulation of Krafla, Iceland (Jonsson, 1980). (XBL 7910-13062)

Figure 2. Injection of cold water into a steam zone. The reservoir is a cylinder with large radius, initially filled with superheated steam at $\mathrm{T}=250^{\circ} \mathrm{C}$, pressure $=38$ bars. Water with $\mathrm{T}=99.3^{\circ} \mathrm{C}$ is injected along the center line at a constant rate of $0.14 \mathrm{~kg} / \mathrm{s} \mathrm{m}$. The numerical simulation employs an axisymmetric grid as used by Garg (1978). (Rock parameters: density $=2650 \mathrm{~kg} / \mathrm{m}^{3}$; specific heat $=$ $1000 \mathrm{~J} / \mathrm{kg}{ }^{\circ} \mathrm{C}$; porosity $=20 \%$; heat conductivity $=$ $5.25 \mathrm{~W} / \mathrm{m}{ }^{\circ} \mathrm{C}$; permeability $=10^{-13} \mathrm{~m}^{2}$; residual immobile water saturation $=40 \%$.) The simulation uses time steps from 2500 to $10,000 \mathrm{sec}$, with throughputs of up to 6 . The arrows labeled $\mathrm{C}$ and $\mathrm{H}$ show the locations of the hydrodynamic front if all injected water were to remain at injection temperature (C) or were heated up to initial reservoir temperature (H).

(XBL 7911-13092) 
Injection of $120^{\circ} \mathrm{C}$ water, 300 meters away from the production injection starts 16 years after production, injection from the bottom

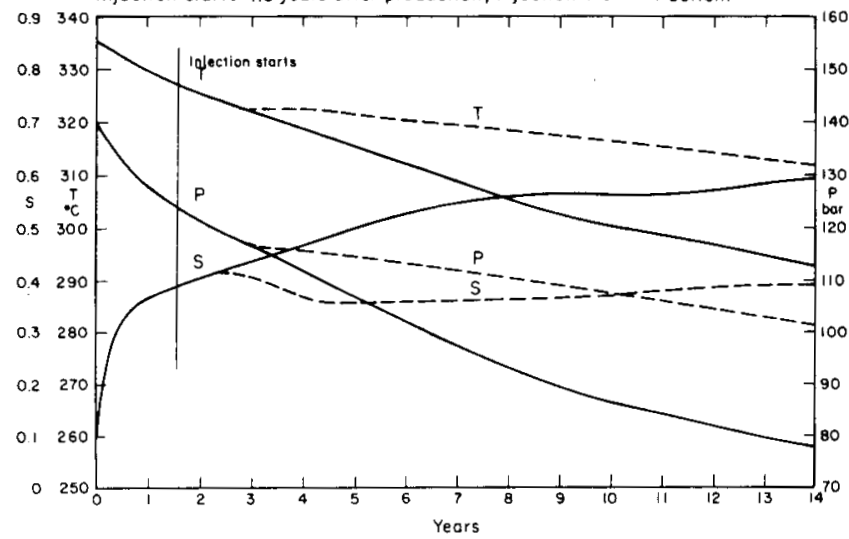

Figure 4. Simulated performance of Krafla reservoir. Temperature, pressure, and vapor saturation at the we 11 block are given as function of time with injection (dashed lines) and without injection (solid lines). Production rate is $45 \mathrm{~kg} / \mathrm{sec}$ and injection rate is $22.5 \mathrm{~kg} / \mathrm{sec}$. Typical time steps in the simulation are $1.25 \times 10^{6} \mathrm{sec}$, with throughputs of about 0.1 (Jonsson, 1980).

(XBL 798-11415K)

\section{SIMULATION OF SERRAZZANO FIELD}

The most complex simulation effort undertaken with SHAFT79 to date is a case study (history match) of the Serrazzano reservoir. Serrazzano is one of the distinct zones of the extensive geothermal area near Larderello in central Tuscany, Italy. Detailed production data gathered since 1939 and an extensive body of geologic and hydrologic work make Serrazzano an attractive example for developing geothermal reservoir simulation methodology (see Pruess, 1979b). Figure 5 gives a map of the reservoir, and Figure 6 shows the geologically accurate mesh as developed by Weres (1977). Conceptual model of the reservoir and parametrization of the problem are discussed in Pruess (1979b) and Weres (1977).

Many parameters are only partially known, and are determined in trial-and-error fashion by comparing simulated reservoir performance with field observations. A valuable criterion for determining absolute permeabilities is that well blocks must remain very close to steady flow conditions. Our most complete simulation so far covers the period from 1960 to 1966. With the permeability distribution as indicated in Figure 5, we achieve steady flow for all wells producing since 1961 or earlier to within $2 \%$ for the entire 6 -yr period modeled (i.e., the difference between inflow and production for any well block never exceeds $2 \%$ ).

From mass balance considerations it can be shown that most of the fluid reserves in Serrazzano are in place in liquid form. Little is known, however, about the distribution of pore water in the reservoir. Making the tentative assumption that liquid water is distributed throughout most of the reservoir, we compute a pressure decline (see Figure 7) which is slower than observed in the field by a factor of approximately 3.5. In the simulation, pressure declines slowly because

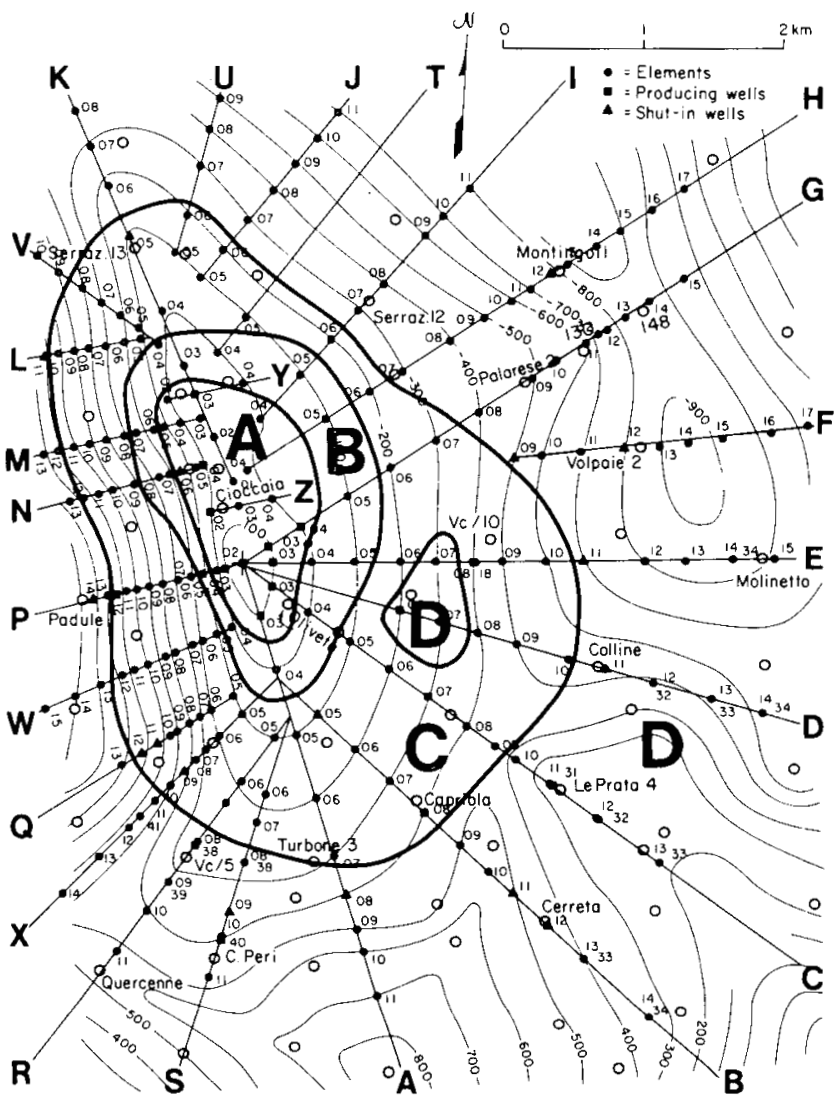

Figure 5. Aerial map of Serrazzano geothermal reservoir. The thin contour lines show elevations of the cap rock as determined from drill logs. The straight lines labeled A to $\mathrm{Z}$ indicate the locations of geological cross sections used in constructing a threedimensional finite difference grid (Weres, 1977). Locations of elements (nodes) are also shown. A - D are regions of different permeability as determined in the simulation: $A=0.75 \times 10^{-12} \mathrm{~m}^{2} ; B=0.25 \mathrm{x}$ $10^{-12} \mathrm{~m}^{2} ; \mathrm{C}=0.75 \times 10^{-13} \mathrm{~m}^{2} ; \mathrm{D}=0.15 \times 10^{-13} \mathrm{~m}^{2}$.

(XBL 7910-12576)

boiling is spread out over a large volume. We conclude that in most of the reservoir volume no liquid water is present, and we shall modify our initial conditions accordingly in subsequent simulations. We also need to correct some imbalances in initial conditions, which are apparent from the initial nonmonotonic behavior of pressure in Figure 7.

\section{CONCLUS ION}

The simulator SHAFT79 uses efficient methods for computing mass- and energy-transport in geothermal reservoirs, and allows for a flexible description of irregular geometric features. A broad range of applications, including idealized systems as well as large field problems, demonstrates its 

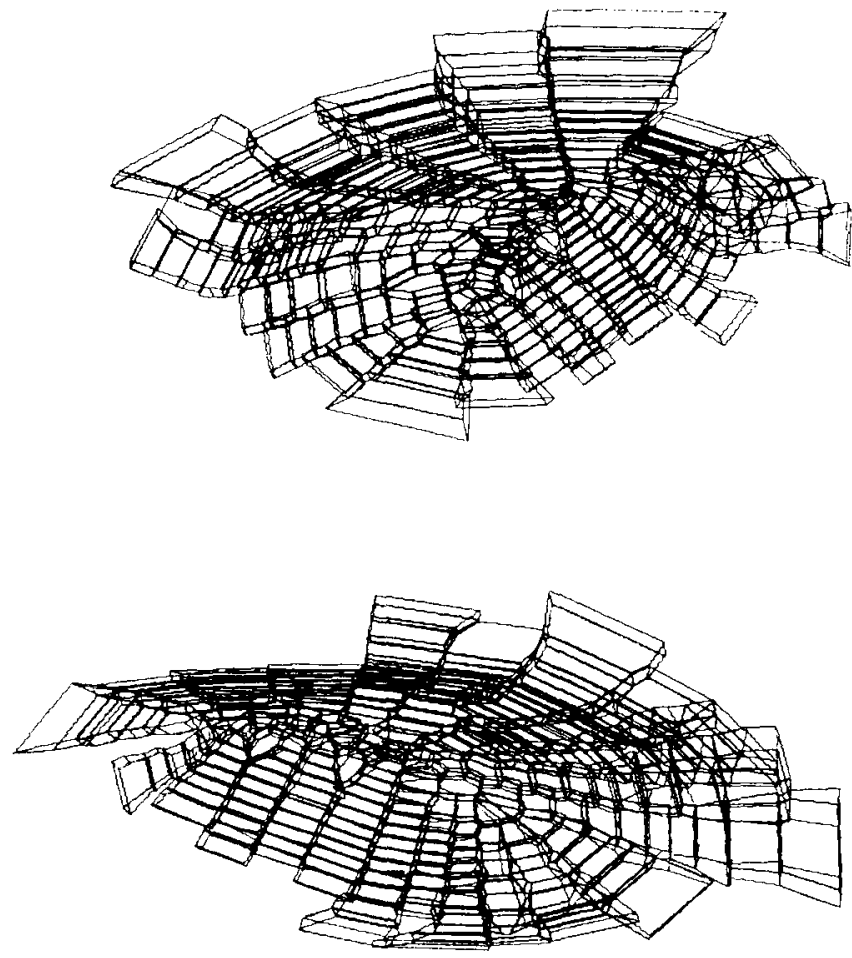

Figure 6. Serrazzano grid. The computer-generated geologically accurate grid of the Serrazzano reservoir as developed by Weres (1977) is shown in two rotated perspective views. This three-dimensional grid represents a reservoir that is a curved thin sheet approximately $1 \mathrm{~km}$ from top to bottom, with an aerial extension of about $25 \mathrm{~km}^{2}$. It has 234 polyhedral elements, with 679 polygonal interfaces between them. There are up to 10 interfaces per element.

(XBL 787-9570)

usefulness for geothermal reservoir studies. Further development work is presently under way to improve on some of the restrictive approximations made in the formulation of the physical model.

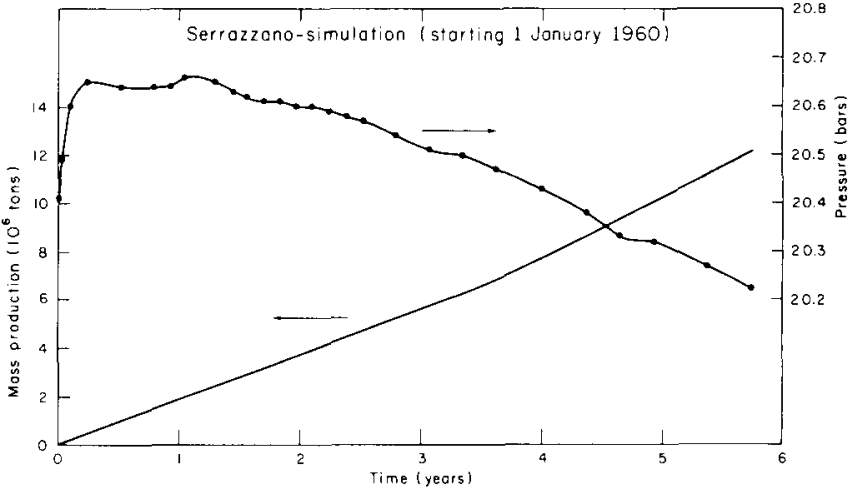

Figure 7. Average reservoir steam pressure and cumulative fluid production as calculated in Serrazzano simulation. Typical time steps in the simulation are 10 to 50 days, with throughputs of up to 65 .

(XBL 7911-13093)

\section{REFERENCES CITED}

Duff, I. S., 1977. A set of FORTRAN subroutines for sparse unsymmetric linear equations. Harwe11/0xfordshire, Great Britian, Report AERE-R 8730 .

Garg, S. K., 1978. Pressure transient analysis for two-phase 1 iquid water/steam geothermal reservoirs. Dallas, Society of Petroleum Engineers, paper SPE-7479.

Jonsson, V., 1980. Two-dimensional model of injection into a 1iquid-dominated two-phase production reservoir. Berkeley, Lawrence Berkeley Laboratory, LBL-10003 (in prep.).

Pruess, K., Zerzan, J. M., Schroeder, R. C., and Witherspoon, P. A., 1979a. Description of the three-dimensional two-phase simulator SHAFT78 for use in geothermal reservoir studies. Dallas, Society of Petroleum Engineers, paper SPE-7699.

Pruess, K., Bodvarsson, G., Schroeder, R. C., Witherspoon, P. A., Marconcini, R., Neri, G., and Ruffilli, C., 1979b. Simulation of the depletion of two-phase geothermal reservoirs. Dallas, Society of Petroleum Engineers, paper SPE-8266.

\title{
PROPERTIES OF $\mathrm{H}_{2} \mathrm{O}-\mathrm{CO}_{2} \mathrm{MIXTURES} \mathrm{FOR} \mathrm{GEOTHERMAL} \mathrm{RESERVOIR} \mathrm{AND}$ WELLBORE SIMULATORS
}

\author{
E. R. Iglesias and R. C. Schroeder
}

\section{INTRODUCT ION}

Discharges from hydrothermal reservoirs often contain considerable amounts of noncondensible gases (White et al., 1971; Burgassi et al., 1975; Weres et a1., 1977). By far the dominant species is the weakly polar, slightly soluble carbon dioxide mole- cule (E1lis and Mahon, 1977; Wahl, 1977). The total pre-exploitation $\mathrm{CO}_{2}$ content of these reservoirs ranges probably as high as several percent by mass (e.g., Sutton and McNabb, 1977; Gislason et al., 1978). These high gas contents result in hydrothermal fluid thermodynamic properties significantly different from those of pure water. Properties 
affected include pressure, density, enthalpy, compressibility, vapor saturation, etc. (Strauss and Schubert, 1979a,b; Grant, 1977).

The current LBL geothermal reservoir and wel1bore simulators assume pure water as the only fluid component in the system. We therefore felt that a wider and more realistic prediction capability required inclusion of $\mathrm{CO}_{2}$ as a second component to these codes. Two-component simulators would find immediate application in modeling $\mathrm{CO}_{2}-\mathrm{rich}$ hydrothermal fields (e.g., the Serrazzano, Italy, and Krafla, Iceland, reservoirs).

Implementation of the envisioned multiphase, multicomponent simulators requires formulation of the physical properties of the $\mathrm{H}_{2} \mathrm{O}-\mathrm{CO}_{2}$ mixtures and development of appropriate computational techniques. We feel that the computational tools developed for pure water simulators can be adapted to handle this problem. In this report, we focus on the description of a simplified thermodynamic model of watercarbon dioxide mixtures that has been formulated. Unlike previous studies (e.g., Zyvoloski and O'Sullivan, 1980; Strauss and Schubert, 1979a,b; Grant, 1977; Sutton, 1976), which consider only twophase situations, this model applies to compressed solutions, two-phase mixtures, and superheated gas mixtures.

\section{A SIMPLE MODEL}

The basic assumption is that of thermodynamic equilibrium. Within the typical ranges spanned by the relevant thermodynamic variables in hydrothermal reservoirs, a water-carbon dioxide mixture may be in three different states: a compressed liquid solution, a liquid in equilibrium with a vapor phase, and a "superheated" gas.

In a two-phase situation, the liquid phase contains dissolved gas, and the gas phase is a mixture of steam and $\mathrm{CO}_{2}$. We assume that $\mathrm{CO}_{2}$ partitions between the two phases according to Henry's Law. The total pressure is computed as the sum of the saturation pressure of pure water $\mathrm{P}_{1}{ }^{*}$ and the partial pressure of $\mathrm{CO}_{2}, \mathrm{P}_{2}$. The gas phase density is taken to be equal to the saturated steam density $\rho_{1 G}^{t}$ divided by the steam mass fraction in the gas phase $y_{1}$. Furthermore, the liquid density is estimated as the saturated water density $P_{1 L}^{\star}$ divided by the water mass fraction in the solution $x_{1}$. The gaseous $\mathrm{CO}_{2}$ specific enthalpy $h_{2 G}$ is computed from an analytical fit to experimental data due to Sweigert et al. (1946); by addition of $h_{2 G}$ with the heat of solution we obtain the specific enthalpy of the dissolved $\mathrm{CO}_{2}, \mathrm{~h}_{2 \mathrm{G}}$. The enthalpies for the liquid and gaseous phases are computed from:

$$
\begin{aligned}
& h_{L}=x_{1} h_{1 L}^{*}+x_{2} h_{2 L} \\
& h_{G}=y_{1} h_{1 G}^{*}+y_{2} h_{2 G},
\end{aligned}
$$

where the asterisks refer to saturated water properties. Other thermodynamic variables of interest, such as total density, vapor and liquid saturation, and internal energy are derived from the formulation just described.
In the compressed liquid region the $\mathrm{CO}_{2}$ partial pressure is computed from Henry's Law, and the water partial pressure $P_{1}$ by the difference $\left(P-P_{2}\right)$. The water density $\rho_{1 L}(P, T)$ is taken from steam tables, and the liquid density is estimated as $\rho_{\mathrm{L}}=\rho_{1 L} / \mathrm{x}_{1}$. The liquid specific enthalpy is computed from expression (1), replacing $h_{1 L}^{*}$ by $h_{1 L}$ which accounts for the effects of pressure in the water enthalpy.

The partial pressures of steam and $\mathrm{CO}_{2}$ in the superheated gas region are estimated as $P_{1}=y_{1} P$, $\mathrm{P}_{2}=\mathrm{y}_{2} \mathrm{P}$ (Sutton, 1976). The gas density is taken as $\rho_{G}=\rho_{1 G}\left(P_{1}, T\right) / y_{1}$. The specific gas enthalpy is computed from expression (2), replacing $h_{1 G}^{*}$ by $\mathrm{h}_{1 \mathrm{G}}$.

Approximate analytical expressions for the boundaries of the two-phase region, boiling and dew curves, have been derived as follows:

$$
\begin{aligned}
& P_{B}(\lambda, T)=P_{1}^{*}(T)+18 k(T) /[(44 / \lambda)-26] \\
& P_{D}(\lambda, T)=P_{1}^{*}(T) /(1-\lambda),
\end{aligned}
$$

where $\mathrm{K}(\mathrm{T})$ is Henry's Law constant and $\lambda$ the total $\mathrm{CO}_{2}$ mass fraction.

Illustrative results are presented in Figures 1 through 4. Clearly, two-phase situations develop

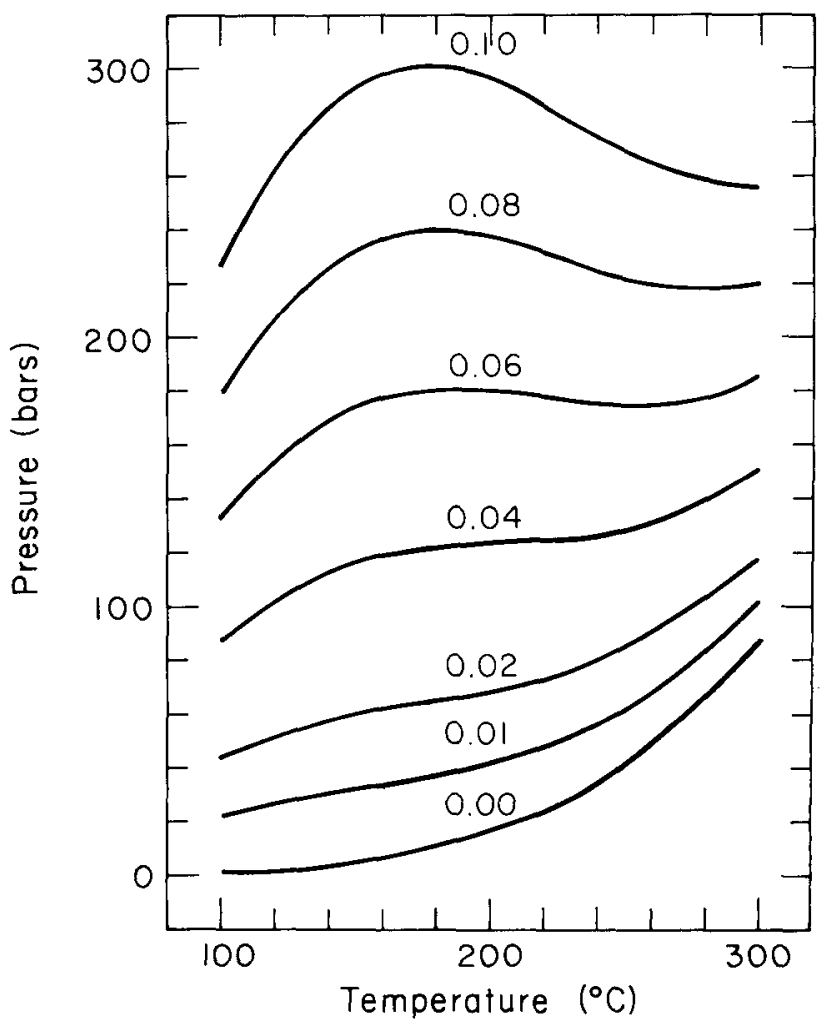

Figure 1. Boiling curves for $\mathrm{H}_{2} \mathrm{O}-\mathrm{CO}_{2}$ mixtures. Total $\mathrm{CO}_{2}$ mass fractions are indicated on the curves.
(XBL 795-853) 


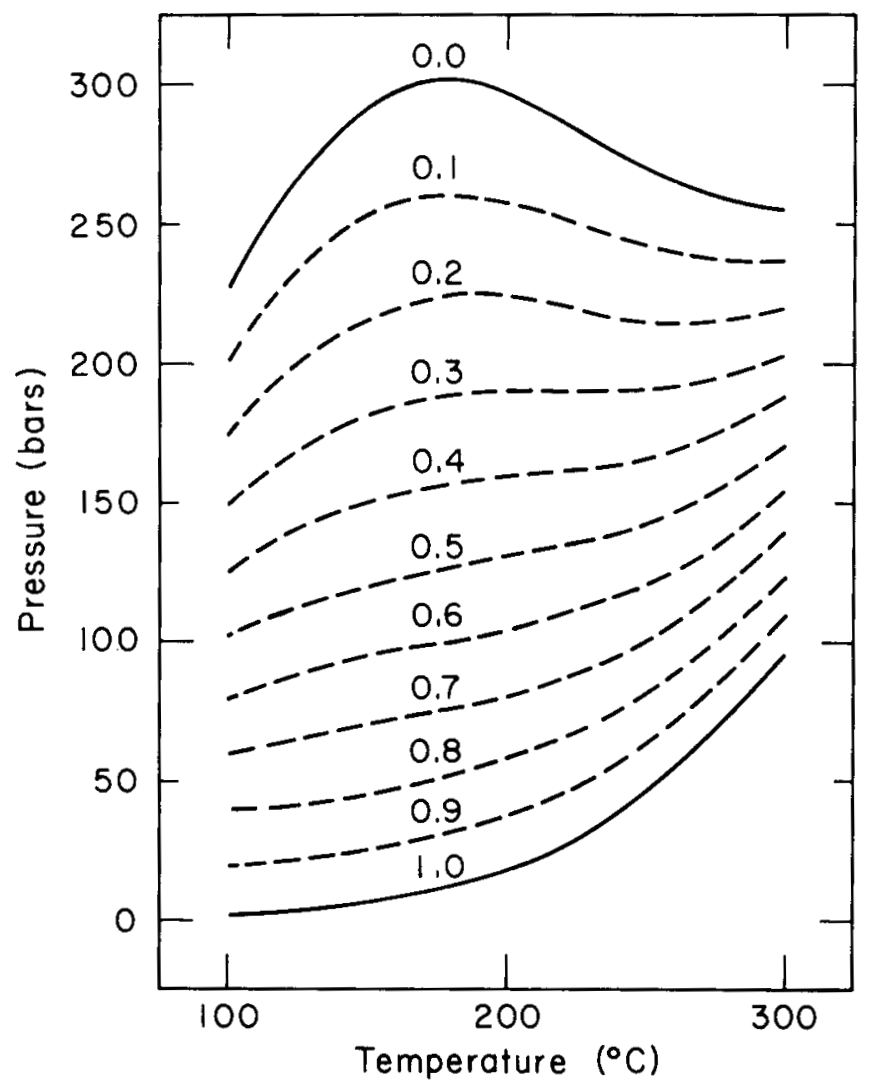

Figure 2. Vapor saturation curves (values of $\mathrm{S}_{\mathrm{v}}$ indicated on the curves) for an $\mathrm{H}_{2} \mathrm{O}-\mathrm{CO}_{2}$ mixture. The total $\mathrm{CO}_{2}$ mass fraction is $\lambda=0.1$.

(XBL 801-6762)

for pressures and temperatures at which pure water exists as a compressed liquid, even for relatively small $\mathrm{CO}_{2}$ total mass fractions. This may have significant implications in fluid reserve assessment and well test interpretation. Figure 1 indicates the interesting possibility of inverse isobaric condensation and evaporation taking place at high $(\geq 5 \%)$ carbon dioxide contents; this may introduce peculiar effects in hydrothermal fluid flow patterns. Our results also indicate that $\mathrm{CO}_{2}$ may significantly contribute to the fluid enthalpy, particularly in reservoir gas caps where the carbon dioxide mass fraction is high.

This simple model is also currently being implemented in a steady-state wellbore code (Miller, 1979 , personal communication).

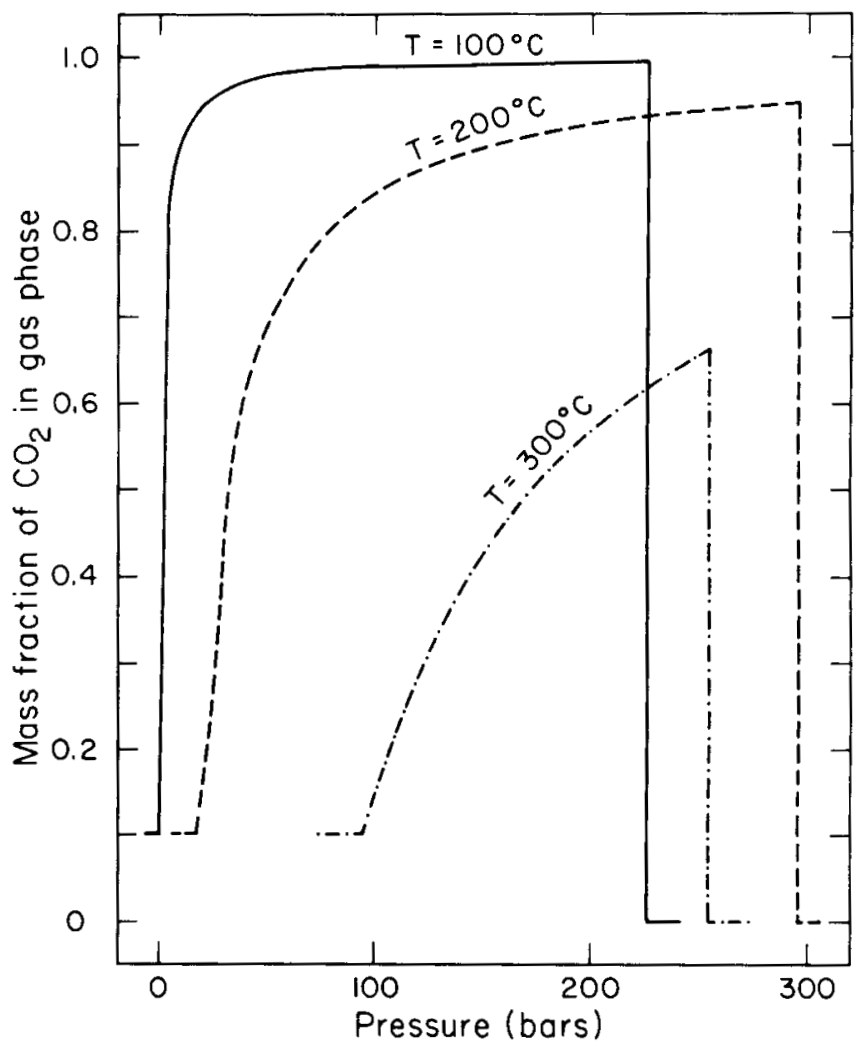

Figure 3. $\mathrm{CO}_{2}$ mass fraction in the vapor phase as a function of pressure and temperature. The total $\mathrm{CO}_{2}$ mass fraction is 0.1 . (XBL 801-6763)

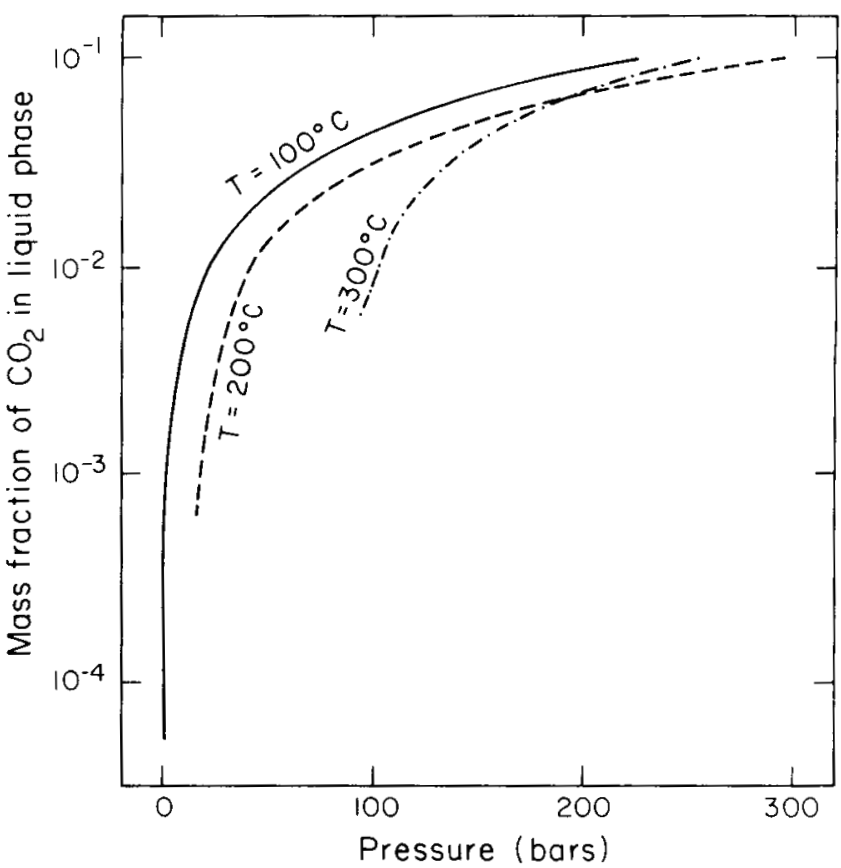

Figure 4. $\mathrm{CO}_{2}$ mass fraction in the liquid phase as a function of pressure and temperature. The total $\mathrm{CO}_{2}$ mass fraction is 0.1 .

(XBL 801-6764) 
SUMMARY

The main advantage of the model just described is its simplicity. Only the thermodynamic properties of the pure components plus Henry's Law are used to estimate the properties of the mixture. In this economical way a qualitative understanding of compressed $\mathrm{CO}_{2}-\mathrm{H}_{2} \mathrm{O}$ solutions, two-phase and superheated gas mixtures is achieved. The accuracy of the mode1, however, is only fair, degrading rapidly with increasing temperatures, pressures and concentrations. This is of course because the simple assumptions adopted become inadequate outside a fairly restricted range of values of $P, T$, and $\lambda$. To overcome these difficulties a new, more accurate model is currently under development. The new model treats the mixture nonidealities on a rigorous thermodynamic basis, including corrections for pressure, temperature, and composition effects.

\section{REFERENCES CITED}

Burgassi, P., Stefani, G. C., Cataldi, R., Rossi, A., Squarci, P., and Taffi, L., 1976. Recent developments of geothermal exploration in the Travale-Radicondoli area, in Proceedings, Second United Nations Symposium on the Development and Use of Geothermal Resources, San Francisco, May 1975. Washington, D.C., U.S. Government Printing Office, v. 3, p. 1571-

E11is, A. J., and Mahon, N. A. J., 1977. Chemistry and geothermal systems. New York, Academic Press.

Gislason, G., Armannsson, A., and Hauksson, T., 1978. Thermal behavior and dissolved gases in the Krafla geothermal system, Iceland.
Icelandic National Energy Authority, report, OSJHD- 7846 .

Grant, M. A., 1977. Broadlands: a gas dominated geothermal field. Geothermics, v. 6, no. 9, p. $9-29$.

Strauss, J. M., and Schubert, T., 1979a. Effect of $\mathrm{CO}_{2}$ on the buoyancy of geothermal fluids. Geophysics Research Letters, v. 6. no. 1, p. 5-8.

1979b. Thermodynamic properties for the convection of steam-water- $\mathrm{CO}_{2}$ mixtures. Reprint submitted to the American Journal of Science, March 1979.

Sutton, F. M., 1976. Pressure-temperature curves for a two-phase mixture of water and carbon dioxide. New Zealand Journal of Science, v. 20, p. 297.

Sutton, F. M., and McNabb, A., 1977. Boiling curves at Broadlands geothermal field, New Zeal and. New Zeal.and Journal of Science, v. 20, p. 333.

Sweigert, R. L., Weber, P., and Allen, R. L., 1946. Thermodynamic properties of gases: carbon dioxide. Ind. Engin. Chem., v. 30, . 185.

Wahl, E. F., 1977. Geothermal energy utilization. New York, Wiley-Interscience.

Weres, 0., Tsao, K., and Wood, B., 1977. Resource, technology, and environment at The Geysers. Berkeley, Lawrence Berkeley Laboratory, LBL-5231.

White, D. E., Muffler, L. J. P., and Truesdell, A. H., 1971. Vapor-dominated hydrothermal systems compared with hot-water systems. Economic Geology, v. 66, p. 75-97.

Zyvoloski, G. A., and O'Sullivan, M. J., 1980. Simulation of a gas dominated, two-phase geothermal reservior. SPE Journal, v. 20, p. 52-58.

\title{
PRELIMINARY STUDIES OF THE RESERVOIR CAPACITY AND LONGEVITY OF THE BACA GEOTHERMAL FIELD, NEW MEXICO
}

\author{
G. S. Bodvarsson, S. P. Vonder Haar, M J. Wilt, and C. F. Tsang
}

\section{INTRODUCTION}

The Baca geothermal field is located in the Valles Caldera, New Mexico, about 55 miles north of Albuquerque. The field is being developed by the Union Oil Company of California and the Public Service Company of New Mexico (PNM). To date, 18 geothermal wells have been drilled in the Valles Caldera, varying in depth from 2000 to $9000 \mathrm{ft}$ (Union and PNM, 1978). Six of the wells have been drilled in the Sulfur Creek area, the remainder along Redondo Creek (Figure 1).

The wells in the Sulfur Creek area have penetrated a high-temperature but low-productivity formation. In the Redondo Creek area, the wells have encountered a high-temperature $\left(\geq 550^{\circ} \mathrm{F}\right)$ liquiddominated reservoir.

It is extremely important to make reliable estimates of the mass of hot water in place (reservoir capacity) and the length of time the reservoir can supply steam for a 50-MW power plant (reservoir longevity). Reservoir longevity depends both on the reservoir capacity and on the overall development plan for the field (flow rates, injection, etc.). Our paper (Bodvarsson et a1., 1979) represents the first in a series of studies of the reservoir capacity and longevity of the Baca field.

\section{THE YEAR'S ACTIVITIES}

In this first study, the reservoir capacity was estimated by volumetric means using existing geological, well, and geophysical data. An initial study of reservoir longevity was also made using the two-phase numerical simulator SHAFT79 (Preuss et al., 1979) developed at LBL. Because of the lack of available data, we made a number of assumptions during the course of the study. Therefore, the results presented are preliminary estimates only.

Figure 1 is a base map of the Valles Caldera showing temperature contours, resistivity survey lines, and major faults. Geologic cross sections of the Valles Caldera region are shown in Figure 2 (see also Dondanville, 1971; Slodowski, 1977; Bailey 


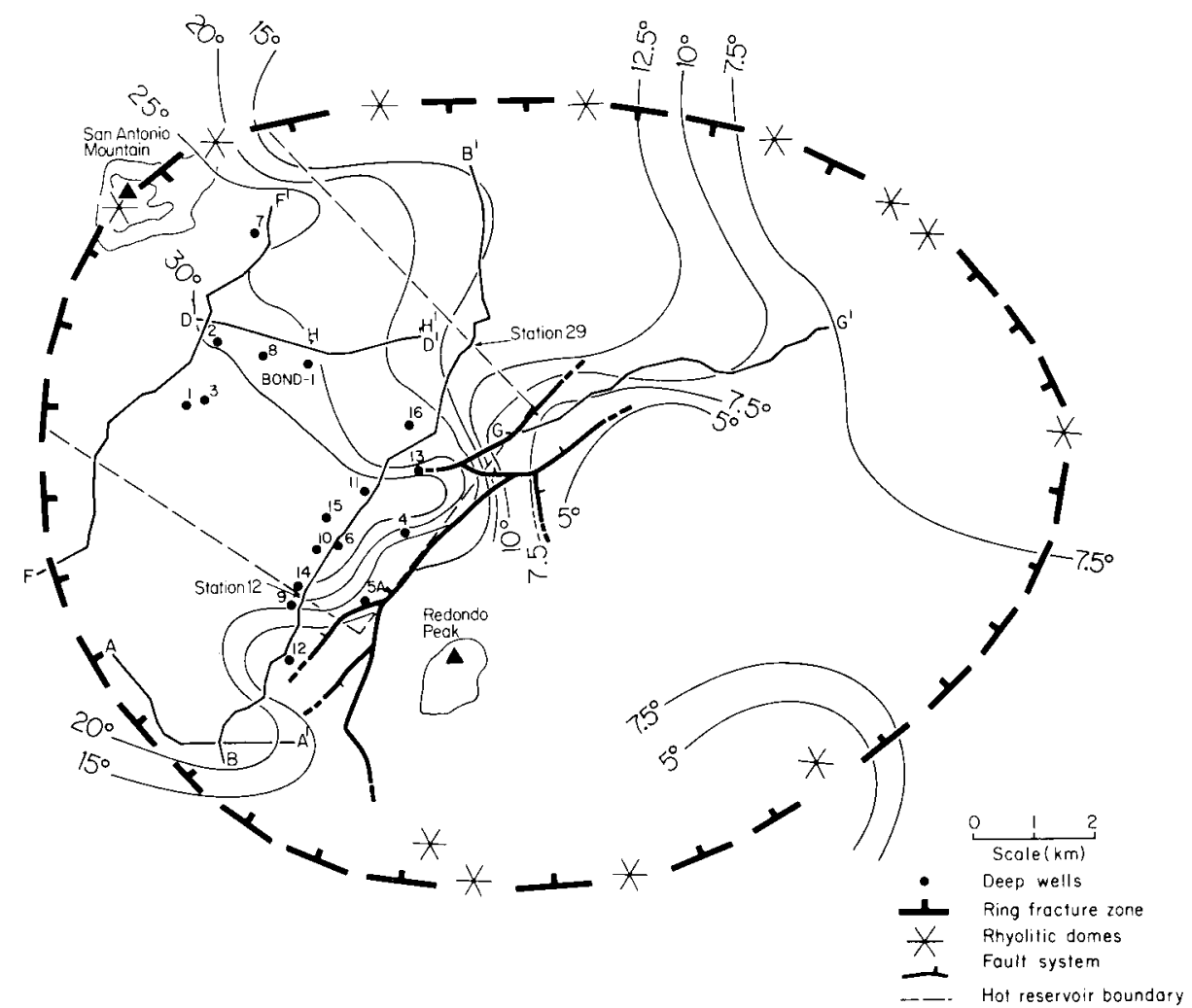

Figure 1. Base map of the Valles Caldera showing shallow temperature gradients ( $\left.{ }^{\circ}\right)$, geophysical survey lines (e.g., A-A'), specific faults, and the estimated hot reservoir boundary.

(XBL 7912-13349)
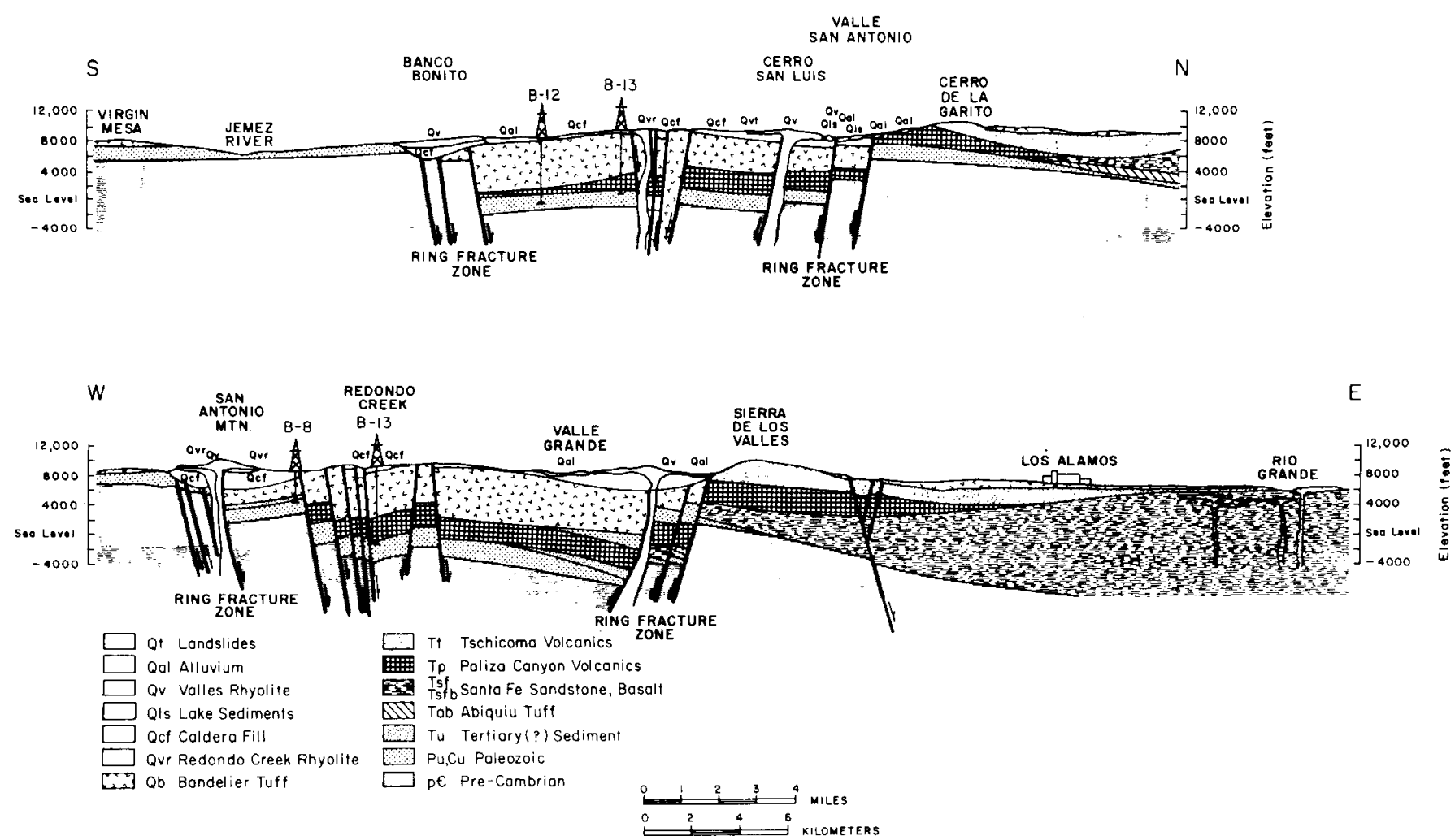

Figure 2. Geologic cross sections of the Valles Caldera Region. (XBL 799-11548A) 
and Smith, 1978). The Bandelier tuff, the producing formation at Baca, is composed of several members of closely welded to nonwelded rhyolitic tuff and tuff breccia. Up to $6300 \mathrm{ft}$ of this rock has been penetrated by the wells in Redondo Creek, but the bulk of the produced fluid comes from the deeper, more permeable layers. From temperature logs of the wells in the Redondo Creek area, an average reservoir thickness of $2000 \mathrm{ft}$ was estimated. An average reservoir porosity of $5 \%$ was estimated from well resistivity logs and core data (Core Laboratories, 1975).

Geophysical data (Union Oil Co., 1972; Geonomics, 1976) shallow temperature contours and deep temperature data (Union Oil Co. and PNM, 1978) were used in estimating the areal extent of the reservoir. The reservoir temperature contours (Figure 3) are not very reliable due to the limited amount of data, but they do indicate a sharp temperature gradient southeast of the main temperature anomaly. This boundary coincides with a major northeast-southwest fault (Figure 1) that may act as an impermeable barrier. Figure 4 shows the shallow temperature gradients and the telluric profiles along line $B-B^{\prime}$, which is directed along the length of Redondo Canyon. An estimation of the

\section{Valles Caldera}

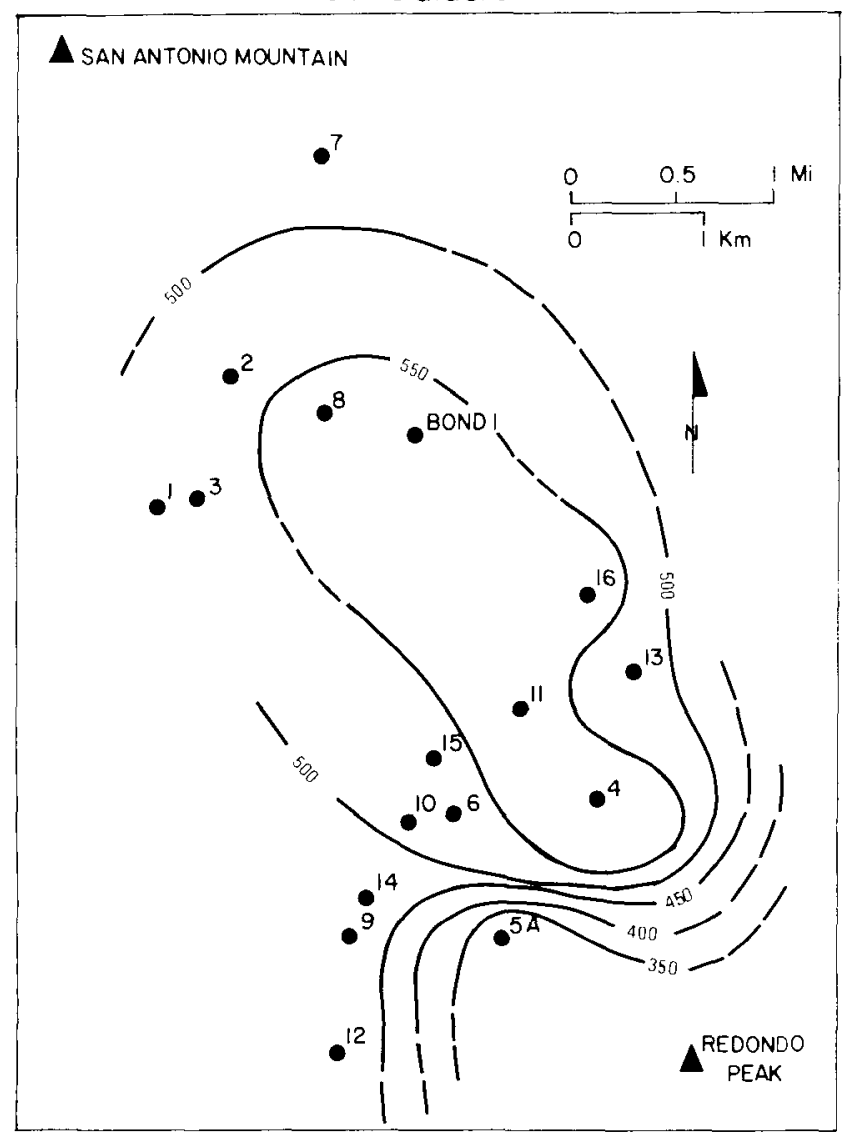

Figure 3. Deep reservoir temperature contours ( $3000 \mathrm{ft}$ above sea level), in degrees.

(XBL 794-7414B) hot reservoir boundaries in the north-south direction is made from these data. The results are indicated by the dotted 1 ine in Figure 4 .

The data presently available are too limited to allow the western boundary of the hot reservoir to be established. To allow an optimistic estimation, the hot reservoir in this direction was assumed to extend to the ring fracture zone. Some geophysical data, and the fact that the Sulfur Creek wells are dry, seem to indicate a more reasonable boundary close to the Bond-1 well.

Using the above criteria, the areal extent of the hot reservoir was estimated to be $40 \mathrm{~km}^{2}$ and the porosity-thickness product to be $100 \mathrm{ft}$. These values correspond to a reservoir capacity of $2.2 \mathrm{x}$ $10^{12} \mathrm{lb}$ of hot fluid in place.

The longevity of the Baca field has been studied using the numerical simulator SHAFT79 (Preuss et al., 1979). The reservoir was simulated using one basic rectangular mesh, with dimensions corresponding to those estimated in the previous section. In a few case studies, elements were added to obtain the required boundary conditions. Due to symmetry, only half of the system was modeled (Figure 5). Wells were not simulated individually, but rather the fluid was produced uniformly over one node representing half of the well field (assumed to be $1 \mathrm{~km}^{2}$ ).

The parameters used in the simulation are given in Table 1. Most of these were taken directly from data reports released to the public by Union Oil Company. The relative permeability curves used were the Corey curves (Faust and Mercer, 1979), with residual liquid and steam saturations of 0.30 and 0.05 respectively.

Five cases were studied using a constant mass flow rate. The value used was based upon the amount of steam theoretically required for a 50-MW power

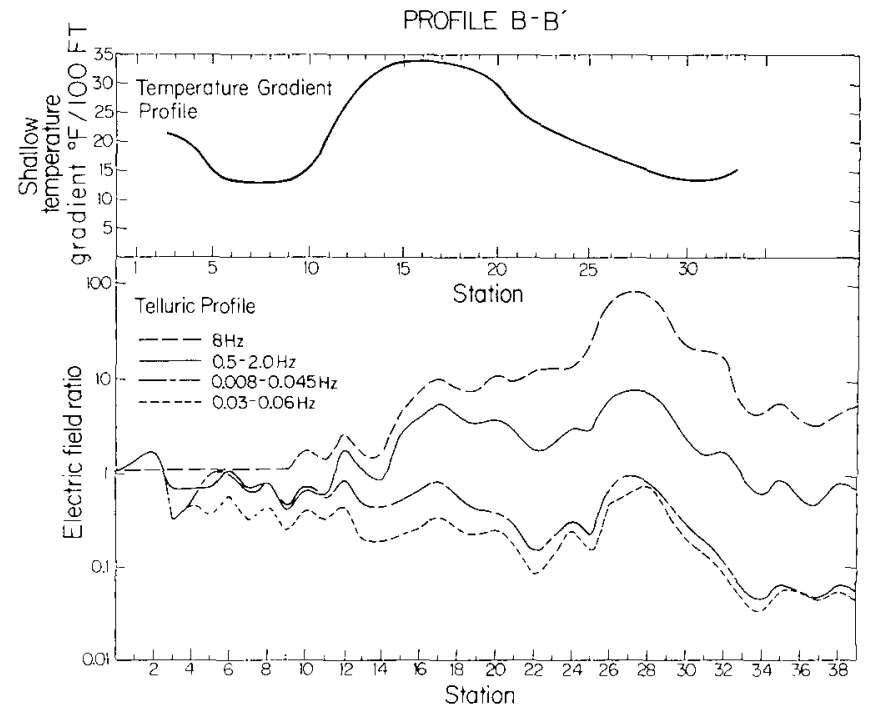

Figure 4. Shallow temperature gradients and telluric profiles along line B-B'. (XBL 7912-13350) 


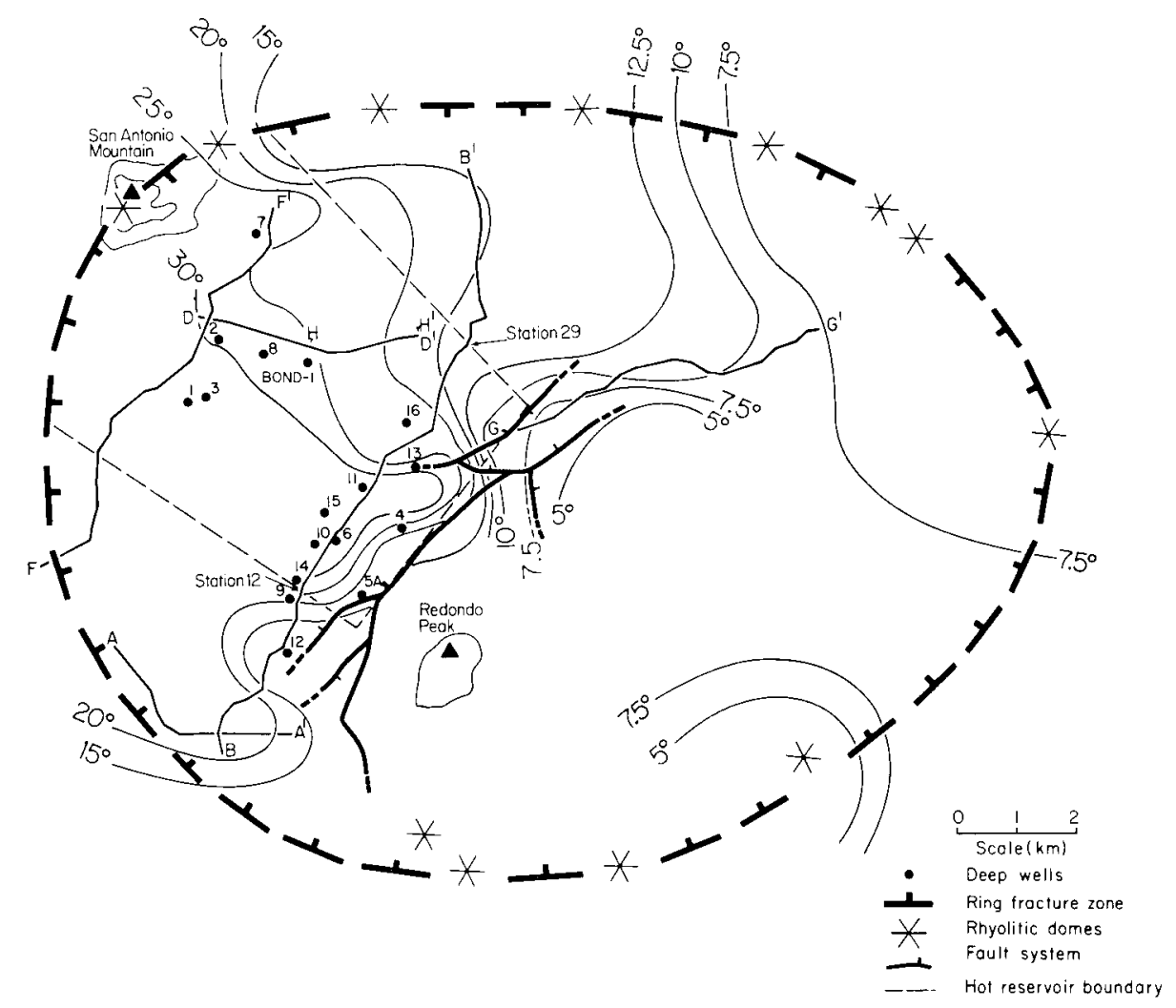

Figure 1. Base map of the Valles Caldera showing shallow temperature gradients ( ${ }^{\circ}$ ), geophysical survey lines (e.g., $A^{-} A^{\prime}$ ), specific faults, and the estimated hot reservoir boundary.

(XBL 7912-13349)
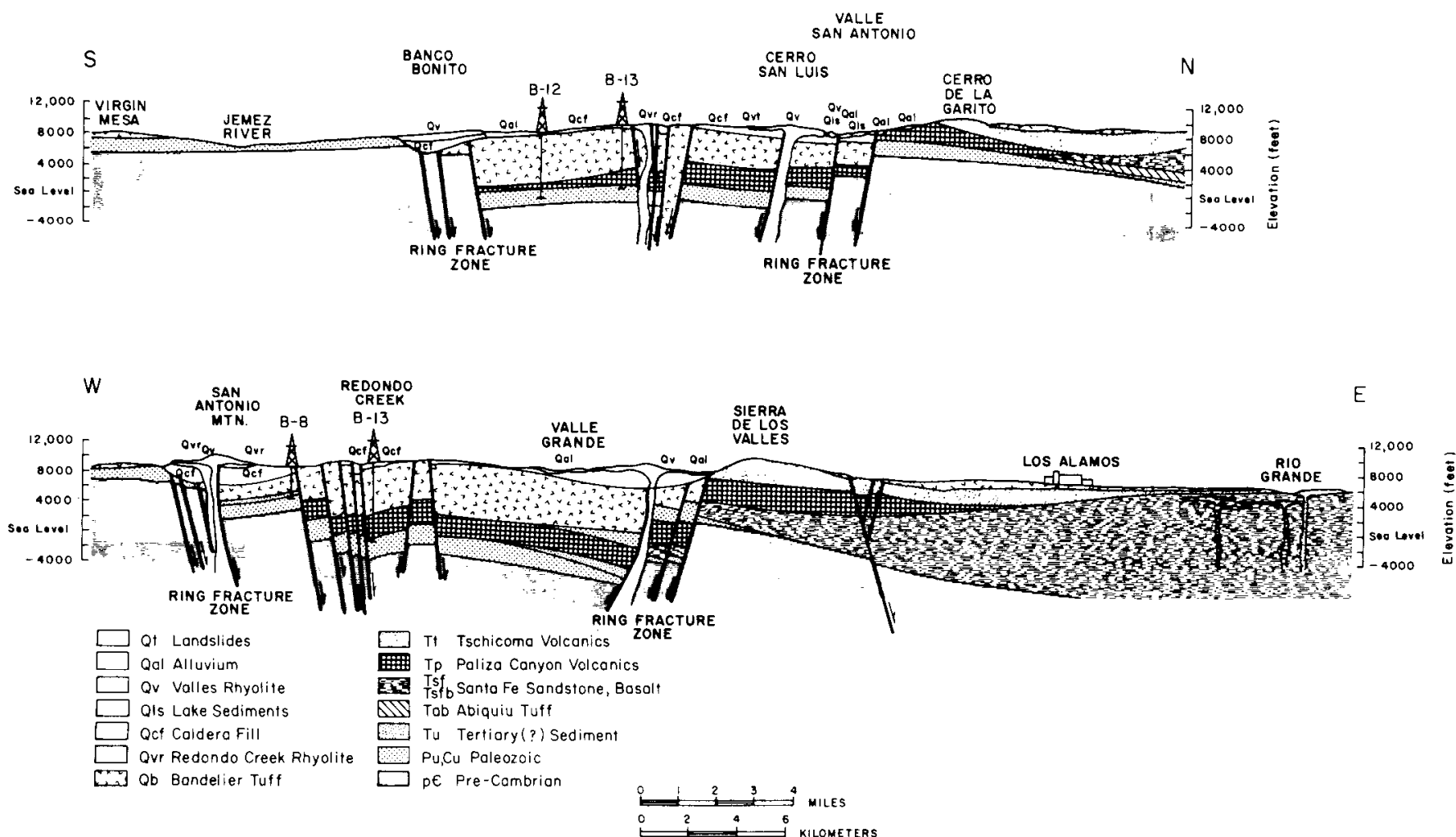

Figure 2. Geologic cross sections of the Valles Caldera Region. (XBL 799-11548A) 
and Smith, 1978). The Bandelier tuff, the producing formation at Baca, is composed of several metnbers of closely welded to nonwelded rhyolitic tuff and tuff breccia. Up to $6300 \mathrm{ft}$ of this rock has been penetrated by the wells in Redondo Creek, but the bulk of the produced fluid comes from the deeper, more permeable layers. From temperature logs of the wells in the Redondo Creek area, an average reservoir thickness of $2000 \mathrm{ft}$ was estimated. An average reservoir porosity of $5 \%$ was estimated from well resistivity logs and core data (Core Laboratories, 1975).

Geophysical data (Union Oil Co., 1972; Geonomics, 1976) shallow temperature contours and deep temperature data (Union Oil Co. and PNM, 1978) were used in estimating the areal extent of the reservoir. The reservoir temperature contours (Figure 3) are not very reliable due to the limited amount of data, but they do indicate a sharp temperature gradient southeast of the main temperature anomaly. This boundary coincides with a major northeast-southwest fault (Figure 1) that may act as an impermeable barrier. Figure 4 shows the shallow temperature gradients and the telluric profiles along line $B^{\prime} B^{\prime}$, which is directed along the length of Redondo Canyon. An estimation of the

\section{Valles Caidera}

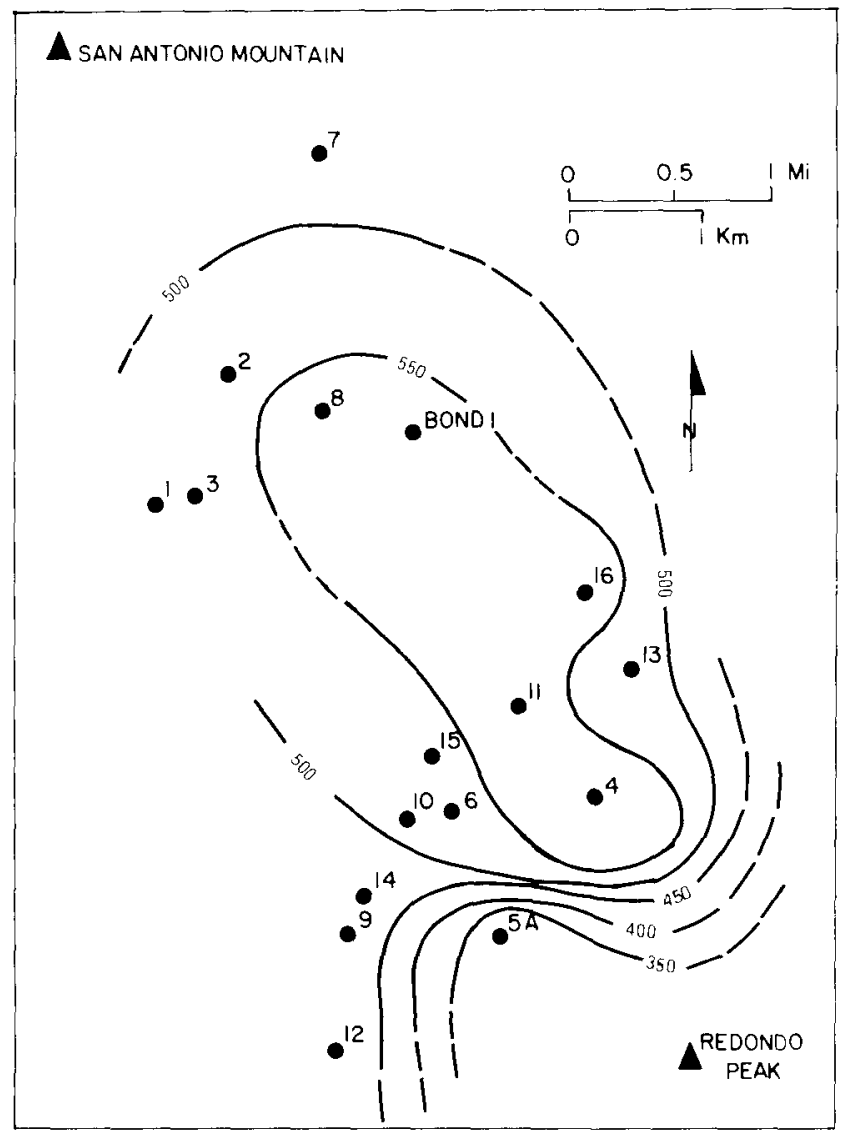

Figure 3. Deep reservoir temperature contours ( $3000 \mathrm{ft}$ above sea level), in degrees.

(XBL 794-7414B) hot reservoir boundaries in the north-south direction is made from these data. The results are indicated by the dotted 1 ine in Figure 4 .

The data presently available are too limited to allow the western boundary of the hot reservoir to be established. To allow an optimistic estimation, the hot reservoir in this direction was assumed to extend to the ring fracture zone. Some geophysical data, and the fact that the Sulfur Creek wells are dry, seem to indicate a more reasonable boundary close to the Bond-1 well.

Using the above criteria, the areal extent of the hot reservoir was estimated to be $40 \mathrm{~km}^{2}$ and the porosity-thickness product to be $100 \mathrm{ft}$. These values correspond to a reservoir capacity of $2.2 \mathrm{x}$ $10^{12} 1 \mathrm{~b}$ of hot fluid in place.

The longevity of the Baca field has been studied using the numerical simulator SHAFT79 (Preuss et al., 1979). The reservair was simulated using one basic rectangular mesh, with dimensions corresponding to those estimated in the previous section. In a few case studies, elements were added to obtain the required boundary conditions. Due to symmetry, only half of the system was modeled (Figure 5). Wells were not simulated individually, but rather the fluid was produced uniformly over one node representing half of the well field (assumed to be $\left.1 \mathrm{~km}^{2}\right)$.

The parameters used in the simulation are given in Table 1. Most of these were taken directly from data reports released to the public by Union Oil Company. The relative permeability curves used were the Corey curves (Faust and Mercer, 1979), with residual liquid and steam saturations of 0.30 and 0.05 respectively.

Five cases were studied using a constant mass flow rate. The value used was based upon the amount of steam theoretically required for a 50-MW power

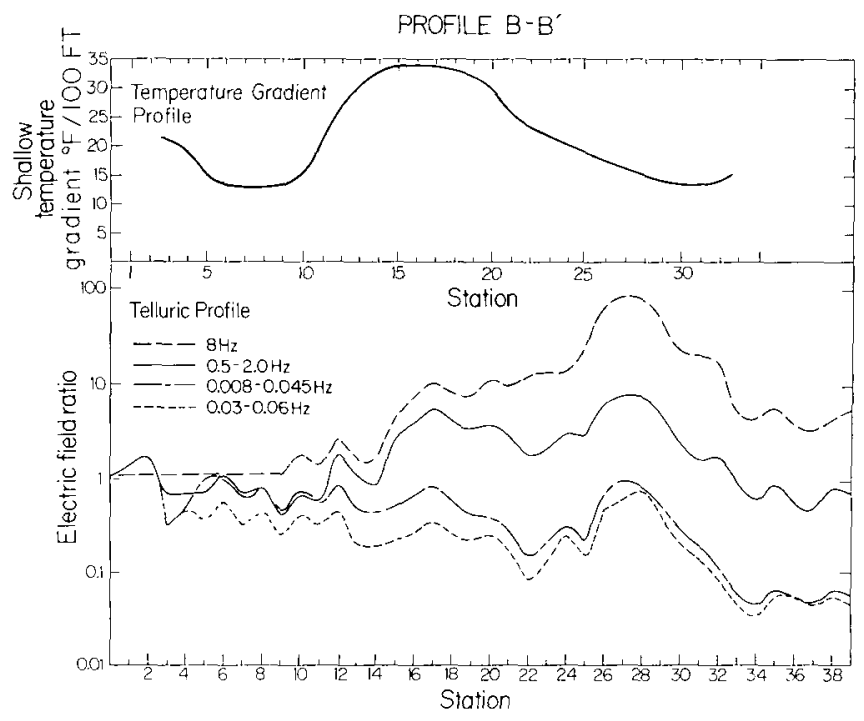

Figure 4. Shallow temperature gradients and telluric profiles along line B-B'. (XBL 7912-13350) 
The Mesh Used In The Simulation

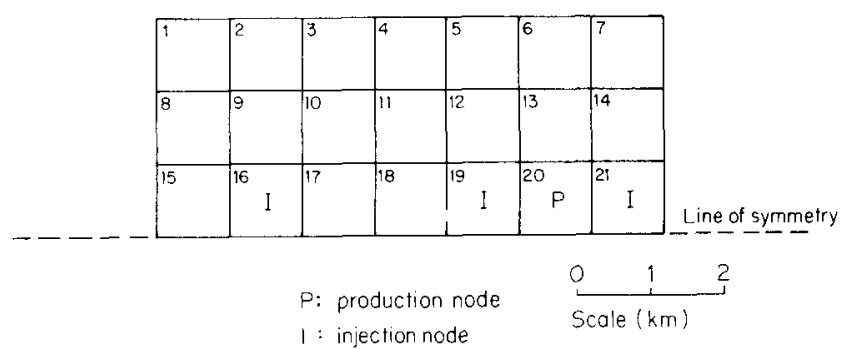

Figure 5. The mesh used in the longevity study for "closed" reservoir cases.

(XBL 7912-13354)

plant and a constant value of the mass fraction of steam in the separators (Union Oil Co. and PNM, 1978). The five cases studied were a bounded reservoir, an infinite reservoir, and three injection cases. Each case was run until the pressure in the production node dropped below the designated wel1head pressure of 10 bars (Union Oil Co. and PNM, 1978). The longevity of the field in each case was defined as the time it took to reach this point. In Figure 6, the pressure, temperature, and vapor saturation at the production node are plotted versus time for three of these cases.

The simulation of the closed reservoir was terminated after 7.4 years due to the low pressure in the production node. As Figure 6 shows, the pressure falls very rapidly at first until the production node goes two-phase. Under two-phase conditions, the pressure is related not to the

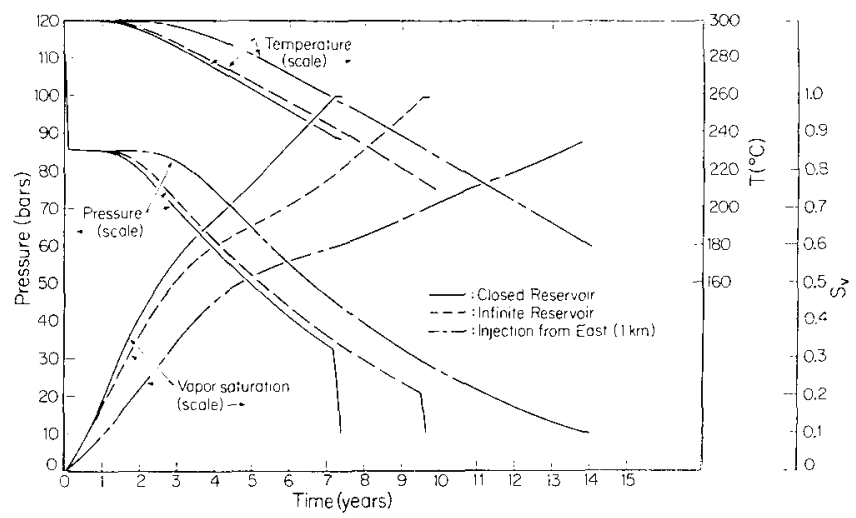

Figure 6. The temperature, pressure, and vapor saturation behavior in the production node for three of the constant flow rate cases.

(XBL 7912-13352)

density but to the temperature. The pressure first stabilizes after the node becomes two-phase because of the large heat capacity of the node and the low initial boiling rates. Later, the pressure declines gradually with the temperature. When saturation reaches 1.0 , the pressure again becomes dependent on density, and the low inflow of fluid from adjacent nodes (due to the low absolute permeability and the effect of the relative permeability curves) causes the pressure to drop very rapidly.

For the infinite case, the pressure in the production region dropped below 10 bars after about 10 years, again due to the limited flow of the fluids into the production node (low-permeability effects). It therefore appears that the controlling

Table 1. Parameters used in simulation.

Constant flow rate

Rock heat capacity

Permeability thickness

Thermal conductivity

Porosity thickness

Initial pressure

Initial temperature

Enthalpy of saturated steam in flash tank

Enthalpy of saturated 1iquid in flash tank

Steam requirement for a 50-MW plant

Enthalpy of the Eluid entering the well

Steam quality in flash tank

Total flow rate

$$
\begin{aligned}
& Q_{T}=330 \mathrm{~kg} / \mathrm{s} \\
& \mathrm{C}_{\mathrm{v}}=950 \mathrm{~J} / \mathrm{kg}^{\circ} \mathrm{C} \\
& \mathrm{kh}=6,000 \mathrm{md} \mathrm{ft} \\
& \lambda=2.0 \mathrm{~J} / \mathrm{s} \cdot \mathrm{m} \cdot{ }^{\circ} \mathrm{C} \\
& \phi H=100 \\
& P_{i}=110 \mathrm{bars} \\
& T_{i}=300^{\circ} \mathrm{C} \\
& H_{s v}=2,772,000 \mathrm{~J} / \mathrm{kg} \\
& H_{s 1}=734,380 \mathrm{~J} / \mathrm{kg} \\
& Q_{s v}=892,0001 \mathrm{bs} / \mathrm{hr} \\
& H_{W v} \\
& \mathrm{~S}_{\mathrm{qv}} \\
& Q_{t}
\end{aligned}
$$


factor limiting the reservoir longevity is the low permeability-thickness product rather than the amount of hot water in place.

Three injection cases were simulated using an injection flow rate of half the production mass flow rate; water was injected into nodes 16,19 , and 21 (Figure 5). For all three cases, the pressure into the production node dropped below 10 bars after 13 or 14 years. Figure 6 shows that with injection, the pressure falls below 10 bars before the production node reaches superheated steam conditions. This behavior is due to increased boiling in the production node because more water is coming in. The boiling causes the temperature, and consequently the pressure, to drop steadily.

A few cases were run using a time dependent flow rate based upon the steam quality in the separators and the theoretical steam requirement for a 50-MW power plant. Four cases were run using this approach: a closed reservoir, a semi-closed reservoir, an infinite reservoir, and a closed reservoir with recharge from deeper layers. In the semi-closed case, the northeast and the southwest boundaries were expanded from 3 to $10 \mathrm{~km}$, leaving the other two boundaries unchanged. No injection runs were made, because very little separated water was obtained after about three years of simulation, and the injection of such a small amount of water would not alter the results significantly. Figure 7 shows the calculated flow rate as a function of time for the bounded reservoir case.

The closed reservoir case and the semi-closed reservoir case give very similar results; the pressure in the production node drops below 10 bars after 25 and 26 years, respectively. For the "infinite reservoir" case, the required amount of steam was supplied for 35 years before the pressure fell below 10 bars.

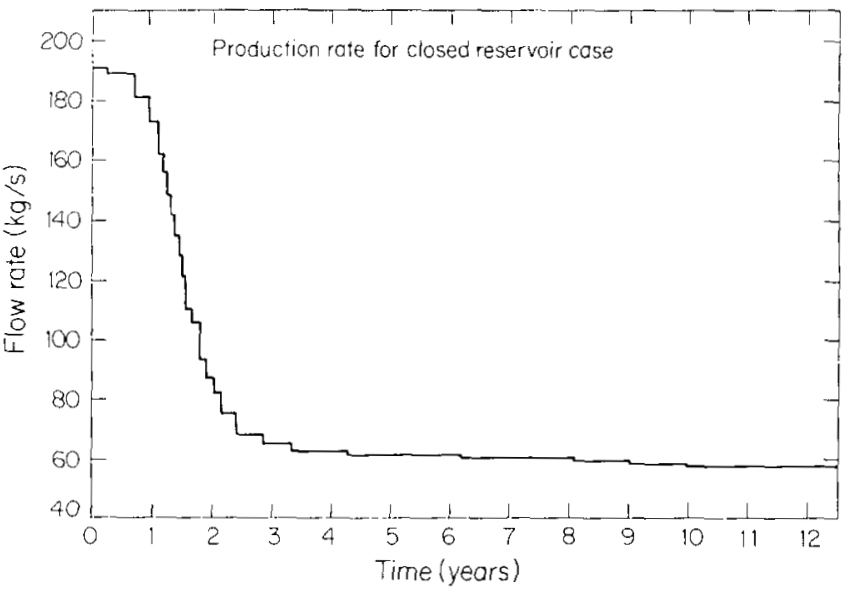

Figure 7. Production rate versus time for the closed boundary case.

(XBL 7912-13353)

Finally, a run was made assuming that the reservoir was recharged from deeper layers through a $20 \mathrm{~m}$ wide fault zone extending along Redondo Creek (recharging nodes 5, 13, and 20). The fault zone was modeled as a constant pressure boundary $600 \mathrm{~m}$ below the assumed reservoir, having a permeability-thickness product of $60,000 \mathrm{md}$. ft. The results obtained indicate a reservoir longevity of 49 years under these conditions. Table 2 summarizes the primary results from all of the cases studied.

In conclusion, the study indicates a reservoir capacity on the order of $2.2 \times 10^{12} \mathrm{lbs}$ of hot fluid and a longevity of 7 to 50 years for the Baca geothermal field. The primary factor limiting the longevity of the field is the low permeabilitythickness factor ( $k h$ ), which causes very localized boiling around the production region.

Table 2. Summary of cases and primary results.

Conditions at the end of the run

\begin{tabular}{|c|c|c|c|c|c|c|c|}
\hline Case & Flow rate & $\begin{array}{l}\text { Boundary } \\
\text { conditions }\end{array}$ & Injection & $\begin{array}{l}\text { Time } \\
\text { (yrs) }\end{array}$ & $\begin{array}{c}\text { Pressure } \\
\text { (bars) }\end{array}$ & $\begin{array}{l}\text { Temp. } \\
\left({ }^{\circ} \mathrm{C}\right)\end{array}$ & $\begin{array}{l}\text { Vapor } \\
\text { satur- } \\
\text { ation }\end{array}$ \\
\hline 1 & Constant & Closed & None & 7.4 & 10 & 237 & 1.0 \\
\hline 2 & Constant & "Infinite" & None & 9.6 & 10 & 214 & 1.0 \\
\hline 3 & Constant & Closed & $4 \mathrm{~km} \mathrm{to} \mathrm{NW}$ & 12.9 & 10 & 180 & 0.99 \\
\hline 4 & Constant & Closed & $1 \mathrm{~km}$ to $\mathrm{NW}$ & 13.7 & 10 & 180 & 0.91 \\
\hline 5 & Constant & Closed & $1 \mathrm{~km}$ to $\mathrm{NE}$ & 14.0 & 10 & 180 & 0.87 \\
\hline 6 & Variable & Closed & None & 25 & 10 & 214 & 1.0 \\
\hline 7 & Variable & "Semi-infinite" & None & 26 & 10 & 213 & \\
\hline 8 & Variable & "Infinite" & None & 35 & 10 & 185 & 1.0 \\
\hline 9 & Variable & Bounded with a fault & None & 50 & 10 & 180 & 0.48 \\
\hline
\end{tabular}


PLANNED ACTIVITIES FOR 1980

During the next fiscal year, additional studies of the longevity of the Baca field will be carried out. The effects of relative permeabilities and the size of the production area will be studied, and construction of a geological model of the field will be initiated.

\section{REFERENCES CITED}

Bailey, R. A., and Smith, R. L., 1978. Volcanic geology of the Hemez Mountains, New Mexico, in, J. W. Hawley, ed., Circular 163. New Mexico Min. Mines, p. 184-196.

Bodvarsson, G. S., Vonder Haar, S., Wilt, M. J., and Tsang, C. F., 1979. Preliminary studies of the reservoir capacity and the longevity of the Baca geothermal field, New Mexico. Berkeley, Lawrence Berkeley Laboratory, LBL-10227, $18 \mathrm{p}$.

Core Laboratories, Inc., 1975. Special core analysis study of Baca no. 13 wel1. Union Oil Company.

Dondanville, R. F., 1971. Hydrological geology of the Valles Caldera, New Mexico. Union Baca Project Report, $36 \mathrm{p}$.
Faust, C. R., and Mercer, J. W., 1979. Geothermal reservoir simulation; numerical solution techniques for liquid and vapor dominated hydrothermal systems. Water Resources Research, v. 15, no. 1 , p. 31-46.

Geonomics, Inc., 1976. Magnetotelluric-telluric profile survey of the Valles Caldera prospect. Union Oil Company.

Grant, M., 1979. Interpretation of downhole measurements at Baca. Proc. 4th Workshop on Geothermal Reservoir Engineering, Stanford University.

Pruess, K., Zerzan, J. H., Schroeder, R. C., and Witherspoon, P. A., 1979. Description of the three-dimensional two-phase simulator SHAFT78 for use in geothermal reservoir studies. Paper presented at Petr. Eng. Meeting in Denver, Colorado, February 1-2, 1979.

Slodowski, T. R., 1977. Geological resume of the Valles Caldera. Union Baca Project Report, $11 \mathrm{p}$.

Union Oi1 Company of California, 1972. Additional electrical geophysical surveys of the Valles Caldera area. Union Oil Company.

Union Dil Company of California and Public Service Company of New Mexico, 1978. Geothermal Demonstration P1ant--Technical and Management Proposal to DOE, $120 \mathrm{p}$.

\title{
MODELING TRANSIENT TWO-PHASE FLOW IN A WELLBORE
}

\author{
C. W. Miller
}

\section{INTRODUCTION}

For a complete analysis of a geothermal system, it is necessary to model flow in the wellbore and in the reservoir. Several numerical codes to simulate the two-phase flow in the wellbore have been reported in the geothermal literature including those of Gould (1974), Juprasert and Sanyal (1977), and Sigiurs and Farouq (1979). However, they all assume steady state flow. Such types of models can be used to approximate downhole conditions from wellhead measurements or vice versa but only after the well has been flowing at a constant rate for a while. They are not useful in describing the wellbore flow during a well test. At early times, after a flow rate change has been made at wellhead, the mass flow rate into the well ( $\dot{\mathrm{m}}_{\text {in }}$ ) does not equal the mass flow rate out of the well ( $\dot{\mathrm{m}}_{\text {out }}$ ), because wellbore storage is important. Under such circumstances, a steady-state model, which naturally assumes $\dot{\mathrm{m}}_{\mathrm{in}}=\dot{\mathrm{m}}_{\text {out }}$, is not appropriate. Wellhead data taken during this early time cannot be related accurately to downhole pressures using a steadystate model, and a transient model is needed. Besides relating wellhead and downhole pressures during a well test, one can use such a code to understand the initial pressure changes with time in the well after a flow rate change. Because of heat transfer in the wellbore and the relatively large value of permeability-thickness found in a geothermal field, the drawdown or buildup curve does not necessarily coincide with what is predicted by well test analysis developed by the petroleum industry (Miller, 1979a).

\section{ACTIVITIES IN 1979}

A transient two-phase numerical code that solves one-dimensional flow including heat and mass transfer has been developed. The wellbore model has been coupled to a reservoir model of simple, one-phase radial flow in a porous medium. The program WELBORE solves the equations of mass, momentum, and energy and uses an equation of state to relate the density to pressure and energy. The Navier Stokes equation is used for the momentum equation in contrast to assuming Darcy flow as for flow in a porous medium. Thermodynamic equilibrium is assumed so the equation of state is given by an analytical representation of the the steam tables. For the initial development of the model, the velocities of the two-phases were assumed equal. The four unknowns that must be determined are pressure, energy, density, and velocity.

The basic approach is to solve the four equations using a finite-difference approximation with a partially implicit method. Terms that would impose very restrictive time steps because of the fluid compressibility were solved implicitly while the other terms were evaluated explicitly for ease and computational efficiency. The solution procedure is: (1) to write the change in density, $\mathrm{d} \rho$, in terms of the change in pressure, $d P$, and the change in enegy, de; (2) to solve the energy equation for the quantity de; and ( 3 ) to combine the continuity and momentum equation to give an expression for the new pressure in terms of known values. Combining the equations results in an 
expression

$$
A P=B
$$

where $A$ is a tri-diagonal matrix, which can easily be inverted, and $B$ is a matrix that is a function of the old values of density, pressure, velocity, and energy.

To use this method, the equation of state is written in the form

$$
d \rho=(\partial \rho / \partial P)_{e} d P+(1 / \rho)(\partial \rho / \partial e) \rho d e
$$

instead of $\rho=f n(P, e)$. At the end of the calculation, the computed density is compared to the density calculated from $p=f n(P, e)$. If there is any significant difference, the pressure is calculated a second time using an average of the derivatives $\partial \rho / \partial \mathrm{P}$ and $(1 / \rho)(\partial \rho / \partial \mathrm{e})$. More details are given in Miller $(1979 b)$.

The transient wellbore code was used to investigate the propagation of a pressure pulse down the wellbore after a flow rate change was made at wellhead. Figures 1 and 2 illustrate the pulse as a function of time for flow in a liquid filled well and for flow in the well, where the fluid flashes part of the way up the bore. In the first figure (1iquid filled well), one sees that initially there is no change downhole until the pulse has time to propagate through the bore. Once the pulse reaches the well/reservoir boundary, it interacts with that boundary. In some cases the pulse is partially reflected, propagating back up the bore. The change in wellhead and downhole pressures will be different until this transient motion dies out.

In Figure 2, one sees the pulse propagation in a fluid that is flashing in the bore. In this case, the pulse reflects off the flash point and oscillations in pressure occur in the two-phase region. Again, changes in wellhead pressure are quite different from downhole transients and are not representative of the reservoir itself. Nevertheless, given appropriate boundary conditions, one can use the transient code to solve for the flow in the bore and to essentially eliminate the well as an unkonwn. Even without the correct boundary con-
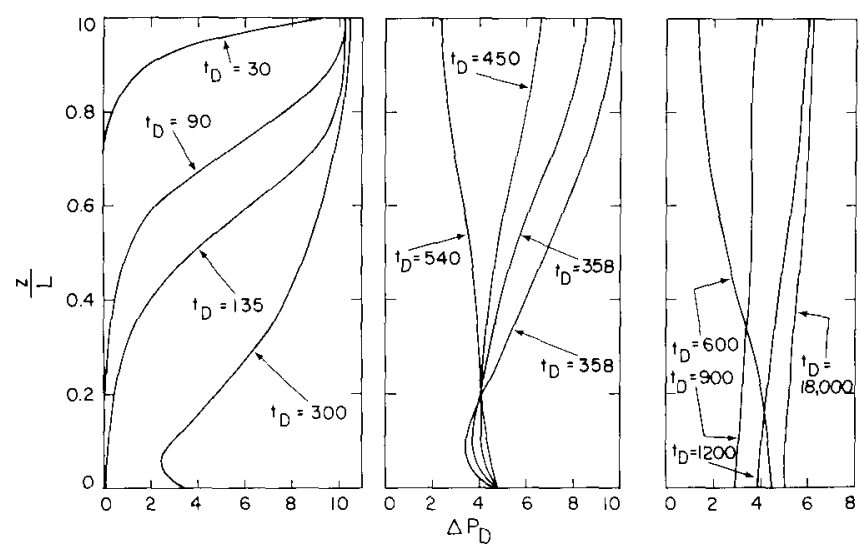

Figure 1. Propagation of pressure pulse down a well as a function of time for a liquid-filled well.

(XBL 794-7404)

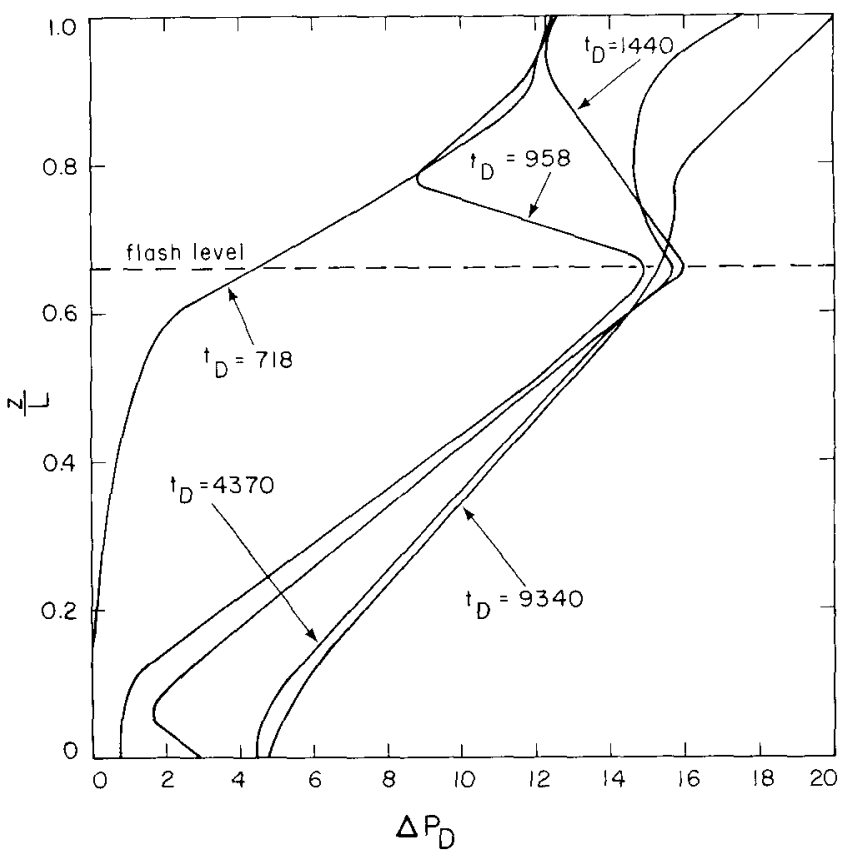

Figure 2. Propagation of a pressure pulse down a wellbore in a two-phase well as a function of time.

(XBL 794-7403)

ditions, one could first estimate the properties of the reservoir and then use the wellbore code with a reservoir model to determine if these properties gave the measured values of pressure and flow rate.

\section{FURTHER INVESTIGATIONS}

Several different combinations of boundary conditions are possible with the program WELBORE. They include: (1) downhole pressure and wellhead flow rate; or (2) wellhead and downhole pressures. It is also of interest to be able to specify wellhead pressure and wellhead flow rate and to determine the downhole pressure and flow rate. Work is being initiated on including this option. Also to improve the mode1, slip is being added, i.e., the velocities of the two phases will not be assumed to be equal. The slip will be given by empirical correlations. With the slip in the model, an attempt will also be made to relate wellhead data to what actually happens downhole. To further improve the mode1, a second component, say $\mathrm{CO}_{2}$, will be added. Then one can look at the flow of two components as well as two phases.

\section{REFERENCES CITED}

Gould, T. L., 1974. Vertical two phase steam water flow in geothermal wells. Journal of Petroleum Technology, v. 26, p. 883-892.

Jupraset, S., and Sanyal, S. K., 1977. A numerical simulator for flow in geothermal wellbores. Geothermal Resources Council Transactions, v. 1, p. 159-161.

Miller, C. W., 1979a. Wellbore storage in geothermal we1ls. Dallas, Society of Petroleum 
Engineers, SPE-8203.

1979b. Numerical model of transient two phase flow in a wellbore. Berkeley, Lawrence Berkeley Laboratory, LBL-9056.
Sugiurs, T., and Farouq, S. M., 1979. A comprehensive wellbore steam-water flow model for steam injection and geothermal applications. Dallas, Society of Petroleum Engineers, SPE-7966.

\title{
CORRECTION OF DOWNHOLE PRESSURE TRANSIENTS MEASURED WITH A FLUID-FILLED CAPILLARY TUBE
}

\author{
C. W. Miller and J. M. Zerzan
}

\section{INTRODUCTION}

One of the limiting factors in the well testing of a geothermal reservoir is the ability to measure downhole pressure transients. Many existing pressure tools, developed for the petroleum industry, cannot withstand the high temperature and high salinity of the geothermal brine. The main problem is the pressure transducer itself. One method that has been used to alleviate the problem is to keep the pressure transducer at wellhead and to transmit downhole pressure changes to wellhead through a fluid-filled capillary tube. The fluid used in the tube should not flash or condense at the temperatures and pressures of interest. Also, the diameter of the tubing must be small enough so that the tubing can be handled at wellhead and lowered into the well. Such a system is marketed for use by the petroleum and geothermal field by the Sperry Sun Company and has been used at Lawrence Berkeley Laboratory for a number of well tests. However, an analysis was done on the system in the previous year (Miller and Haney, 1978), and it was shown that the fluid transmission line delayed and distorted the pressure signal significantly. The time delay of the system was on the same order of magnitude or longer than the response time of the reservoir in many cases. The effect of tubing diameter, fluid type, temperature changes, and temperature and pressure levels were investigated. Nevertheless, because of the desirability of being able to continuously monitor the downhole pressure during a test, and the unavailability of alternate methods at the moment, the system is still being used or being considered for many well tests. The main effort then in 1979 was to investigate whether one could determine an accurate method of correcting for the effect of the measuring instrument, the fluid transmission line in this case.

\section{ACTIVITIES IN 1979}

In the previous work, the fluid transmission system was modeled for the fluid being either a gas or a 1iquid. Given the pressure disturbance generated downhole, one could calculate, then, what would arrive at the wellhead. For the liquid-filled tube, the propagation of the pressure disturbance was controlled by a diffusion-like equation because of the large friction effects. For a gas-filled tube, the pressure disturbance had to be modeled by a wavelike equation that had a damping term to account for the frictional losses. However, to correct for the effects of the fluid transmission line on the signal, one must be able to solve the inverse problem. That is, given the measured pressure signal, it is necessary to determine the downhole pressure that caused the signal. The problem is not straightforward because the specification of the cause of the disturbance (the measured pressure) does not result in a wel1-posed problem. A unique solution may not exist, meaning that different disturbances could result in the same signal arriving at the pressure transducer. At present, it has been possible to obtain reasonable solutions to this inversion problem for the case of the liquidfilled tube, because the equation governing the signal propagation was linear in most cases, and when it was nonlinear, the coefficients were a function of the position only and not a function of position and time. For the gas-filled tubing, the equation governing the signal propagation is highly nonlinear, and it is not clear that a unique solution exists for the measured data. An inversion technique was applied to the liquid case and excellent results were obtained.

As stated above, the liquid-filled tubing was modeled by a diffusion-1ike equation. This same type of equation is important in heat conduction problems, and the solution to this inverse problem has been considered previously. Exact solutions are available for the linear case (Burggraf, 1964). However, the exact solution requires a continuous pressure measurement in time, because the inverse solution is a convergent series dependent on derivatives of pressure with time. The more distorted the signal, the more higher-order derivatives are needed. Accurate measurements of these derivatives may not be realistic.

Another method of inverting data is the nonlinear estimation technique used by Beck (1970). The method is to minimize the difference between the calculated response of the system for a guessed value of pressure or the derivative of the pressure at the bottom of the well and the measured response over some time interval. Because there is a delay in time before the changes downhole can be measured at the wellhead, the minimization is done over a number of "future times," with the number of future times depending on just how long the delay is. If a signal takes $10 \mathrm{sec}$ to produce a "measurable" value at wellhead, then the minimization is done over the time $t^{\ell}$ to $t^{\ell}+10 \mathrm{sec}$. For a longer delay, the minimization is done over a longer time A measurable value depends on the accuracy of the pressure transducer used. More details of the method are given by Miller and Zerzan (1979).

The method was used to invert the measured data. Results of the inversion are given in Figures 1 through 3 . For the first two cases, the measured data were obtained by using a simulation drawdown curve and then finding out what would be measured at wellhead for that curve. Then these 


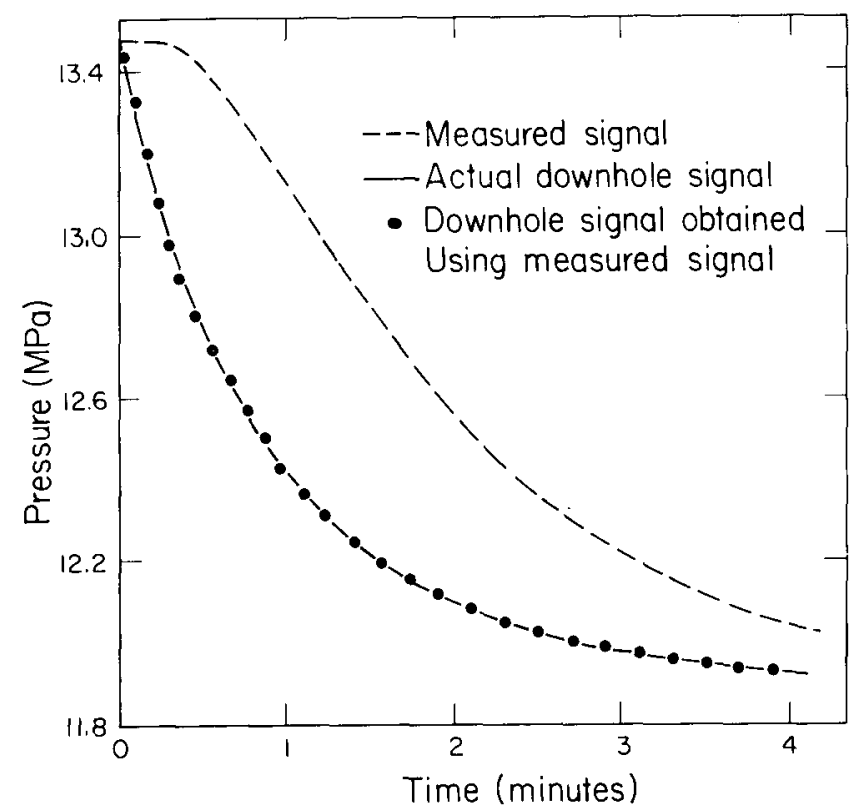

Figure 1. Comparison of a simulated downhole pressure signal and the signal obtained using the "measured" signal; diffusivity of oil is $40,000 \mathrm{~m}^{2} / \mathrm{sec}$ and tube length is $2400 \mathrm{~m}$.

(XBL 797-2060)

"measured data" were inverted using the minimization technique to try to obtain the original drawdown curve. For Figure 1, the simulation was done for a high-temperature oil with a diffusion coefficient of $40,000 \mathrm{~m}^{2} / \mathrm{sec}$. For Figure 2 , the simulation was for a low-temperature oil, resulting in a diffusion coefficient of on $1 \mathrm{y} 6,000 \mathrm{~m}^{2} / \mathrm{sec}$. In both cases, the tubing was $2400 \mathrm{~m}$ in length with an inner diameter of $0.14 \mathrm{~cm}$. For the first case, the minimization had to be over $8 \mathrm{sec}$, whereas in

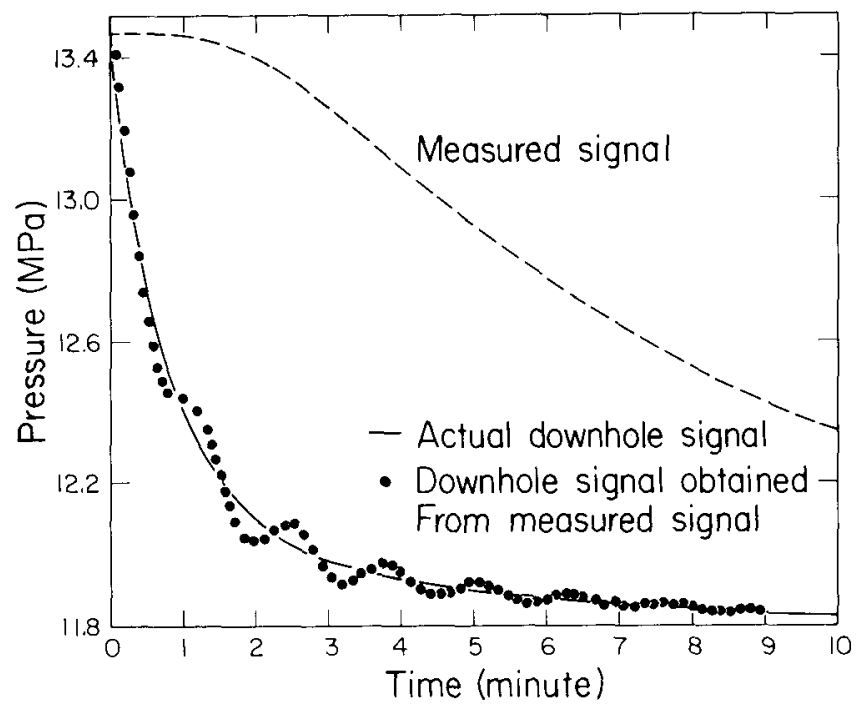

Figure 2. Comparison of a simulated downhole pressure signal and the signal obtained using the "measured" pressure response at wellhead; diffusivity is $6000 \mathrm{~m}^{2} / \mathrm{sec}$ and tubing length is $2400 \mathrm{~m}$.

(XBL 797-2059)

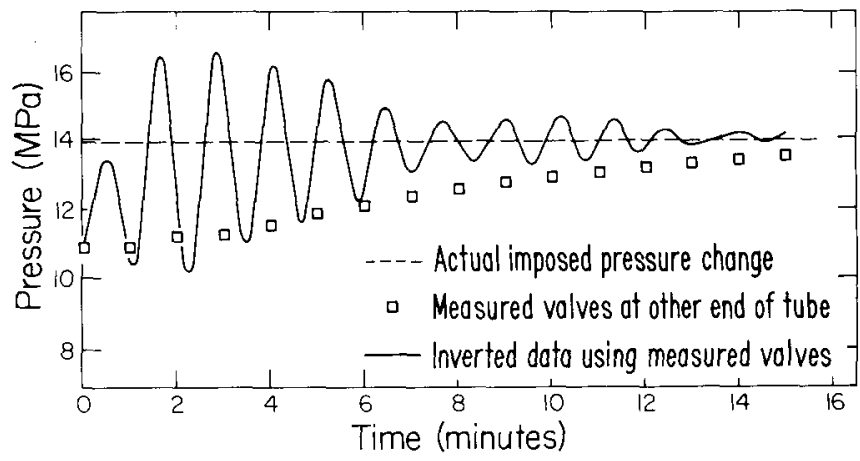

Figure 3. Comparison of an actual step change in pressure and the signal obtained using the measured pressure response; diffusivity is $6000 \mathrm{~m}^{2} / \mathrm{sec}$ and tubing length is $2400 \mathrm{~m}$.

(XBL 797-2081)

the second case it was necessary to use a delay of $40 \mathrm{sec}$. For the same drawdown curve, a more distorted curve will be measured as the signal delay time increases. Also, as the drawdown curve increases in steepness, the measured signal increases in distortion. As the curve distorts more, oscillations appear when solving the inverse case. Nevertheless, the oscillations are symmetic about the actual solution. Realizing this result, one could obtain the solution by first inverting the signal, and then, knowing that the actual solution is not oscillatory, one obtains the actual solution by assuming that the oscillations are symmetric about it. Using this assumed solution, one can recalculate the expected values and compare with the measured one.

To check the inverse technique, the numerical solution was compared to an experiment. However, the only experimental data available were for the case where a step change from 10.9 to $14.0 \mathrm{MPa}$ was imposed at one end of a capillary tube and then the pressure signal was measured at the second end. This situation is one of the "worst cases," i.e., a very steep change with a long delay time (40 sec). The measurements were obtained for a tube $2400 \mathrm{~m}$ long with an inner diameter of $0.14 \mathrm{~cm}$ and for 10 centistoke silicone oil at $20 \mathrm{C}$. Figure 3 shows the imposed change, the measured pressure at the second end of the tube, and the values calculated when trying to invert the data. The oscillations are larger than the original step change, so the inversion in this case should not be taken too seriously, but it must be noted that even in this case, the oscillations are damped and symmetric about the actual signal. If one followed the above method of calculating the inverse solution and then taking the average of the oscillations, the solution obtained even in this case would be fairly reasonable.

A method of correcting for the measuring instrument has been determined for the liquid-filled capillary tubing. It must be noted, though, that the fluid is affected by any temperature changes in the well during a test. The temperature changes show up as a source of the pressure in the modeling of the fluid transmission line. To invert the measured data at wellhead, one must have some idea 
of the changes in temperature with time, which is a large limitation on the use of the instrument.

\section{PLANNED ACTIVITIES}

It is still of interest to consider the highly nonlinear problem of the inverse case for a gasfilled tube. One reason is that the gas is significantly less affected by temperature changes then the liquid-filled tube. Secondly, given a method of modeling the two-phase transient flow in the wellbore itself (Miller, 1979), another possible way of obtaining the downhole pressure transients is to use the wellhead data itself without having to resort to a fluid transmission line. Such a technique will be considered in the future.

\section{REFERENCES CITED}

Burggraf, O. R., 1964. An exact solution of the inverse problem in heat conduction theory and applications. Journal of Heat Transfer, v. $86 \mathrm{C}, \mathrm{p} .373$.

Beck, J. V., 1970. Nonlinear estimation applied to the nonlinear inverse heat conduction problem. International Journal of Heat and Mass Transfer, v. 13, p. 703-716.

Miller, C. W., 1979. A numerical model of transient two phase flow in a wellbore. Berkeley, Lawrence Berkeley Laboratory, LBL-9056.

Miller, C. W., and Haney, J., 1979. Response of pressure changes in a fluid filled capillary tube, in Proceedings, Second Invitational Well Testing Symposium. Berkeley, Lawrence Berkeley Laboratory, LBL-8883.

Miller, C. W., and Zerzan, J. M., 1979. Downhole pessure changes measured with a fluid filled capillary tube. Dallas, Society of Petroleum Engineers, SPE-8233.

\section{WELLBORE STORAGE EFFECTS IN GEOTHERMAL WELLS}

\section{W. Miller}

The established techniques of well testing in the petroleum industry, which are used to assess the characteristics of oil and gas reservoirs, have been extended to the geothermal field. However, there are several important differences between a geothermal field and an oil or gas reservoir, and it is necessary to understand how these differences will influence the analysis of well test data. There are two important differences. (1) The value of $\mathrm{kh} / \mu$ (permeability-thickness/viscosity) is usual$1 y$ much larger in a geothermal field than an oil or gas reservoir because of the large value of $h$ and relatively small value of $\mu$. (2) Heat loss in the wellbore during a well test of a geothermal field can be important while it is ignored for a test of an oil or gas field. The increased value of $\mathrm{kh} / \mu$ means that for the same storage capacity of the reservoir, the time for the reservoir to be able to supply the desired flow rate for a given pressure drop will decrease. The significance of this effect is that as the time for the reservoir to respond decreases, the nonuniform transients in the well itself can become important. The drawdown in a well test has been derived previously assuming that the fluid in the wellbore is well-mixed and responds uniformly in time to pressure changes, i.e. an infinite speed of propagation. As the reservoir responds faster the latter assumption is not valid and vastly different wellbore storage curves are obtained. The second problem of heat loss always exists in the testing of a geothermal field and is important even when the semilog straight-line. region is expected.

\section{ACTIVITIES IN 1979}

Work was one on understanding and characterizing the expected drawdown pressure response during a we11 test of a geothermal field. The effort was directed at understanding the early time changes affected by the relatively large value of $\mathrm{kh} / \mu$ and also the longer time effect of heat transfer.
Wellbore storage is the capacity for the well itself to absorb or supply any part of the mass flow rate out of the we11/reservoir system. When the mass flow rate at the surface is increased (or decreased), the change in pressure is felt initial$1 y$ only in the we1l. After a certain amount of time, depending on the properties of the reservoir and the conditions in the well, the reservoir will start to supply part of the flow. As transient changes in the well die out, the sandface flow rate increases and approaches the surface flow rate, and one can think of the time for this to occur as the time constant of the reservoir.

If the pressure changes with time in the well are not a function of position, then a graph of pressure versus time on a $\log -\log$ plot will have unit slope, implying that the well supplies the flow rate changes in a uniform manner. All wellbore storage curves generated in the petroleum industry have this unit slope. However, there is a finite time for changes made at the surface to arrive downhole, and it is not possible for the well to respond initially in a uniform manner. During that time, the wave generated when a change is made in flow rate at the surface is important and the measurement of pressure changes with time $(\mathrm{dP} / \mathrm{dt})$ at any one point in the well cannot characterize the average of $\mathrm{dP} / \mathrm{dt}$. Before a well-mixed condition is valid, the wave nature of the original disturbance must be damped out. There are cases when the reservoir can supply fluid before $\mathrm{dP} / \mathrm{dt}$ in the well is uniform. For these cases, a unit slope of $10 \mathrm{~g}$ $P$ vs $\log t$ is not measured and another nondimensional time has been derived to characterize the resultant curves.

For a given value of $C_{D}$ (ratio of the storage capacity of the well to that of the reservoir), it has been possible to derive a quantity $t_{R W}$, which is the ratio of the time for the reservoir to respond to that of the well. The quantity was 
determined to be

$$
\frac{\mu}{\mathrm{kh}} \frac{\mathrm{r}_{w}^{2}}{2} \frac{1}{\rho_{\text {s.f. }}}\left(\frac{\partial \rho}{\partial P}\right)_{\mathrm{s}}^{1 / 2}
$$

where $r_{w}$ is the radius of the wel1, $\rho_{s . f}$. is the density of the fluid at the sandface, and $(\partial \rho / \partial P)_{\mathrm{s}}^{1 / 2}$ is the average isentropic compressibility of the fluid in the well. Using a transient numerical model of the flow in the wellbore (Miller, 1979a), it has been possible to determine the expected drawdown response for a homogeneous single-phase reservoir with either single-phase or two-phase flow in the wellbore for the adiabatic case.

Figure 1 illustrates the results of these calculations for a $C_{D}=25$, giving the nondimensional pressure $P_{D}$, versus the nondimensional time, $t_{D}$. plotted in the figure are: (1) the $\mathrm{C}_{\mathrm{D}}=0$ case for a finite well radius; (2) the drawdown curve generated assuming the fluid in the wellbore responds uniformly; and (3) the actual drawdown curves that result as the value of the $t_{\mathrm{RW}}$ decreases. After a flow change has been made at wellhead, nothing is measured downhole until the disturbance arrives. However, once the wave reaches the well/reservoir interface, the pressure change increases abruptly and approaches the wellbore storage curve based on the uniform theory. If the reservoir cannot supply the surface flow rate for the pressure pulse that arrives downhole, then the well must continue to supply the desired flow rate and $P_{D}$ vs $t_{D}$ curve approaches the unit slope. Most oil and gas fields are in this category. But as $\mathrm{kh} / \mu$ increases for the same value of $C_{D}$, the reservoir is capable of supplying a much larger quantity of fluid in a shorter time and the measured $P_{D}$ vs $t_{D}$ curve approaches the uniform theory curve at times later than the expected unit slope. Curves of this steep nature have been observed in geothermal field tests (Narasimhan and Witherspoon, 1977) and were not previously explained. As $t_{R W}$ decreases, the reservoir

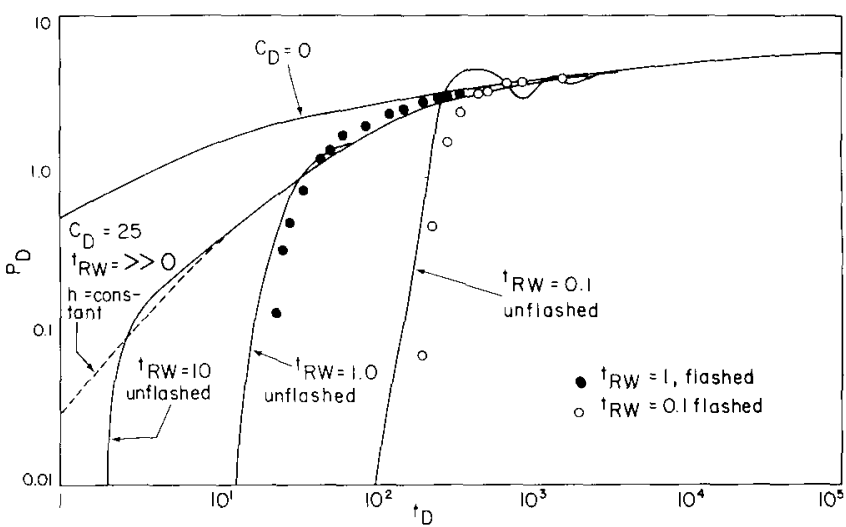

Figure 1. Nondimensional pressure vs nondimensional time for different values of $t_{R W}$ with $C_{D}=25$. Calculations are done for fluid that is both flashed and unflashed.

(XBL 794-7402)

may be able to supply more fluid than the well could for the same pressure drop and oscillations would be measured. The quantity $t_{R W}$ was shown to describe this early time behavior in many cases and details are given in Miller (1979b).

The effect of heat transfer on the well tests was also considered. Heat transfer is especially important when a new well is tested because the rock surrounding the bore is still relatively cool. However, heat transfer will always be important in a two-phase well because of the large temperature changes that occur when the flash level rises or falls. Even after the early-time wellbore storage changes are over, heat transfer can alter the slope of the semilog plot of $P$ vs $\log t$ from $q \mu / 4 \pi \mathrm{kh}$ ( $q$ is the volume flow rate) requiring a different analysis of the data than has been developed in the petroleum industry.

Figure 2 is a plot of $P$ vs $t$ for a buildup and a subsequent drawdown test. To simulate the heat

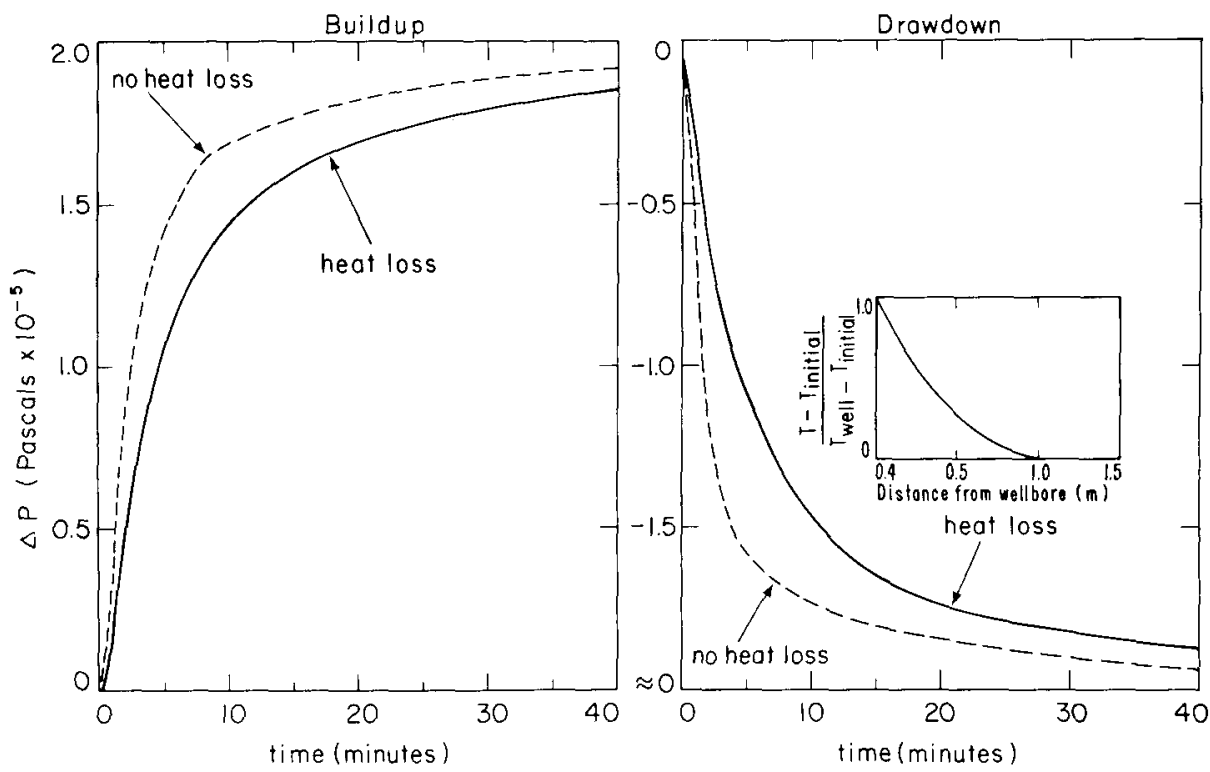

Figure 2. Effect of heat transfer on the buildup and drawdown curve.

(XBL 794-7412) 
loss from the well, a typical geothermal temperature gradient was assumed far from the well and a small temperature buildup was used near the bore. A nondimensional representative temperature profile is given by the insert in the figure. This is a typical temperature buildup. The effects shown in the figure will increase for colder wells. In Figure 2, the graph on the left is a plot of the pressure buildup and then drawdown when the heat loss is ignored. The graph on the right is a plot of those properties when heat transfer is allowed to take place. The figure shows that the heat transfer causes the pressure to initially change at a slower rate both for the buildup and the drawdown test. During a buildup test, the enthalpy of the exiting fluid decreases because of the increased time that the fluid is in the well. As the enthalpy decreases, the fluid can condense or compress more for the same pressure so more fluid flows into the well with a smaller pressure rise. Also the time required until a semilog straight line is measured increases and the slope of this line changes from that predicted in the petroleum industry (see Milller 1979b).

\section{PLANNED ACTIVITIES}

In the future, it would be of interest to investigate the drawdown response for a multilayer reservoir when the time response of the reservoir is relatively fast. It is also of interest to investigate the pressure response when flashing occurs in the reservoir itself instead of just in the well and to consider the effects of slip between the phases of the well test results.

\section{REFERENCES CITED}

Miller, C. W., 1979a. Numerical model of transient two-phase flow in a well bore. Berkeley, Lawrence Berkeley Laboratory, LBL-9056.

, 1979b. Wellbore storage effects in geothermal wells. Dallas, Society of Petroleum Engineers, SPE-8203.

Narasimhan, T. M., and Witherspoon, P. A., 1977. Reservoir evaluation tests on RRGE 1 and RRGE 2, Raft River Geothermal Project, Idaho. Berkeley, Lawrence Berkeley Laboratory, LBL-5958.

\title{
HYDRAULICS OF A WELL INTERCEPTING A SINGLE HORIZONTAL FRACTURE
}

\author{
G. S. Bodvarsson, T. N. Narasimhan, and C. F. Tsang
}

\section{INTRODUCTION}

Since the $1960 \mathrm{~s}$, considerable work has focused on the problem of isothermal flow to a well intercepting a single fracture. The primary emphasis has been placed upon understanding the flow characteristics of a system with a vertical fracture; the horizontal fracture case has received relatively less attention. The interest in vertical fracture stems from the common belief that vertical fractures generally result from hydraulic fracturing experiments.

The orientation of fractures created by hydraulic fracturing techniques is controlled by the in-situ stress condition at each specific site. Because the fracture propagates perpendicular to the least principal stress, horizontal fractures are generally created at shallow depths, and vertical ones at greater depths. Recent studies by Zoback et al. (1977) have indicated that horizontal fractures can be created at considerable depths in certain tectonically active regions.

Fractures are also commonly found naturally. For example, in volcanic regions, the primary fluid conduits may be the contact zone between adjacent lava beds (Thorsteinsson and Eliasson, 1970; Benson et al., 1979). The contacts will in general behave as horizontal fractures of large areal extent in well tests. An understanding of the flow characteristics to a well intercepting a horizontal fracture is very important in the analysis of well tests in groundwater and geothermal reservoirs.

This brief report focuses on the pressure response in a well intercepting a finite-capacity horizontal fracture. The model used is calibrated against an analytical solution for the uniformflux horizontal fracture case. Some examples of the effects of fracture permeability and radial extent on the pressure response are given.

\section{PREVIOUS WORK}

A number of studies have focused on fracture network problems using a grid of equally spaced horizontal fractures (Kazemi, 1979; Boulton and Streltsova, 1977; Najurieta, 1979). Hartsock and Warren (1961) studied numerically the psuedo-steadystate behavior of horizontally fractured wells. They calculated skin factors for different geometric and material parameters, assuming radial flow four fracture radii away from the well. Warren (1962) later extended the study, developing an expression for the skin factor.

Gringarten (1971) studied the unsteady-state pressure response in a well intersecting a horizontal fracture. In the study he considered a confined aquifer with a single horizontal fracture (Figure 1). All of the flow into the well was assumed to be via the fracture and the fluid entering the fracture was assumed to enter uniformly over the fracture area (uniform flux). The results of the study were presented in a set of type curves (Figure 2). Gringarten found that the system under the assumed conditions could be characterized by two dimensionless parameters (dimensionless time and pressure) in addition to the parameter

$$
h_{D}=\frac{h}{r_{f}} \sqrt{\frac{k r}{k_{z}}} .
$$




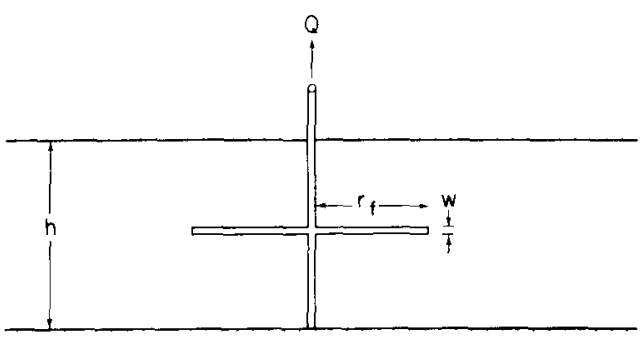

Figure 1. Cross section of a horizontal fracture model.

(XBL 804-7003)

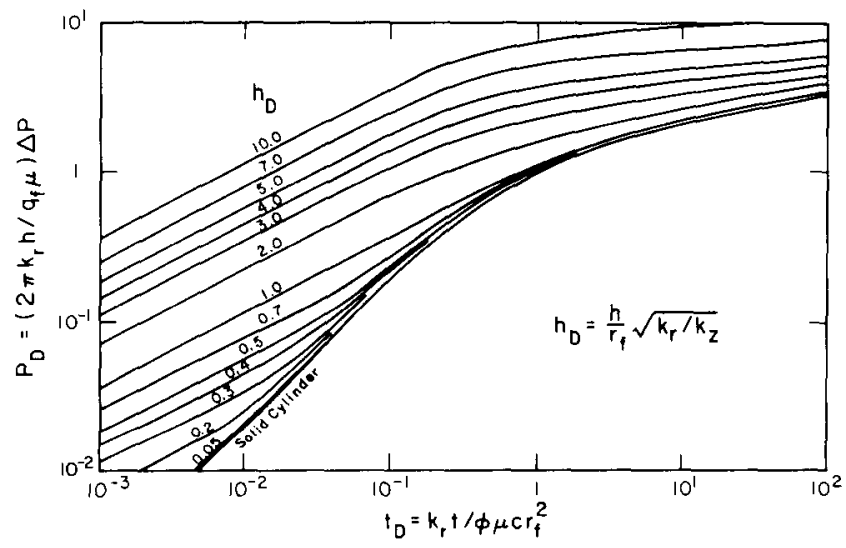

Figure 2. Type curves for a uniform flux horizontal fracture system (Gringarten, 1971). (XBL 804-7009)

\section{NUMER ICAL STUDIES}

For this study the numerical code TERZAGI was used. The program solves the mass balance equation for isothermal fluid flow. It employs the integrated finite-difference method (IFDM) to characterize the flow regime (Narasimhan and Witherspoon, 1978) and solves the sets of nonlinear equations using an efficient sparse solver (Duff, 1977).

An axisymmetric mesh was used in the study (Figure 3). Gravity effects and tip flow were neglected. Due to symmetry, only half of the flow field needed to be considered. The block size was increased logarithmically in the radial direction. Ten to twenty fracture elements were used, depending upon the permeability and radial extent of the fracture.

\section{Comparison with Gringarten's Solution}

The first problem solved using the numerical simulator was identical to the one solved analytically by Gringarten (1971).

In the problem as defined by Gringarten there is actually no well; rather the fracture behaves as a source (sink). Thus for the purpose of comparison with Gringarten's solutions, in the numerical simulation the well element had to be removed and sources (sinks) of variable strength placed in the fracture elements. In this way, one of the most

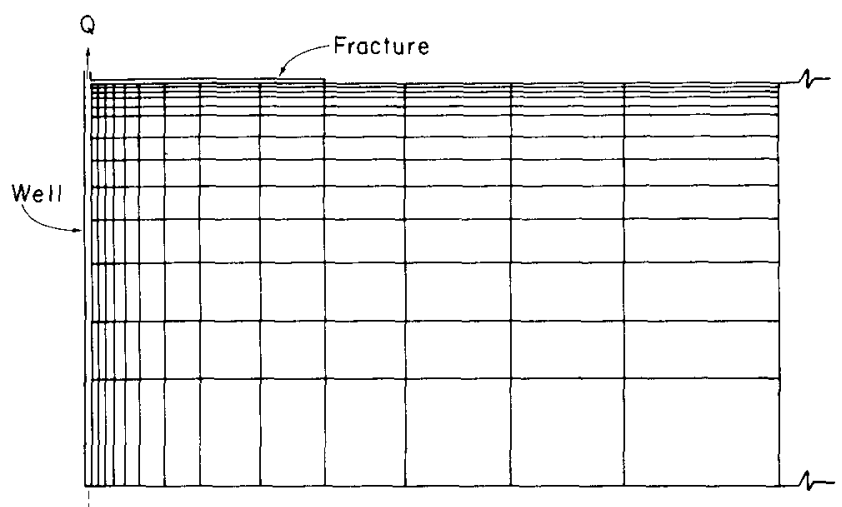

Axis of

symmetry

Figure 3. The mesh used in the numerical simulation studies.

(XBL 804-7003)

critical assumptions made by Gringarten, the uniform flux assumption, was satisfied. Two cases were simulated, i.e., $h_{D}=1$ and $h_{D}=4$. Figure 4 shows the comparison between the numerical and the analytical solutions for one of these cases.

\section{Finite Conductivity Horizonta1 Fracture}

The horizontal fracture problem solved analytically by Gringarten was based upon several important assumptions. The most critical assumption is that the same mass of fluid enters the fracture everywhere (uniform flux conditions). This assumption should not be critical at early times when linear vertical flow from the reservoir to the fracture occurs. At later times, however, radial flow to the fracture region starts to dominate and the bulk of the fluid enters the fracture close to the tip of the fracture. The uniform flux as sumption therefore creates an unrealistically large pressure drop in the fracture elements close to the well.

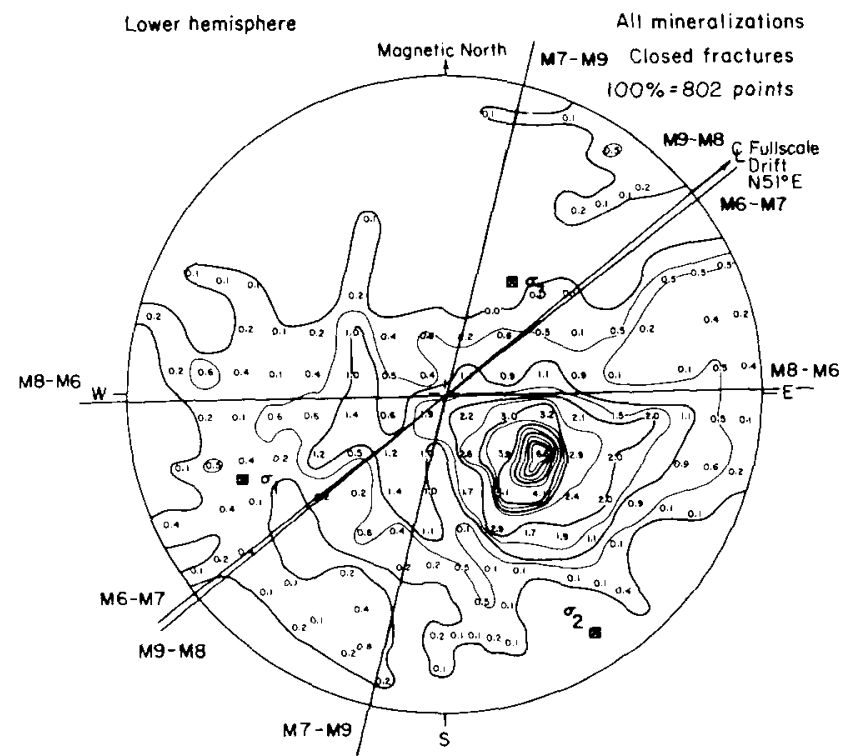

Figure 4. Schmidt equal-area pole plot for vertical $E$ and $M$ holes, H9\% occurrence.
(XBL 801-6786A) 
In our numerical study we allow unrestricted flow to the fracture and the well. Fluid is allowed to flow from both the fracture and the rock matrix to the well depending upon the pressure gradients (Darcy's law). The fracture has a finite but constant permeability and contains only slightly compressible fluid (water).

Typical curves of dimensionless pressure versus dimensionless time at the well are shown in Figure 5. For all of the three curves the same $k_{f} / k_{r}$ ratio is used, but with different fracture radii $\left(r_{f}\right)$. All other parameters remain the same. At early times the curves coincide, as wellbore effect and fracture storage effects dominate the pressure response. Later on, as the pressure pulse hits the fracture radial boundary and fluid from the formation starts to enter the fracture, the curves start to diverge from the mother curve. The less the radial extent of the fracture $\left(r_{f}\right)$, the sooner the curves start to divert. Theoretically, the early part of the curves can be used to determine the transmissivity ( $k w$ ) and the storativity $\left(\phi_{f} \mu c_{f}\right)$ at the fracture. The time of departure from the mother curve can be used to determine the fracture radius $r_{f}$. The later time data can be analyzed to obtain the parameters of the in-situ rock.

The permeability ratio between the fracture and the residual rock, $k_{D}=k_{f} / k_{r}$, is an important parameter that can be used to characterize a finite conductivity horizontal fracture system. Our studies have shown that this parameter is unique at practical dimensionless times. That is, if the $k_{D}$ is kept constant, the pressure response at the well will remain the same, regardless of individual values of the rock and the matrix permeabilities. Figure 6 shows $P_{D}$ vs $t_{D}$ curves at the well for different values of the parameter $k_{D}$. In these runs a rather large wellbore ( 8 in.) was used, as reflected distinctly in the long duration of the unit slope (wellbore effects). The bottom curves correspond to an infinite fracture permeability, whereas the top curve represents the Theis curve with wellbore storage $\left(C_{D}=0.466\right)$. The dotted line represents Gringarten's analytical solution for $h_{D}=1$, which is the value used in the simulation. As the figure shows, the analytical curve compares fairly well with the curves representing very high fracture conductivity.

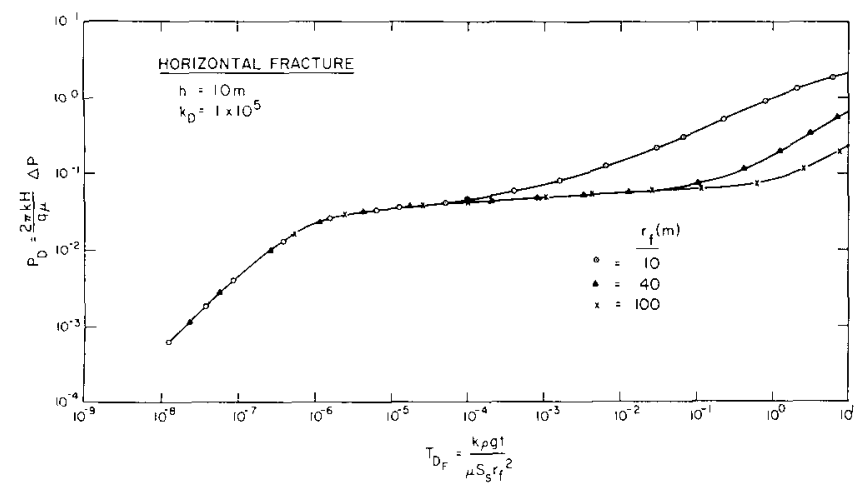

Figure 5. Typical pressure response at a well intercepting a finite conductivity horizontal fracture.

(XBL 804-7002)

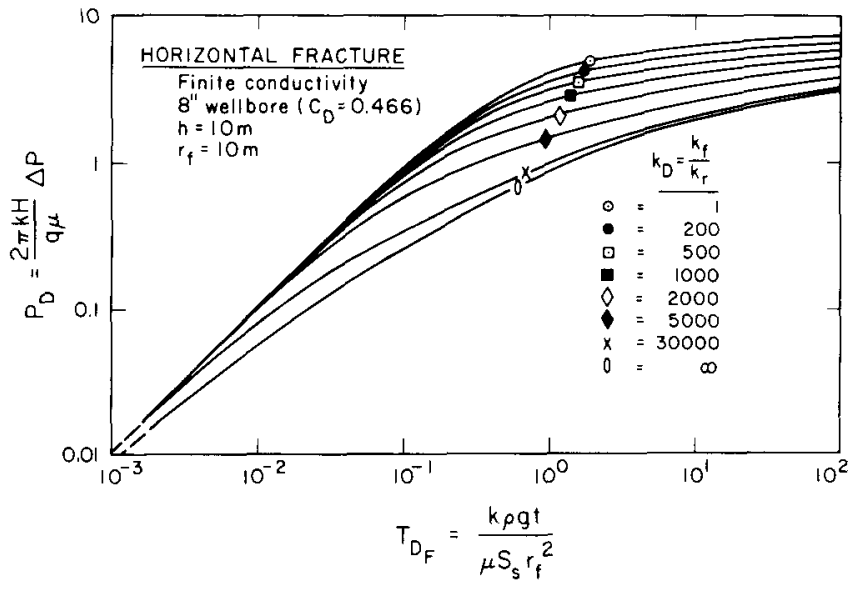

Figure 6 . The effects of $\mathrm{kp}$ on the pressure response at the well.

(XBL 804-6897)

The effects of wellbore storage, chocked fracture, fracture skin and skin around the wellbore have also been studied. The limited space in this report does not allow elaboration upon the results obtained.

The numerical studies have shown that the dimensionless parameter $h_{D}$, as defined by Gringarten (1971) is not a unique parameter for the horizontal fracture model we used. The reason for this is probably that we do not employ the apparently unrealistic "uniform flux" assumption in our model. The use of the presently available type curves for horizontal fracture systems may, therefore, lead to serious errors in the determination of the fracture and formation parameters.

\section{FISCAL YEAR 1980 ACTIVITIES}

During the next fiscal year our studies will be continued. Emphasis will be placed upon identifying the important dimensionless parameters that can be used to characterize finite conductivity horizontal fracture systems.

\section{REFERENCES CITED}

Benson, S., Goranson, C., and Schroeder, R., 1979. Evaluation of City Well 1, Klamath Falls, in Annual Report Earth Sciences Division, 1979 (this volume).

Boulton, N. S., and Streltsova, T. D., 1977. Unsteady flow to a pumped well in a fissured water-bearing formation. Journal of Hydrology, v. 35, p. 257-269.

Duff, I. S., 1977. MA28: A set of FORTRAN subroutines for sparse unsymmetric linear equations. Harwel1/0xfordshire, Great Britain. Report AERE-R8730.

Gringarten, A. C., 1971. Unsteady state pressure distribution created by a we11 with a single horizontal fracture, partial penetration, or restricted entry (Ph.D. dissertation). Stanford University, $110 \mathrm{p}$.

Hartsock, J. H., and Warren, J. E. The effect of horizontal hydraulic fracturing on well performance. Journal Petroleum Technology, v. 1, p. 1050-1056. 
Kazemi, H., 1969. Pressure transient analys is of naturally fractured reservoirs with uniform fracture distribution. Soc. Petr. Eng., v. 9, p. 451-462.

Najurieta, H. L., 1979. Interference and pulse testing in uniformly fractured reservoirs. Dallas Society of Petroleum Engineers. $\mathrm{SPE}-8283$.

Narasimhan, T. N., and Witherspoon, P. A., 1978. An integrated finite difference method for analyzing fluid flow in porous media. Water Resources Research, v. 14, no. 2, p. 255-261.

Thorsteinsson, T., and Eliasson, J., 1970. Geo- hydrology of the Laugarnes hydrothermal system in Iceland, in Proceedings, U.N. Symposium on the Development and Utilization of Geothermal Resources. Geothermics, Special Issue 2, v. 2, part 2, p. 1191-1204.

Warren, J. E., 1962. Discussion on a mathematical model for water movement about bottom-water drive reservoirs. Society Petroleum Engineers Journal, v. 14, p. 367-368.

Zoback, M. D., Healy, J. H., and Roller, J. C., 1977. Preliminary stress measurements in central California using the hydraulic fracturing technique. Pageoph. v. 115, p. 135-152.

\title{
PRELIMINARY STUDY OF SUBSIDENCE AT WAIRAKEI, NEW ZEALAND, USING A NUMERICAL MODEL
}

\author{
T. N. Narasimhan and K. P. Goyal
}

\section{INTRODUCTION}

Significant ground subsidence ( $4.5 \mathrm{~m}$ maximum) has been observed at Wairakei, New Zealand, following geothermal fluid extraction since the late 1950 s (Stilwell et al., 1975). The observed subsidence presents two peculiar features. The first is that the subsidence bowl is offset from the main production area (Figure 1). Secondly, a plot of reservoir pressure drop versus subsidence at benchmark A97 (Figure 2) shows that the rate of subsidence with reference to pressure increases drastically after the pressure drop exceeds approximately 15 bars. While this combination of observed behavior should be explainable in more than one way, it appears that a combination of heterogeneity and preconsolidation of the formation material could provide a logical framework for characterizing Wairakei subsidence.

The purpose of the present study is to investigate in a phenomenological fashion whether the observed features at Wairakei can be reasonably explained in terms of heterogeneity and preconsolidation. This work is not intended as a detailed model of the Wairakei system; rather, it is merely a preliminary investigation as to whether heterogeneity and preconsolidation can provide a practical basis for understanding in the Wairakei phenomenon.

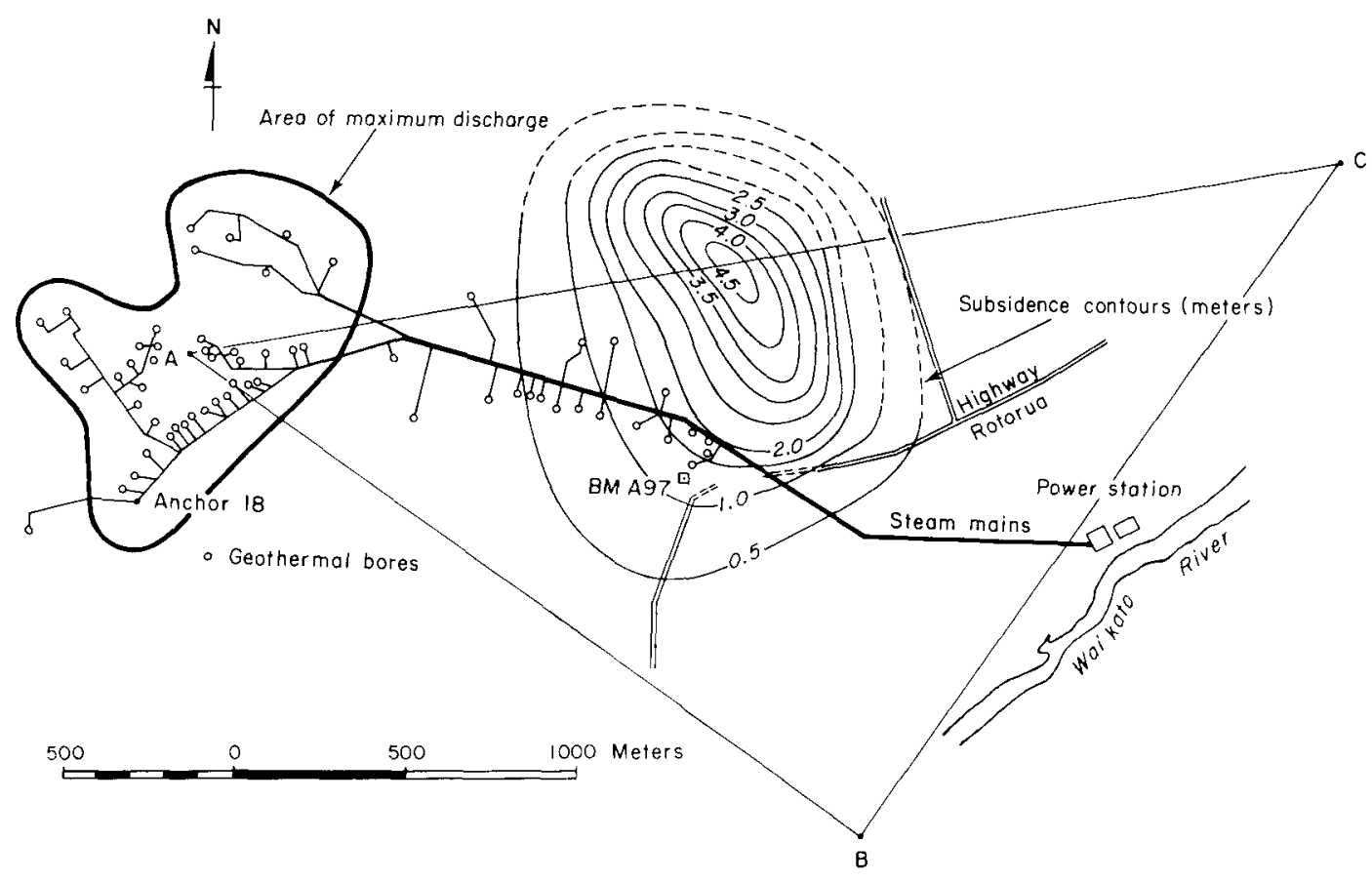

Figure 1. Total subsidence contours at Wairakei, New Zealand, and the area of investigation ABC (from Stilwell et al., 1975).

(XBL 7911-13203) 


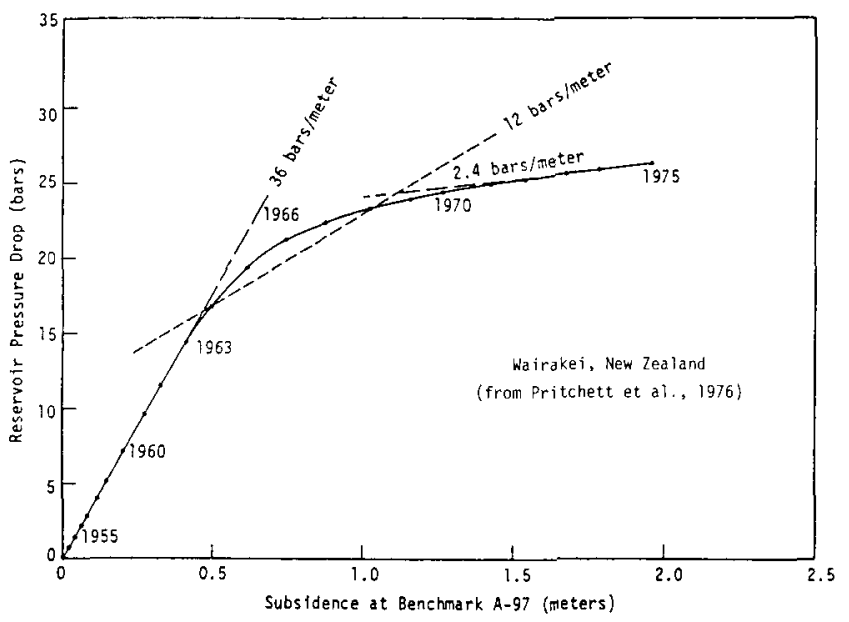

Figure 2. Reservoir pressure drop versus subsidence observed at the Wairakei geothermal field, New Zealand.

(XBL 773-8173)

\section{RESULTS}

The geology of the Wairakei field has been discussed by Grindley (1965), Healy (1965), and Grange (1937); reservoir engineering data have been compiled by Pritchett et al. (1978). It can be noted from Figure 1 that the subsidence bowl is offset from the main production area. This subsidence pattern is possible if the Huka Falls formation (assumed to be relatively more compressible than the Wairakei formation layer) is thicker in that region. Or, alternatively, the compressibility of the formation in the highly subsidized zone is greater than in other areas. In our idealized model, we use the first approach with a reasonable compressibility value of the Huka Falls formation. It can be noted from Figure 2 that the drop in the reservoir pressure is linearly proportional to subsidence during early production times. However, in later periods, reservoir pressure seems to stabilize while subsid ence continues. Such behavior could be explained if one assumes that the deforming material passes from a state of preconsolidation to one of normal consolidation. Our preliminary model, then, studies the effect of heterogeneity and plasticity on the subsidence phenomenon.

For purposes of simulation, we can idealize the system as consisting of Waiora aquifer, the Huka Falls formation, and the overburden which extends to the ground surface. This idealized model is shown in Figure 3. The thickness of the overburden (Holocene Pumice and Wairakei Breccia) is assumed to be $200 \mathrm{~m}$ (Pritchett et al., 1978, Table $5.1, \mathrm{p} .30$ ). The depth of the reservoir, including Huka Falls formation, is assumed to be $400 \mathrm{~m}$. The maximum thickness of the Huka Falls formation is assumed to be $200 \mathrm{~m}$ near the zone of maximum subsidence (Pritchett et al., 1978, Figure 5.21 , p. 52).

To model subsidence, we have used an idealized graded thickness of the Huka Falls formation of 40 , $80,120,160$, and $200 \mathrm{~m}$ (Figure 4). The maximum thickness of $200 \mathrm{~m}$ over the nodes 138, 145, and 146 corresponds to the area of maximum subsidence (Figure 1). Node 107 is modeled as a production zone, indicative of the area of maximum discharge in Figure 1. To offset the subsidence bow1 from the main production area, the thickness of the overburden is increased to $360 \mathrm{~m}$ over the nodes 207 to 216. The rest of the volume elements represent the Waiora formation. Impermeable boundary conditions are imposed on the sides $A B$ and $A C$. An initial potential of $600 \mathrm{~m}$ of water is specified everywhere in the system. Material properties used in the model are as follows:

\section{Huka Fa1ls Formation}

Permeability $=10^{-14} \mathrm{~m}^{2}$ (Mercer et a1., 1975).

Coefficient of compressibility for virgin curve $\left(a_{\mathrm{v}}\right)=5 \times 10^{-8} \mathrm{~m}^{2} / \mathrm{N}$

Coefficient of compressibility for swelling curve $\left(a_{\mathrm{vs}}\right)=5 \times 10^{-9} \mathrm{~m}^{2} / \mathrm{N}$

\section{Waiora Formation}

Permeability $=8.5 \times 10^{-14} \mathrm{~m}^{2}$

Coefficient of compressibility for virgin as well as swelling curve $\left(a_{v}=a_{v s}\right)$ $=10^{-10^{2}} / \mathrm{N}$

Relative density of the saturated soil $=2$.

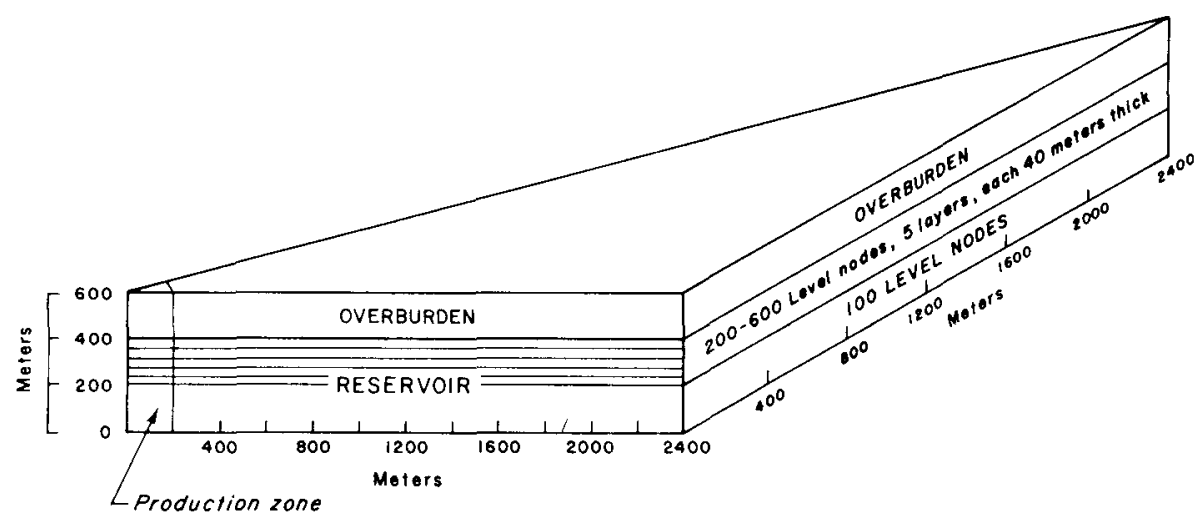

Figure 3. An idealized three-dimensional subsidence model of the Wairakei geothermal system.

(XBL 7911-13085) 


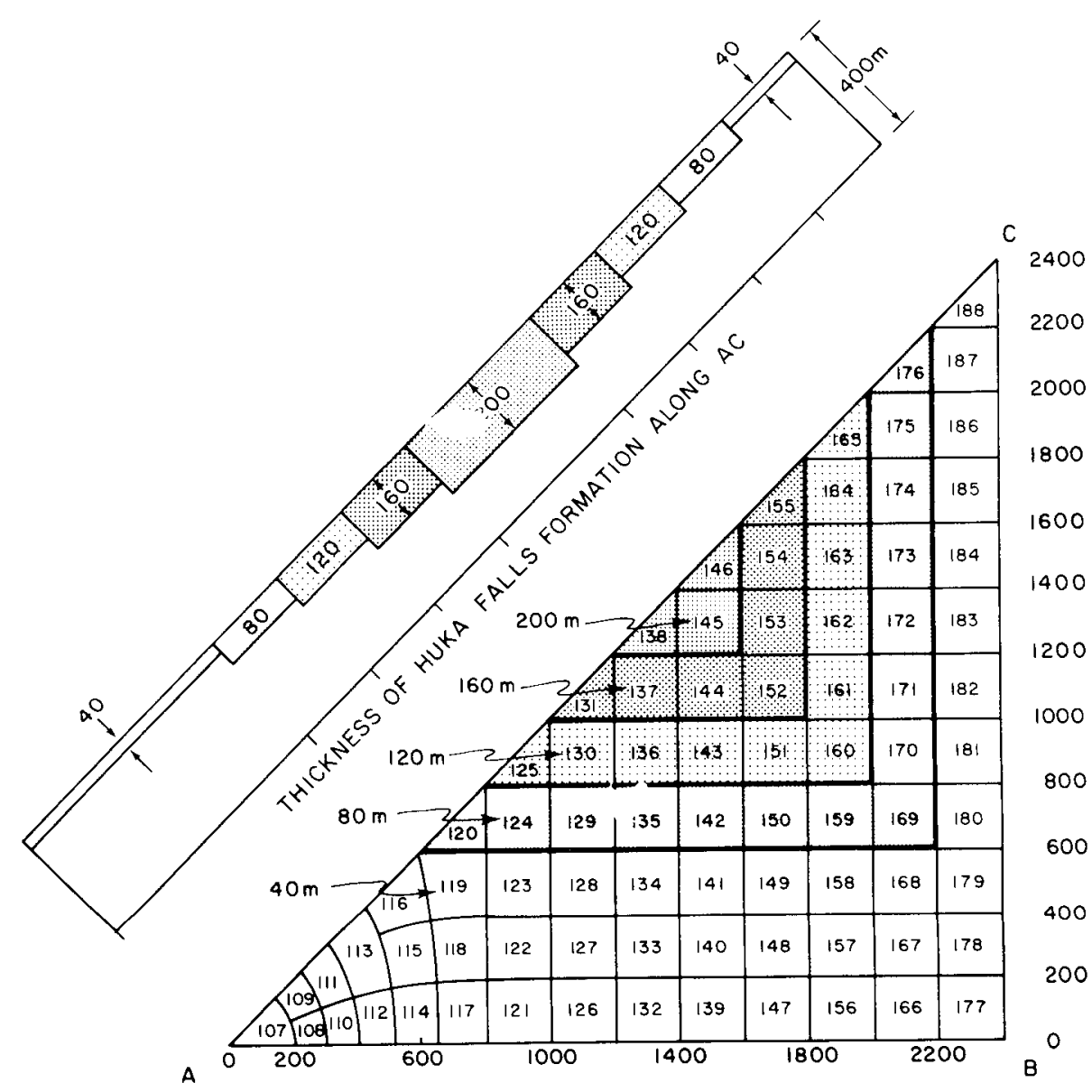

Figure 4. The thickness of the Huka Falls formation and the node numbers used in the model.

(XBL 7911-13083)

This model also assumes that the soil is preconsolidated. The preconsolidation pressure over and above hydrostatic pressure is about $225 \mathrm{~m}$ of water. The properties used for the liquid are:

$$
\begin{array}{ll}
\text { Viscosity } & =0.2 \text { centipoise } \\
\text { Density } & =940 \mathrm{~kg} / \mathrm{m}^{3} \\
\text { Compressibility } & =4.9 \times 10^{-10} \mathrm{~m}^{2} / \mathrm{N}
\end{array}
$$

Total mass production for the Wairakei/Tuahara system as of December 31, 1976, was $2329 \times 10^{9} 1$ bs (Pritchett et al., 1978). This amounts to an average volumetric production rate of about $1.48 \mathrm{~m}^{3} / \mathrm{sec}$. Since our triangular model (Figure 4) considers on $1 y 1 / 8$ of the total area, the production rate is correspondingly reduced to about $0.185 \mathrm{~m}^{3} / \mathrm{sec}$. It can be noted that this rate applies to both Wairakei and Tuahara fields. To consider only the area of maximum discharge (Figure 1), this amount should be somewhat reduced. In this study, we have considered an average production rate of 0.1 $\mathrm{m}^{3} / \mathrm{sec}$. This amount is produced from node 107 at the depth of $500 \mathrm{~m}$.

Subsidence produced under aforementioned conditions is shown in Figure 5. A comparison with Figure 1 shows that the results are qualitatively

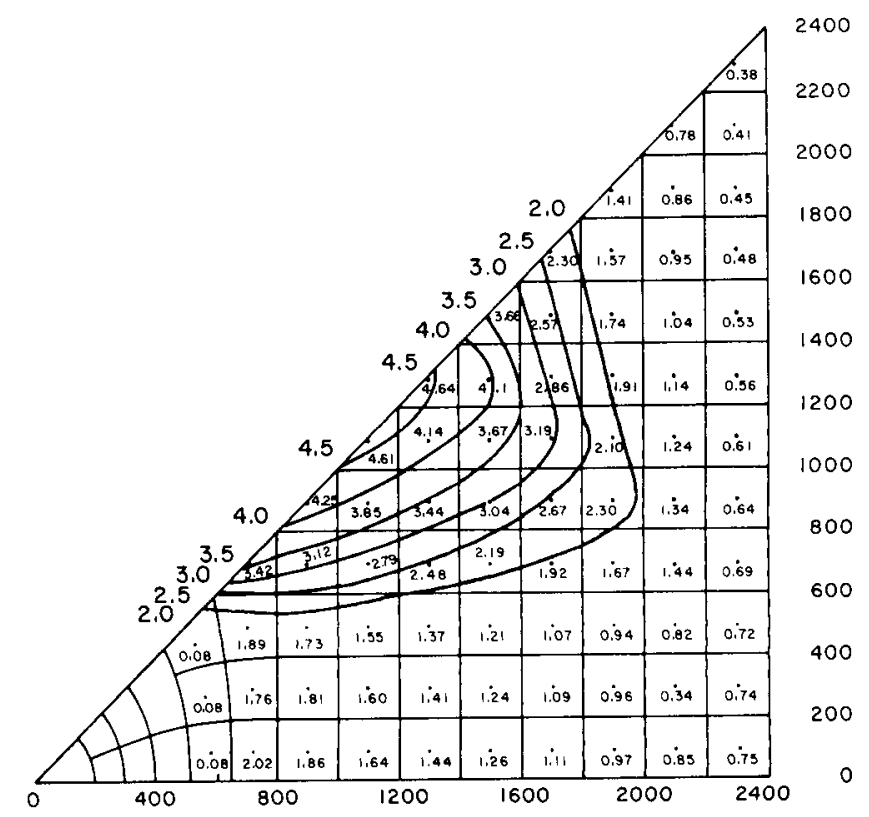

Figure 5. Subsidence contours in meters after 21 years of production. 
similar. Measured and calculated reservoir pressure drop vs subsidence at the benchmark $A 97$ and node 142 are shown in Figure 6. A qualitatively similar pattern is seen for the preconsolidated soil. This figure also shows the behavior of the normally consolidated soil, which is quite different from that of the preconsolidated soil.

In summary, we developed and tested a preliminary model to explain subsidence at the Wairakei

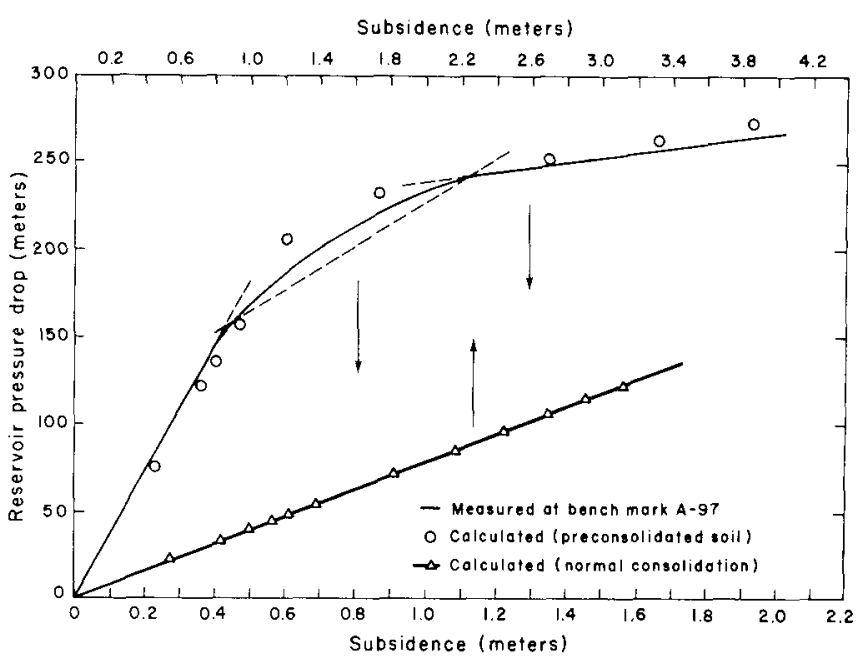

Figure 6. Comparison of the measured subsidence with that calculated at node 142 .

(XBL 7911-13408) field and obtained results which are qualitatively similar to those measured at the site. The effect of preconsolidation stresses seems to be important in explaining the changing slope of the reservoir pressure-subsidence relationship shown in Figure 2.

\section{REFERENCES CITED}

Grange, L. I., 1937. The geology of the RotoruaTaupo Subdivision, Rotorua and Kaimanawa Divisions. DSIR Bulletin 37.

Grindley, G. W., 1965. The geology, structure, exploitation of the Wairakei field, Taupo, New Zealand. N.Z. Geol. Surv. Bull. 75, 131.

Healy, J., 1965. Geology of the Wairakei geothermal field. Proceedings, Eighth Commonwealth Mining and Metallurgical Congress, Australia and New Zealand, New Zealand Section.

Mercer, J. W., Pinder, G.F., and Donaldson, I. G., 1975. A Galerkin-Finite element analysis of the hydrothermal system at Wairakei, New Zealand. Journal of Geophysical Research, v. 80 , no. 17, p. $2608-2621$.

Pritchett, J. W., Garg, S. K., and Browne11, D. H., 1976. Numerical simulation of production and subsidence at Wairakei, New Zealand. Stanford Geothermal Program, Report SGP-TR-20. Stanford, California, p. 310-323.

Pritchett, J. W., Rice, L.F., and Garg, S. K., 1978. Reservoir engineering data: Wairakei geothermal field, New Zealand. La Jolla, California, Systems, Science and Software, SSS-R-78-3597-1, v. 1 .

Stilwel1, W. B., Hal1, W. K., and Tawhai, J., 1975. Ground movements in New Zealand geotherma1 fields. Proceedings of the Second United Nations Symposium on the Development and Use of Geothermal Resources, v. 2, p. 1427-1434.

\section{USE OF PRESSURE TRANSIENT ANALYSIS IN MODELING THE HYDRAULIC FRACTURING PROCESS}

\section{W. A. Palen and T. N. Narasimhan}

The flow of fluids in reservoirs containing large fractures is vitally important in many geoenergy resource systems. The use of massive hydraulic fracturing (MHF) for the creation of large hydraulic fractures of up to $500 \mathrm{~m}$ in length is used extensively in the petroleum industry to stimulate tight gas formations whose very low permeability $\left(0.5\right.$ to $\left.5 \times 10^{-16} \mathrm{~m}^{2}\right)$ severely curtails production. The use of hydraulic fracturing is also visualized in the geothermal area for the creation of circular vertical fractures used in the hot-dry-rock (HDR) concept. In HDR, the fracture is created at depth in a region exhibiting high geothermal temperatures. Water is swept over the fracture faces, and the heated fluid is pumped to the surface utilization facilities. Horizontal fractures are used in some coal gasification processes to create coal bed channels for mixing of steam, oxygen, and air necessary for gas production.

To evaluate the success and to predict the future performance of such systems, it is important to know the physical properties of the created fracture system. Such properties include the average width, w, and the characteristic half-length, $\mathrm{x}_{\mathrm{f}}$, or radius $\mathrm{r}_{\mathrm{f}}$, of the fracture. Several methods published in the petroleum literature have resulted in type curves for the analysis of pressure buildup data in systems involving a well intercepting a single, vertical, rectangular fracture. These methods include analytical treatments assuming no pressure gradients (infinite fracture conductivity) in the fracture (Gringarten et al., 1975); semianalytical treatments correcting for a finite fracture conductivity (Cinco-Ley et al., 1978); and numerical methods employing a finite difference scheme (Agarwal et al., 1979).

Previous work has included another approach to analyzing the pressure behavior of a well intercepting a finite vertical fracture. Program TERZAGI was employed in calculating pressure buildup type curve data similar to that generated by the above-mentioned authors. 


\section{THE YEAR'S ACTIVITIES}

TERZAGI is a fully numerical program developed by LBL to handle three-dimensional, single-phase, isothermal transient flow. The computational algo$r$ ithm is based on the integrated finite-difference method (Narasimhan and Witherspoon, 1976) and handles arbitrarily nonlinear variations in permeability in addition to one-dimensional consolidation. The program was modified to handle Darcy flow in fractures and to handle permeability variation in the fracture in the case where a constant fracture width, w, cannot be reasonably assumed. The fracture permeability $\mathrm{K}_{f}$ was made a function of the pressure distribution in the fracture; i.e., the fracture was allowed to "breathe."

The work was summarized by Narasimhan and Palen (1979). The publication includes the effects of: wellbore storage, skin factor around the fracture (due to poor fluid cleanup), effects of fracture storage; uneven wing length (asymmetrical fracture), choked flow (uneven proppant dispersa1), and pressure dependent permeability on the type curves. Results indicated that in a sufficiently large fracture, fracture storage will dominate wellbore storage during early time data for a significant period and must be corrected for. The effect of choking the fracture was also found to be dramatic. A permeability reduction of 10 in the choked region increases the drawdown of the system throughout the duration of the test for wells with an $r_{r}=7.62 \mathrm{~cm}$. The effect of reducing the choked area permeability by 100 was observed to produce a test result that could invalidate the conventional calculation of the physical properties of the system.

An important conclusion of the work was that a variety of conditions may occur in a realistic fracture situation that would make type curve analysis extremely difficult, if not impossible. A similar study was carried out by LBL researchers for the case of a horizontal fracture (Bodvarsson and Narasimhan, 1980).

Consideration of this problem has led to the development of program HYDFR. Program HYDFR was designed to handle the problem of analyzing the pressure transient data recorded during the actual hydraulic fracturing process. It was hoped that a parameter analysis could provide insight not only into the dimensions of the fracture system but also into the in-situ rock stresses and formation strength.

\section{CURRENT WORK}

HYDFR is a program designed specifically to handle the highly nonlinear problem of a growing hydraulic fracture. As such, it borrows heavily from its parent program, TERZAGI, and shares the common IFDM formulation. The extra computational effort involved in solving the growing fracture was expedited by replacing the iterative solver in the original program with a direct solver that is many times faster (Bodvarsson et al., 1980). The increased speed of the solution algorithm allowed the preliminary modeling to be done that otherwise would have been cost prohibitive.
The program is based on a surface energy concept of fracture extension. The fracture system before extension is modeled in Figure 1. Initially, noda1 elements exist representing the surface pumps and tubing, the pressurized tubing in the well, the packer cavity, and an initial fracture surface. Once the pumping is initiated, the program monitors the cavity pressure until the rupture pressure $\mathrm{P}_{b}$ is reached. Once this pressure is reached, flow is allowed into the first fracture element. The total available energy of the system is defined as the PV work done to inject fluid into the fracture less the work done overcoming the earth stresses in the formation and the energy lost in creating the fracture surface. If sufficient energy is available in the system and the pressure in the initial fracture element exceeds the earth stress, the fracture grows outward as a plane. The program generates its own mesh, creating the additional fracture elements and simple reservoir elements to allow for fracturing fluid penetration (leak of $f$ ). The two requirements for extension are available excess surface energy to extend the fracture and the sufficient pressure in the downstream elements to open the fracture against earth stresses.

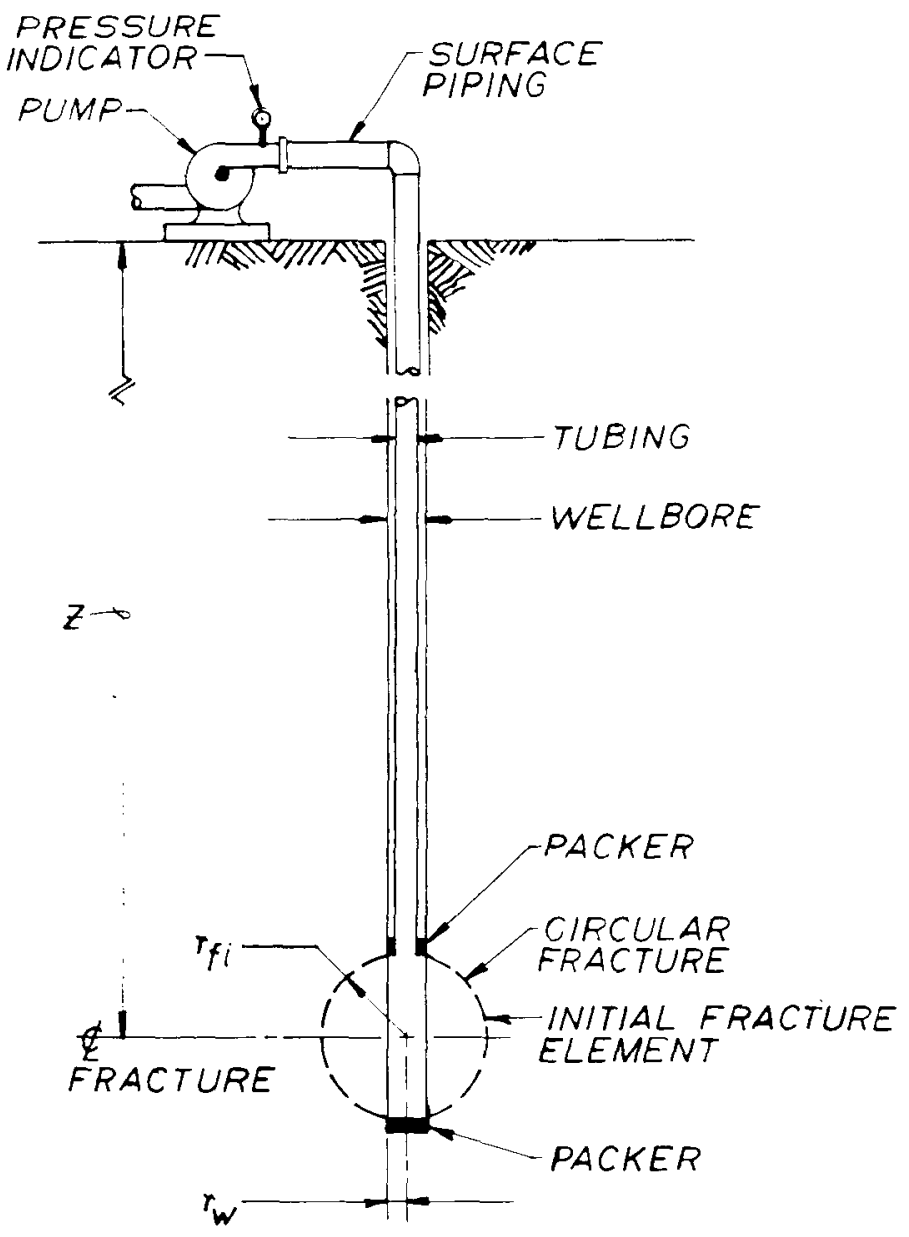

Figure 1. Initial representation of growing fracture mesh.
(XBL 806-9919) 
Two basic geometries have been modeled with HYDFR. A rectangular geometry is used to study vertical fracture development in layered anisotropic formations such as oil fields. A circular geometry is used to model vertical fractures in an isotropic medium such as used in geophysics and HDR experiments (where gravity effects are neglected) or for a horizontal fracture.

The pressure profile generated by the model is depicted in Figure 2. Shown here is the simulator's transient pressure profile vs actual field data gathered by Mark Zobak of the U.S. Geological Survey. Agreement is generally good over the first two pressure cycles. Adjusting the parameters of the model indicate that the fracture radius at the end of the second fracture cycle was $9.5 \mathrm{~m}$ and that the maximum stable width was approximately $10^{-4} \mathrm{~m}$. other parameters may be inferred from the study of these particular data, but while the range of variation of these parameters of the earth stresses, formation strength, and surface energy requirements is sma11, it cannot be stated that the best fit data is unique due to the interrelationship of the parameters in the model.

\section{PLANNED ACTIVITIES}

The simulation will be used to examine the possibility of using the fluid viscosity and pumping rate to control the growth of the fracture system. This is hoped to aid in not only optimizing the fracture penetration when desired, but also to control the growth when working in sensitive formations.

REFERENCES CITED

Agarwal, R. G., Carter, R. D., and Pollock, C. B., 1979. Evaluation and performance prediction of low permeability gas wells simulated by massive hydraulic fracturing. Journal of Petroleum Technology, p. 362-372.

Bodvarsson, G. S., Lippmann, M. J., and Narasimhan, T. N., 1980. Recent modifications of the numerical code CCC, in Earth Science Division Annual Report 1979 (this volume).

Bodvarsson, G. S., and Narasimhan, T. N., 1980. Hydraulics of a well intercepting a single horizontal fracture, in Earth Sciences Division Annual Report $19 \overline{79}$ (this volume).

Cinco-Ley, H., Samaniego, F., and Domínguez, A., 1978. Transient pressure behavior for a well with a fracture-conductivity vertical fracture. Society of Petroleum Engineers Journal, v. 18, no. 4.

Gringarten, A. C., Ramey, H. J., and Raghavan, R., 1975. Applied pressure analysis for fractured wells. Journal of Petroleum Technology, v. 15, p. 887-892.

Narasimhan, T. N., and Palen, W. A., 1979. A purely numerical approach for analyzing flow to a well intercepting a vertical fracture. Dallas, Society of Petroleum Engineers, SPE-7983.

Narasimhan, T. N., and Witherspoon, P. A., 1976. An integrated finite difference method for analyzing fluid flow in porous media. Water Resources Research, v. 12, no. 1, p. 57-66.

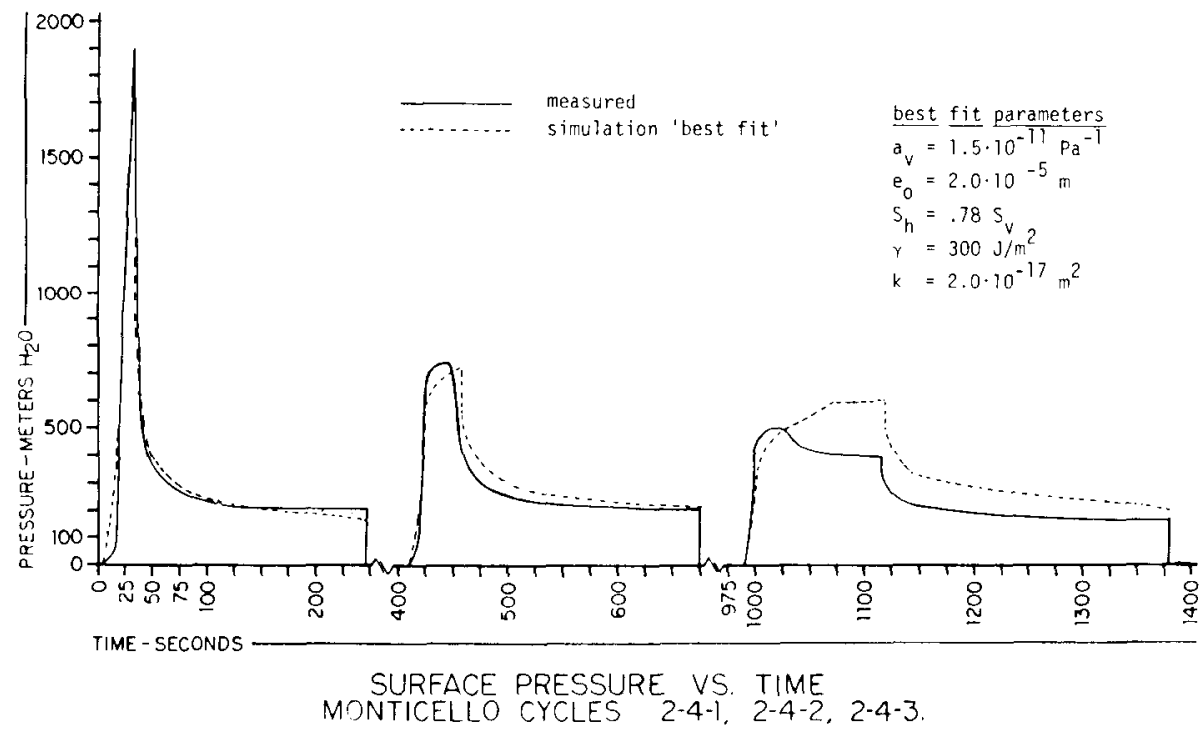

Figure 2. Calculated vs observed pressure transient of the Monticello data.

(XBL 806-9931) 


\section{Geothermal Environmenta』Research}

\section{GEOTHERMAL SUBSIDENCE RESEARCH PROGRAM}

\section{J. E. Noble}

\section{INTRODUCTION}

As with the development of any energy source, problems encountered may limit development. For geothermal energy, one such problem may be land deformation associated with the removal or injection of geofluids in the reservoir.

The objective of geothermal subsidence research is to control or mitigate, within predictable limits, potential subsidence associated with geothermal development. This objective will be accomplished by understanding the compaction subsidence phenomena associated with geothermal energy development. The Geothermal Subsidence Research Program (GSRP) is designed to develop a comprehensive understanding of the compaction-subsidence phenomena and provide:

1. The means for developers to build and operate geothermal facilities within prescribed limits of 1 and subsidence and deformation.

2. The basis for policy-makers to regulate geothermal facilities with respect to potential subsidence.

A workshop was held in 0ctober 1978 for the purpose of making a mid-course correction to the original subsidence research plan. The goals of the workshop were to:

- Review the results of the completed GSRP research

- Advise on changes needed to the program's research plan

- Assess the adequacy of the plan, and

- Make recommendations on revisions to the original plan.

As a consequence of the workshop, the nine research categories of the original plan were grouped into three general research areas. In turn, these major areas were divided into specific research topics:

1. Subsidence Research Monitoring and Measurement

- Direct surface subsidence monitoring

- Indirect technique, both surface and subsurface, to monitor and measure reservoir compaction

- Wellbore measurements to directly monitor and measure reservoir compaction

2. Reservoir Compaction and Subsidence Prediction

- Understanding the physical processes that cause compaction and subsidence

- Laboratory studies of the compaction and subsidence phenomena

- Assessment and development of compactionsubsidence models
3. Compaction and subsidence impact assessment

- Compaction and subsidence case studies

- Assessment of the economic costs and environmental effects of compaction and subsidence.

PROGRAM PROGRESS IN FISCAL YEAR 1979

At the start of fiscal year 1979, several general contract objectives were stated for the Geothermal Subsidence Research Program:

1. Supplemental Case History--Chocolate Bayou Objective: Expand the Chocolate Bayou case study in order to make the study more comprehensive. An expanded study could also be useful as a model to researchers at the Brazoria Geopressure field located south of the Chocolate Bayou field.

2. Hostile Environment Tool Development objective: The four suggestions made by Woodward-C1yde Consultants for improved we11bore extensometers will be component tested.

3. Assessment of Radioactive Bullets Objective: Additional review of radioactive bullet logging will be made to assess the applicability of this technique to monitoring subsurface compaction.

4. Assessment of Indirect Techniques Objective: Indirect measurement methods, i.e. gravity, resistivity and microseismicity, have promise as inexpensive, areal survey techniques. Research will be conducted to evaluate the ability of these methods to detect changes in the physical properties of a geothermal reservoir and to relate these changes to reservoir compaction and subsidence.

5. Assessment of Physical Subsidence Theories Objective: A step toward greater predictive capability is assessing existing subsidence theory and its applicability to geothermal reservoirs. Most subsidence theories were developed to describe the compaction of oil and gas reservoirs or of relatively shallow unconsolidated aquifers. The applicability of these theories to deep, thermodynamically complex geothermal systems will be examined.

6. Creep Phenomena and Inelasticity

objective: Related to the assessment of existing subsidence theory is an assessment of rock creep and inelasticity at high temperature and high pressure. The effects of these phenomena are little understood and limit accuracy in predicting subsidence. Research will be conducted to study their contribution to compaction and subsidence. 
During fiscal year 1979 , contracts were issued to accomplish each of these objectives. Some of these contracts will be continued in fiscal year 1980. The following is a review of the fiscal year 1979 accomplishments of the contracts issued:

\section{Supplemental Case History--Chocolate Bayou}

Principal Investigator: Barbara Turner (ESA Associates)

Objective. Expand the Chocolate Bayou Case Study to make it more comprehensive. An expanded study will be useful as a model to researchers at the Brazoria Geopressure Field located south of the Chocolate Bayou Field.

Progress. The ESA data assessment availability and evaluation study is completed. The general, conclusions and recommendations are:

1. Sufficient data appear to be available for modeling the Chocolate Bayou field, although some data on material properties may have to be extrapolated from well testing and core analysis of the Pleasant Bayou wells.

2. The 1978 to 1979 releveling data show that subsidence of Chocolate Bayou is continuing but at a lower rate than previously. Maximum subsidence between 1943 and 1979 was $2 \mathrm{ft}(0.61 \mathrm{~m})$.

3. The relationships among observed subsidence, groundwater production, and hydrocarbon extraction were investigated in more detail for this report. The results of this analysis indicate that hydrocarbon production has contributed to the observed subsidence. In particular, a comparison of the 1959 to 1973 elevation changes at shallow benchmarks with changes at deep benchmarks set on abandoned oil and gas well casings shows a very close correspondence between the amounts and rates of subsidence. It is expected that collection and analysis of more site-specific fluid extraction data would make it possible to determine how much subsidence has been due to groundwater production and how much from producion of deep fluids.

\section{Subsidence Instrumentation Development}

\section{Principal Investigator: A. Veneruso}

\section{(Sandia Laboratories)}

Objective. Provide LBL technical guidance and support in the development of hostile environment instrumentation for subsurface subsidence research.

Progress. With the successful testing of seven switches (all to $300^{\circ} \mathrm{C}$ ), the reed switch testing was completed. The switches were all built by the Hamlin Company of Lake Mills, Wisconsin, and are all commercially available from component suppliers. The switches tested were:
Type

MRHDT

MTHG2

MARH2

MINI-2S-115

MMRR-2-185

MSDR 4

DRR-129-425

Because there are many different current, voltage, size and performance variations, selection of a particular switch is dependent on the specific application.

The development of high-temperature magnetic materials, refractory thin-film resistors, capacitators, conductor interconnections, and the hightemperature line driver has been accelerated. Some of the line driver circuits have been fabricated in tandem, rather than in sequence.

3. Assessment of Radioactive Formation Markers to Monitor Reservoir Compaction

Principal Investigator: Dr. M. Dorfman

(U. of Texas)

objective. To assess the usefulness of radioactive bullet logging in measuring and monitoring differential compaction on a geothermal reservoir.

Progress. A comprehensive literature review has been carried out, followed by personal discussions with engineers of Atlantic-Richfield, Schlumberger, Dresser Atlas, and Welex. The first three companies have been involved in significant compaction measurement studies using radioactive bullets at Prudhoe Bay, Alaska; Gronigen, Holland; and Long Beach, California, respectively. The last three companies are major well-logging businesses. Using the best tools and procedures, the distance between radioactive bullets spaced about $40 \mathrm{ft}$ apart can be determined with a standard deviation of $0.01 \mathrm{ft}$.

The temperature $1 \mathrm{imit}$ is about $500^{\circ} \mathrm{F}$ for all components except the bullets, for which the limitation is approximately $350^{\circ} \mathrm{F}$. Radioactive jet markers are available which have a limit of $500^{\circ} \mathrm{F}$. The pressure limit is approximately 20,000 psi.

The uniaxial compaction coefficients measured on Frio cores from the Pleasant Bayou \#2 well (Brazoria County, Texas) range from about $5 \times 10^{-7}$ to $10^{-6}$ psi, taking into account both short-term and long-term (creep) effects. For this well, the above precision of bullet location should permit meaningful compaction measurements when flowing pressure drawdown from the initial reservoir pressure is more than about $360 \mathrm{psi}$ to $180 \mathrm{psi}$, respectively.

There is some evidence that laboratory measurements of compaction coefficients on cores are not always reliable in predicting compaction in the field. For example, at Groningen, Holland, predicted compaction based on laboratory data was three times greater than observed compaction using radioactive bullets. In other words, the above estimate of required pressure drawdown for meaning- 
ful compaction measurements with radioactive bullets should be used with caution.

Also, the above estimate does not take into account any possible "strengthening" of the system near the wellbore due to the steel casing and cement. The radioactive bullet will probably not penetrate more than 6 in. to 1 ft from the wellbore. This is the region with the greatest pressure drawdown when the well is flowing and hence has the greatest potential for compaction. For wells with several thousand pounds drawdown, and with good bonds between casing and cement and between cement and formation, the compaction in the region occupied by the bullets would almost certainly not be as great as that measured in the absence of the relatively strong casing and cement. It is possible that this effect contributed to the discrepancy between observed and predicted compaction at Groningen.

For reservoirs in basement or metamorphic rocks, with relatively low porosity such as found at The Geysers, California, the observed compaction coefficients are expected to be considerably smaller than calculated, and the required pressure drawdowns correspondingly larger for meaningful compaction measurements. Since these wells are usually completed without running casing through the producing interval, the "strengthening" effect discussed above would not occur here. Also, in hard rocks, use of radioactive jets as markers might be preferable to radioactive bullets, since bullet penetration might be extremely variable.

4. Indirect Methods: Seismic Assessment

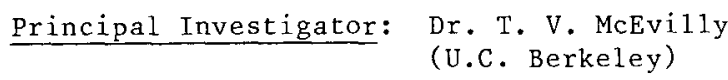

Objective. To map lateral and vertical variations in velocity and attenuation (both $P$ and $S$ waves) throughout the production zone. Also studied are the source dynamics of the microearthquakes so that we might infer stress orientation, stress drops, and source dimensions relative to production activities (withdrawal, reinjection) and the reservoir boundaries. If subsidence occurs on a significant scale these data may be able to delineate regions of discrete movement or stress release.

Progress. During fiscal year 1979 the major effort was directed toward fabrication of the Automatic Seismic Processor (ASP) and an in-field vehicle to house the ASP.

Gravity Assessment

Principal Investigator: Dr. R. B. Grannell (Long Beach State University)

Objective. To assess the applicability of surface gravity measurements to monitoring the response of a geothermal reservoir to exploitation. If gravity surveys can be shown to be applicable, it could provide a cost-effective indirect method to indicate net mass changes in the subsurface due to extraction and/or injection of geothermal fluids. Some causes of net mass changes could be alteration of the subsurface chemical/thermodynamic environment, changes in the volume of subsurface forma- tions, or changes in formation void ratios. How these changes are subsidence-related is of paramount interest to the Geothermal Subsidence Research Program.

In fiscal year 1979 the following tasks were accomplished:

Task 1: An assessment was made of the applications of surface gravity measurements to monitoring the various subsidence-related net-mass formation changes that could be caused by exploitation of a geothermal reservoir. Each application required a well-documented theoretical basis, a technical feasibility statement indicating the accuracy by which the changes could be repeatably measured, and a review of the instruments and techniques currently available for such studies.

Task 2: A comprehensive plan was recommended for implementation of a gravity study to investigate and monitor subsidence-related formation changes. of particular interest were methods of repeatable data acquisition and analysis, and the use of corroborating surface geophysical techniques such as seismic velocity studies.

Task 3: A suitable site was identified where the recommended plan could be implemented, including sufficient corroborating geological, geophysical, and geothermal resource data to support the selected sites. Discussions with the field operators have begun to gain permission to conduct a field gravity survey in fiscal year 1980 .

\section{Assessment of Physical Theory}

Principal Investigators: Dr. M. Carroll (U.C. Berke ley) and Dr. John Rudnicki (U. of Illinois)

Objective. To assess the adequacy of constitutive theory to define deformation.

Progress. Dr. Carroll (UCB): A report has been submitted on the study of analytical and numerical solutions for elastic deformation of weakened half-space under gravity. In the report, constitutive relations are developed for mechanical response of dry or fluid-saturated porous material beyond the linear range. The main emphasis is on hydrostatic loading and unloading response, although deviatoric effects are also treated. The technique focuses on the manner in which localized shear stresses in the solid material are treated. A theoretical derivation of an initial yield surface for porous material is also described.

Dr. Rudnicki (University of Illinois): As part of the work on time-dependent behavior of brittle rock, Dr. Rudnicki has reviewed experimental work on the growth of cracks in brittle rock. This experimental work provides an indication of the kinetic relations that link the rate of microscale deformation mechanisms to applied stress. Rudnicki has started to evaluate the role of coupling between deformation and pore-fluid diffusion in elastic fluid-infiltrated porous bodies. This coupling is often neglected in modeling studies, but has proven to be of importance in a variety of geophysical and geotechnical problems. The problem chosen for study is the simplest problem for a finite 
body exhibiting full coupling, that of a hollow sphere subjected to radial stress and pore fluid pressure at its boundary.

6. Physical Properties of Rocks Associated with Subsidence

Principa1 Investigators: A. Abou-Sayed, John Schat $\bar{z}$, and Ken Wolgemuth (Terra Tek, Inc.)

Objective. To study high temperature and pressure compressibility of cores from geothermal reservoirs at East Mesa, California, and Cerro Prieto, Mexico.

Progress. All basic mechanical testing has been completed on both Cerro Prieto and East Mesa cores. Essentially completed are the elastic or short-term compaction studies of East Mesa cores, and these same studies are nearly completed on cores from Cerro Prieto. In addition to the elastic tests, Cerro Prieto core permeablities have been measured and presented in a paper at the Second Symposium on the Cerro Prieto Geotherma1 Field, held in Mexicali, Mexico.

Long-term compaction (creep) studies of the Cerro Prieto cores have continued. Fulure work, after completion of all short-term tests, will emphasize a relatively small number of high-quality creep tests on both East Mesa and Cerro Prieto cores. Both fine-grain and coarse-grain material are being studied to evaluate the effect of grain size or rock compaction.

Of notable interest were the apparent chemical changes occurring in the cores during compaction tests, especially long-term tests. Long-term testing had a strong tendency to increase the silica content of the fluid. The final silica content of the fluid from several of these tests exceeded the total solubility of silica at test conditions. It is hypothesized that pressure point dissolution of silica causes the formation fluid to be supersaturated.

Basic conclusions at this time are as follows:

1. For short-term tests, the reservoir is stiffer for pore pressure reduction than it is for confining pressure increase.

2. Short-term compaction moduli are consistent with the behavior of sandstone at this porosity.

3. Creep compaction occurs and is a significant effect, leading to long-term compaction moduli that are several times smaller than short-term.

4. Rebound moduli are significantly larger than compaction moduli indicating the irreversibility of the behavior.

5. Silica concentration in fluids goes up with time during testing, hinting that pressure solution may be associated with the compaction.

6. Permeability decreases both with temperature increase and time. The precise magnitude of reductions or its importance is uncertain.
In addition to the above contracts, several contracts issued in the last quarter of fiscal year 1978 were substantially concluded in fiscal year 1979. The following is a review of the accomplishments of those contracts:

1. Modeling of the Physical Processes of Subsidence

Principal Investigator: Ian Miller

(Golder Associates, Inc.)

Objective. To assess the individual attributes of particular mathematical models in their own right and to determine, through studies of both real and hypothetical subsidence case histories, the significance of different mathematical model attributes. The result of this research will be synthesized to give detailed assessments of the available models, recommendations for the capabilities of desirable new models, and a general perspective on the limits of mathematical models.

Progress. Proficiency assessment has been completed on the following models:

- Hand calculation of one-dimensional compaction

- One-dimensional calculation stress-seepage mode1

- Nucleus of strain

- Boundary integral equation method

- Displacement discontinuity method

- Finite element mode1

- $\operatorname{ccc}$

Conclusions of their assessment are as follows:

Overall Approach: It appears that the development of highly sophisticated, coupled models for reservoir flow and deformation is not desirable at this time. Not only is the use of overly sophisticated models not justified by available data, but, as was shown in the Austin Bayou case study, coupling of flow deformations increases cost more than it does accuracy. Conceptual models should be developed to as great a level of sophistication as is permitted by available data. Mathematical models should be selected that are appropriate to the sophistication of the conceptual model. In some cases, where production can be assumed known, reservoir flow modeling may not be necessary. This was the case at Austin Bayou.

Reservoir Flow Models: Further theoretical development of reservoir flow models appears to be appropriate. At present, 1 ack of adequate reservoir flow theory represents a significant limitation to predicting the subsidence of geothermal reservoirs. Current theories have not, in general, been adequately tested. In addition, further theoretical work might be appropriate in the fields of multiphase and fracture/porous media flow. We anticipate a rapid evolution in the state-of-theart of heat/fluid flow over the next few years. Mathematical models should be developed not only using state-of-the-art theoretical developments, but also using simplifying assumptions such that the model could be implemented by the lay engineer. Possible simplifying assumptions include lower dimensionality, restricted physical processes, and 
limitation of calculation to static equilibrium conditions.

Deformation Models: Current theory appears to be adequate for all practical deformation modeling problems. Although assumptions of homogeneity, isotropy, and linear elasticity are frequently gross, they of ten appear to be adequate considering the level of inaccuracy introduced by lack of data. There is no single model that is superior to all others. Golder tested six different models and found that each one was valuable in some situations and that none of them was good in all situations. The range of mathematical models now available is sufficient for most reservoir deformation problems. What is needed is not newer, more sophisticated mathematical models, but more useable versions of current models. Some criteria for models are:

- Available in the public domain

- Wel1-documented with regard to both theory and usage

- Simplified input and automatic element generation

- Clear, comprehensive output, and where appropriate, plotting capabilities

- Improved efficiency

- Increased flexibility by development of models that incorporate a variety of current techniques in a single model.

Availability in the public domain might be facilitated by development of a public library of well-documented mathematical models.

In addition to the contracts, Lawrence Berkeley Laboratory conducted its own investigation into subsidence phenomena during fiscal year 1979. A study was made of the Wairakei subsidence problem using the LBL computer subsidence simulator TERZAGI. The objective of this study was to develop a subsidence model of a geothermal field qualitatively similar to the Wairakei field.

Results of the study pertain solely to reservoir deformation according to the one-dimensional consolidation theory. It was assumed that the vertical displacements obtained at the interface of the reservoir and overburden are completely transmitted to the ground surface. The purpose of the present study was to make a preliminary study of the ground subsidence observed over the geothermal field at Wairakei, New Zealand, and to find whether the field observations can be reasonably explained in terms of the well-known geotechnical principles of consolidation. As the study is preliminary in nature, the geothermal system has been treated as an isothermal, liquid system.

Subsidence predicted by the TERZAGI code qualitatively matches the observed Wairakei subsidence feature. The study successfully demonstrated the development and testing of a preliminary model to explain subsidence in the Wairakei field and to obtain results which are qualitatively similar to those measured at the site.

\section{PLANS FOR FISCAL YEAR 1980}

The following projects have been planned for fiscal year 1980 .

1. The LBL computer code TERZAGI will be modified to model lateral reservoir deformation and be further validated. CCC, a nonisothermal compaction mode1, will be modified to compute coupled reservoir-overburden deformation.

2. The creep study of geothermal reservoir cores will continue and be expanded to investigate the role of pressure solution and microcrack progagation as a mechanism for creep compaction.

3. Sandia and LBL will make an assessment of service company borehole tools that show promise for being upgraded to use under geothermal conditions. They will be field tested, and recommendations for enhancement will be made.

4. The Geysers and Cerro Prieto geothermal fields will be evaluated using the Automatic Seismic Processor system. Data from these monitoring surveys will be used to analyze and model compaction-related reservoir stress changes.

5. A high-precision surface gravity study will be conducted at the Cerro Prieto and Heber geothermal fields. The objective will be to establish a base line for detection of net-mass changes related to withdrawal or injection of geofluids.

\section{REFERENCES CITED}

Earth Sciences Division, Lawrence Berkeley Laboratory, 1979. News from subsidence. Berkeley, Lawrence Berkeley Laboratory, PUB-286.

Grimmud, P., Turner, B. L., and Framer, P. A. (Systems Control, Inc.), 1978. Areas of ground subsidence due to geofluid withdrawal. Berkeley, Lawrence Berkeley Laboratory, LBL-8618, GSRMP-4.

O'Rourke, J. E., and Ranson, B. B. (Woodward-C1yde Consultants), 1979. Instruments for subsurface monitoring of geothermal subsidence. Berkeley, Lawrence Berkeley Laboratory, LBL-8669, GSRMP-2.

Pinder, G. F., 1979. State-of-the-art review of geothermal reservoir modeling. Berkeley, Lawrence Berkeley Laboratory, LBL-9093, GSRMP-5.

Van Til, C. J. (Woodward-Clyde Consultants), 1979. Guideline manual for surface monitoring of geothermal areas. Berkeley, Lawrence Berkeley Laboratory, LBL-8617, GSRMP-3.

Vaughan, C. K., and Harding, R. C., 1979. Environmental economic effects of subsidence. Berkeley, Lawrence Berkeley Laboratory, LBL-8615, GSRMP-1. 


\title{
INDUCED SEISMICITY STUDIES AT THE CERRO PRIETO, MEXICO, AND EAST MESA, CALIFORNIA, GEOTHERMAL FIELDS
}

\author{
E. L. Majer and T. V. McEvilly
}

\section{INTRODUCTION}

The utility of microearthquake studies in geothermal regions is not restricted to exploration applications. Information from these studies may be important in delineating reservoir boundaries and in monitoring environmental effects such as subsidence and induced seismicity in producing geothermal fields. By utilizing the variation in propagation characteristics of $P$ and $S$ waves as well as the source characteristics of microearthquakes, information relating to the stress field, temperature, and fluid state can, in principle, be obtained. Continuous monitoring of these properties in producing geothermal fields may provide a means to detect dynamic reservoir boundaries, areas of recharge, and changing fluid state.

As a reservoir is produced there will undoubtedly be relatively large stress and/or thermal gradients produced by the withdrawal and reinjection of fluids. Stress gradients may affect the nature of seismicity, especially in a region as tectonically active as the Salton Trough. Although the Cerro Prieto field and other geothermal regions in the Imperial Valley (such as East Mesa, Brawley, and Herber) are fluid dominated, continued production may induce areas of steam domination. Recent laboratory wave-propagation studies (Nur and Winkler, 1979) indicate that relative $P$ and $S$ wave attenuation studies may be particularly useful for delineating regions of partial saturation. Therefore, it is hoped that continuous microearthquake monitoring with occasional detailed wave propagation studies will be able to detect subtle changes in the static and dynamic properties of the reservoir.

\section{CERRO PRIETO}

In Februrary 1978 a velocity, attenuation, and preliminary microearthquake study was carried out at Cerro Prieto (Majer et a1., 1979). Based on the results of that study, a permanent fivestation array was designed to monitor continuously the temporal and spacial variation in seismicity throughout the production zone. The five closely spaced stations were located to supplement the data from the CICESE stations surrounding the production region, as shown in Figure 1. Also shown in Figure 1 are the regions of high seismicity detected during the 1978 study. As can be seen, none of the seismically active regions (shaded) lie within the production zone. Only several events with magnitude greater than 1 were detected in the reservoir region, these all occurring on one day. The permanent stations were located such that minimum ambiguity would occur in fault plane solutions for events within the reservoir. The 1978 study indicated that the events within the field were on northwest-southeast trending faullts with right lateral strike-slip motion. However, if the Cerro Prieto field is in a region of transverse faulting, (i.e. a spreading center) normal faulting would be expected.

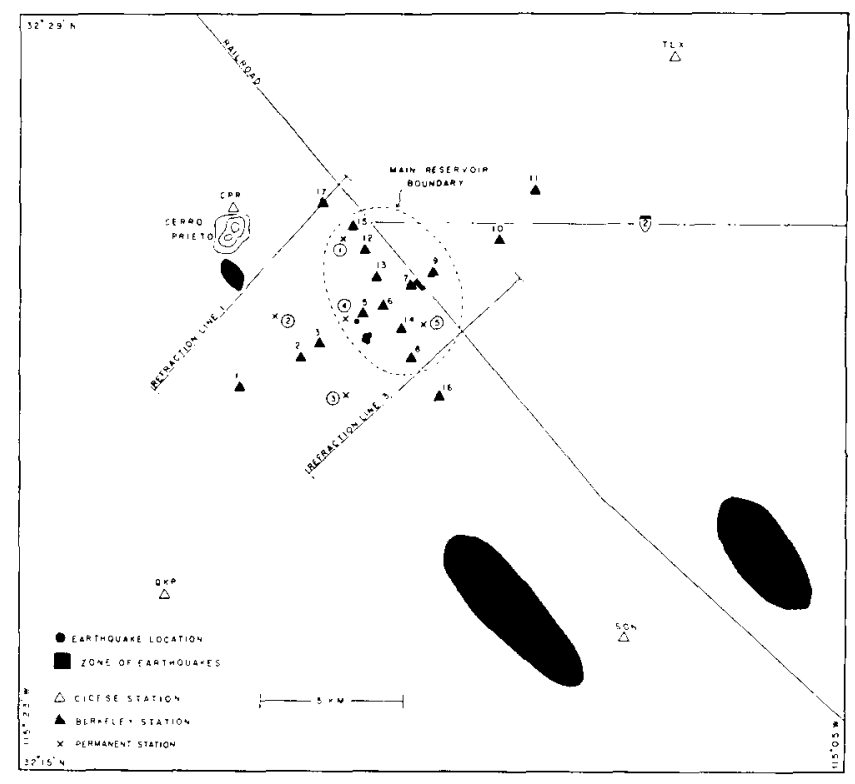

Figure 1. Station locations of permanent array relative to 1978 Cerro Prieto study. Seismic activity is indicated by the shaded regions.

(XBL 789-10723)

Data are collected at each station with a three-component $4.5-\mathrm{Hz}$ geophone package in a $100-\mathrm{m}$ borehole. The holes were drilled and cased by the Comision Federal de Electricidad de Mexico. At the top of each hole an instrument box houses a Sprengnether $D R-100$ event recorder and five $2.5-\mathrm{V}$ McGraw-Edison air-cell batteries (Figure 2). Aircell batteries were chosen for long 1 ife because of their high amp-hour rating ( $1200 \mathrm{~A}-\mathrm{hr})$, although their peak output is on 1 y between $1 / 2$ and $1 \mathrm{~A}$. The batteries should last one year with the DR-100. The DR-100 is a triggered digital cassette recorder. The recorders are set at 200 samples/sec with triggering levels (short-term and long-term average) appropriate for microearthquake detection (Figure 3). Although the signal-to-noise ratio is improved by $20 \mathrm{~dB}$ by placing the geophones at depth, other problems were encountered. In addition to the disadvantage of the permanence of the borehole sites, the near $100^{\circ} \mathrm{C}$ temperature of the water produced $0-r i n g$ deterioration in the sondes, thus causing the geophone packages to leak. Standard O-rings had to be replaced with Viton or silicon rings. It was also necessary that the standard rubber cable be replaced with a PVC-shielded cable. For continuous monitoring above $100^{\circ} \mathrm{C}$, Teflon-coated wire is recommended.

Each station is connected by a single-twisted pair of wires, forming a loop around the array (Figure 4). Also in the loop is a central site housing a visual monitor and time-code clock. The triggering of the recorders is controlled by the recorder at a selected site. Except for this site 


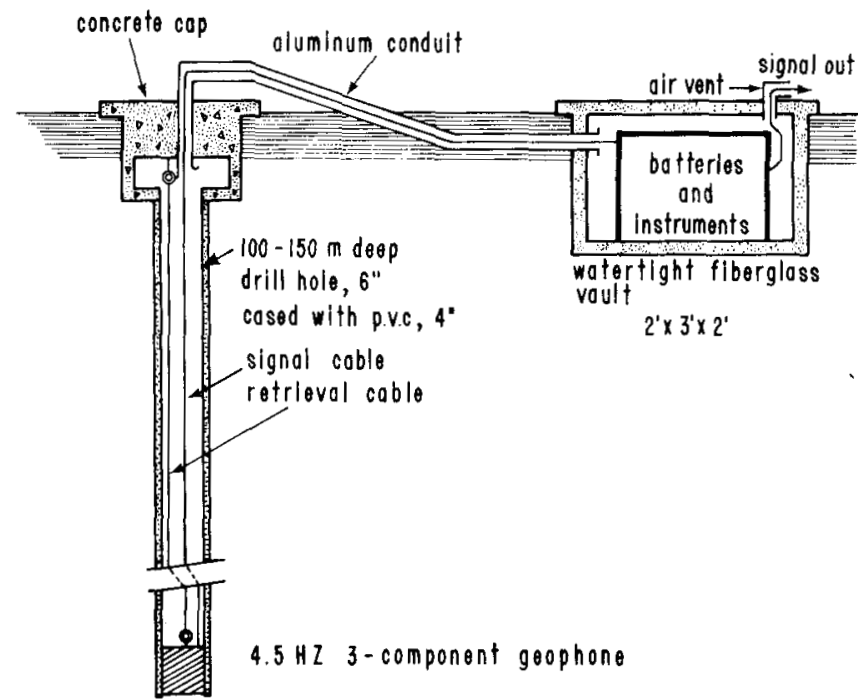

Figure 2. Cerro Prieto network station configuration.

(XBL 787-1966)

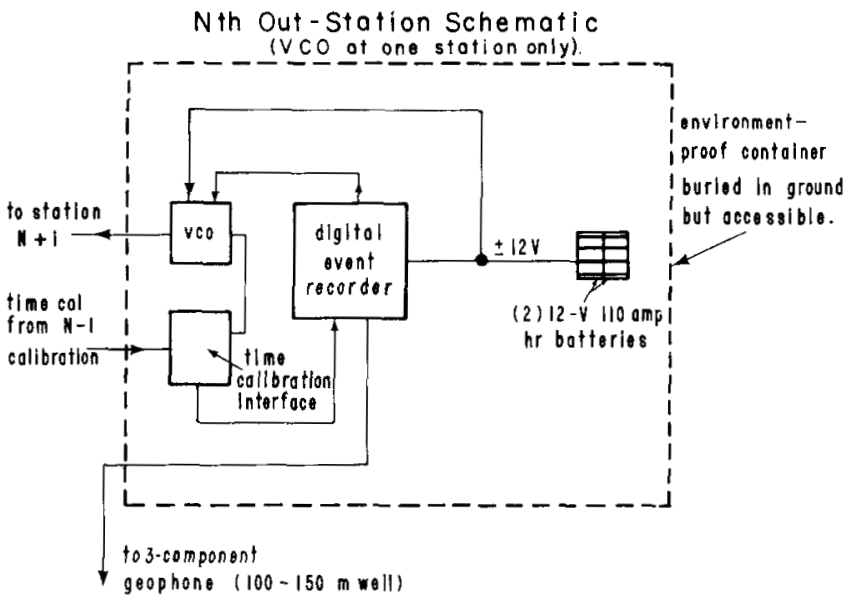

Figure 3. Cerro Prieto station electronics showing a trigger control and vco for visual monitor at central sie.

(XBL 787-1968)

(the quietest) all other recorders have their internal triggering disabled. When the selected site detects an event it sends a trigger pulse to the other recorders via the wire loop. A separate twisted pair from the quiet site (the station nearest the volcano) carries an FM signal to a discriminator at the central site for visual monitoring on a drum recorder. The original plan was to send a time code fiducial to each station via one wire of the twisted pair loop and to carry the FM signal from any selected site on the remaining wire of the twisted pair loop. Each station was to trigger separately; however, due to constant construction many false triggers would often run the tapes out before any earthquakes could be recorded. Also, if the twisted part was broken it had to be reconnected with the proper polarity for the time fiducial and visual monitor to function.

\section{Station Array}

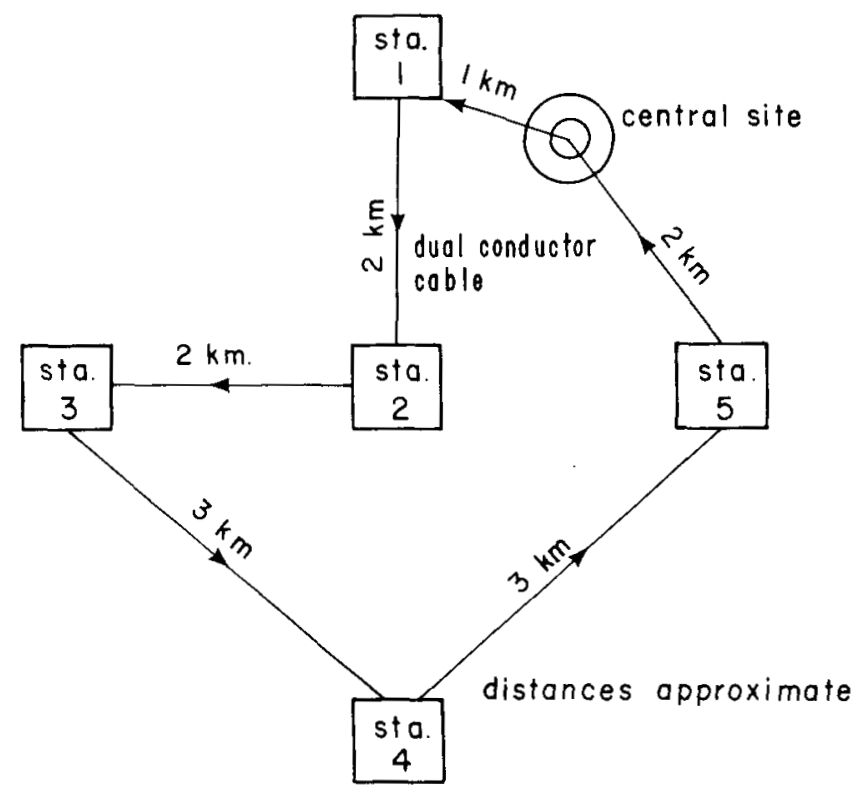

Figure 4. Cerro Prieto array plan, showing connection to central site with twisted pair.

(XBL 787-1967)

As configured now, the twisted pair carrying the trigger pulse can be connected without regard to polarity, thus significantly reducing repair time. However, there is no longer a time pulse fiducial carried to each station. Due to simultaneous triggering there is no longer a need for one.

The array became operational in September 1979. However, since the magnitude 6.5 Imperial Valley earthquake of October 15, 1979, the array has been saturated with aftershocks of this sequence. Other problems are being addressed such as high noise levels in the field (particularly when downhole packages failed and we resorted to surface geophones), effects of high ambient temperatures in the summer, and wire breakage due to construction activity. These problems have been overcome and the downhole sensors are again operational, yielding a five-station, 15-component array providing high-quality digital data which will allow detailed studies of the microearthquake activity associated with the production of the Cerro Prieto geothermal reservoir. Seismic source parameters such as fault orientation and slip direction, in addition to moment and corner frequency, will provide details of source dynamics relative to the withdrawal and reinjection of fluids. Complementing the data will be extensive geophysical, hydrological, and geochemical studies currently being carried out.

\section{EAST MESA}

In April 1979 a three-component $4.5-\mathrm{Hz}$ geophone in a 100-m well and a triggered digital cassette recorder were placed at the East Mesa 
geothermal test facility in the Imperial Valley, California. The hole is centered among the geothermal leases of Republic Geothermal, Magma Power, and the East Mesa test facilities. The purpose of the project is to collect background seismicity data $\left(\mathrm{M}_{\mathrm{L}}>1.0\right)$ before and during commercial production. Magma Power intended to place $13 \mathrm{MW}$ of power on line in the summer of 1979, with Republic adding $11 \mathrm{MW}$ soon after. However, as of February 1980 , routine power generation had not begun.

Before this study, there had been several other seismicity studies at the East Mesa geothermal area. One study (Combs and Hadly, 1977), claims a seismicity rate in the region of 1 to 2 events a day, $1.5<M<2.98$. (December 1974 to December 1975). However, subsequent monitoring by the U.S. Bureau of Reclamation (1976 to 1978) detected no locatable events in the same area, $M_{L}>1.5$ (Howard et al., 1978).

As of February 1980, the present instrument had not detected any events with S-P times of less than $2.5 \mathrm{sec}$, i.e., within 15 to $20 \mathrm{~km}$. However, since October 1979, the cassette recorder has been saturated with the aftershocks of the October 15 Imperial Valley earthquake (epicenter $20 \mathrm{~km}$ to the west). Within several months the number of aftershocks will have fallen off sufficiently to have continuous monitoring with a bi-monthly rate of tape change. It is interesting to note that the earthquake sequence associated with the main shock on October 15 had no detectable effect on seismicity or well performance in the production zone at East Mesa and Cerro Prieto.

\section{REFERENCES CITED}

Combs, J., and Hadley, D., 1977. Microearthquake investigations of the East Mesa geothermal anomaly, Imperial Valley, California. Geophysics, v. 42, p. 17 .

Howard, J. H., Apps, J. A., Benson, S. M., Goldstein, N. E., Graf, A. N., Haney, J. P., Jackson, D. D., Juprasert, S., Majer, E. L., McEdwards, D. G., McEvil1y, T. V., Narasimhan, T. N., Schechter, B., Schroeder, R. C., Taylor, R. W., van de Kamp, P. C., and Wolery, T. J., 1979. Geothermal resource and reservoir investigations of U. S. Bureau of Reclamation leaseholds at East Mesa, Imperial Valley, California. Berkeley, Lawrence Berkeley Laboratory, LBL-7094.

Majer, E. L., McEvilly, T. V., Albores, A. L., Diaz, S. C., 1979. Seismological studies at Cerro Prieto, in Proceedings, First Symposium on the Cerro Prieto Geothermal Field, Baja California, Mexico, September 1978. Berkeley, Lawrence Berkeley Laboratory, LBL-7098, p. $239-249$.

Nur, A., and Winkler, K., 1979. The relative effects of pore fluids on seismic attenuation and velocities. Presented at the 29 th Meeting Society of Exploration Geophysicists, New Orleans, La.

\section{REMOVAL OF SILICA FROM CERRO PRIETO BRINES}

\section{O. Weres and L. Tsao}

\section{INTRODUCTION}

The work reported here was conducted in support of the ongoing studies of brine reinjection at Cerro Prieto being conducted by the personnel of the Comision Federal de Electricidad (CFE) and the Instituto Investigaciones Eléctricas (IIE). It was part of the research project at the Lawrence Berkeley Laboratory (LBL) which is part of the CFE/ DOE Cooperative Program at Cerro Prieto.

The geothermal brine at the Cerro Prieto field in Baja California, Mexico, is among the hottest in the world, and contains a large amount of dissolved silica. When the brine is flashed down to atmospheric pressure, the dissolved silica rapidly polymerizes, and begins to precipitate out. In the past, this has not caused serious problems because the separated brine was disposed of by dumping it into a large evaporation pond. However, the capacity of the field has now been doubled, and brine reinjection is now considered essential to maintain productivity. Reinjection of untreated brine is not possible because the colloidal silica in it would rapidly plug the reinjection well. We were given the assignment of researching the chemistry of silica in the flashed brine at Cerro Prieto, and proposing a practical brine treatment process for field testing.

\section{EXPERTMENTAL METHODS}

We worked in the laboratory with synthetic brines formulated to closely resemble the freshly flashed brine at Cerro Prieto. Two such synthetic brine formulations were used. They differed from real Cerro Prieto brines only in that they contained a buffering compound to control the $\mathrm{pH}$ during the experiment, and did not contain any bicarbonate. (We did not seek to experimentally study the precipitation of calcium carbonate.)

The experiments were run at near $100^{\circ} \mathrm{C}$. Two solutions, one acid and one alkaline, were prepared and preheated. They were then mixed to actually constitute the synthetic brine and initiate the silica polymerization reaction. During the experiments, both dissolved and total silica (i.e., including the colloidal silica) were periodically determined. The dissolved silica concentration was directly determined by the molybdate yellow method. To determine total silica, the sample was first reacted with sodium hydroxide solution to dissolve the colloidal silica, and then analyzed by the molybdate yellow method. The difference between the two values is the amount of colloidal silica present in the brine. The experimental methods and results of this work are discussed in detai1 by Weres and Tsao (1980) and Weres and Iglesias (1980). 


\section{RESULTS}

The pH of the freshly flashed brine at Cerro Prieto is typically about 7.35. At this $\mathrm{pH}$ and $100^{\circ} \mathrm{C}$, the dissolved silica in the brine polymerizes rapidly, but the colloidal silica thus formed does not settle out well. However, it may be caused to settle out ("flocculate") better by increasing the $\mathrm{pH}$. This is illustrated in Figure 1. This figure presents the results of two experiments. In one of them the brine $\mathrm{pH}$ was not changed after the experiment was started, while in the other, the $\mathrm{pH}$ was increased by adding base after dissolved silica concentration had dropped to a steady value. Increasing the $\mathrm{pH}$ quickly caused most of the colloidal silica to flocculate and settle out.

In our laboratory work sodium hydroxide was used as a matter of convenience. In practice, lime ( $\mathrm{CaO}$ ) would be used because it is much cheaper. Theoretical calculations of the buffering capacity of the brine indicate that only about $30 \mathrm{~g}$ of lime would be needed per metric ton of brine to effect the treatment (see Weres et al., 1980, and Iglesias and Weres, this volume). The cost of this little lime would be negligible, even if the total brine flow at Cerro Prieto were treated. Because the needed $\mathrm{pH}$ increase is so small (about one-half unit) undesirable side effects, such as the precipitation of calcium carbonate should not arise, (See Weres et al., 1980, and Iglesias and Weres, this volume.)

We also tested a variety of commercially available organic flocculating agents. Of these, only compounds of the quaternary ammine type were found to be effective, and even these were effective with only one of the synthetic brine formulations but not with the other. Adding base to increase the $\mathrm{pH}$, on the other hand, was invariably effective with either synthetic brine.

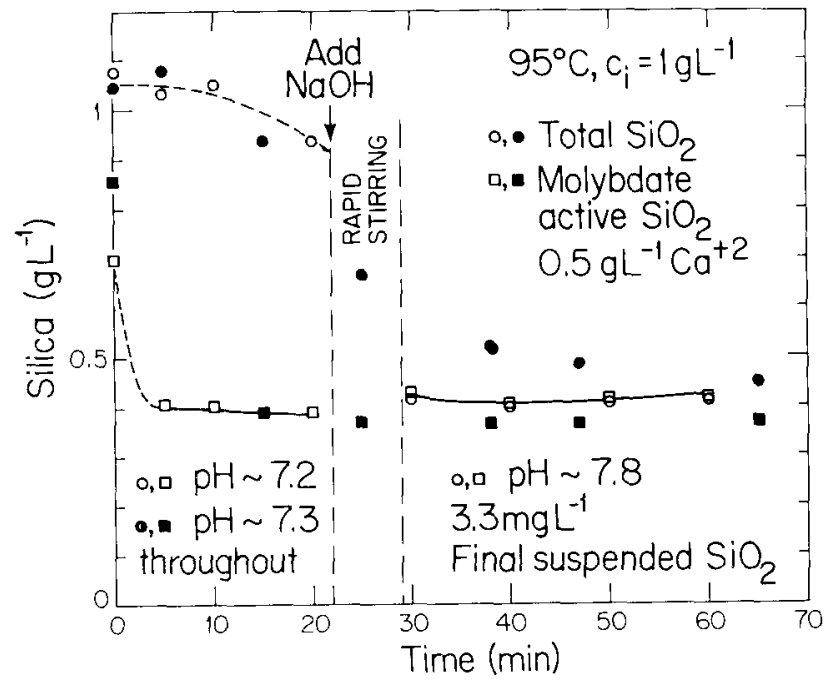

Figure 1. Results of two experiments on Cerro Prieto brines.

(XBL 799-2976)

These results were confirmed in the field at Cerro Prieto using freshly flashed brine from the two wel1s $M-14$ and $M-30$. In both cases, increasing the $\mathrm{pH}$ caused the silica to flocculate out. The quaternary amines were effective with brine from $M-14$, but not with that from $M-30$. All in a11, increasing brine $\mathrm{pH}$ appears to be the cheap and reliable treatment of choice.

These results led us to recommend the following brine treatment to our Mexican colleagues: age the fresh brine for a few minutes to allow the dissolved silica to polymerize, add lime slurry, stir the brine rapidly for a few minutes, and then separate the flocculated silica from the brine in a clarifier. A schematic of a pilot plant to test this process as well as closely related similar processes is shown in Figure 2.

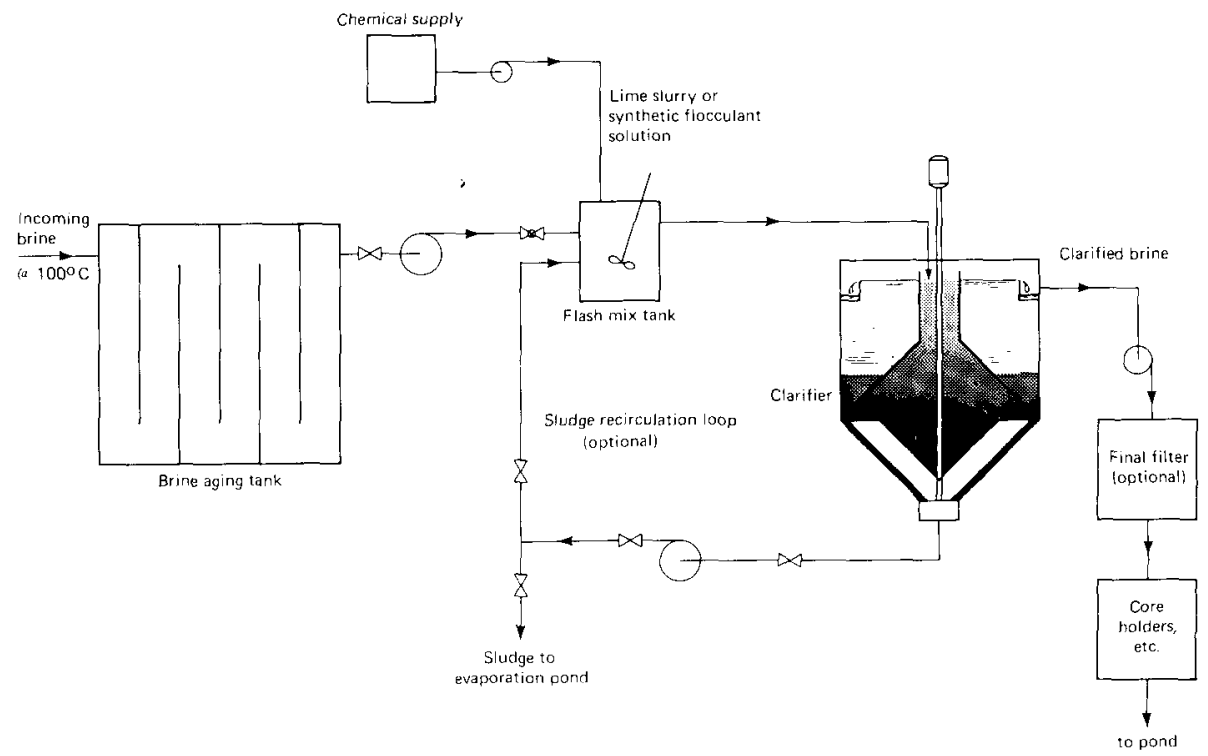

Figure 2. Schematic pilot plant to test the recommended brine treatment process.

(XBL 799-2849) 
This pilot plant has actually been built and operated by the IIE chemists at Cerro Prieto, and the results confirm those of our laboratory work

(R. Hurtado J., report in preparation).

REFERENCES CITED

Weres, 0., and Tsao, L., 1980. The chemistry of silica in Cerro Prieto brine, in Proceedings,
Second Symposium on the Cerro Prieto Geothermal Field, Baja California, Mexico, October 1979. Mexicali, Comisión Federal de Electricidad (in press).

Weres, 0., Tsao, L., and Iglesias, E., 1980. The chemistry of silica in Cerro Prieto brine. Berkeley, Lawrence Berkeley Laboratory, LBL-10166.

\title{
THEORETICAL STUDIES OF CERRO PRIETO BRINES CHEMICAL EQUILIBRIA
}

\author{
E. R. Iglesias and O. Weres
}

\section{INTRODUCTION}

Surface equipment scaling and formation damage due to mineral deposition are risks normally associated with the reinjection of geothermal brines (Howard et al., 1978; Cuellar, 1976). Prereinjection treatment of the brines can provide a solution to these problems (Quong et al., 1978; Weres et al., 1980), which are essentially site-specific due to the wide variation in chemical composition found in geothermal reservoirs (E1lis and Mahon, 1977; Wah1, 1977). Because of our involvement in the Mexican-American Cooperative Project we are interested in prereinjection treatment of Cerro Prieto brines. A scheme for silica removal from separated brines, based on an increase of the natural $\mathrm{pH}$, has been developed by Weres and Tsao (1979). In a related effort, which is the subject of this report, we studied the potential for scaling induced by the silica removal treatment and found it significant. We then proposed and discussed a way to avoid this potential problem which we found both technically and economically feasible.

The chemical equilibrium model used in these studies is described in the next section. The important mineral saturation ratios and the proposed treatment are discussed in the last section.

\section{THE CHEMICAL MODEL}

The adopted model is described in detail elsewhere (Iglesias and Weres, 1980). This model has been implemented in a compact, fast FORTRAN package called HITEQ. The data base covers the range 0 to $300^{\circ} \mathrm{C}$. Input parameters are confining pressure, total enthalpy, composition and (optional) $\mathrm{pH}$. The output provides temperature, enthalpies of water, steam and noncondensible gases, partial pressure of the gas phase components, steam and water masses, $\mathrm{pH}$, ionic strength, the liquid concentrations of the dissolved species, and the saturation ratios of calcite $\left(\mathrm{CaCO}_{3}\right)$, aragonite $\left(\mathrm{CaCO}_{3}\right)$, witherite $\left(\mathrm{BaCO}_{3}\right)$, strontianite $\left(\mathrm{SrCO}_{3}\right)$, anhydrite $\left(\mathrm{CaSO}_{4}\right)$, gypsum $\left(\mathrm{CaSO}_{4} \cdot 2 \mathrm{H}_{2} \mathrm{O}\right)$, barite $\left(\mathrm{BaSO}_{4}\right)$, and celestite $\left(\mathrm{SrSO}_{4}\right)$.

\section{PREREINJECTION TREATMENT}

Elsewhere (Quong et al., 1978; Weres and Tsao, 1979), a scheme for silica removal from separated brines, based on increasing their $\mathrm{pH}$, is discussed. This change of $\mathrm{pH}$ may induce unwanted supersaturation of the brines with respect to other minerals such as calcite or witherite.
In order to assess the possible side effects of this silica removal scheme in Cerro Prieto brines, we used HITEQ to compute the chemical equilibrium of a representative brine (Table 1 ) and then varied the $\mathrm{pH}$ by addition of $\mathrm{H}_{2} \mathrm{SO}_{4}$ and $\mathrm{Ca}(\mathrm{OH})_{2}$. The corresponding saturation ratios are presented in Figure 1. These results have been checked against computations kindly undertaken by D. L. Lessor at Battelle Northwest Laboratories, in an attempt to detect possible discrepancies. It was reassuring to find good agreement with the updated (September 1979 data base) version of Battelle's code.

Increasing the brine $\mathrm{pH}$ brings about potential scaling problems as indicated by the high saturation ratios calculated for the carbonates. These problems can be circumvented by reducing the bicarbonate content of the brine before the silica removal treatment is applied. This can be accomplished by first decreasing the brine $\mathrm{pH}$ at intermediate pressures ( $P_{\text {well }}$ lhead $\geq P>1$ atm) thus inducing conversion of sizable amounts of solution bicarbonate into carbon dioxide, which then can be stripped from the solution by allowing the pressure to decrease and thereby causing further flashing. A possible implementation of this scheme is shown in Figure 2. The first separator pressure has been adopted according to current practices (Alonso et al., 1979).

Table 1. Average brine composition of Cerro Prieto geothermal fluids.

\begin{tabular}{lcl} 
Chemical & ppm & molal \\
\hline $\mathrm{Na}$ & 6,610 & 0.288 \\
$\mathrm{~K}$ & 1,436 & 0.037 \\
$\mathrm{Mg}$ & 1.2 & 0.00005 \\
$\mathrm{Ca}$ & 328 & 0.008 \\
$\mathrm{Sr}$ & 15.8 & 0.00018 \\
$\mathrm{Ba}$ & 11.3 & 0.000082 \\
$\mathrm{~B}$ & 11 & 0.001 \\
$\mathrm{C} 1$ & 11,970 & 0.340 \\
$\mathrm{CO}_{2}$ & 44 & 0.001 \\
$\mathrm{SO}_{4}=$ & 9.6 & 0.0001 \\
$\mathrm{SiO}_{2} \simeq 500(1000)^{*}$ & & $0.008(0.016)$
\end{tabular}

$\mathrm{pH}\left(100^{\circ} \mathrm{C}\right) \simeq 7.35$

*In solution after (before) amorphous silica precipitation. 


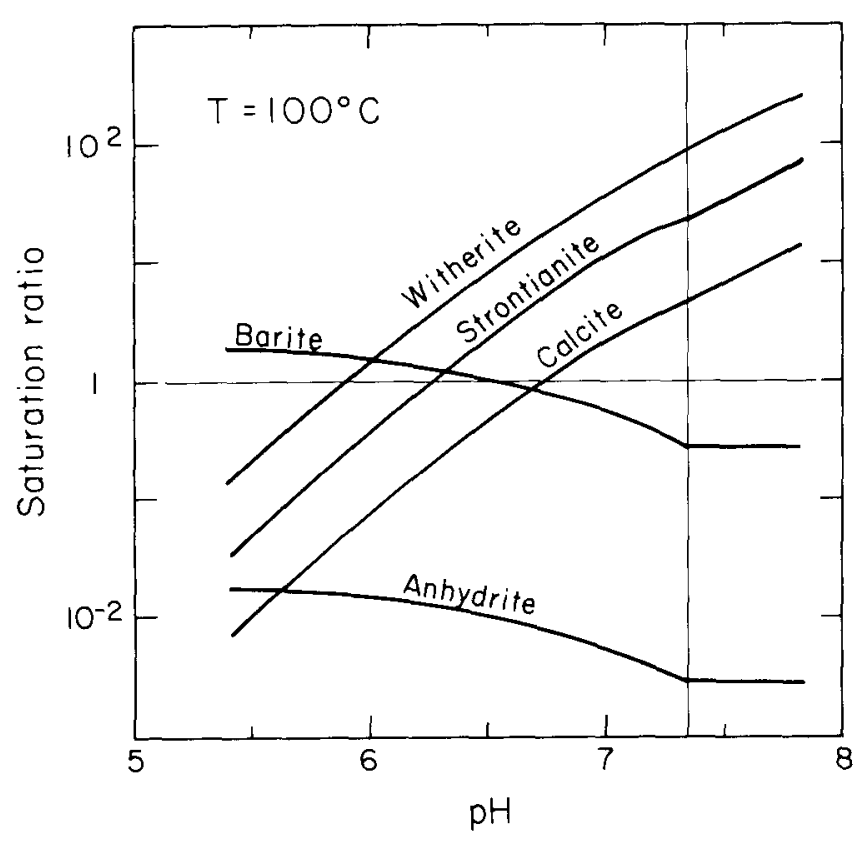

Figure 1. Effects of adjusting $\mathrm{pH}$ on saturation ratios of carbonate and sulfate minerals for a typical separated Cerro Prieto brine.

(XBL 7912-13481)

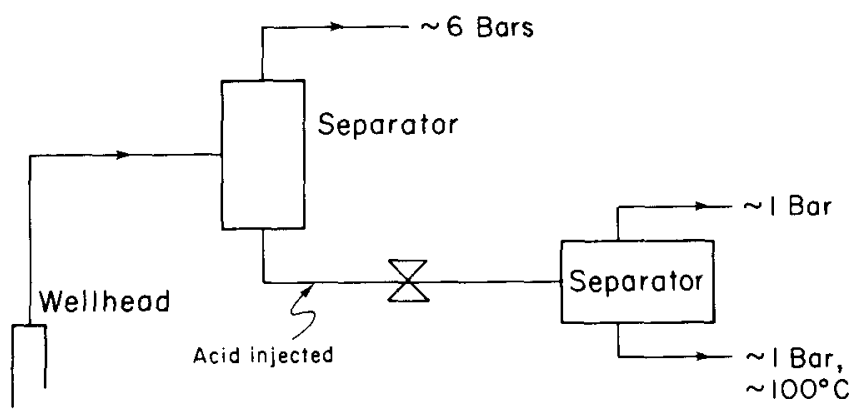

Figure 2. Schematic of the proposed scheme of acid injection for inhibition of carbonate minerals deposition.

(XBL 7912-13484)

Using HITEQ we find that the reconstructed brine at 6 bars and $159^{\circ} \mathrm{C}\left(\mathrm{SiO}_{2} \simeq 1000 \mathrm{ppm}\right.$ before silica precipitation) has a $\mathrm{pH}=7.02$ and equilibrium ratios $\mathrm{CO}_{2}: \mathrm{HCO}_{3}{ }^{-}: \mathrm{CO}_{3}=:: 0.22: 0.773: 0.007$. Figure 3 shows the computed equilibrium shift when $\mathrm{H}_{2} \mathrm{SO}_{4}$ is added. At $\mathrm{pH}=5$ we find $\mathrm{CO}_{2}: \mathrm{HCO}_{3}:: 0.961$ : $0.039 ; 0.6$ mmoles $/ \mathrm{kg}$ of added $\mathrm{H}_{2} \mathrm{SO}_{4}$ were required to lower the $\mathrm{pH}$ to this value. We envision no or minor corrosion problems at this moderate $\mathrm{pH}$ value. The computed saturation ratios in this condition, depicted in Figure 4, indicate that barite may be a limiting factor for use of inexpensive $\mathrm{H}_{2} \mathrm{SO}_{4}$.

Flashing the acidified brine to $P \simeq 1$ bar we compute $\mathrm{pH}=6.34$ and the total amount of carbon dioxide and bicarbonate remaining in the liquid phase is reduced.

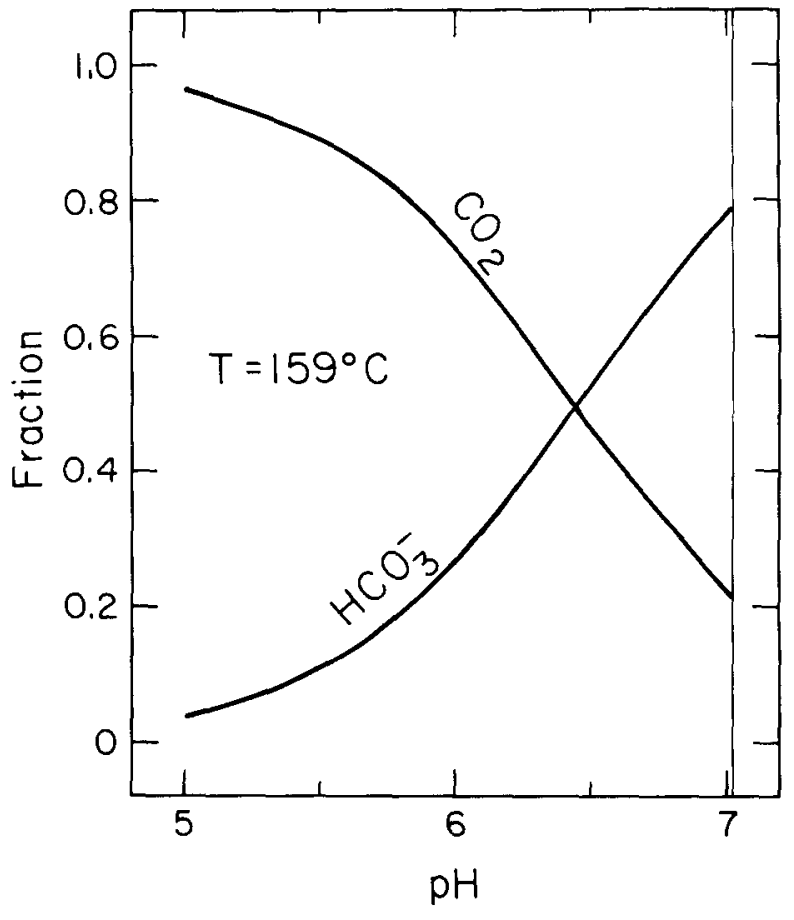

Figure 3. Carbon dioxide partition in the first separator $(P \simeq 6$ bars) as a function of $\mathrm{pH}$.

(XBL 7912-13483)

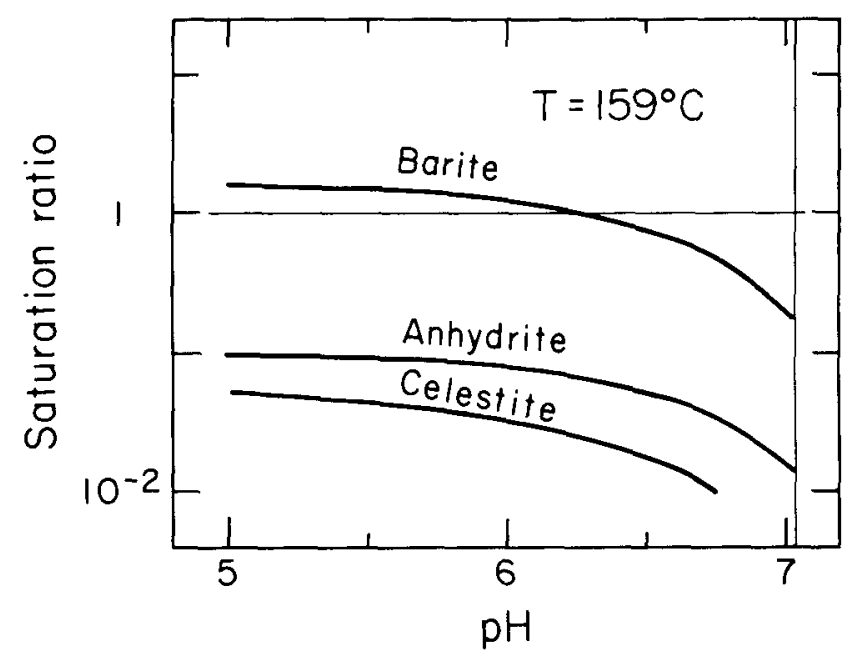

Figure 4. Effects of adding sulfuric acid on the saturation ratios of sulfate minerals (carbonate minerals out of scale) in the first separator.

(XBL 7912-13480)

Increasing the $\mathrm{pH}$ of the separated brine by addition of $\mathrm{Ca}(\mathrm{OH})_{2}$ we $\mathrm{find}$ the saturation ratios of Figure 5, which indicate that the proposed scheme can indeed control carbonate precipitation in treated Cerro Prieto brines. The amount of $\mathrm{Ca}(\mathrm{OH})_{2}$ necessary to increase the $\mathrm{pH}$ of the separated brine to $\simeq 7.8$, as required by the silica removal treatment, was found to be about $0.5 \mathrm{mmole} / \mathrm{kg}$. The 


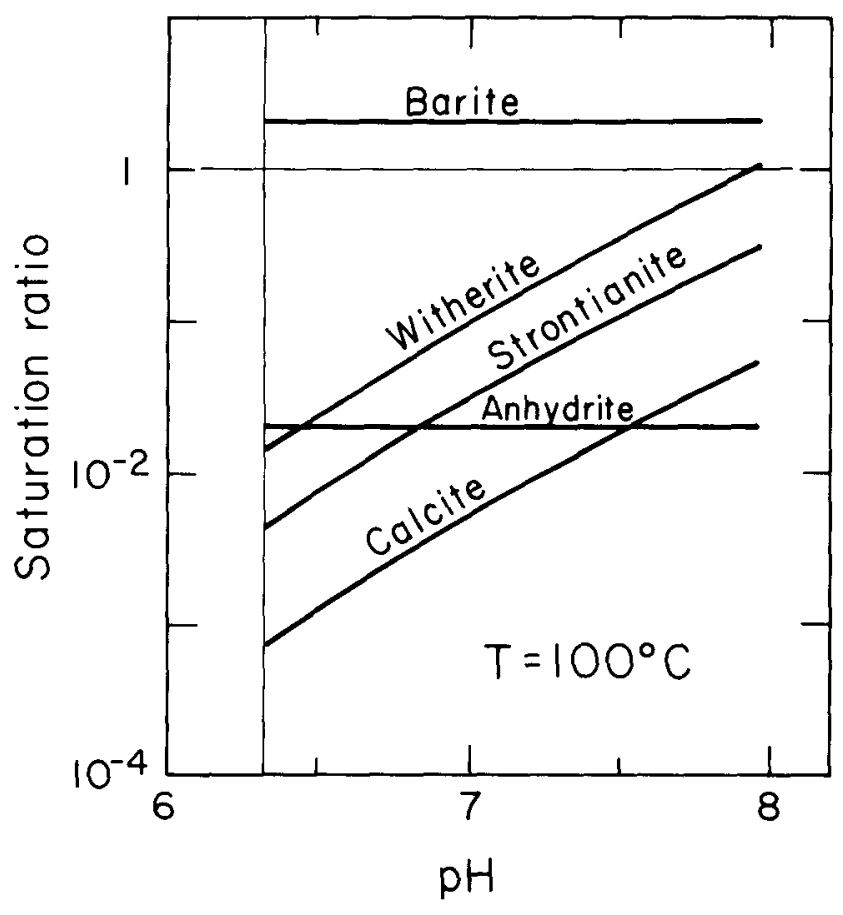

Figure 5. Effects of then adding calcium hydroxide on the saturation ratios of relevant minerals in the second separator $(P \simeq 1$ bar $)$.

(XBL 7912-13482)

brine is found to be supersaturated with respect to barite. This problem may be solved by replacing $\mathrm{H}_{2} \mathrm{SO}_{4}$ by $\mathrm{HCl}$, though at higher cost.

Adopting $20 \mathrm{~kg}$ of separated brine per $\mathrm{kWh}$ we estimate that the treatment with $\mathrm{H}_{2} \mathrm{SO}_{4} \operatorname{cost} 2.0 \times$ $10^{-5} \$ / \mathrm{kWh}$; using $\mathrm{HC} 1$ instead, we find a cost of $2.17 \times 10^{-4} \$ / \mathrm{kWh}$. The cost of the lime treatment is, in both cases, $2.00 \times 10^{-5} \mathrm{~s} / \mathrm{kWh}$. The prices of chemicals were taken from the Chemical Marketing Reporter (January 21,1980 ) as $\$ 15.00 /$ ton for tanks of smelter grade $100 \% \mathrm{H}_{2} \mathrm{SO}_{4} ; \$ 62.50 /$ ton for $\mathrm{HC1} 18^{\circ}$ Baume ( $29 \%$ by weight $\mathrm{HCl}$ ); and $\$ 32.50 /$ ton for $\mathrm{CaO}$ pebble. Prices of the acids are for the West Coast; the lime price is f.o.b.

We concluded that the proposed scheme for the prereinjection brine treatment in Cerro Prieto is both technically and economically feasible. This tentative conclusion should be confirmed by experimental work due to uncertainties (e.g., validity of the Debye-Hückel approximation, values of the equilibrium constants) associated with the chemical model.

\section{REFERENCES CITED}

Alonso, H., Dominguez, B., Lippmann, M. J., Molinar, R., Schroeder, R. C., and Witherspoon, P. A., 1980. Update of reservoir engineering activities at Cerro Prieto, in proceedings of the Fifth Annual Stanford Geothermal Reservoir Engineering Workshop.

Cuellar, G., 1976. Behavior of silica in geothermal waste waters, in Proceedings, Second United Nations Symposium on the Development and Use of Geothermal Resources. San Francisco, May 1975. U.S. Government Printing Office, v. 2, p. 1243.

El1is, A. J., and Mahon, W. A. J., 1977. Chemistry and geothermal systems. New York, Academic Press.

Howard, J., Apps, J. A., Benson, S., Goldstein, N. E., Graf, A. N., Haney, J., Jackson, D., Juprasert, S., Majer, E., McEdwards, D., McEvilly, T. V., Narasimhan, T. N., Schechter, B., Schroeder, R., Taylor, R., van de Kamp, P., and Wolery, T., 1979. Geothermal resources and reservoir investigations of U.S. Bureau of Reclamation leaseholds at East Mesa, Imperial Valley, California.

Quong, R., Schoepflin, F., Stout, N. D., Tardiff, G. E., and McLain, F. R., 1978. Processing of geothermal brine effluents for injection. Geothermal Resources Council, Transactions, v. 2, p. 551 .

Wah1, E. F., 1977. Geothermal Energy Utilization. New York, John Wiley and Sons.

Weres, 0., and Tsao, L., 1980. The chemistry of silica in Cerro Prieto brines, in Proceedings, Second Symposium on the Cerro Prieto Geothermal Field, Baja California, Mexico, October 1979. Mexicali, Comisión Federal de Electricidad.

Weres, 0., Tsao, L., and Iglesias, E., 1980. The chemistry of silica in Cerro Prieto brines. Berkeley, Lawrence Berkeley Laboratory, LBL-10166 (in press). 